\title{
Violencia escolar relacionada con barras de fútbol en Bogotá
}

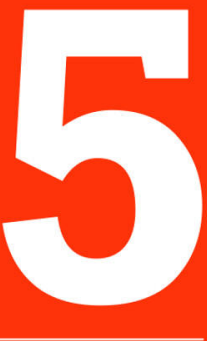

COLECCIÓN TESIS DOCTORAL 


VIOLENCIA ESCOLAR RELACIONADA CON BARRAS DE FÚTBOL EN BOGOTÁ 


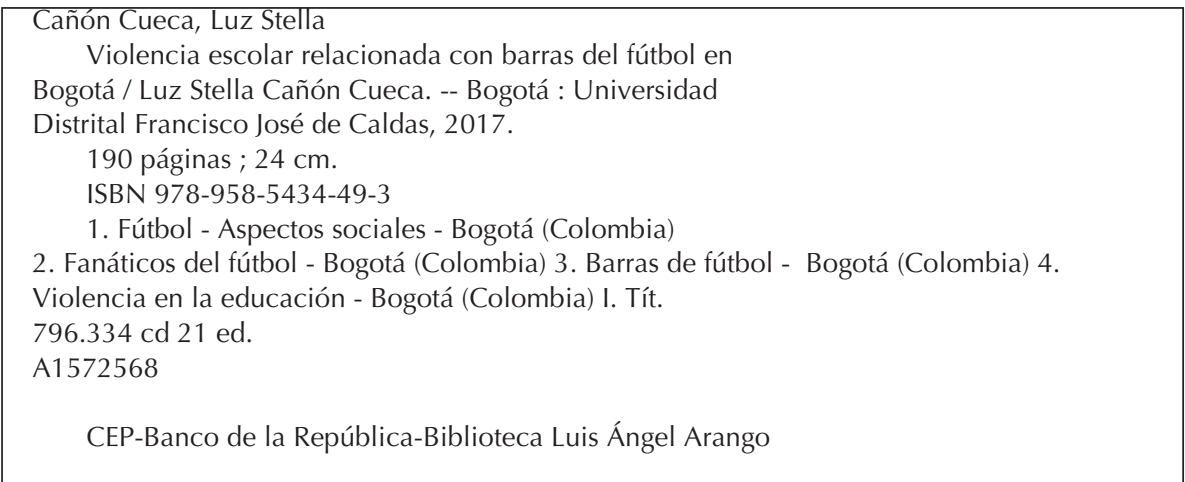

(C) Universidad Distrital Francisco José de Caldas

ISBN Impreso: 978-958-5434-49-3

ISBN Digital: 978-958-5434-50-9

Primera Edición: Bogotá, Colombia, 2017

\section{Preparación Editorial}

Doctorado Interinstitucional en Educación

http://die.udistrital.edu.co/publicaciones

Sede Universidad Distrital Francisco José de Caldas

Aduanilla de Paiba, Edificio de Investigadores, calle 13 No. 31-75

Asistente editorial eventosdie@udistrital.edu.co

PBX: (57+1) 3239300, ext.6330-6334

\section{Fondo de Publicaciones}

Universidad Distrital Francisco José de Caldas

www.udistrital.edu.co

Carrera 24 No. 34 - 37

PBX: $(57+1) 3239300$, ext.6201

publicaciones@udistrital.edu.co

\section{Diseño, Corrección de Estilo, Diagramación e impresión}

Editorial Magisterio

Esta edición 2017 y sus características son propiedad de la Universidad Distrital José Francisco Caldas, por lo que queda prohibida la reproducción total o parcial por cualquier medio, sin la autorización previa por escrito de los editores.

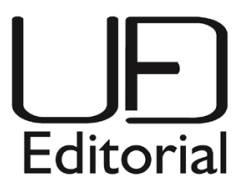


VIOLENCIA ESCOLAR RELACIONADA CON BARRAS DE FÚTBOL EN BOGOTÁ
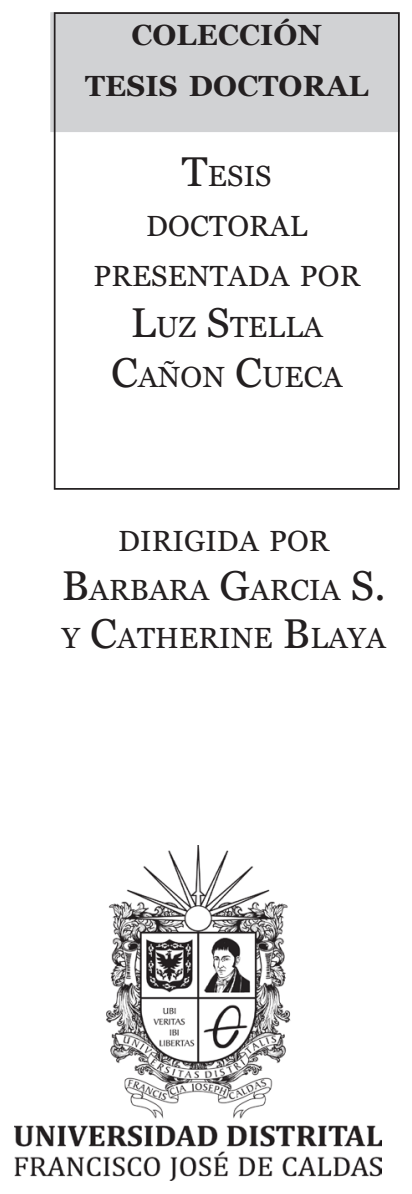


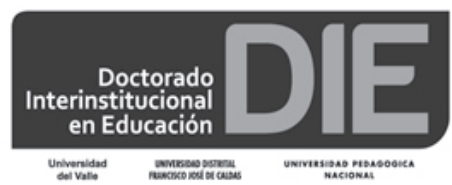

Comité Editorial-CADE

Álvaro García Martínez

Presidente CADE

William Manuel Mora Penagos

Representante de los grupos de investigación: Investigación en Didáctica de las Ciencias, Interculturalidad, Ciencia y TecnologíaINTERCITEC, GREECE y del Grupo Didáctica de la Química-DIDAQUIM, del Énfasis de Educación en Ciencias.

Juan Carlos Amador Baquiro

Representante de los grupos de investigación:

Moralia, Estudios del Discurso, Filosofía y Enseñanza de la Filosofía, Grupo de investigación Interdisciplinaria en Pedagogía de Lenguaje y las Matemáticas-GIIPLyM y Jóvenes, Culturas y Poderes, del Énfasis de Lenguaje y Educación.

\section{Rodolfo Vergel Causado}

Representante de los grupos de investigación: Grupo de Investigación Interdisciplinaria en Pedagogía de Lenguaje y las Matemáticas GIIPLyM, Matemáticas Escolares Universidad Distrital-MESCUD y EDUMAT, del Énfasis de Educación Matemática.

Bárbara García Sánchez

Representante del grupo de investigación: Formación de Educadores, del énfasis de Historia de la Educación, Pedagogía y Educación Comparada.

Harold Castañeda-Peña

Representante de los grupos de investigación: Aprendizaje y Sociedad de la Información y Formación de Educadores, del énfasis de ELT EDUCATION.

\section{Universidad Distrital}

Francisco José de Caldas

\author{
Carlos Javier Mosquera Suárez \\ Rector (E)
}

Giovanni Rodrigo Bermúdez Bohórquez

Vicerrector Académico

Comité Editorial Interinstitucional-CAIDE

Carlos Javier Mosquera Suárez

Director Nacional

Alexander Ruiz Silva

Coordinador DIE

Universidad Pedagógica Nacional

Álvaro García Martínez

Director DIE

Universidad Distrital

Francisco José de Caldas

\section{Santiago Adolfo Arboleda Franco}

Coordinador DIE

Universidad del Valle 


\section{Contenido}

INTRODUCCIÓN

1. LoS JÓVENES EN Bogotá 17

SOBRE EL CONCEPTO DE JUVENTUD

JUVENTUD COMO CAPITAL SOCIAL: UNA VISIÓN PROPOSITIVA 19

JÓVENES EN BOGOTÁ: ENTRE LA EXCLUSIÓN Y LA FRUSTRACIÓN 23

JÓVENES EN BOGOTÁ: HABITANDO ¿̇QUÉ CIUDAD? 27

VIOLENCIA JUVENIL Y CONTRAVENCIONES INFANTO-JUVENILES 44

2. DE FÚtBol, VIOLENCIA Y CORRUPCIÓN 55

El FÚTBOL: UNA HISTORIA DE VIOLENCIA

EL FÚTBOL COLOMBIANO: LA PERPETUA IMPROVISACIÓN 58

FÚtbOL Y NARCOTRÁFICO EN COLOMBIA:

LA INFESTACIÓN DEL DEPORTE

3. Violencia ESCOLAR RELACIONADA CON

BARRAS DEL FÚTBOL EN BOgOTÁ 67

ORIGEN DEL BARRISMO EN BOGOTÁ

CONCEPTOS DE BARRA DEL FÚTBOL, BARRABRAVA, BARRISTA Y BARRISMO $\quad 75$

HACIA UNA DEFINICIÓN DE BARRA DEL FÚTBOL

$\begin{array}{ll}\text { EL BARRABRAVA } & 78\end{array}$

¿QQUIÉN ES UN BARRISTA?

¿Y... ¿QQUÉ ES EL BARRISMO? 82 
LOS JÓVENES BARRISTAS ESCOLARES

CARACTERIZACIÓN DEL GRUPO DE BARRISTAS 89

BARRISMO, MASCULINIDAD Y VIOLENCIA 96

VIAJAR CON EL EQUIPO:

LA PROMESA CUMPLIDA DE RIESGO, AVENTURA Y EMOCIÓN 103

BARRISTAS ESCOLARES:

LA SENSIBLE FRONTERA ENTRE LA AFICIÓN Y LA DELINCUENCIA 107

MuJER Y BARRISMO: UNA PARTICIPACIÓN QUE SE TRANSFORMA 117

4. FAMILIA Y BARRISMO:

NORMATIVIDAD VS. AUTORIDAD 127

$\begin{array}{ll}\text { CONTEXTO } & 127\end{array}$

Formas DE ORGANIZACIÓN FAMILIAR EN COLOMBIA 130

PARTICULARIDADES DE LA ORGANIZACIÓN FAMILIAR

DE LOS JÓVENES BARRISTAS

CONCEPCIONES DE LA FAMILIA EN TORNO A LA

PARTICIPACIÓN DE LOS HIJOS EN EL BARRISMO

El Código de Infancia y Adolescencia

(-LEY 1098) Y LA PROTECCIÓN DE LOS MENORES

5. ESCUELA Y BARRISMO 163

LA VIOLENCIA EN LA ESCUELA 165

BARRAS DEL FÚTBOL: VIOLENCIA CONTRA LA ESCUELA 166

Contravenciones JUVENILES EN LA ESCUELA 174

6. BARRIO Y CIUDAD:

LOS TERRITORIOS DEL BARRISTA 179

VIOLENCIA URBANA 179

JÓVENES: FORMAS DE HABITAR Y APROPIAR EL ESPACIO BARRIAL 182

El TERRITORIO. ACEPCIONES Y

PARTICULARIDADES PARA EL BARRISTA 187

7. CONCLUSIONES Y RECOMENDACIONES 193

$\begin{array}{ll}\text { REFERENCIAS } & 197\end{array}$ 
A mis estudiantes barristas...

Porque siempre habrá otros modos de disfrutar su afición 



\section{INTRODUCCIÓN}

El presente estudio constituye un esfuerzo por comprender una de las violencias que afecta la vida de las escuelas en Bogotá, producida por la vinculación de jóvenes escolarizados con el fenómeno del barrismo del fútbol y las diversas situaciones a las que se encuentra ligado, entre otras, el consumo y distribución de sustancias psicoactivas, el porte y uso de armas, el acercamiento a pandillas y bandas delincuenciales. Del mismo modo, el propósito es encontrar una explicación a los comportamientos de los estudiantes que se adhieren a estos grupos, de ahí que se da una mirada a la situación que deben afrontar en espacios de socialización como la escuela, la familia y el barrio.

Parte del interés en el desarrollo de esta investigación radica en encontrar respuestas a cierto tipo de acciones de carácter violento que se vienen presentando en Bogotá, dentro y fuera de las instituciones educativas. Muchas de ellas han sido asociadas por docentes y directivos a problemas de la dinámica escolar; sin embargo, las formas, manifestaciones y características de ocurrencia dejan ver que algo diferente está sucediendo.

En Colombia, especialmente en Bogotá y las grandes ciudades, la violencia generada por las barras del fútbol se ha convertido en un problema cotidiano, hechos sucedidos en los últimos tiempos relacionados con la participación de jóvenes hinchas de equipos de fútbol así lo evidencian; asimismo, en las instituciones educativas de la ciudad comienzan a conocerse acciones violentas producto de la pertenencia de jóvenes a grupos de barristas, que han llevado a las aulas sus adherencias y convierten los alrededores de los colegios en espacios de confrontación con hinchadas de otras instituciones o del mismo sector, lo que produce en los barrios inseguridad y zozobra entre las comunidades, para las cuales su presencia en el entorno comienza a volverse incómoda. 
Un hecho que se ha vuelto común en varias escuelas de la ciudad es la confrontación de grupos de jóvenes que portan armas blancas y objetos contundentes con los que se agreden y atacan los edificios escolares, las casas de vecinos y los negocios de los barrios. Estos actos han sido atribuidos a rencillas entre muchachos que quieren entrar en defensa de sus instituciones, pero quienes han asumido el vandalismo como escudo son jóvenes que actúan encapuchados, amparados por las multitudes de escolares que portan los uniformes de sus escuelas y en las que se infiltran agitadores pertenecientes a grupos de pandillas y bandas que pretenden intervenir en apoyo de estudiantes que al interior de los colegios cohonestan su accionar y hacen parte de grupos de informantes, redes de tráfico de psicoactivos, hurto y ajuste de cuentas, tal y como lo relatan los mismos estudiantes. Las comunidades y los afectados les han identificado como pertenecientes a grupos del barrismo que se atacan por la adhesión a - y defensa de-sus equipos.

Frente a esta problemática las preguntas que articulan el tema son:

1. ¿Cómo interactúan los diversos factores para que se configuren hechos de violencia en relación con el deporte, particularmente el fútbol? y ċcuál es el sentido que tiene para los jóvenes escolarizados la pertenencia a grupos de barristas, qué buscan?, si se entiende que la violencia es un problema en el que interactúan factores incidentes de diverso orden, como por ejemplo las relaciones familiares, la vida escolar, la pertenencia a grupos, las dinámicas barriales, las formas de habitar, entre otras.

2. ¿Cuál ha sido el desarrollo histórico del fenómeno de las barras del fútbol en Bogotá, en los últimos diez años? Si bien el fenómeno se ha hecho presente y evidente con más fuerza en los últimos cinco años, también es cierto que es relativamente reciente en el ámbito deportivo local y nacional; aún no puede compararse con otros del continente, como el movimiento barrabrava argentino o las 'torcidas' brasileras, de los cuales es más bien tributario; igualmente, los movimientos de hinchadas futboleras europeas son particularmente modelos que los jóvenes barristas han adoptado, pero estos están todavía muy lejos de lograr una identidad propia que identifique las grupalidades que constituyen como seguidores de equipos nacionales. 
3. ¿Qué caracteriza esa violencia dentro de la escuela? La violencia que se investiga en este trabajo no es la misma que ocurre dentro del estadio, tiene características que la diferencian, en especial por sus componentes rituales y la defensa a ultranza de los espacios tanto escolares como barriales.

4. ¿Qué relación presentan las barras del fútbol escolares con bandas y pandillas de los barrios donde las amenazas y las confrontaciones se han vuelto comunes? Se ha reconocido por parte de la comunidad educativa que en las escuelas y los barrios hay presencia de grupos de barristas del fútbol que alteran la convivencia, y también se sabe que a las confrontaciones dadas en el entorno barrial acuden otros actores, ajenos a la escuela, que portan armas y participan activamente en la contienda.

5. Un aspecto que ha llamado la atención en los últimos tiempos es la presencia femenina en los grupos de barristas. El cuestionamiento que surge está relacionado con la participación de ellas en los actos que se producen en los estadios y fuera de estos. En tal sentido, en esta investigación es relevante indagar qué papel desempeñan las mujeres dentro del grupo de barristas y cómo se integran a su dinámica.

Según información de la Secretaría de Gobierno de Bogotá, un alto porcentaje de los jóvenes que conforman las barras tienen unas características sociales y económicas complejas, en el fútbol encuentran un espacio de pasiones por naturaleza, una respuesta a las cohibiciones que tienen en su actuar diario, de manera que se desinhiben y exaltan sentimientos de rechazo a temas como la autoridad, la tolerancia, el respeto a la diferencia y la resolución pacífica de conflictos. Esta afirmación, obtenida de las memorias del programa institucional "Goles en Paz”, de la Consejería para la Vida Sagrada, es un ejemplo de cómo alrededor de las barras del fútbol giran problemas sociales que, mezclados con el espectáculo del deporte, requieren atención con el fin de frenar la violencia que surge de la interacción de los jóvenes con este tipo de eventos.

El método que se empleó para el desarrollo de este trabajo es el de los núcleos de educación social (NES), basados en la investigación- 
acción (IA), cuya característica principal es la de que involucra a los miembros de la comunidad en el proyecto de investigación y en las acciones de transformación, considerados como agentes de cambio. De esta manera, la comunidad es el centro del proceso de investigación y a la vez sujeto de estudio. El término procede de los trabajos realizados por Kurt Lewin (1940), psicólogo social, quien ligaba el enfoque experimental de la ciencia con programas de acción social. Lewin denominó investigación-acción a la investigación comparativa sobre condiciones y efectos de varias clases de acción social. En palabras sencillas, la IA es un proceso de investigación orientado al cambio social caracterizado por la toma de decisiones en forma democrática. La IA identifica una serie de actividades que se someten a la observación, la reflexión y el cambio, al igual que presenta como particularidad la vinculación de los implicados en el proyecto de investigación.

Desde el punto de vista epistemológico esta investigación asume los postulados de la sociología comprensiva de Max Weber y la sociología de la interacción de Erving Goffmann. A partir de los postulados weberianos, lo que se pretende es conocer el fenómeno de las barras del fútbol desde adentro, con el fin de establecer sus peculiaridades, en el entendido de que, como señala Weber (1984), cada acción humana siempre tiene un significado; la idea, entonces, es develar lo que hay detrás de ellas para comprenderlas. Desde la perspectiva de la sociología de la interacción de Goffman (1970), "se plantean las relaciones que se pueden establecer cuando la gente se encuentra, las formas que adoptan estas interacciones, las reglas que se producen y los roles que se juegan en esa interacción en escenarios naturales" (p. 11), para ello se requiere la copresencia del otro; es lo que también ha llamado "interacción cara a cara'.

Desde el anterior enfoque se explica la forma como se establece la vinculación entre los grupos de barristas, quienes en la vivencia de su rol van perfilando un estilo de relación que tras la escenificación de dicha membrecía adquiere un tipo de orden social propio, el cual se evidencia en la estructuración misma de la barra. La jerarquía es el nodo principal de la organización, hecho que los seguidores entienden y aceptan ubicándose cada uno en su posición, lo que a su vez esta- 
blece unas reglas de convivencia que favorecen la cohesión a partir de normas implícitas seguidas estrictamente, es la manera como se certifica la calidad del vínculo y el grado de pertenencia al grupo social que integran.

Con base en los aportes de la IA, el método de investigación empleado sigue las orientaciones del modelo de los NES, entendida como una propuesta

de trabajo comunitario para prevenir las violencias en la escuela, la familia y el barrio. Así mismo, constituyen un grupo comunitario de discusión, un espacio no-excluyente en el que a través del reconocimiento previo de los individuos, de las familias, de la escuela y del entorno se interviene de manera focalizada con el propósito de detectar y prevenir factores de riesgo social, desde el 'adentro' planteando acciones transformadoras. (García \& Guerrero, 2012a, pp. 37-69)

Finalmente, esta investigación busca contribuir al conocimiento del fenómeno del barrismo y sus dinámicas en el entorno escolar, a fin de promover acciones formativas que permitan a los jóvenes asumir la práctica del deporte, bien como hinchas o como deportistas, de un modo tal que les conduzca al sano disfrute del tiempo libre y a la generación de espacios lúdico-recreativos para el encuentro y la interacción con los demás. 



\section{Los Jóvenes en Bogotá}

\section{SOBRE EL CONCEPTO DE JUVENTUD}

El concepto de juventud ha sido abordado desde diferentes perspectivas. En general hay acuerdo en que no es una expresión que pueda universalizarse por cuanto responde a criterios particulares de cada sociedad; es un término difuso, dado que es imposible establecer el límite que separa una edad de otra y el momento específico en el que se realizan sus tránsitos; así mismo, es un vocablo al cual se le han atribuido diversos significados y tiende a relativizarse. Más allá de contemplar el concepto desde particularidades como la edad, que antropológicamente buscan un orden u organización que favorezca la adopción de ciertas características para poder estandarizar las condiciones de ser joven, ser joven es un conjunto de eventos alrededor de los que se construye su condición, la cual pasa por el reconocimiento como sujeto de derechos, actor social determinante en la transformación de su entorno y a quien es necesario abrir posibilidades de realización.

Las sociedades modernas se han quedado cortas frente a las expectativas de los jóvenes en los años sesenta y setenta del siglo XX; ante la imposibilidad de responder a sus demandas, emergen nuevas concepciones planteando la cesación de las responsabilidades juveniles, que anteriormente se consideraban el paso de la juventud a la adultez, esto es, la vinculación al trabajo y la constitución de familia, espacio que se denominó moratoria social y se aplica de forma diferenciada a grupos que pueden atribuirse un tiempo de espera; la moratoria constituye un ajuste social frente al reconocimiento de la clase media, que luego de la Revolución Industrial busca organizar la vida de los jóvenes.

Margulis y Urresti (2002) consideran que 
la moratoria social alude a que, con la modernidad, grupos crecientes que pertenecen por lo común a sectores sociales medios y altos, postergan la edad del matrimonio y la procreación durante un periodo cada vez más prolongado, tienen la oportunidad de estudiar y de avanzar en su capacitación en instituciones de enseñanza que, simultáneamente, se expanden en la sociedad. (p. 5)

La moratoria solo puede ser disfrutada por sectores sociales que tienen ciertos privilegios, en tanto que los jóvenes de sectores menos favorecidos deben afrontar tempranamente las responsabilidades del trabajo y ven disminuir paulatinamente sus posibilidades, colocándose de este modo en desventaja, mientras los más favorecidos pueden aprovechar este tiempo en capacitarse y prepararse para laborar.

El tratamiento de la juventud como generación, según Lozano (2003), "refiere a una condición histórica" (p. 12). Torres (1998) introduce también esta categoría al reseñar las

diferencias que se dan en tiempo y espacio, indicando con ello que la juventud no es un grupo poblacional ausente de los procesos sociales y que tampoco se representa de igual manera, aún dentro del mismo espacio social, que puede variar de acuerdo a condiciones de distinto orden establecidas en la vivencia de su realidad. (p. 7)

Desde el punto de vista de Bourdieu (1980), la noción de generación expresa las relaciones de poder, es decir, "los jóvenes son los que luchan por el poder frente a los viejos” (p. 143). Denota esta concepción una especie de fronterización en la que la edad se asocia a una serie de condiciones relativas al comportamiento, a las obligaciones, que han sido asignadas socialmente en lo que Bourdieu denomina "la reproducción", que marcan los tiempos de transición entre una etapa y otra. Por su parte, Leccardi y Feixa (2011) afirman que el concepto de generación ha pasado al menos por

tres momentos históricos coincidiendo con situaciones sociopolíticas concretas, un primer momento se sitúa en el periodo entre guerras en la década de los años 20', y su fundamento filosófico se centró en el relevo generacional; un segundo momento en los años 60 caracterizado por las protestas juveniles 
que los autores identifican con el vacío generacional y el conflicto generacional; el último momento hace referencia a los años 9o'[,] la clave que corresponde a este periodo es el desarrollo de la tecnología digital[,] destacándose la experticia de los jóvenes frente a estos procesos innovadores. (p. 13)

Esta concepción indica que el término se relaciona con un tránsito temporal conectado a hechos históricos que marcan un punto de quiebre a partir del cual los grupos nacidos en un cierto momento viven bajo el influjo de hechos que los caracterizan y crean una conciencia generacional.

\section{JUVENTUD COMO CAPITAL SOCIAL: UNA VISIÓN PROPOSITIVA}

En esta investigación la apuesta es por considerar la juventud como capital social. Una mirada más positiva e inclusiva respecto de los jóvenes es aquella que parte de considerarlos agentes participativos en los espacios en los cuales interactúan, esto es: la familia, la escuela y sus comunidades, reconocer en ellos la posibilidad de ser actores estratégicos del desarrollo. Las teorías tradicionales sobre la juventud comienzan a ser cuestionadas por considerarse discursos normativos y paternalistas, que en nada han favorecido el progreso. Las múltiples formas de vivir la juventud se piensan hoy de modo más objetivo y se orientan a valorarla por sus propias realizaciones, sus necesidades y sus potencialidades. Piotti (2000), citada por Caputo y Palau (2004), indica que

ahora para intervenir hay que cambiar la dirección de nuestra mirada y empezar a conocer a los niños y adolescentes desde ellos mismos, desde sus propias necesidades, inquietudes y saberes, empezar a reconocerlos con sus potencias y capacidades, con un poder, que es el poder del crecimiento, con una entidad propia, con fuerza discursiva y organizativa. (p. 9)

Estamos ante una mirada diferente en la noción de juventud, que pasa de la observación victimizante al reconocimiento de los jóvenes como sujetos de acción en la sociedad, capaces de integrarse y organizarse; jóvenes preparados para interrogarse acerca de las cuestiones sociales 
y su papel político, de su participación, pero por encima de todo, capaces de interpelar su función particular, de exigir sus derechos y de manifestarse frente a la injusticia, la inequidad y la exclusión. Esta mirada encuentra en Caputo y Palau (2004) tres categorías para el análisis de la juventud e indican que estas deberían ser tenidas en cuenta para formular las políticas oficiales, a saber: "las cuestiones vinculadas con el capital social, la capacidad para introducir emprendimientos y el desafío de la ciudadanía” (p. 9).

El concepto de capital social es muy empleado en las ciencias sociales, al igual que fundado en el de capital humano. Saiz y Rangel (2008) dicen que "aparece como uno de los desarrollos conceptuales más prometedores, para explicar las causas del desarrollo o del subdesarrollo y proponer alternativas más allá de las inversiones tradicionales en capital físico o humano" (p. 251). Una visión de juventud desde el capital social considera las posibilidades juveniles como aporte importante para el desarrollo social; Bourdieu (1984) y Trigilia (2003) lo definen como un "conjunto de recursos, una red de relaciones sociales de las que disponen los sujetos, más o menos institucionalizadas de conocimiento o reconocimiento mutuo" (pp. 2-3), se interpreta así la idea de capital como un poder que estructura las relaciones sociales.

Kliksberg (1999) amplía el concepto ratificando que "es el único capital que no disminuye o se agota con el uso, al contrario, entre más se usa, más crece” (p. 89). Contemplar al joven desde el punto de vista del capital social es reconocer el valor de sus realizaciones, es una manera positiva de considerarlo como actor social. Por su parte, Caputo \& Palau (2004) consideran que es hacia la "formación del capital social que se deben orientar los procesos de desarrollo de las comunidades en las que viven generaciones de jóvenes" (p. 11).

Concebir al joven desde la ciudadanía lo convierte en sujeto de derechos. Se entiende aquí la ciudadanía como una condición de pertenencia del individuo a una comunidad política; constituye una relación entre el individuo y el Estado, que es quien garantiza el disfrute de los derechos, y el ciudadano que se compromete a cumplir sus deberes. La modernización de la sociedad constituye un rasgo de seguridad que les permite a los ciudadanos liberarse de las imposiciones porque final- 
mente comprenden qué es lo que se espera de ellos y lo que se busca al establecer la norma e igualmente valoran el orden social que beneficia a todos y genera mejores modelos de relación con los demás, lo que les facilita afrontar sus relaciones con mayor confianza en los demás. Por otra parte y con referencia a los jóvenes, "el bajo grado de ciudadanía juvenil alimenta o refuerza la exclusión social, llevando a la persona a la agresividad, el hastío, la desconfianza, la depresión, hasta inclusive a conductas proclives al paternalismo o directamente al inmovilismo" (Caputo \& Palau, 2004, p. 11).

Lo anterior se concibe también como desciudadanización, cuando la persona no siente que se le reconocen sus derechos y por el contrario se percibe fuera de la sociedad y de los compromisos que ella le atribuye, lo que trae consigo desconfianza y desaliento cuando no encuentra a quién recurrir, e incluso, puede perderse el sentido de la existencia. La exclusión confronta al sujeto con la imposibilidad de ser y por ende con la dificultad de concretar su proyecto vital. Los esfuerzos por vincular los jóvenes a la vivencia de la ciudadanía se reflejan en la promulgación de sus derechos específicos, en Colombia mediante la Ley de Infancia y Adolescencia, con lo que se da cumplimiento a los mandatos internacionales de instaurar para toda la población el reconocimiento expreso de los derechos sociales, políticos y económicos. Frente a este aspecto es necesario admitir que existe temor generalizado a permitir la participación de los más jóvenes, con lo que se evidencian limitaciones en el cumplimiento de la norma. Por ello es importante alentar la participación juvenil, por cuanto es de esta forma que se vinculan a los procesos sociales y políticos y se constituyen en parte de su dinámica para poder viabilizar sus iniciativas.

La última categoría señalada por Caputo \& Palau (2004) para abordar el concepto de juventud es la de emprendimiento. En lo que respecta a la capacidad emprendedora, esta se interpreta como la posibilidad de transformación social; el concepto fortalece y complementa los dos anteriores, debido a que emprender significa, también, mejoramiento del capital social, lo que a su vez alude al desarrollo de la ciudadanía. Emprender implica igualmente cambiar la cultura de las personas en torno a la posibilidad que tienen de comprometerse en la evolución de las condiciones personales y de sus comunidades. 
Los abordajes anteriores dan pistas sobre cómo enfrentar la situación desigual por la que atraviesan, pero especialmente son acercamientos más humanos que favorecen la interacción en la que se ponen en juego las habilidades, la creatividad y los valores de los jóvenes; es de este modo como asumimos al joven frente a la posibilidad de intervenir propositivamente en la solución de sus problemáticas y las de sus comunidades, con lo que podrá iniciar tareas de emprendimiento, organización y asociación con otros para constituir una fuerza deliberante y democrática que pueda participar en el escenario social y producir cambios. Chicos como los integrantes de las barras del fútbol han mostrado que es posible, con una orientación positiva y propositiva, reforzar las relaciones de solidaridad desde las que puedan recuperar la confianza y reconstruir los lazos sociales que se han roto debido a su comportamiento.

Ser joven en este momento no es fácil, las búsquedas de sí mismo y de su lugar en el mundo se conjugan y producen un horizonte de desconcierto donde los espacios que antes fueron el soporte para el desarrollo, como la familia, ya no lo son; es un tiempo marcado por la incertidumbre que socialmente tampoco tiene respuesta para sus expectativas. Dice Brater (1999) que "con el proceso de individualización, han sido eliminados los datos externos básicos que ofrecían, al menos, una tosca dirección y una cierta seguridad moral al precario proceso de búsqueda propio de la juventud” (p. 138), esto es, que los adultos ya no son un referente y la sociedad tampoco tiene respuesta a sus búsquedas vitales, así como tampoco las normas de los adultos son ajustables a los estilos juveniles, fórmulas que fueron útiles para sus padres, pero que para ellos representan modos poco significativos de proceder. Aquí cobra importancia la visión de un joven más proactivo, solidario y autónomo reconociendo los aportes que éste puede hacer, con capacidad de emprendimiento, vale decir, con capacidad para transformar y transformarse socialmente y formado para el ejercicio de una ciudadanía activa, reconocido como sujeto de derechos. 


\section{JÓVENES EN BOGOTÁ: \\ ENTRE LA EXCLUSIÓN Y LA FRUSTRACIÓN}

La juventud al ser un producto social, es una condición que se construye y reconstruye en el devenir de las sociedades y en la interacción social.

Carmen Rengifo Castillo Jóvenes, conflictos urbanos y alternativas de inclusión

\section{JÓVENES PROBLEMA O LOS PROBLEMAS DE LOS JÓVENES}

En este apartado presentamos los problemas más sentidos que afrontan los jóvenes en la actualidad y las implicaciones que tienen en su desarrollo, con base en el imaginario social que los considera problemáticos, desde una mirada desprevenida (¿o prevenida?), como etiquetaje, en la que no se hace alusión a la multiplicidad de situaciones difíciles por las que atraviesan.

El presente de la población juvenil, no solo en Colombia, sino en general en el contexto latinoamericano, es deficitario. Asistimos a un deterioro paulatino de las condiciones de vida en muchos países que se manifiesta en mayor brecha de pobreza, cuyas características más visibles están representadas en la desigualdad y la exclusión; bajo acceso a la educación, precarización del empleo e incertidumbre, y la situación aumenta en poblaciones consideradas vulnerables, por ejemplo indígenas y afrodescendientes, o aquellos afectados por el conflicto armado que no han sido objeto de atención específica por parte de las políticas públicas. Los alcances de las políticas públicas diseñadas para los jóvenes no superan las expectativas y están produciendo pobres resultados, allí se encuentra la raíz de diversos problemas a los que se enfrenta hoy nuestro continente.

Desde 1990 ha tomado importancia el interés por reducir la desigualdad en Latinoamérica, considerado el continente con mayor desigualdad, esto afecta directamente las condiciones de vida de todos los pobladores, pero son los jóvenes quienes han sufrido con mayor rigor la escasez de empleo y el bajo ingreso a la educación superior, a la salud y a los servicios básicos. 
El siglo XX consideraba al joven beneficiario de las políticas públicas, mientras que el siglo XXI reconoce en él un actor participante en las cuestiones que les aquejan; hechos importantes como los avances tecnológicos y las mejores condiciones demográficas en relación con la considerable disminución de los nacimientos, pronosticaban un mejor desarrollo regional. Se estima que "si en el pasado y desde la lógica de la reproducción, los jóvenes solo debían prepararse para ser adultos (asumiendo paulatinamente roles adultos, como trabajadores y ciudadanos, fundamentalmente) en la sociedad del conocimiento (actualmente en construcción) deberán ser los abanderados del cambio y la modernización social” (Rodríguez, 2002, p. 218).

Es urgente pensar en estrategias que vinculen la mayor cantidad de jóvenes al empleo, a la educación, la salud, la cultura y la recreación; se cuenta con un gran potencial que puede hacer la diferencia en los temas de crecimiento y mejoramiento de la igualdad y la equidad (temas que la mayor parte del tiempo han estado ausentes en las agendas políticas de los países), lo cual puede contribuir a solucionar conflictos como la violencia y la inseguridad. Es claro que las políticas de juventud registran un gran atraso en relación con la preparación para la transición social.

Donas (2001) indica que "los niveles de desigualdad e inequidad no son similares para todos los jóvenes y por ello deben pensarse estas diferencias a la hora de implementar programas o políticas relativas a estas poblaciones" (p. 25). Igual sucede con la consideración de que, aunque las problemáticas del continente son muy parecidas, deben tratarse de acuerdo con las realidades de cada uno de los países, sin embargo son sensibles los problemas de educación (acceso, cobertura, permanencia, calidad), salud (básicamente la atención en sexualidad: maternidad temprana, control natal, enfermedades de origen sexual, entre otras), el trabajo en condiciones de igualdad, recreación y cultura. La apuesta es por el desarrollo de sus potencialidades y creatividad, de tal forma que sea posible el disfrute de sus derechos ciudadanos en comunidades armónicas y solidarias; desde luego, son retos importantes para el desarrollo de Latinoamérica. Estos desafíos que plantea Donas serán difíciles de alcanzar porque muchos de ellos están ligados 


\section{a situaciones estructurales de los Estados que no pueden solucionarse a corto plazo y requieren de una decidida voluntad política (Tabla 1).}

Tabla 1. Desafíos y retos de los jóvenes latinoamericanos

\begin{tabular}{|c|c|c|c|c|}
\hline $\begin{array}{c}\text { Desafíos } \\
\text { políticos y de } \\
\text { ciudadanía }\end{array}$ & $\begin{array}{c}\text { Desafíos de } \\
\text { exclusión }\end{array}$ & $\begin{array}{c}\text { Desafíos de } \\
\text { inclusión }\end{array}$ & $\begin{array}{c}\text { Desafíos en } \\
\text { el ámbito de } \\
\text { los valores }\end{array}$ & $\begin{array}{l}\text { Desafíos de } \\
\text { inequidad }\end{array}$ \\
\hline $\begin{array}{l}\text { Necesidad } \\
\text { de recono- } \\
\text { cimiento } \\
\text { político-so- } \\
\text { cial del grupo } \\
\text { adolescente- } \\
\text { juvenil: } \\
\text { Reconoci- } \\
\text { miento de } \\
\text { los jóvenes y } \\
\text { adolescentes } \\
\text { como ciuda- } \\
\text { danos; } \\
\text { Necesidad } \\
\text { de reconocer } \\
\text { la diversi- } \\
\text { dad dentro } \\
\text { del grupo } \\
\text { adolescente- } \\
\text { juvenil in- } \\
\text { cluyendo las } \\
\text { diferencias } \\
\text { de género; } \\
\text { Política } \\
\text { explícita } \\
\text { para el grupo } \\
\text { adolescente- } \\
\text { juvenil, } \\
\text { inserta en la } \\
\text { política social } \\
\text { del país. }\end{array}$ & $\begin{array}{l}\text { Las opciones } \\
\text { de parti- } \\
\text { cipación } \\
\text { social de los } \\
\text { adolescentes } \\
\text { y jóvenes son } \\
\text { muy limita- } \\
\text { das: } \\
\text { Participación } \\
\text { social en } \\
\text { salud; } \\
\text { Deprivación } \\
\text { económica, } \\
\text { educativa, } \\
\text { recreativa y } \\
\text { cultural; } \\
\text { Carencia de } \\
\text { seguridad } \\
\text { social; } \\
\text { Carencia de } \\
\text { legislación; } \\
\text { Carencia de } \\
\text { salud inte- } \\
\text { gral; } \\
\text { Desempleo. }\end{array}$ & $\begin{array}{l}\text { Estar } \\
\text { incluido en } \\
\text { el inicio de } \\
\text { una aparente } \\
\text { tranquili- } \\
\text { dad y un } \\
\text { sentimiento } \\
\text { positivo: } \\
\text { Visión peyo- } \\
\text { rativa estig- } \\
\text { matizante; } \\
\text { Consumido- } \\
\text { res y fomen- } \\
\text { tadores de } \\
\text { consumo; } \\
\text { Actores y } \\
\text { objeto de } \\
\text { violencia, } \\
\text { explotación y } \\
\text { abuso. }\end{array}$ & $\begin{array}{l}\text { Cultura de } \\
\text { consumo - } \\
\text { Consumo de } \\
\text { cultura: } \\
\text { Cultura del } \\
\text { riesgo, del } \\
\text { placer y del } \\
\text { cuerpo; } \\
\text { Sexualidad y } \\
\text { genitalidad; } \\
\text { Relaciones } \\
\text { entre géne- } \\
\text { ros; } \\
\text { Familia } \\
\text { como en- } \\
\text { tidad de } \\
\text { cambio; } \\
\text { La maqui- } \\
\text { naria de la } \\
\text { violencia y } \\
\text { el valor de la } \\
\text { vida; } \\
\text { Virtualidad. }\end{array}$ & $\begin{array}{l}\text { Inequidades } \\
\text { en salud, } \\
\text { educación, } \\
\text { empleo y } \\
\text { seguridad } \\
\text { social: } \\
\text { Adolescentes } \\
\text { y jóvenes } \\
\text { organizados } \\
\text { tanto en el } \\
\text { planteamien- } \\
\text { to y solucio- } \\
\text { nes de los } \\
\text { problemas } \\
\text { como en la } \\
\text { ejecución } \\
\text { de políti- } \\
\text { cas, planes, } \\
\text { programas y } \\
\text { proyectos que } \\
\text { surjan para ir } \\
\text { reduciendo la } \\
\text { inequidad. }\end{array}$ \\
\hline
\end{tabular}

Fuente: Donas (2001, pp. 25-38). 
Socialmente los jóvenes participan y se visibilizan tratando de buscar un lugar en las dinámicas de las ciudades, para lo que emplean muchas formas expresivas que los hacen en ocasiones incómodos para sus comunidades, familias y escuelas. Las miradas adultas sobre los jóvenes por lo general tienden a tergiversar y hacerse ideas respecto de situaciones o signos que para ellos tienen significado y para el adulto representan un desafío, finalmente se produce un choque en el que la ruptura relacional se hace evidente. Duarte (2001) señala:

"Son cada vez mayores las distancias y los puentes rotos que van surgiendo entre el mundo juvenil y el mundo adulto, cuestión que aflora en las familias, en las escuelas, en las comunidades locales, en las organizaciones de diverso tipo y en los propios grupos de jóvenes. Todo esto pone un matiz de dificultad en la consideración que las distintas sociedades van mostrando hacia ellos y ellas, así también se generan actitudes de tensión permanente de las y los jóvenes hacia sus entornos ( $p .58$ ).

En Bogotá los jóvenes irrumpen en la cotidianidad de manera abrupta, para marcar con fuerza su aparición en la escena social. En 1984 un joven sicario, de tan solo 16 años, enviado desde Medellín, asesina de varios disparos y desde una motocicleta al ministro de Justicia de la época, Rodrigo Lara Bonilla. El joven, Byron de Jesús Velásquez, es retenido en el lugar de los hechos y su compañero cae abatido por la escolta del ministro. A partir de este momento se desata en el país la peor oleada de violencia entre el Estado y los carteles del narcotráfico, que afectó profundamente a la justicia, jueces, investigadores y otros funcionarios, quienes se convirtieron en objetivo de estos delincuentes. Asimismo, el país comienza a conocer la vinculación de políticos, autoridades y funcionarios estatales con estas organizaciones criminales, situación que aún no se supera.

Con hechos como el anterior, la mirada que se cierne sobre los jóvenes les identifica como problema y los imaginarios que circulan sobre ellos muestran una realidad trágica en la que sus comportamientos comienzan a ser criticados y satanizados. El joven, sus manifestaciones, producciones, modos de ser y su condición son objeto de permanente desconfianza. La participación juvenil en la vida cotidiana del país se convierte en tema de los medios de comunicación y con ello se develan 
los múltiples escenarios en los que se ven implicados, especialmente la delincuencia, consumo de drogas, reclutamiento forzado y también voluntario en ejércitos de grupos ilegales, porte de armas, entre otros, que los han convertido en poblaciones vulnerables y vulneradas al ser captadas por actores al margen de la ley que bajo promesas de un futuro mejor los inducen a comprometerse en actividades ilícitas.

Este panorama ha encontrado en los jóvenes al sujeto por definición portador de violencia; el imaginario predominante en la sociedad es el de joven problema; así, la mirada difundida acerca de lo juvenil se funda en preconceptos generalmente negativos, al punto que ser joven es una condición que se asocia al desorden, el vandalismo, consumo de drogas y alcohol, delincuencia o cualquier otro comportamiento intolerable.

\section{JÓVENES EN BOGOTÁ: HABITANDO ¿QUÉ CIUDAD?}

Bogotá ha venido registrando un crecimiento demográfico acelerado e inequitativo debido a la migración generada por el desplazamiento forzado, producto del conflicto armado que vive el país. No es posible comprender en Colombia ninguna situación sin que ello remita al conflicto armado y el impacto que este ha producido desde los puntos de vista político, económico y social. La degradación paulatina del conflicto ha dejado al país con diversos problemas, uno de ellos es la crisis humanitaria producida por fenómenos como el desplazamiento, que ha tenido incidencia no solo en las poblaciones rurales de casi todos los departamentos del país, sino también en las grandes ciudades. Londoño (2004) afirma que "Bogotá es el segundo centro receptor de población desplazada en Colombia, después de Medellín” (p. 368).

La principal dificultad cuando se trata de caracterizar este fenómeno en Bogotá radica en la dispersión de información. Entidades públicas y privadas difieren ampliamente en las cifras 
y datos; así por ejemplo, el sector oficial (Acción Social y Fundación Social, s. f.), sostiene que la ciudad ha recibido, entre 1997 y 2010, 292.913 personas cuya composición familiar es de cuatro miembros aproximadamente; el Departamento Administrativo de Planeación Distrital y la Corporación Arco Iris afirman que hasta el 2004 habrían llegado 558.140 personas; Codhes y la Fundación de Atención al Migrante refieren que entre 1985 y 2006 Bogotá recibió 624.286 personas, que representaría más del 16\% del total nacional (Tabla 2).

Tabla 2. Recepción de población en situación de desplazamiento forzado en Bogotá

\begin{tabular}{|c|c|c|}
\hline \multicolumn{3}{|c|}{ Entidades y datos sobre recepción de población en situación } \\
de desplazamiento forzado en Bogotá
\end{tabular}

* Programa de Integración a la Universidad.

** Consultoría para los Derechos Humanos y el Desplazamiento.

*** Fundación de Atención al Migrante.

Fuente: elaboración de la autora con base en Acción Social \& Fundación Social (s. f., p. 17).

Fuente: elaboración de la autora con base en DANE, Censo 2005 (citado por De Roux, 2010). 
Es importante agregar que muchas personas no se inscriben en los registros oficiales porque las circunstancias del desplazamiento las obligan a permanecer en el anonimato para preservar sus vidas o evitar la estigmatización. El informe señala que el desplazamiento ha mostrado una dinámica que se orienta por los trasegares del conflicto, al registrarse mayor afluencia de personas entre los años 2002-2006, período que coincide con la ruptura de los diálogos de paz en el gobierno de Andrés Pastrana y el primer gobierno de Álvaro Uribe; posteriormente, entre 2006 y 2010 se presenta aumento sustancial del número de migrantes, que corresponde a la escalada de la confrontación armada entre el Estado, los grupos insurgentes y las bandas emergentes. Urge entonces establecer la verdadera dimensión del fenómeno, unificar las cifras y formular políticas adecuadas para la atención de estas poblaciones. Con este panorama y los datos que aportan cada una de las entidades, se presentan algunas particularidades del desplazamiento forzado en la capital colombiana.

Según datos de la Personería de Bogotá (2006), esta entidad recibió "11.00o declaraciones de desplazados que corresponden a la llegada de 40.291 personas que huían del conflicto armado, de ellos 20.911 fueron menores de edad, 10.932 mujeres y 8.784 hombres" (s. p.). El desarraigo marca la vida de estas personas y su llegada a la ciudad se hace en condiciones de extrema vulnerabilidad, agravada en la mayoría de los casos por ubicarse en zonas igualmente vulnerables y complejas socialmente, así lo ratifica el estudio de Hernández \& Gutiérrez (2010) al señalar que "la mayoría de la población que llega a la ciudad se ubica en localidades pobres de la zona suroriental como Ciudad Bolívar, Usme, San Cristóbal y Rafael Uribe; de la zona suroccidental Bosa y Kennedy, y en la zona noroccidental en Suba y Engativá" (p. 25). Hernández \& Gutiérrez también establecen el número de personas que fueron desplazadas a nivel nacional, e indican que entre 2005 y 2008 más de 1.200.000 personas fueron expulsadas de sus lugares de origen, en 2009 el promedio nacional de desplazamiento fue de 1.500 personas por día.

Este fenómeno, con todas sus situaciones conexas, como el desarraigo, la violencia, la desestructuración familiar, la violencia intrafamiliar, el desplazamiento intraurbano (el estigma de ser desplazado), entre 
otras, es lo que se ha llamado la urbanización de la guerra. Este escenario entremezclado con problemáticas como las milicias urbanas, el narcotráfico, el paramilitarismo, el accionar de grupos del crimen organizado, son responsables de la violencia e inseguridad en las ciudades. En el balance sobre la política pública de juventud, De Roux (2010) señala que los jóvenes en la ciudad constituyen la cuarta parte del total de la población, es decir, según datos obtenidos del censo de 2005: "la población joven en Bogotá está conformada por 1.595.176 personas con edades entre los 14 y los 25 años"; la distribución por sexo y edad se presenta en la Tabla 3.

Tabla 3. Población joven en Bogotá, 2005

\begin{tabular}{|c|c|c|c|}
\hline Edad & Total & Hombres & Mujeres \\
\hline $14-17$ & 462.351 & 230.988 & 231.363 \\
\hline $18-26$ & 1.132 .825 & 536.627 & 596.198 \\
\hline Total & 1.595 .176 & 767.615 & 827.561 \\
\hline
\end{tabular}

Fuente: Comité Distrital de Vigilancia Epidemiológica (201o, p. 43)

En este mismo informe se reconoce a los jóvenes como aquella facción de la población que afronta con mayor intensidad problemas sociales como desempleo, embarazo no deseado, pandillismo, hechos violentos, consumo de sustancias psicoactivas, violencia física y sexual, suicidio, entre otros, datos que igualmente fueron tomados de los informes anuales del Instituto Nacional de Medicina legal y Ciencias Forenses, así como de estudios hechos por entidades distritales. Esto ha permitido corroborar que la situación actual de los jóvenes es crítica y que la atención a los temas que les afectan - aunque se han hecho esfuerzos en las sucesivas administraciones por atenderlos- presentan aún grandes limitaciones; en campos como el empleo, el acceso a la educación superior, la formación para el trabajo, el emprendimiento, entre otros, los avances siguen siendo insuficientes.

En el informe de De Roux (2010) se indica que en Bogotá son los jóvenes quienes más se suicidan, los hombres entre 20 y 24 años y las mujeres entre 15 y 24 años. Por otra parte, Taborda \& Téllez (s. f.) señalan que el suicidio varía por localidad; en 2005 las tasas más altas se registraron en las localidades de "Santa Fe (33,6\%), Candelaria 
(25,5\%), Ciudad Bolívar (20,6\%), Fontibón (19,4\%), Mártires (14,7\%), Suba (10,4\%), Usme (9,5\%) Usaquén (8,3\%). Es de anotar que en las localidades objeto de este estudio los suicidios representan el $81 \%$ del total de aquellos que ocurren en Bogotá (Tabla 4). Así mismo, 36 gestantes intentaron suicidarse en el año 2008. La variable ocupación en relación con el suicidio muestra que son los estudiantes quienes más incurren en este tipo de decisiones.

Tabla 4 . Localidades con mayor índice de suicidio en Bogotá

\begin{tabular}{|c|c|}
\hline Localidad & Porcentaje de suicidios \\
\hline Santa Fe & 33,6 \\
\hline Candelaria & 25,5 \\
\hline Ciudad Bolívar & 20,6 \\
\hline Fontibón & 19,6 \\
\hline Mártires & 14,7 \\
\hline Suba & 10,4 \\
\hline Usme & 9,5 \\
\hline Usaquén & 8,3 \\
\hline Fuente: elaboración de la autora con base en Taborda y Téllez (s. f.). \\
\hline
\end{tabular}

En 2009 y 2010 las estadísticas de la Veeduría Distrital (2008) señalan el suicidio juvenil como la tercera causa de muerte entre los jóvenes de la ciudad, las localidades en donde más se produjeron estos casos son Kennedy (seis), Ciudad Bolívar (cinco) y Fontibón (cinco); de los veintinueve casos de jóvenes ocurridos en la ciudad dieciocho fueron hombres (62\%) y once mujeres (38\%) (Gráfico 1). Agrupados los resultados de suicidio consumado entre 2006-2009 se encuentra que, tal y como lo plantea el informe de De Roux (2010), los jóvenes en el rango de edad entre los 15 y 24 años siguen siendo quienes más cometen suicidio en la ciudad; el informe del Comité Distrital de Vigilancia Epidemiológica indica que la forma más utilizada para suicidarse es el ahorcamiento.

En relación con el delito sexual, los datos de este estudio indican que en 2008 se produjeron 2.540 denuncias por este hecho en personas con edades entre los 5 y los 20 años; de estos, 2.109 casos fueron de mujeres y niñas. En el 2008 se reportaron 573 casos de embarazo en 
Gráfico 1. Suicidio consumado en Bogotá, 2006-2009

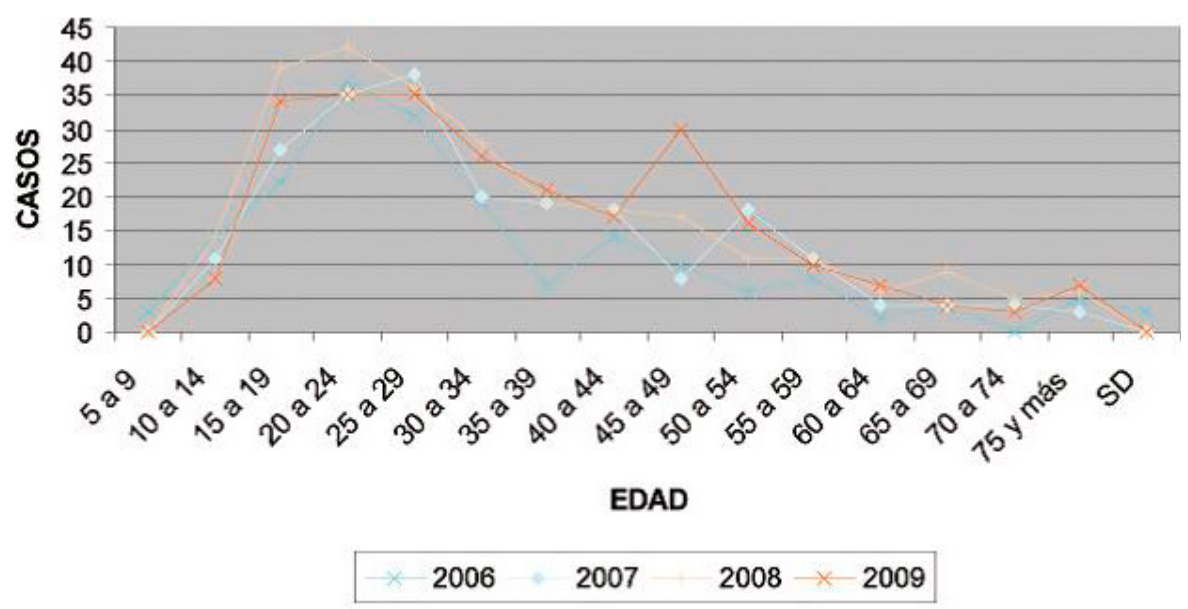

niñas entre 10 y 14 años. Estos embarazos generalmente se asocian con abuso sexual y se consideran también de alto riesgo. Este tema ya ha alcanzado importancia nacional y es objeto de atención de la política pública.

En lo concerniente al consumo de sustancias psicoactivas, De Roux (2010) sostiene que la participación de la población infantil y juvenil es alarmante. En 2006 se reportaron 3.946 casos de jóvenes; en 2007 llegó a 4.847, de los cuales 3.887 fueron de hombres y 960 mujeres, y las edades entre 11-21 años, así como 1.783 casos de menores. El consumo de estas sustancias se concentra entre jóvenes de 11 a 25 años y la sustancia de inicio es el alcohol. Puede apreciarse entonces que la condición del consumo va en aumento y que la población en mayor riesgo es precisamente aquella que se encuentra en la edad de escolarización.

El Instituto para la Investigación Educativa y el Desarrollo Pedagógico y el Colegio Claustro Moderno (2010) convocaron a 10.000 estudiantes de 42 instituciones educativas públicas y privadas de la ciudad con motivo del estudio sobre la caracterización de la población escolar en Bogotá, y se establecieron aspectos importantes relacionados con los ámbitos de desarrollo cognoscitivo, físico y socioafectivo de la 
población escolar en todos los grados. En lo atinente al consumo de otras sustancias el informe señala que la edad promedio de inicio del consumo de cigarrillo en escolares es a los 13 años, el incremento del consumo se produce en los grados $10 .^{\circ} \mathrm{y} 11 .^{\circ} \mathrm{y}$ el consumo es mayor en colegios privados; igualmente, se pudo establecer que el $25 \%$ de los encuestados es fumador frecuente. El estudio llama la atención sobre un porcentaje importante de estudiantes de 10 años en colegios públicos que manifiestan haber empezado a fumar.

En relación con la intención de consumir sustancias, 13\% de los encuestados manifestaron haber pensado en experimentar esta posibilidad, sobre todo en los grados $9^{\circ}, 10^{\circ}$ y $11^{\circ}$. Sobre los tipos y variedad de sustancias psicoactivas que consumen los escolares se indica que la sustancia de mayor demanda es la marihuana, especialmente en los colegios públicos; pero quizá lo más valioso de este informe radica en el reconocimiento de un nuevo espectro de sustancias psicoactivas que comienzan a aparecer como de uso frecuente entre los estudiantes, es el caso del dick, popper $^{1}$ y cripie $^{2}$.

El dick ${ }^{3}$ es una sustancia que se ha venido analizando como parte de las drogas emergentes en el país; en el Estudio nacional de consumo de sustancias psicoactivas en población escolar Colombia 2011

aparece mencionado su consumo entre los jóvenes en el departamento de Risaralda con un 10,6\%. El consumo del cloruro de metileno entre adolescentes escolarizados ha sido objeto de preocupación por las autoridades sanitarias y educativas, considerando el reporte de la muerte de una menor de edad en Bogotá, por esta causa. (p. 79) (Gráfico 2)

1 Popper o rush: sustancia inhalante cuyo compuesto es el nitrito de amilo. Se usa en medicina como vasodilatador y antídoto de intoxicación cianhídrica; es una droga de uso recreativo, incolora y de olor fuerte característico, suele emplearse para potenciar el deseo sexual, se reporta uso de la sustancia en discotecas desde los años setenta, hay indicios de que su consumo continuado puede producir daño neurológico y pérdida temporal de la visión. También se le llama el 'pegante de los ricos' y se mezcla con todo: licor, perico (cocaína)...

2 Cripi: tipo de marihuana que durante su proceso de cultivo ha sido tratada para potenciar sus efectos. Se cultiva en invernadero en condiciones controladas.

3 Dick: la sustancia conocida como dick, ladys o "fragancia" contiene cloruro de metileno (diclorometano), agente volátil, solvente, presente en una gran cantidad de productos comerciales con aplicaciones como adelgazante de pinturas, quitamanchas y otros; es utilizada para efectos recreativos en Colombia y otros lugares del mundo. 
Gráfico 2 Drogas de consumo en la población escolar de Bogotá, 2010

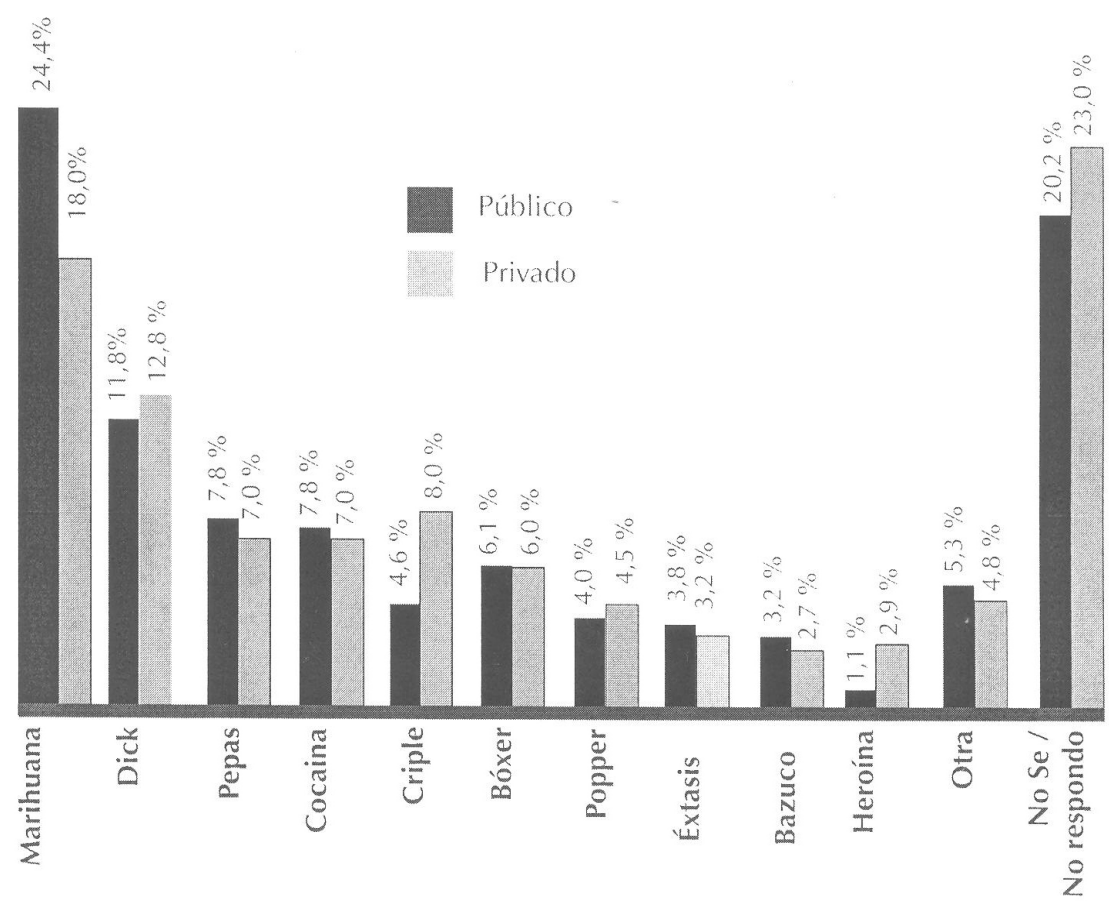

Fuente: Instituto para la Investigación Educativa y el Desarrollo Pedagógico y Claustro Moderno (2010, p. 168)

Una situación complicada en la ciudad con relación a los jóvenes y la cotidianidad es la seguridad. Infortunadamente, en los últimos tiempos los jóvenes han protagonizado hechos que atentan contra la convivencia social, con los que se han visibilizado negativamente en la escena pública. El joven, en medio de su vulnerabilidad, resultado de su inexperiencia social, establece relaciones que ofrecen vida intensa y riesgo, en una urgente búsqueda de sentido; entonces hay cabida para todo aquello que produzca emoción, sensación, quizá este es el motivo de la trasgresión, y como expresa Perea (2008), “el vínculo da muestras de deshacerse por todo lado, el joven no se siente parte de su familia, ni de la escuela y mucho menos de la sociedad que lo estigmatiza, lo excluye y ha precarizado sus condiciones de vida" (p. 32). Un informe de la Secretaría de Integración Social indica que hay más menores delinquiendo en la ciudad, los datos que aporta la entidad se 
apoyan en los reportes de jóvenes que ingresaron al Sistema de Responsabilidad Penal para Adolescentes (SRPA) por haber presentado conductas punibles (Tabla 5).

Tabla 5. Ingreso al Sistema de Responsabilidad Penal para Adolescentes

\begin{tabular}{|c|c|}
\hline Año & Número de casos que ingresaron al SRPA \\
\hline 2009 & 3.653 \\
\hline 2010 & 5.121 \\
\hline 2011 & 5.710 \\
\hline
\end{tabular}

Fuente: elaboración de la autora con base en la Secretaría de Integración Social de Bogotá (citado por Malaver, 2012).

Esta condición de fragilidad del joven es el factor que permite a la delincuencia (bajo la promesa de emoción, autonomía y libertad sin límite proveer las posibilidades para el consumo y también el deseo de pertenencia a grupos) su fácil captación, por lo cual termina mezclado en actividades al margen de la ley. La imagen del joven trasgresor está fijada públicamente, como se mencionó en este documento, desde la década de los ochenta, tras la muerte del ministro de Justicia a manos de un joven sicario al servicio del cartel de Medellín, momento en que la sociedad percibe al joven como parte del conflicto. La osadía de este adolescente indica que algo pasa con los muchachos, así entonces, la tarea de la sociedad consistió en prepararse para asumir su contención, y una situación que se observa poco es el papel que desempeñan los adultos en la inducción de jóvenes al delito, situación para la que se requiere establecer los niveles de responsabilidad adulta en la comisión de estos delitos.

Repasando las cifras históricas de indicadores como la muerte violenta en Bogotá, entre 1997 y 2006 se nota un descenso sensible en esta categoría; sin embargo, en el 2007 se percibe que comienza a tener un comportamiento creciente. El estudio sobre las condiciones de seguridad (Veeduría Distrital, 2008) introduce en su análisis las muertes violentas de menores de 18 años. Estas muertes constituyen una preocupación, pues revela un indicador crítico en la ciudad con tendencia creciente; en 2009 los menores figuraron bastante en las estadísticas de homicidios en la capital. El comportamiento de esta variable muestra también, en 2010, aumento de muerte juvenil. Esto, añadido a las 
muertes por suicidio y las accidentales, deja ver un escenario preocupante en torno a la situación de los jóvenes.

En la Tabla 6 se muestra el comportamiento de la muerte violenta de jóvenes en la ciudad, durante los años 2008, 2009 y 2010. El informe de Medicina Legal de 2010 indica que "en la violencia contra los jóvenes en general se están reflejando el bullying o matoneo escolar y la pertenencia a las barras bravas" (El Tiempo, 2011d).

Tabla 6

Muertes violentas de menores de 18 años en Bogotá, 2008-2010

\begin{tabular}{|l|l|l|l|}
\hline \multirow{2}{*}{ Manera } & \multicolumn{3}{c|}{ Número de casos } \\
\cline { 2 - 4 } & \multicolumn{2}{|c|}{2008} & \multicolumn{2}{c|}{2009} & \multicolumn{2}{c|}{2010} \\
\hline Homicidio & 92 & 130 & 133 \\
\hline Accidentes de tránsito & 30 & 37 & 22 \\
\hline Suicidio & 30 & 24 & 29 \\
\hline Muertes accidentales & 34 & 29 & 38 \\
\hline Total & 186 & 220 & 222 \\
\hline
\end{tabular}

Fuente: elaboración de la autora con base en Veeduría Distrital (2008).

Los datos del Instituto de Medicina legal y Ciencias Forenses en 2011 reportan 145 casos de homicidios de jóvenes en Bogotá, lo que muestra tendencia ascendente. El tema de la seguridad en las ciudades, no solo en Colombia, sino en muchas partes del mundo, es una preocupación. Cada día es más evidente que las formas de urbanizar y fenómenos como el conflicto, han ido construyendo un imaginario de ciudad en el que la idea de vulnerabilidad siempre está presente, manifiesta en las maneras de habitar y percibir el entorno. Para Vásquez y Giraldo (2009), "la seguridad ciudadana es el bien público que sustenta la protección de la integridad física y moral de las personas” (p. 13); considerada como bien público, la seguridad debe constituirse en la meta social más importante, que requiere la contribución de todos.

La seguridad representa para la sociedad el principio de la calidad de vida; en ello se fundamentan el desarrollo, el trabajo, la tranquilidad y la integridad. En Bogotá la seguridad se ha convertido en una preocupación colectiva. La percepción que la gente tiene sobre la inseguridad 
(según datos de la encuesta de percepción y victimización de Bogotá) es que ha aumentado, y "los factores que determinaron esta sensación fueron la presencia de grupos con el $45 \%$ (principalmente delincuencia común) y el deterioro de las condiciones socioeconómicas con $41 \%$ (en particular el desempleo).

Perea (2004) afirma que "cuando la inseguridad se convierte en el principal y más apremiante problema ciudadano es preciso mirar con detenimiento lo que allí está en juego" (p. 142). Esto, pensando en el estereotipo del joven como imagen de la inseguridad, que ha sido dotado de peligrosidad por aspectos que en muy pocas ocasiones tienen que ver con el carácter violento que se le atribuye. En el contexto social se ha vuelto común satanizar la música, el vestido, el corte de cabello o la pertenencia a grupos, esto no tendría nada de particular si tras ello no apareciera la estigmatización que en nombre del control promueven la persecución y la muerte, sin desconocer que muchos jóvenes se han vinculado a grupos al margen de la ley, lo que no hace más que agravar la situación. Al respecto Perea sentencia: "Parece entonces que ser joven y ser violento, de un tiempo para acá, vienen a ser una misma y única cosa. Se les asocia no sólo con el acto sangriento, se les funde también con el hecho criminal” (2004, p. 143).

La tasa de criminalidad en la ciudad indica, de acuerdo con el Gráfico 3 , que en por lo menos diez localidades existen altos índices de homicidio. La zona céntrica de Bogotá registra las cifras más altas de este delito.

Gráfico 3. Tasas de homicidios por localidad

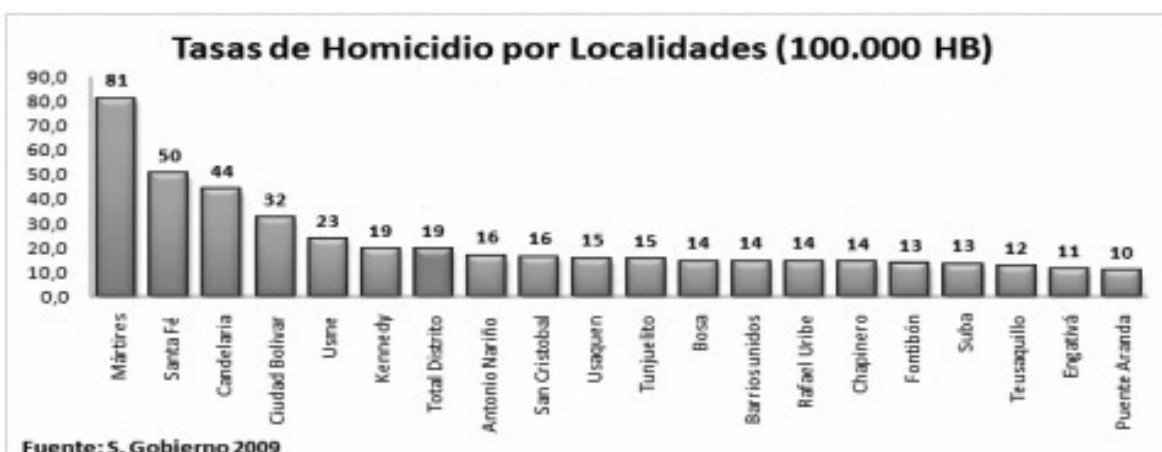


Según Bogotá Cómo Vamos (2009b), los principales motivos de homicidio en la ciudad están relacionados con

venganza el 36,3\%; riñas y discusiones 18,6\%; resistencia al robo $10 \%$; la mayor parte de estos hechos se produce en el espacio público, $63 \%$, y en establecimientos públicos el 16,3\%. Desde el punto de vista de las víctimas el $70 \%$ de ellas presenta un rango de edad entre 15 y 35 años. (p. 4)

Un aspecto clave en esta mirada es el tema de la "limpieza social," la evidencia más perversa de la estigmatización de los jóvenes. Rojas (1994) la define señalando que "es un fenómeno fundamentalmente urbano surgido a finales de la década de los 70’ y comienzos de los 80’ que consiste en la eliminación sistemática de personas consideradas socialmente indeseables" (p. 9). En Colombia se utiliza el término "desechable" para referirse a personas en condición de marginalidad que son objeto de este tipo de prácticas. "La eliminación sistemática de pobres y desposeídos no es simplemente un problema de brutalidad policial. En lo más profundo, ella es el resultado de un sistema económico y político que le echa la culpa a los pobres por su pobreza” (Rojas, 1994, p. 9).

Esta práctica se ha constituido en la herramienta que de tiempo en tiempo se emplea para causar terror entre la población y desde la cual se realiza un control social extremo. "Progresivamente la lista de amenazados se amplía, ahora incluye también a miembros de las barras bravas, estudiantes y a profesores de colegios, así como a los líderes de organizaciones juveniles" (Cepeda, 2009). El periódico El Tiempo (2009a) tituló "Miembros de barras bravas y estudiantes de colegio, amenazados por panfletos en Ciudad Bolívar”, el artículo indica que en la localidad de Usme dos jóvenes aparecieron asesinados e igualmente menciona que sujetos en motocicletas de alto cilindraje toman fotos frente a los colegios y disparan. También son objetivo de estos grupos drogadictos, prostitutas y ladrones. En relación con el tema, el estricto control social que se ejerce en ciertas zonas de la ciudad ha encontrado en la 'limpieza social' su máxima expresión, con ella esperan 'enderezar' a los jóvenes; esta práctica promueve el aconductamiento so pena de perder la vida si no se asumen las normas de la comunidad.

Durante el proceso de investigación, tres de las instituciones educativas participantes recibieron panfletos en los que eran señalados estudiantes 
con nombres y alias, se les acusaba de ladrones, asaltantes, consumidores y expendedores de sustancias; se les conminaba a cambiar su comportamiento y se solicitaba a las instituciones que excluyeran a quienes aparecían en las listas. En el documento se impuso además como hora límite para transitar por los barrios las diez de la noche y podían salir solo a las cinco de la mañana. $\mathrm{Al}$ comentar con los estudiantes el tema hicieron descripción de vehículos que parquean frente a los colegios y toman fotos de estudiantes; refirieron persecuciones por personas desconocidas. "Nosotros ya no salimos por las noches al parque a jugar básquet, la limpieza no respeta a nadie, lo bajan a uno y ahí qué... ¿qquién responde?" (comentario EC- 3/1, entrevista en febrero 20 de 2009). La limpieza social solo tiene un rostro... el de la víctima.

Una de las muchas características de la limpieza social es el altísimo nivel de impunidad, porque se denuncia poco y cuando se hace la justicia no obra con celeridad para aclarar los casos; asimismo, el señalamiento que se hace por los jóvenes ha producido que se conviertan en objetivo de estos grupos, que actúan de diversas formas para cumplir sus fines; se sabe que el modus operandi no es igual en todos los sectores de la ciudad, algunas veces aparecen listas de advertencia, o se producen ataques individuales y grupales cuando los jóvenes se reúnen para departir. Un rasgo de esta problemática es que la mayoría de veces es cohonestada por las comunidades, ello deja en claro la imposibilidad de los organismos del Estado para afrontar la problemática con políticas más coherentes que generen la participación. De algún modo esto legitima la violencia en contra de los jóvenes. Rojas (1994) establece que la limpieza social tiene como objetivo "erradicar un tipo de identidad individual y grupal, que es interpretada por los promotores de esta forma de violencia como amenazante del orden social y de la moral ciudadana" (p. 10), esta violencia tiene un aspecto terrorífico con el que esperan contener el ímpetu juvenil, sentenciándolos panfletariamente: "Los niños buenos se acuestan temprano... a los demás los acostamos nosotros"4.

4 Sentencia contenida en los panfletos que anunciaban la "limpieza social" en sectores populares de Bogotá, enunciada por un escolar participante en esta investigación, quien dijo haber recibido uno en su hogar. 
En algunas comunidades de la ciudad se propician acciones de hecho en contra de los jóvenes. En el sector del Colegio N. ${ }^{\circ} 3$ sucedieron hechos de limpieza social durante el proceso de investigación. Los estudiantes relataron que habían aparecido dos jóvenes asesinados en dos barrios aledaños, con letreros que los identificaban como ladrón a uno y consumidor al otro. Asimismo, en esta misma institución la representante de los estudiantes de la jornada nocturna señaló que en los alrededores de este colegio hay mucha inseguridad, manifiesta en atracos con arma, robos al comercio, ataque a personas, entre otros; dentro del plantel la problemática de seguridad también es vivida, muestra de ello es la alusión hecha al efecto que generaron los volantes de limpieza en las actividades escolares:

Lo último fue el miércoles que repartieron unos pasquines avisando a los muchachos de limpieza, motivo por el cual anoche salimos temprano, anoche se soltó una hora antes porque aquí hay un grupo del Bienestar Familiar (procedentes del conflicto armado y en proceso de reinserción) que están en hogares, en ese grupo hasta el año pasado se trabajaba bien con ellos.

Otro aspecto relevante de la seguridad es el porte ilegal de armas. Según datos de la Secretaría de Gobierno de Bogotá (El Tiempo, 2011g), el tráfico ilegal de armas movió alrededor de 12 millones de pesos diarios en el año 2010 (USD 6.564 aprox.), en el 2009 había superado los 14 millones de pesos al día (USD 7.663 aprox.). El porte de armas fue mencionado como una de las problemáticas más notorias en las cinco instituciones estudiadas en nuestra investigación y es causa de inseguridad en las comunidades y localidades. Aunque se han hecho esfuerzos por controlar el porte de armas en el escenario escolar y de los jóvenes en general, estas siguen siendo preocupación de las autoridades, que han realizado campañas para que sean entregadas voluntariamente. La Tabla 7 registra las armas incautadas en Bogotá por porte ilegal, entre los años 2009-2010.

Los datos muestran que hubo menos porte ilegal de armas en el año 2010 con relación al 2009. Las localidades en las que se realizó esta investigación figuran entre las que el porte ilegal de armas es mayor; en 2010 la mayor incautación de armas ilegales se produjo en Ciudad Bolívar (337) y en toda la ciudad, en ese mismo año, se incautaron 
3.250, mientras que en el 2009 fue en Kennedy (343 armas) y en la ciudad durante dicho año se recuperaron 4.351. En lo que respecta a los costos de las armas (Tabla 8), se encontró que el alquiler de una en la ciudad puede valer $\$ 100.000$.

Tabla 7. Armas incautadas por porte ilegal en Bogotá según localidad

\begin{tabular}{|c|c|c|}
\hline \multirow{2}{*}{ Localidad } & \multicolumn{2}{|c|}{ Año } \\
\hline & 2009 & 2010 \\
\hline Ciudad Bolívar & 325 & 337 \\
\hline Kennedy & 343 & 295 \\
\hline Suba & 225 & 197 \\
\hline Rafael Uribe & 215 & 192 \\
\hline Bosa & 184 & 191 \\
\hline Engativá & 200 & 170 \\
\hline San Cristóbal & 52 & 135 \\
\hline Usaquén & 127 & 122 \\
\hline Usme & 167 & 108 \\
\hline Puente Aranda & 70 & 77 \\
\hline Santa Fe & 85 & 67 \\
\hline Fontibón & 60 & 65 \\
\hline Los Mártires & 66 & 62 \\
\hline Tunjuelito & 92 & 52 \\
\hline Teusaquillo & 48 & 52 \\
\hline Antonio Nariño & 56 & 43 \\
\hline Chapinero & 43 & 39 \\
\hline Barrios Unidos & 63 & 38 \\
\hline Candelaria & 12 & 6 \\
\hline Otras unidades policiales & 229 & 167 \\
\hline Total & 2.762 & 2.415 \\
\hline Valor (\$) & 5.164 .500 .000 & 4.377 .650 .000 \\
\hline
\end{tabular}


Tabla 8. Costo de armas en el mercado ilegal en Bogotá, 2011

\begin{tabular}{|l|l|l|}
\hline \multicolumn{1}{|c|}{ Tipo de arma } & \multicolumn{1}{|c|}{$\begin{array}{c}\text { Costo en el mercado ilegal } \\
\text { (pesos colombianos) }\end{array}$} & \multicolumn{1}{c|}{$\begin{array}{c}\text { Costo en } \\
\text { dólares } \\
\text { (aprox.) }\end{array}$} \\
\hline Revólver & Entre 100.000 y 200.000 & $55-110$ \\
\hline Pistola & Entre 500.000 y 1.000.000 & $277-554$ \\
\hline Fusil o miniuzi & Entre 1000.000 y 1.500.000 & $555-832$ \\
\hline Granadas & 185.000 & 103 \\
\hline Ametralladora & 37.500 .000 & 20.798 \\
\hline \multicolumn{2}{|l|}{ Fuente: elaboración de la autora con base en El Tiempo, 2011g, p. 2). } \\
\hline
\end{tabular}

De los 129 homicidios cometidos en Bogotá en enero de 2011, 64\% (83 casos) se cometieron con arma de fuego; $91,4 \%$ de las armas utilizadas eran ilegales. En la operación promovida por la administración se recogieron 465 armas de fuego, cuyo costo se estimó en $\$ 83$ millones (USD 46.813, aprox.).

Finalmente, en 2010, de acuerdo con el Informe Distrital de Derechos Humanos, el Comité Distrital y los comités locales llaman la atención "sobre la grave situación de violencia en los colegios de Bogotá. Esta violencia tiene manifestaciones graves como amenazas, lesiones y homicidios, agresiones físicas y verbales, trata de personas, expendio y consumo de drogas, hurtos y creación de pandillas". Asimismo, mencionan al ciberbullying como un comportamiento que debe ser observado, además de otros en los que se usan medios tecnológicos para proferir amenazas y hacen un llamado para que los datos sobre este particular se registren de manera diferenciada de tal forma que se puedan hacer análisis más amplios; además señalan la necesidad de orientar la cátedra de derechos humanos hacia la realidad que viven los colegios de Bogotá.

Mención especial merecen los toques de queda para jóvenes que con ocasión de la aplicación del Decreto 013 de 2009 fijó horarios para la venta de alcohol en seis localidades y nueve zonas de la ciudad, lo cual limita la movilidad de los menores de 18 años en estos espacios. "Esto niega a los jóvenes el derecho a la ciudad con el argumento de dismi- 
nuir el delito los fines de semana, la medida genera mayor estigmatización sobre los jóvenes y refuerza los imaginarios negativos sobre ellos" (Bogotá Cómo Vamos, 2009a, p. 6). La actual administración refiere que su propósito en términos de seguridad es la convivencia, debido a que la mayor parte de homicidios y lesiones personales ocurre por esta variable. En este informe se ratifica que el trabajo debe hacerse simultáneamente en convivencia, seguridad y cultura ciudadana.

En dicho contexto y utilizando como apoyo el mapa de los puntos críticos para los jóvenes en la ciudad, puede decirse que la criminalización de lo juvenil se da amparada en un discurso de peligrosidad que se ha construido alrededor de su situación y manifestaciones, pero que responde a problemas estructurales relacionados más con la aplicación de la política social que con el hecho mismo de su edad; se alude al joven con un lenguaje despectivo y las miradas que se ciernen sobre él tienen altísima carga de desconfianza, con lo que se le subvalora y se le considera en minusvalía con relación al adulto.

El joven, hay que decirlo, se ha asociado al crimen, participa del desorden, pero detrás de esto no subyace únicamente el deseo de trasgresión; es la expresión de carencias, frustración, de una búsqueda inmensa de sentido en la que no encuentra asidero, en la que no hay respuestas... es un camino en solitario. El panorama físico de la ciudad desde el que se pretende indicar los lugares de riesgo para los jóvenes muestra abiertamente que no hay un sitio en el que estén seguros, con lo cual se evidencia que la exclusión no es solamente un discurso, es una realidad representada en la imposibilidad de habitar, de transitar, de apropiar el espacio de la ciudad (Figura 1).

El panorama que ofrece la ciudad para los jóvenes no es tampoco muy alentador. Se pretende hacerlos responsables de las graves problemáticas por las que atraviesa la capital, entre ellas la seguridad, cuando esta responde a muchas otras variables, tales como la utilización de los menores por parte de adultos para la comisión de delitos aprovechando su edad, así como al manejo del tema por parte de las autoridades, las bajas o ninguna pena para cierto tipo de delitos, la aplicación de la ley a menores y las presiones sociales para que se disminuya la edad de penalización, sin ofrecer alternativas de educación trabajo, salud y 
participación de los jóvenes. Así mismo es poco lo que se ha discutido en torno al tema de la justicia restaurativa para jóvenes infractores, específicamente en lo atinente a la pérdida de capital humano que con la aplicación de una normatividad eficiente permita el rescate de estos jóvenes para la vida en sociedad.

\section{VIOLENCIA JUVENIL Y CONTRAVENCIONES INFANTO-JUVENILES}

La violencia juvenil es una categoría que se analiza entre las que se producen en el ambiente escolar y en contra de la escuela. Los jóvenes se han hecho partícipes de diversas formas de violencia, se han visibilizado con acciones que alteran la vida de la comunidad y, al igual, sufren la estigmatización que los convierte en delincuentes, ser joven se ha convertido en condición suficiente para ser estigmatizado. La violencia escolar y juvenil se ha convertido en un fenómeno creciente, está presente en diversos ámbitos sociales, ha permeado el entorno de las escuelas y es objeto de discusión sobre todo en lo referente a la formulación de las leyes para menores que buscan su penalización cada vez más temprana. García (2004) escribe al respecto que

la violencia es un síntoma de una mala convivencia $y$, por tanto, reflejo de un lazo social en deterioro que habrá que reforzar o reconstruir en la escuela. El joven violento entonces, atenta contra ese lazo social, la convivencia escolar. Más aún, para algunos sería un "antisocial" que habría que penalizar. (p. 2)

Se denomina violencia juvenil las infracciones a la ley cometidas por jóvenes que afectan el entorno escolar y barrial, las que en general producen alteración de la vida social. Este tipo de violencia se reconoce como parte de las violencias de la escuela, en tanto quienes la ejercen están vinculados a la vida escolar, y sus manifestaciones se asocian además al acoso y el maltrato escolar. Corresponde a hechos como hurto, porte y uso de armas, consumo y distribución de sustancias psicoactivas, y vandalismo. También se asume como tal el acoso sexual, que Chaux (2006) identifica con "aquellas conductas en las que el/la estudiante son víctimas de propuestas, comentarios, gestos, sonidos o insinuaciones de tipo sexual" (p. 35), actos que se conside- 
ran en conflicto con la ley y se asumen como tales los realizados por los jóvenes en el barrismo deportivo. La violencia escolar, pese a que hace parte de las contravenciones juveniles, no constituye hechos punibles y su atención es más de carácter pedagógico y formativo, hablamos por ejemplo de hechos como el acoso, el abuso, el hurto, las riñas callejeras, entre otros.

Este tipo de violencia constituye un fenómeno netamente urbano y la afectación de los jóvenes se da en doble vía, la de agresor y víctima. La violencia juvenil ha sido reconocida como un fenómeno que responde a condiciones de desigualdad y exclusión. Abramovay (2005a) explica que

a lo largo de las últimas décadas, América Latina viene siendo reconocida como un ejemplo de ese fenómeno de profunda desigualdad y exclusión social. Los jóvenes latinoamericanos, y dentro de ellos los comprendidos entre los 15 y 24 años, constituyen la franja de población más expuesta a la violencia. (pp. 53-66)

Es preciso aclarar respecto de agrupaciones juveniles como las barras del fútbol, que muchas de ellas surgen sin un propósito antisocial. En el caso del barrismo la motivación primordial es acompañar a su equipo; sin embargo, este objetivo se distorsiona cuando ingresan a los 'parches' personas con otros propósitos o que han tenido vidas asociadas a la delincuencia y que son capaces de promover comportamientos negativos.

Las autoridades, los medios de comunicación y las comunidades tienden a identificar a las barras y a los grupos de jóvenes con pandillas juveniles. Decker (citado en Rodríguez, 2009) indica que estos grupos juveniles presentan tres tipos de organización:

- Pandillas episódicas: aquellas que se organizan para pasar el tiempo y ocasionalmente cometen delitos.

- Pandillas celulares: organizaciones de pocos miembros que se conforman clandestinamente y por lo general se crean para llevar a cabo actos criminales. 
- Pandillas corporativas: son grupos que se organizan con fines de lucro, con frecuencia integrados por adultos jóvenes que han estado en prisión; algunas de ellas actúan a escala nacional.

Lo anterior explica la diferencia entre los tipos de pandillas. En el primer grupo estarían las barras del fútbol por su modo de organización y el sentido que le dan a su membresía; su conformación tiene un sentido deportivo que es a la vez lúdico, y cuando las condiciones del estadio se alteran es posible la comisión de pequeños delitos que se producen de forma espontánea. En Bogotá las barras futboleras están conformadas de modo heterogéneo, así que no se puede afirmar que las circunstancias sociales de pobreza, marginalidad, desempleo, sean condición suficiente para la aparición de la violencia. Muchas pueden ser las causas que producen dichas confrontaciones, bien por el tipo de relaciones intergrupales que se establecen, la infiltración de las barras por grupos interesados en producir desmanes, por las dinámicas mismas del espectáculo que generan en medio de las celebraciones un escalamiento de la emocionalidad en el que se pierde el control, o por actos propios del barrismo que perturban a las hinchadas; asimismo, por la vinculación de otros actores, a quienes interesa que el espectáculo del fútbol se desarrolle de tal manera que beneficie a algunos agentes relacionados con la actividad, o que se produzcan actos tras los cuales se ocultan, por ejemplo, ajustes de cuentas u otras actividades delictivas, documentadas por los medios y las autoridades tras hechos graves que se han producido en los estadios. Los tiempos son de incertidumbre y las desigualdades en que viven los jóvenes conducen a que se haga evidente el descontento frente a la falta de oportunidades, que debilitan cada vez más su confianza en el futuro. Hopenhayn (2006) asevera que "sin futuro, los diques de contención de la violencia delictual y expresiva también se debilitan” (p. 46). Ante un futuro poco prometedor, los jóvenes se arriesgan, se visibilizan y se exponen, con sus expectativas rotas, al reclamar por la fuerza los derechos que les han sido arrebatados.

Violencia juvenil y delincuencia juvenil se utilizan con frecuencia como sinónimos, pero es importante aclarar que la primera se explica en el campo de la edad y corresponde entonces a las contravenciones a la ley cometidas por jóvenes, y la segunda, desde el punto de vista jurí- 
dico, se aplica a lo inadmisible en el contexto legal. Rodríguez (2005) explica que en Latinoamérica se destacan tres procesos que permiten dimensionar la situación en nuestros países, "el primero de ellos se refiere a la dinámica de las pandillas (maras) juveniles en Centroamérica; el segundo, a la presencia de niños y adolescentes en el conflicto armado colombiano y el tercero a la violencia juvenil en Brasil" (pp. 2-3). Estos tres eventos son un indicador de peso que permite avistar la situación juvenil en nuestro continente, donde ejércitos de jóvenes reclaman ante la exclusión y el abandono oficial.

Estas tres situaciones representativas de la violencia juvenil latinoamericana corresponden a una fuerte realidad que involucra a nuestros jóvenes en situaciones muy complejas y hoy son una preocupación por las escaladas violentas en las que se involucran portando armas y enfrentándose a la autoridad. Estos indicadores deben leerse e interpretarse socialmente. ¿Qué es lo que hay detrás de la decisión de un joven cuando opta por integrarse a grupos irregulares o por confrontar defendiendo su espacio, su territorio, intimidando y convirtiéndose en un problema que ya ha alcanzado estatus de transnacional? La problemática no deja de producir estupor entre la comunidad y es realmente preocupante en el sentido de ser una situación que se ha instalado en la mayoría de los países de América Latina, donde ha encontrado el espacio propicio para crecer y desarrollarse debido a las profundas desigualdades y a la pobreza, y aunque los países grandes, en general, han reducido sus índices de pobreza, la situación sigue siendo difícil para muchos de ellos. Un reporte de Diálogo Interamericano refiere:

aproximadamente uno de cada tres latinoamericanos es pobre (definido como no tener suficientes ingresos para satisfacer sus necesidades básicas). Uno de cada ocho se encuentra en pobreza extrema (definido como no ser capaz de cubrir sus necesidades nutricionales básicas, aún si gastaran todo su dinero en alimentos... el único país que ha logrado reducir sustancialmente la pobreza es Chile, en donde únicamente una de cada ocho personas vive en pobreza. (Puryear \& Malloy, 2009, p. 1)

En relación con la violencia juvenil en Colombia, la participación de los jóvenes en la comisión de delitos se ha convertido en un estereotipo, desde el cual se señala a todos los jóvenes como peligrosos y se 
les ha rotulado como delincuentes por las actividades en las que se implican. Sin embargo, no se puede negar que en mayor proporción los jóvenes participan hoy en delitos y se vinculan con mayor facilidad a grupos al margen de la ley, producto de su misma vulnerabilidad. En esta investigación se ha planteado como hipótesis la conexión de las violencias macro- y microsociales con la diversidad de expresiones delincuenciales juveniles. García y Guerrero (2012b) explican que

las violencias micro y macro son multivariadas expresiones de violencia juvenil, dada por sus estructuras móviles y semiorganizadas que fácilmente derivan en situaciones permanentes o esporádicas de delincuencia que las hace proclives a verse involucradas en circunstancias violentas. Lo que a su vez las coloca en la riesgosa frontera de las violencias organizadas. (p. 23)

A nivel latinoamericano la violencia juvenil nos identifica, es una realidad generalizada en la región que guarda similitudes entre los países, así lo demuestra el estudio de la Comisión Económica para América Latina y el Caribe (Cepal) realizado en doce naciones a fin de identificar las principales problemáticas que afectan a los jóvenes. Además de los denominados problemas 'normales' como la rebeldía, los consumos, el hurto, entre otros, también los chicos asumen compromisos con grupos de violencia transnacional como las maras y el narcotráfico, situaciones que nos llevan a plantear la hipótesis mencionada del vínculo entre las violencias macro- y microsocial. La Tabla 9 devela las dificultades que están afectando el desarrollo de los jóvenes:

Tabla 9. Principales problemas de los jóvenes en América Latina y el Caribe

\begin{tabular}{|c|l|l|l|}
\hline País & \multicolumn{1}{|c|}{$\begin{array}{c}\text { Primero en } \\
\text { importancia }\end{array}$} & \multicolumn{1}{c|}{$\begin{array}{c}\text { Segundo en } \\
\text { importancia }\end{array}$} & $\begin{array}{c}\text { Tercero en } \\
\text { importancia }\end{array}$ \\
\hline \multirow{2}{*}{ Argentina } & $\begin{array}{l}\text { Marginalidad y } \\
\text { falta de expecta- } \\
\text { tivas }\end{array}$ & $\begin{array}{l}\text { Ausencia de pro- } \\
\text { yectos } \\
\text { individuales y } \\
\text { sociales, } \\
\text { drogadicción }\end{array}$ & $\begin{array}{l}\text { Ausencia de pará- } \\
\text { metros y modelos, } \\
\text { desempleo }\end{array}$ \\
\hline
\end{tabular}


Tabla 9. Principales problemas de los jóvenes en América Latina y el Caribe

\begin{tabular}{|c|c|c|c|}
\hline País & $\begin{array}{l}\text { Primero en } \\
\text { importancia }\end{array}$ & $\begin{array}{l}\text { Segundo en } \\
\text { importancia }\end{array}$ & $\begin{array}{l}\text { Tercero en } \\
\text { importancia }\end{array}$ \\
\hline Brasil & $\begin{array}{l}\text { Desigualdades } \\
\text { sociales, } \\
\text { dificultades de } \\
\text { acceso a la educa- } \\
\text { ción y al trabajo }\end{array}$ & $\begin{array}{l}\text { Discriminación y } \\
\text { victimización física } \\
\text { y simbólica por } \\
\text { violencia policial, } \\
\text { muertes violentas }\end{array}$ & $\begin{array}{l}\text { Conflictos recu- } \\
\text { rrentes de consumo } \\
\text { abusivo y tráfico de } \\
\text { drogas }\end{array}$ \\
\hline Chile & Delincuencia & $\begin{array}{l}\text { Violencia en las } \\
\text { escuelas }\end{array}$ & $\begin{array}{l}\text { Violencia en la } \\
\text { pareja }\end{array}$ \\
\hline Colombia & $\begin{array}{l}\text { Conflicto } \\
\text { armado-hurto }\end{array}$ & $\begin{array}{l}\text { Narcotráfico y } \\
\text { delincuencia } \\
\text { común-homicidio }\end{array}$ & $\begin{array}{l}\text { Pandillas y culturas } \\
\text { juveniles, extorsión }\end{array}$ \\
\hline Costa Rica & Rebeldía & $\begin{array}{l}\text { Falta de autoridad } \\
\text { por parte de los } \\
\text { padres de familia }\end{array}$ & $\begin{array}{l}\text { Núcleo en el que se } \\
\text { desenvuelven }\end{array}$ \\
\hline Ecuador & $\begin{array}{l}\text { Maltrato } \\
\text { intrafamiliar }\end{array}$ & $\begin{array}{l}\text { Violencia } \\
\text { intergeneracional }\end{array}$ & Suicidios \\
\hline El Salvador & Pandillas & Delincuencia & $\begin{array}{l}\text { Violencia-maltrato } \\
\text { intrafamiliar }\end{array}$ \\
\hline Guatemala & $\begin{array}{l}\text { Maras (extorsión, } \\
\text { violencia) }\end{array}$ & $\begin{array}{l}\text { Drogadicción y } \\
\text { alcoholismo }\end{array}$ & $\begin{array}{l}\text { Homicidios, fetici- } \\
\text { dios, abuso sexual } \\
\text { infantil }\end{array}$ \\
\hline México & $\begin{array}{l}\text { Violencia } \\
\text { intrafamiliar }\end{array}$ & $\begin{array}{l}\text { Violencia } \\
\text { callejera }\end{array}$ & $\begin{array}{l}\text { Violencia en la } \\
\text { pareja }\end{array}$ \\
\hline Perú & $\begin{array}{l}\text { Delincuencia, } \\
\text { pandillas }\end{array}$ & $\begin{array}{l}\text { Abuso de drogas y } \\
\text { alcohol, violencia } \\
\text { intrafamiliar }\end{array}$ & $\begin{array}{l}\text { Falta de } \\
\text { educación y capaci- } \\
\text { tación adecuada }\end{array}$ \\
\hline $\begin{array}{l}\text { Repúblic a } \\
\text { Dominicana }\end{array}$ & $\begin{array}{l}\text { Consumo de } \\
\text { alcohol y drogas } \\
\text { narcóticas desde } \\
\text { temprana edad }\end{array}$ & $\begin{array}{l}\text { Participación } \\
\text { en el microtráfico } \\
\text { de drogas y } \\
\text { actividades } \\
\text { conexas }\end{array}$ & $\begin{array}{l}\text { Violencia social y } \\
\text { agresividad gene- } \\
\text { ralmente ligada a } \\
\text { lo anterior }\end{array}$ \\
\hline $\begin{array}{l}\text { Rep. Bol. de } \\
\text { Venezuela }\end{array}$ & Robo & $\begin{array}{l}\text { Porte ilícito de } \\
\text { armas }\end{array}$ & Posesión de drogas \\
\hline
\end{tabular}


Los datos revelan que las circunstancias de nuestro continente no difieren en gran medida de un país a otro y se infiere que las raíces de su aparición suelen ser igualmente comunes: pobreza, desigualdad, exclusión y ausencia general de políticas públicas para los menos favorecidos. Hopenhayn (2006), al referirse a la pobreza, afirma que es posible establecer una relación entre aumento de la violencia y desempleo,

así, por ejemplo, Argentina ha padecido un incremento significativo de la violencia en los 90 y a comienzos de la década actual, mientras la tasa de desempleo en el país aumentó de 7.4 en 1990 a 17.2 en 1996. En Colombia la tasa de desempleo se mantuvo casi todo el período 1970-1997 en los dos dígitos, y coincide con el aumento de la violencia urbana. En Venezuela ocurre lo mismo. (p. 51)

El aumento de la violencia juvenil se va estructurando como un fenómeno que, a fuerza de acumular carencias, convierten al joven en el objetivo de las acciones sociales y policiales, en el que la carga de la estigmatización ha difundido un imaginario nefasto que lo señala como criminal. Hopenhayn afirma:

en los procesos de estigmatización operan las profecías autocumplidas. Tanto se dice de un grupo que lleva tal o cual rasgo, que finalmente los individuos que pertenecen a dicho grupo terminan asumiendo el guion que sobre ellos se predica. La violencia puede ser, en parte, efecto del discurso que marca a un colectivo con el fantasma de la violencia. (2006, p. 52)

La violencia juvenil es también considerada como la concreción de la conducta antisocial que refiere al "conjunto de conductas que infringen las normas o leyes establecidas" (Benítez \& Justicia, 2006, p. 95). Farrington (2005) asevera que existen indicadores de la conducta antisocial infantil y adolescente, por ejemplo, "impulsividad, robo, vandalismo, resistencia a la autoridad, agresión física o psicológica, maltrato entre iguales, huida de casa, ausentismo escolar, crueldad hacia los animales, etc.” (p. 177). Desde el punto de vista de las teorías del desarrollo social, Howell (citado por Vásquez, 2003) admite que "el comportamiento delictivo se genera, se nutre y se mantiene dentro de las relaciones sociales" (p. 136), lo cual indica que los comporta- 
mientos de los jóvenes tienen influencia de los grupos en los que interactúan y pueden determinar su conducta, tal sería el caso de los que pertenecen a las barras del fútbol, dada la significatividad del vínculo que establecen con el grupo.

Un aspecto que potencia la imagen negativa de los jóvenes es la percepción de inseguridad que se experimenta en las grandes ciudades, básicamente el miedo se relaciona con la presencia de grupos y personas que parecen sospechosas. El temor se apodera de la gente y afecta la vida social, con lo que igualmente se resquebraja la confianza en el otro, en la autoridad y en la capacidad de respuesta del Estado, lo cual tiene gran repercusión en la interacción social. Kesler (2006) afirma que "en comunidades asoladas por el temor se genera mayor aislamiento entre las personas, que comienzan a desconfiar unas de otras" (p. 61).

Los estudios sobre la violencia juvenil se orientan a la comprensión de factores de riesgo y protección. Torres (2005) expresa:

[e]xisten factores asociados a la violencia que la dinamizan, como las rupturas familiares, el mal uso del tiempo, la desintegración de los valores tradicionales, la marginalidad social; todo esto empuja a los adolescentes a reconstruir su identidad en espacios creados por ellos mismos (pandillas callejeras, barras bravas, etc.). (p. 59)

De este modo se introduce el concepto de factores de riesgo, que se define como "el aumento de la probabilidad [de] que un resultado o contingencia nociva o negativa afecte a una población” (Kazdin, 1993, p. 127). Para el caso de la violencia juvenil se han señalado factores de carácter individual (relativos a la persona), familiares y escolares.

Entre los factores individuales se destacan la falta de habilidades sociales, el fácil acceso a las armas, experiencias de humillación y rechazo, ser víctima de abuso y tener historia de amenaza a otros. Entre los factores familiares pueden destacarse la desestructuración familiar, violencia doméstica, los estilos de crianza, el abuso infantil, hogares con monoparentalidad, baja supervisión de los padres, entre otros. 
Respecto a los factores escolares se mencionan la relación con quienes presentan problemas, el rechazo del grupo, falta de respuestas de los docentes frente a temas como el vandalismo y la agresión, la percepción que tienen los estudiantes de la organización escolar, masificación en el proceso educativo que impide que el estudiante cree vínculos (Justicia et al., 2006, pp.131-150).

Trudel y Puentes (citados por Hein \& Mertz, 2003) amplían dichos factores de riesgo y sostienen que, además de los mencionados, pueden contarse entre los individuales, por ejemplo,

actitudes y valores favorables hacia conductas de riesgo, hiperactividad, temperamento difícil en la infancia; entre los familiares baja cohesión familiar, tener padres con enfermedad mental, estilos parentales coercitivos, ambivalentes o permisivos; igualmente señalan factores relativos a la comunidad tales como bajo apoyo comunitario, estigmatización y exclusión de actividades comunitarias; factores de tipo socioeconómicos $y$ culturales como la pobreza. (pp. 2-3)

Verlinde, Hersen y Thomas (2000) adicionan "la desorganización del vecindario, violencia del entorno, acceso a armas y los prejuicios”. Al conjugarse estos factores puede aumentar el riesgo de aparición de la conducta violenta.

Más allá de establecer las causas que conducen a los jóvenes a participar en hechos de violencia, la tarea primordial es la prevención, mirar cómo desde los diversos ámbitos sociales se puede evitar que los jóvenes se conviertan en infractores de la ley. El Estado, la escuela, la familia, la comunidad barrial y local, están llamados a proveer y garantizar el desarrollo adecuado de niños y jóvenes que hacen parte del presente, que requieren un trato diferenciado a través de políticas de juventud aplicables y eficaces. López (2006) confirma lo anterior al enunciar que

la cuestión más importante sigue siendo el mejorar la identificación de estos grupos de sujetos. Lo que tenemos que hacer es intentar reproducir en esos chicos de riesgo, los factores que -creemos- pueden hacerles inmunes al primer delito, o bien que puedan evitar que sigan implicados en comportamientos delictivos. (p.117) 
Si bien es cierto que los jóvenes en la ciudad por sus acciones y por efectos mediáticos representan la cara de la inseguridad, también es importante decir que son vulnerables, estamos ante muchachos que se forjan con graves dificultades en su tránsito generacional, expuestos a riesgos por su condición, que encuentran en la violencia una forma de manifestar su descontento por las diferentes problemáticas que afrontan centradas en los conceptos de desigualdad y exclusión. Saravi (2006) explica que "los jóvenes están acumulando desventajas y vulnerabilidad para afrontar su adultez” (p. 94).

Figura 2. Violencias macro- y microsocial: relación con violencia juvenil

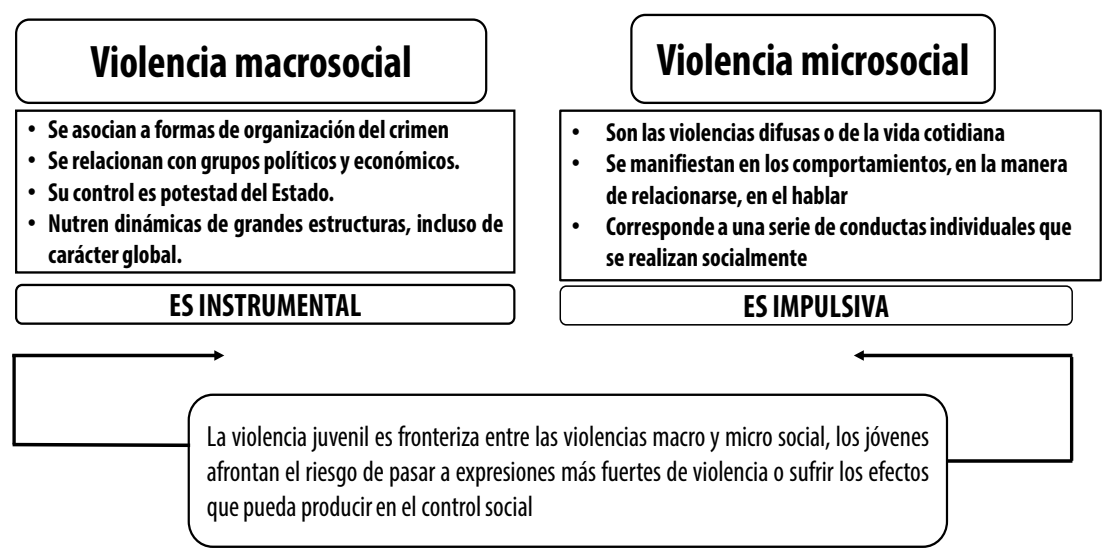

Fuente: elaboración de la autora con base en García y Guerrero (2012b, pp.18-23). 



\section{De FÚtBol, VIOLENCIA Y CORRUPCIÓN}

\section{EL FÚTBOL: UNA HISTORIA DE VIOLENCIA}

Algunos datos generales sobre el origen antiguo del fútbol revelan una actividad que nace en Egipto como parte de rituales relacionados con la fertilidad. Los persas e hindúes practicaron también juegos de pelota semejantes al balonmano de hoy. Se dice que fueron los chinos quienes primero utilizaron una esfera de raíces cubierta de cuero. La Edad Media se considera el tiempo de los juegos de pelota, que no solamente se emplearon para distracción de la población, sino que despertaron tal fervor que incluso "Ricardo Corazón de León llegó a proponer al caudillo musulmán Saladino, que dirimieran cuestiones sobre la propiedad de Jerusalén con un partido de pelota” (educar. org), sin embargo este juego fue prohibido por su carácter violento. El nombre de la pelota en la antigua Grecia era esfaira, al pasar el concepto a los romanos estos la llamaron pila, vocablo que con el uso se transformó en pilotta.

Los antecedentes del deporte se asignan a griegos y romanos, $y$ algunos de estos se caracterizaban por su violencia y crueldad. Por ejemplo, las competencias de cuadrigas en las que se conformaban dos equipos en donde la vestimenta y la actitud de los participantes causaban horror; en las noches se convertían en bandas de asaltantes[,] "se volvió peligroso llevar botones de cinturones de oro o dejarse ver a altas horas de la noche por las calles. He aquí posiblemente, a los antecesores de los violentos en el deporte. (Dunning, 2003, p. 63)

Se recuerdan, igualmente, las justas del coliseo en las que se ejecutaban prisioneros antes de las competencias de cuadrigas. Fueron también griegos y romanos quienes practicaron por primera vez el fútbol; se atribuye a los romanos la llegada del juego a las islas Británicas. Los juegos griegos fueron conocidos también por su violencia, es el caso 
del pancracio, una mezcla de boxeo y lucha. Elías (citado por Dunning, 2003) afirma que "los competidores luchaban con todas las partes del cuerpo. Estaba permitido sacarse los ojos, poner zancadilla, cogerse por los pies, la nariz y las orejas, luxar los dedos de la mano y los brazos y aplicar llaves de estrangulamiento" (p. 64). Los juegos violentos se toleraron bajo el argumento de que eran preparatorios para la guerra. El fútbol se constituyó paulatinamente en un deporte en el que la violencia era un elemento propio de su práctica.

Los deportes del Medioevo inicialmente se asociaron más a la clase social, tal es el caso de los torneos, la cacería, el tiro con arco y los juegos populares:

Era propio de los caballeros el torneo y la cacería, para la clase media el tiro al arco y para el pueblo los juegos populares, las peleas de gallos y perros. Los juegos fueron transformándose más en espectáculo debido a la presencia de mujeres, lo que se considera un aspecto civilizador. (Dunning, 2003, p. 64)

En el siglo XII se encuentran evidencias de la práctica del fútbol en Inglaterra. En la Edad Media se conocieron varios tipos; básicamente era un fútbol que tenía lugar entre grupos rivales en villas y ciudades y también entre pueblos y parroquias. Tomaban parte gran cantidad de jugadores y los arcos podían estar separados a gran distancia uno del otro. Estos juegos, que a menudo eran violentos, peligrosos, estaban asociados con el carnaval, por lo cual recibió el nombre de fútbol de carnaval. Algunos de estos juegos sobrevivieron en Inglaterra hasta bien entrado el siglo XX. Una sucesión de edictos de reyes ingleses llevaron a la supresión del fútbol.

El harpastum (juego romano de la pequeña pelota) estaba inspirado en una práctica griega que utilizaba una vejiga de buey como pelota. Se sabe también que el emperador Julio César era gran admirador del harpastum e incentivaba la práctica entre sus tropas con el ánimo de entretener y mantener físicamente a los soldados. La fuerza del juego producía muertos y heridos. Se cuenta que el emperador se enteró de que en el juego de la mañana solo habían muerto 25 hombres por lo que llamó a Espartaco, general de los ejércitos, y le dijo que si el número de muertos continuaba tan bajo, prohibiría la práctica entre los 
hombres y lo limitaría solo a las mujeres. Al día siguiente el número de muertos fue 47. (Arcanxel, 2010, s. p.)

Las diversas modalidades que adoptó el fútbol en la Antigüedad revelan su origen agresivo. El fútbol y el rugby descienden de juegos populares de la Edad Media caracterizados por su práctica violenta, entre los que además destacan el hurling, el knappan, el camp ball, entre otros. La asistencia como espectador a estos juegos se consideró un acto riesgoso por afectar directamente la integridad de los asistentes. El fútbol se jugó en Liverpool hacia el año 1500 y quienes participaban en él fueron conocidos por su beligerancia. Dunning (2003) afirma que la mayoría de las veces el juego terminaba con "grandes daños, parte de la multitud en estado cataléptico, el cuerpo contusionado o aplastado, piernas, brazos y cabezas rotos y algunos lisiados o en peligro de muerte" (p. 67). El hurling se jugaba a campo traviesa y fue descrito como de máximo peligro, quienes lo practicaban "terminaban con contusiones, maltrechos o fracturados, tornaban a casa como de una batalla”. Sobre el knappan se mencionó que fue un juego en el que se cobraban viejas cuentas.

La mayoría de estos juegos se realizaban a campo abierto, abarcaban grandes distancias, y con multitud de participantes; para su práctica se emplearon zapatos con punteras metálicas, palos y elementos contundentes, con lo cual se le imprimió mayor violencia. Paulatinamente, la constante mejora de las condiciones de la población hizo posible la transformación de las costumbres en los juegos y dado el gran poder que fue alcanzando el Estado se establecieron en las clases sociales exigencias que produjeron la práctica de nuevos hábitos; de los primeros deportes, a los modernos, se dio un gran paso que permitió establecer normas transformadoras que fueron mostrando gradualmente, más que la civilización del deporte, una forma diferente de asumir las prácticas violentas y mantener unos comportamientos que obligaran al control de los participantes. 


\section{EL FÚTBOL COLOMBIANO: LA PERPETUA IMPROVISACIÓN}

El siguiente texto se elaboró con datos cronológicos recuperados de la página web de la Federación Colombiana de Fútbol.

Los inicios del fútbol en Colombia se sitúan entre los años 1900 y 1906, con el arribo de ingenieros ingleses que vinieron a construir el ferrocarril de Puerto Colombia en Barranquilla, quienes en los descansos de las labores organizaban el juego con obreros y jóvenes del lugar. Los primeros equipos que se conformaron lo hicieron en 1906, el Barranquilla Fútbol Club, Santander, Juventus y Unión Colombia. Como organización nace en 1924, con la fundación de la Asociación Colombiana de Fútbol, cuyo reconocimiento jurídico se logró en 1927, mediante resolución firmada por el entonces presidente, Miguel Abadía Méndez. Posteriormente la liga de fútbol establece contactos en las provincias para empezar a difundir este deporte y crear las ligas regionales. Su reconocimiento internacional se produce en 1936, tras la firma de la resolución $N^{\circ} 72$ por parte del presidente Alfonso López Pumarejo. Una vez cumplido este trámite, se hace oficial la petición a la FIFA y a la Conmebol para la vinculación de Colombia a estas agremiaciones internacionales. La gestión estuvo en manos de Carlos Laffourie Roncallo, quien llevó a feliz término este proceso y posteriormente fue nombrado como presidente del primer consejo directivo de la agremiación; así mismo nace el primer colegio de árbitros en 1934.

En el año de 1937, con motivo de la celebración del cumpleaños de la ciudad de Cali se organizan diversos eventos, entre ellos el fútbol. Fueron invitados equipos extranjeros, pero no se contaba con un seleccionado nacional capaz de afrontar este compromiso; se procedió entonces a organizar de emergencia (como muchas selecciones del pasado cercano), un grupo con los mejores jugadores de las diferentes regiones que se habian destacado en los cotejos internos. Los convocados fueron Roberto Meléndez, Severiano Lugo y el portero Escorcia de la Costa Atlántica; Carlos Tulio Obonaga y Omar López, por el Valle del Cauca; y Carlos Álvarez, de Antioquia, entre otros.

En 1948 nace la División Mayor del Fútbol Colombiano y se organiza el primer campeonato profesional, del cual sale vencedor el club Independiente Santa Fe. 
La Dimayor organiza en 1949 su segundo torneo, caracterizado por el retiro de los equipos de la costa Atlántica, tras la quiebra como resultado de muy pobres campañas. La época de oro del fútbol se da hacia 1951 con la llegada de los primeros jugadores extranjeros a los clubes nacionales, gracias a la huelga que había estallado en el fútbol argentino, esto produjo el éxodo de jugadores hacia Colombia; vino inicialmente Adolfo Pedernera a Millonarios y con su intermediación se vincularon también Néstor Raúl Rossi y Alfredo Di Stéfano; este se considera el tiempo de esplendor del fútbol colombiano.

Este hecho provoca un incidente deportivo internacional en el que la Federación argentina denuncia a la Dimayor por contratar de manera irregular a estos jugadores, por tal razón en 1951 Colombia es expulsada de la FIFA, luego de haber sido acusada por los argentinos, de contratar jugadores sin pase internacional. Como resultado de un encuentro celebrado en Lima para discutir la situación, se ordenó a los jugadores argentinos que jugaban en Colombia retornar a sus clubes de origen antes de 1954, con lo que concluiría la llamada época dorada del fútbol nacional. Tras las decisiones anteriores y los acuerdos para su cumplimiento, la FIFA devuelve el reconocimiento a la Asociación Colombiana de Fútbol y la admite nuevamente como miembro. Este incidente deja como secuela la quiebra de varios equipos locales.

Para 1954 la Dimayor agremia 10 equipos profesionales: Nacional, Medellín, Millonarios, Quindío, Deportes Manizales, Boca Juniors, Cali y Santa Fe. En este mismo año el fútbol juvenil hace su aparición en el contexto internacional, con la participación de un seleccionado en el torneo Juventud de América en el que logró una decorosa participación. De 1954 a 1957 los equipos antioqueños se alzan con los campeonatos locales, demostrando con ello su gran momento y su acertada organización.

Los juegos de poder enfrentan en 1964 a la Dimayor y a 10 ligas por la mala administración del fútbol, hubo acusaciones de autopréstamos, mal uso de tiquetes para viajes, viáticos otorgados irregularmente, viajes de dirigentes con dineros de la entidad, entre otros; igualmente se vinculó a algunos periodistas quienes recibieron prebendas a cambio de desprestigiar a las agremiaciones regionales; de esta disputa nace la Fedefútbol, con la presidencia de Alfonso Senior. En 1966 la FIFA, en el congreso de Londres, interviene nuevamente el fútbol colombiano por funcionar con dos entidades, Asdefútbol y Fedefútbol, se nombra 
un comité provisional, y posteriormente en 1976, reconoce nuevamente a la Federación Colombiana de Fútbol que ahora será Colfútbol. El desorden reinante no permitió tener lista a tiempo la representación nacional para enfrentar los compromisos internacionales. Así fueron nombrados un técnico tras otro y conformados seleccionados pocos días antes de los torneos.

La historia del fútbol nacional ha sido el trasegar de la improvisación a la corrupción, promovida por la participación de grupos al margen de la ley en su financiación, e igualmente un ir y venir de desaciertos que han marcado la mediocridad en su organización.

\section{FÚTBOL Y NARCOTRÁFICO EN COLOMBIA: LA INFESTACIÓN DEL DEPORTE}

El 21 octubre de 1983, el entonces ministro de Justicia Rodrigo Lara Bonilla le dijo a todos los medios nacionales e internacionales en una rueda de prensa que «los equipos de fútbol profesional en poder de personas vinculadas al narcotráfico son: Atlético Nacional, Millonarios, Santa Fe, Deportivo Independiente Medellín, América y Deportivo Pereira». Fue la primera vez que se habló de la intervención de dineros ilegales en el fútbol y, lamentablemente, no fue la última.

Pino, Alejandro

("Fútbol, callejón sin salida"), en revista Razón Pública.

Los tiempos de auge del narcotráfico en Colombia pusieron en evidencia su participación en numerosos escenarios de la vida nacional. Quizá no sea aventurado decir que ninguna actividad en el país ha escapado de la influencia del narcotráfico. El deporte no fue ajeno a la tentación del dinero proveniente del negocio ilícito al vincular por igual a jugadores, técnicos, árbitros, socios de clubes y dirigentes con los grandes jefes de estos grupos al margen de la ley. A la vez que el dinero sucio del narcotráfico condujo al fútbol a su época más gloriosa, rápidamente se convirtió en una fuente de lavado de dinero y sus consecuencias no se hicieron esperar: asesinatos, secuestros, sobornos, corredores de apuestas, testaferrato y, por supuesto, la condena internacional. Las décadas de los ochenta y noventa fueron las de más fuerte influjo del narcotráfico en el fútbol, aunque la situación venía 
presentándose desde los setenta, no solo a nivel profesional. Se dice que Pablo Escobar estimulaba el fútbol barrial mediante la construcción gratuita de canchas deportivas iluminadas.

La Superintendencia de Sociedades decidió intervenir el fútbol colombiano debido a las irregularidades que se venían presentando tales como socios vinculados con cédulas falsificadas, irregularidades en el registro (nombres que no coincidían con los archivos de la Registraduría), algunos socios incursos en investigaciones judiciales (pérdida de los derechos políticos), ingresos de dinero que no se pudieron justificar, entre otros. Se inició una época en la que por cuenta del tráfico de drogas se relaciona a los equipos profesionales directamente con los capos de los carteles a través de la compra de jugadores y acciones, negocio mediante el cual se inyectaron grandes cantidades de dinero en los equipos. Clubes como Millonarios recibieron aportes de Gonzalo Rodríguez Gacha; los equipos caleños, de los hermanos Rodríguez Orejuela; los antioqueños, de Pablo Escobar. En la Tabla 10 se relacionan varios equipos de fútbol señalados por la Superintendencia de Sociedades de presentar irregularidades, hecho que produjo su intervención.

Tabla 10. Equipos de fútbol intervenidos en las décadas de los ochenta y noventa

\begin{tabular}{|l|c|c|c|c|}
\hline $\begin{array}{c}\text { Nombre } \\
\text { del club } \\
\text { comprometido }\end{array}$ & $\begin{array}{c}\text { Número } \\
\text { de socios } \\
\text { implicados }\end{array}$ & $\begin{array}{c}\text { Registraduría } \\
\text { (falsificación } \\
\text { de cédulas) }\end{array}$ & $\begin{array}{c}\text { Inconsistencia } \\
\text { en nombres de } \\
\text { socios }\end{array}$ & $\begin{array}{c}\text { Socios con } \\
\text { suspensión } \\
\text { de derechos } \\
\text { políticos }\end{array}$ \\
\hline $\begin{array}{l}\text { Corporación } \\
\text { Deportiva } \\
\text { Independiente } \\
\text { Medellín } \\
\text { (DIM) }\end{array}$ & 85 & 14 & 61 & 1 \\
\hline Once Caldas & 72 & 9 & 32 & 3 \\
\hline $\begin{array}{l}\text { Los } \\
\text { Millonarios }\end{array}$ & 60 & 8 & 30 & \\
\hline $\begin{array}{l}\text { Atlético } \\
\text { Bucaramanga }\end{array}$ & 32 & & & \\
\hline $\begin{array}{l}\text { Deportes } \\
\text { Tolima }\end{array}$ & 30 & & & \\
\hline América de Cali & 59 & & & \\
\hline
\end{tabular}




\begin{tabular}{|l|c|l|l|l|}
\hline Deportivo Cali & 29 & & 29 & \\
\hline Santa Fe & 17 & & & 1 \\
\hline $\begin{array}{l}\text { Atlético } \\
\text { Nacional }\end{array}$ & 15 & & & 1 \\
\hline
\end{tabular}

Fuente: elaboración de la autora con base en Nullvalue (1997).

Nota: Los siguientes clubes aparecen mencionados pero en el documento no se especifica la categoría en la que se encuentran incursos: Unión Magdalena (1), Envigado F. C. (4), Junior (10), Deportes Tuluá (13) y Deportes Quindío (18).

Los hechos narrados a continuación constituyen un resumen de la investigación realizada por Nullvalue (1992), para El Tiempo. El relevo de León Londoño Tamayo en la administración del fútbol nacional, orquestada por Juan José Bellini, dirigente caleño, pone de presente el conflicto regional entre Medellín y Cali por la dirección del fútbol colombiano, que ya venía dándose entre los carteles de las drogas en estas dos ciudades. En una jugada política Bellini admite ante los medios y los demás dirigentes deportivos no estar interesado en el cargo, sin embargo una vez se logra la dimisión de Londoño Tamayo, que fue calificada como "golpe de estado", Bellini se postula en su reemplazo con el apoyo de los clubes Unión Magdalena, Cúcuta, Bucaramanga, Pereira, Quindío y Tolima, que lo llevan a la presidencia de la federación, asume el cargo en marzo de 1992.

En los medios, entre tanto, se especulaba sobre el hecho:

El señor Bellini, además de haberse hecho nombrar de una manera poco ética, entró mandando. No sabemos si por encargo, o a motu propio, decidió tratar de llevarse la sede de la Federación a Cali, cosa que es ilegal si no hay antes una asamblea que lo decida. (Nullvalue, 1992)

En una clara alusión a las relaciones del nuevo dirigente con grupos al margen de la ley, el deseo de Bellini de trasladar la Federación a Cali, de haberse dado, hubiera significado un triunfo del cartel de Cali en la ya planteada pugna regional. No pasó mucho tiempo para que la justicia lo ligara con los hermanos Rodríguez Orejuela, sin embargo los clubes lo ratificaron y siguió en el ejercicio de sus funciones hasta que en noviembre de ese mismo año fue capturado por las autoridades en 
las instalaciones de la Federación, acusado de testaferrato, ya que su nombre aparecía en la libreta de teléfonos perteneciente a José Santacruz Londoño, reconocido narcotraficante del cartel de Cali.

Los sonados casos de corrupción de dirigentes, entre ellos los protagonizados por Bellini, mostraron una realidad en la que fueron comprometidos judicialmente jugadores, directivos, periodistas y árbitros con grupos de traficantes, y fueron cuestionadas las acciones de propiedad de algunos equipos como Millonarios, que desde la década de los ochenta tenía el grueso de estas en manos de los herederos de Gonzalo Rodríguez Gacha; aunque el equipo fue intervenido en varias ocasiones por la Dirección Nacional de Estupefacientes y ha sido sometido a diligencias de extinción de dominio, aún subsisten asuntos accionarios que no han sido resueltos, en los que está involucrada la viuda de Rodríguez Gacha. Se dice que "la participación de la familia de Rodríguez Gacha en Millonarios se oficializó en 1992, cuando, en época de crisis, su viuda Gladys Edilma Álvarez ofreció ayuda al club, como una forma de recordar a su esposo, aportante informal del equipo" (Quevedo, 2001). Tiempo después, ella repitió la operación para beneficiar a sus hijos. La Tabla 11 menciona la relación entre directivos, narcotraficantes y paramilitares.

Tabla 11. Directivos y socios de equipos de fútbol vinculados al narcotráfico

\begin{tabular}{|l|l|l|l|}
\hline Nombre & Equipo & $\begin{array}{c}\text { Relación } \\
\text { con } \\
\text { el equipo }\end{array}$ & \multicolumn{1}{|c|}{ Implicación } \\
\hline & & & $\begin{array}{l}\text { Primer extraditado a } \\
\text { los EE. UU. En señal } \\
\text { de duelo la Dimayor } \\
\text { suspendió la fecha } \\
\text { profesional el 15 de } \\
\text { noviembre de 1984. Su } \\
\text { extradición produjo el } \\
\text { surgimiento del grupo } \\
\text { Mornán Botero }\end{array}$ \\
Atlético & Nacional & Presidente extraditables, \\
& & $\begin{array}{l}\text { liderado por Pablo } \\
\text { Escobar. }\end{array}$ \\
\hline
\end{tabular}


Tabla 11. Directivos y socios de equipos de fútbol vinculados al narcotráfico

\begin{tabular}{|c|c|c|c|}
\hline Nombre & Equipo & $\begin{array}{l}\text { Relación } \\
\text { con } \\
\text { el equipo }\end{array}$ & Implicación \\
\hline $\begin{array}{l}\text { Octavio Piedrahita } \\
\text { (asesinado en } \\
\text { 1986) }\end{array}$ & $\begin{array}{l}\text { Atlético } \\
\text { Nacional- } \\
\text { Valledupar F.C } \\
\text { Deportes } \\
\text { Pereira }\end{array}$ & Presidente & $\begin{array}{l}\text { Se vinculó a los } \\
\text { cabecillas paramilita- } \\
\text { res 'Jorge 40' con el } \\
\text { Valledupar FC, y a alias } \\
\text { Macaco con el Deporti- } \\
\text { vo Pereira. }\end{array}$ \\
\hline $\begin{array}{l}\text { Gonzalo } \\
\text { Rodríguez Gacha, } \\
\text { alias el Mexicano } \\
\text { (dado de baja } \\
\text { por el Ejército en } \\
\text { 1989) }\end{array}$ & Millonarios & Accionista & $\begin{array}{l}\text { Jefe militar del cartel } \\
\text { de Medellín. }\end{array}$ \\
\hline $\begin{array}{l}\text { Rodrigo } \\
\text { Tamayo, Javier } \\
\text { Velásquez, } \\
\text { Mario Valderrama }\end{array}$ & $\begin{array}{l}\text { Deportivo } \\
\text { Independiente } \\
\text { Medellín }\end{array}$ & $\begin{array}{l}\mathrm{Ex} \\
\text { presidentes }\end{array}$ & $\begin{array}{l}\text { Problemas con la } \\
\text { justicia por alianza con } \\
\text { el narcotráfico (apoyó } \\
\text { al Deportivo Indepen- } \\
\text { diente Medellín) }\end{array}$ \\
\hline Juan José Bellini & $\begin{array}{l}\text { América de Cali } \\
\text { Federación de } \\
\text { Fútbol }\end{array}$ & $\begin{array}{l}\text { Ex } \\
\text { presidente }\end{array}$ & $\begin{array}{l}\text { Vinculado al proceso } \\
8000 \text { por su relación } \\
\text { con Miguel Rodríguez } \\
\text { Orejuela, jefe del cartel } \\
\text { de Cali y máximo accio- } \\
\text { nista del América. }\end{array}$ \\
\hline $\begin{array}{l}\text { César Villegas } \\
\text { (asesinado en } \\
\text { 2002) }\end{array}$ & Santa Fe & Presidente & $\begin{array}{l}\text { Acusado de } \\
\text { testaferrato en } 1996 .\end{array}$ \\
\hline $\begin{array}{l}\text { Phanor } \\
\text { Arizabaleta }\end{array}$ & Santa Fe & Directivo & $\begin{array}{l}\text { Condenado a } 28 \text { años } \\
\text { de cárcel por secuestro } \\
\text { y extorsión, quinto en } \\
\text { la línea de mando del } \\
\text { cartel de Cali. }\end{array}$ \\
\hline
\end{tabular}


Tabla 11. Directivos y socios de equipos de fútbol vinculados al narcotráfico

\begin{tabular}{|l|l|l|l|}
\hline \multicolumn{1}{|c|}{ Nombre } & Equipo & $\begin{array}{c}\text { Relación } \\
\text { con } \\
\text { el equipo }\end{array}$ & \multicolumn{1}{|c|}{ Implicación } \\
\hline $\begin{array}{l}\text { Gustavo } \\
\begin{array}{l}\text { Upegui } \\
\text { (asesinado en } \\
\text { 2006) }\end{array}\end{array}$ & Envigado & $\begin{array}{l}\text { Mánager y } \\
\text { accionista }\end{array}$ & $\begin{array}{l}\text { Se le relacionó con la } \\
\text { Oficina de Envigado*. }\end{array}$ \\
\hline
\end{tabular}

Fuente: elaboración de la autora con base en Pino (2010).

El brazo de la delincuencia fue lo bastante largo para invadir el fútbol y permitir que el narcotráfico convirtiera al deporte en una actividad a través de la cual se hicieron ajustes de cuentas en defensa de las grandes inversiones, con las cuales se contrataron jugadores prominentes que en condiciones normales no habrían podido llegar al país; igualmente, muchos jugadores sucumbieron a la tentación del dinero y recibían dádivas de cuya procedencia no se preguntaba, como lo relata el jugador Pareja (2012), cuando recuerda su paso por el fútbol en la década de los noventa: "éramos inmunes a lo que sucedía a nuestro alrededor... ganábamos un partido y de repente había unos US $\$ 8000$ adicionales para nosotros, ¿de quién? Nosotros no sabíamos, nosotros no preguntamos" (El Heraldo, 2012).

El exjugador asimismo afirma que Pablo Escobar solía hacer llevar a la cárcel La Catedral a jugadores famosos y organizaba partidos entre estos y sus lugartenientes; de esta experiencia comenta Pareja, a quien apodaban el Guapo: "él se sentó al lado mío y habló sobre fútbol con gran pasión y conocimiento, por una hora. Él lo sabía todo. Él me dijo ¿por qué le gritás tanto a los réferis, Guapo? Nosotros les pagamos.

* La Oficina de Envigado es una estructura criminal, fundada por Pablo Escobar, que ha tenido a su servicio a personas del mundo de la delincuencia, encargadas del cobro de extorsiones, la mayoría de las cuales están muertas, encarceladas o extraditadas, y otros de bajo perfil que han comenzado a hacerse visibles. Esta oficina también provee pistoleros para el sicariato, además de controlar las rutas del narcotráfico del cartel de Medellín. Se les relaciona igualmente con bandas criminales como Los Urabeños y la desarticulada banda La Terraza, así como con grupos del paramilitarismo y la guerrilla. 
Esto no hace bien" (El Heraldo, 2012). El miedo fue una constante entre los jugadores, que no se atrevieron a rechazar la invitación. Como era de esperarse, Colombia se convirtió en el paraíso del buen dinero para jugadores nacionales y extranjeros. La ofensiva del Gobierno nacional en contra de las organizaciones del narcotráfico dejó a los equipos en una situación agónica de la cual luchan aún por salir y sobrevivir.

Es importante advertir que el Estado ha intentado de muchas formas liberar al deporte del estigma del narcotráfico, se vigilan los movimientos accionarios y los ingresos de dinero, y como efecto de ello en el año 2010, con la aquiescencia de los clubes, el gobierno presentó el proyecto de Ley 073/2010, modificatorio de la Ley 181/1995, con el que busca convertir a los equipos en sociedades anónimas con la finalidad de que los hinchas adquieran acciones de sus clubes y lograr que estos coticen en la Bolsa, así se fortalecerán los mecanismos de control y reglamentará el manejo administrativo; la forma de sanear la actividad deportiva. Lo importante en este caso, es que la ya difícil situación de los equipos logre superarse y que las hinchadas participen activamente en el sostenimiento de la actividad a través de la compra de acciones; quizá de ese modo esto contribuya, también, a que se pueda solucionar el problema de la violencia en los estadios. 


\section{ViolenCia eSCOLAR RELACIONADA CON BARRAS DEL FÚTBOL EN BOGOTÁ}

Las barras del fútbol constituyen hoy por hoy un fenómeno que crece. Tienen unas características que son comunes a todas las hinchadas, solo que como admite Clavijo (2004), "cambian las ciudades y cambian los símbolos, pero no las formas de expresarse” (p. 45). Las barras han hecho de la violencia la forma más común de presentarse ante la opinión pública. En este apartado se interpretan los argumentos expuestos por quienes participaron en la investigación, se trata de encontrar los elementos que le dan sentido a su afiliación con el fin de comprender e identificar aspectos centrales de su experiencia que conduzcan a un conocimiento más completo de la situación. Es importante, a la par, reconocer a los jóvenes que las integran como parte del conglomerado social, que viven una experiencia sujeta a permanentes tensiones pero, a la vez, como constructores potenciales de nuevas realidades, con capacidad para superar y modificar sus actuales comportamientos. A partir de este apartado aparecen datos empíricos, obtenidos del trabajo investigativo, que se identificarán con la fórmula que se ofrece a continuación, tanto para estudiantes como para docentes (Figura 3):

Figura 3. Fórmula
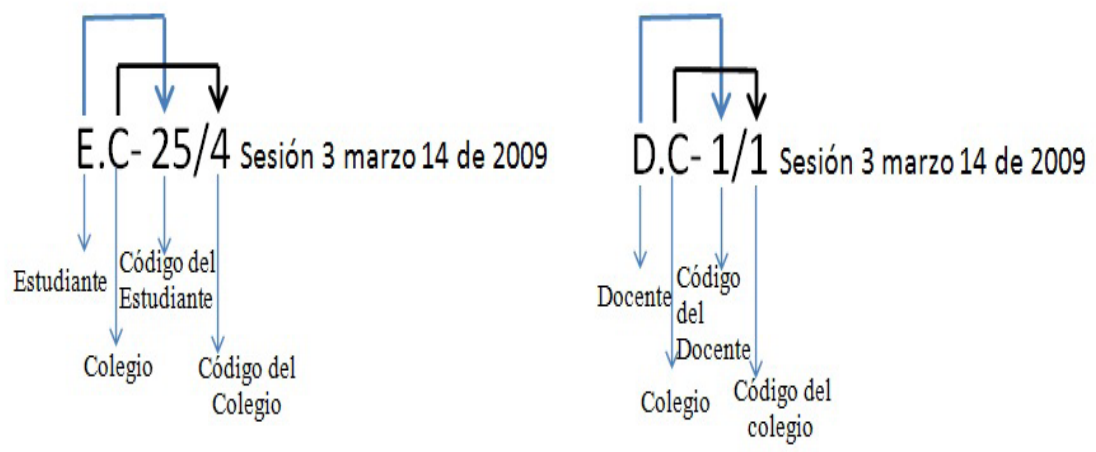


\section{ORIGEN DEL BARRISMO EN BOGOTÁ}

La aparición del barrismo en Colombia, y particularmente en Bogotá, es relativamente reciente. La historia la cuenta un fundador de las barras de Millonarios, hombre de 33 años a quien llamaremos Sopas ${ }^{1}$, uno de los miembros más antiguos. Se considera pionero en la formación de las barras bravas en Colombia, hace parte de la Blue Rain, actualmente una barra grande y en conflicto con los Comandos Azules. Según cuenta, quieren ser una nueva forma de vivir el espectáculo del barrismo, promover la alegría y la diversión en paz, es decir, regresar a la época en que los primeros barristas alentaban y embellecían la jornada futbolera, con la tribuna organizada en forma festiva y con sus cantos de apoyo al equipo, pero sin los problemas actuales: consumo, vandalismo, violencia.

Por allá hacia 1992 yo asistía normalmente al estadio a tribunas calmadas, en esa época en El Campín existía la lateral sur y norte, allí se ubicaba la hinchada común, eran baratas y sanas. De un momento a otro empecé a ver allá en oriental un grupo saltando como por ahí hacia el 92'y yo pensé, me gustaría estar allá, opté por cambiar de tribuna y me trasladé a oriental. (Sopas [entrevista], junio de 2009)

Sencillamente se convocó a un grupo de amigos para alentar a su equipo, el ingreso de este joven a él se dio de una forma natural, sin ningún tipo de ritual o condición más que el deseo de estar allí y un poco de dinero para la boleta.

Más o menos los tenía ubicados, porque en esa época los que la manejaban o la dirigían eran los "Calvos", ellos tenían ahí su cuento del racismo y eso, uno identificaba por las chaquetas naranjas a los manes, yo sabía que ahí estaban los Saltarines de Millonarios[,] que para esa época se conocían así.

La única condición que pusieron fue cantar.

1 Sopas. Seudónimo de un miembro fundador de las barras de Millonarios (entrevista realizada el 19 de junio de 2009). 
$\mathrm{Al}$ parecer los antecedentes de las primeras barras se remontan a los años 1985/1987, en pleno auge del narcotráfico en el fútbol, con un grupo que se hacía llamar Los Búfalos, que se organizó y bautizó así en honor a Juan Gilberto Funes, a quien apodaban el Búfalo de San Luis, "un jugador de raza que jugó en Millonarios, fue la estrella que marcó muchos goles y nos dio los títulos" (Sopas [entrevista], junio de 2009). Las primeras barras aparecieron en Bogotá en 1995, cuando "se establecen las primeras tribunas al estilo argentino y uruguayo" (Puerta, 2002). Sobre este tema Sopas comenta:

Cuando yo era pelao [muchacho] pasaban por el Canal 11 partidos de la liga argentina, y eso fue lo que me influenció a mí [sic], porque yo decía aquí en el estadio El Campín nadie salta, nadie canta, nadie alienta, era diferente, allá toda la gente alentaba; me parecía muy muerto el estadio, entonces eso como que me influenció, era lo que mi sangre de latino me decía que necesitaba, disfrutar el fútbol, entonces opté por cantar y alentar a Millonarios y estar sin camiseta en el estadio, me pareció muy bacano. (Sopas [entrevista], junio de 2009)

La primera barra en consolidarse en la ciudad fue la Blue Rain, en 1992, surgida de la división de Los Búfalos en 1990, de hecho sus primeros miembros. Al poco tiempo nacen los Comandos Azules y la Guardia Albirroja sur, que provienen de la tribuna oriental. Este es un dato particular, porque se pudo establecer que las barras no nacieron en las tribunas populares, "es algo claro, nunca crecieron en las tribunas populares” Amaya (entrevista, 2009) ${ }^{2}$. La Blue Rain fue la primera barra que llevó bandera (trapo) al estadio, era blanca con letras azules que decían: "Millonarios, cada día te quiero más". Quienes conformaron inicialmente el Comando Azul fueron

Beto, que se hacía apodar Lobo Guerrero; Cortinas, la Bruja y Morón, ellos fueron los miembros legendarios de Los Búfalos. De este grupo solamente la Bruja continúa como miembro activo de la barra; Beto trabaja, Martínez es miembro activo de la barra, Cortinas murió y Morón es "un loco cuerdo", está demente producto del consumo de alcohol, lleva una vida bohemia. (Sopas [entrevista], junio de 20o9)

2 Coordinador del programa Goles en Paz (Secretaría de Gobierno, Consejería para la Vida Sagrada, Bogotá). 
La Blue Rain nace por la necesidad de vivir de otra manera el fútbol:

Ya estábamos cansados de la misma monotonía, que no tuviéramos una bandera grande, que nadie cantara; antes del partido se alentaba, pero apenas empezaba el partido, todo el mundo se sentaba, nadie alentaba, nadie gritaba, así que la gente se empezó a asociar y fue un fenómeno raro porque nadie estaba acostumbrado a ver el fútbol de pie ni aquí en Bogotá -y creoni en Colombia. (Sopas [entrevista], junio de 2009)

Ellos optaron por llevar una tira, una bandera, organizar viajes y todo lo que es hoy la actividad de la barra. Sopas menciona en la entrevista a otros fundadores de la barra inicial que han fallecido: Harold, Mario, Cristian y Cuclito.

Beto, que fue el primer líder, falleció por causas que nada tienen que ver con la barra. Me parece a mí que apareció el dinero, aparecieron las boletas, la fama, el poder, y él se deshizo, porque la idea original de la Blue Rain y lo que decía Beto nunca se me va a olvidar: "somos una familia, un grupo de amigos"; pero desgraciadamente apareció el dinero y ahí aparecen las envidias, los malos manejos, los favorecimientos, entonces los que no tenían y no recibían se agruparon y lo sacaron al man, eso por el lado de Beto. (Sopas [entrevista], junio de 2009)

Sopas revela una situación que ha ahondado los conflictos entre estos grupos: las prebendas que reciben los cabecillas o capos de las barras por parte de los dirigentes de los equipos, lo que les permite el acceso a un poder que ostentan frente a los demás y que se convierte en el objeto de la discordia. Esto los ha fortalecido a tal punto que son determinadores de lo que acontece al interior y exterior de la barra, mantienen el control del espacio y de las mínimas cosas que ocurren. No es claro de dónde reciben estos jóvenes las dádivas que los empoderan, pero es un secreto a voces que las manos de la dirigencia deportiva están implicadas. Es por ello que el control de esta situación es complejo, dado que hay muchos intereses en esta actividad.

Continuando con su relato, Sopas refiere que

por el lado de Andrés Martínez, él fue miembro activo por largo rato, creo que fue el sucesor de Beto y ahí con Juan Manuel Triana iban de la mano, Andrés tuvo un problema con otro 
miembro fundador, entonces renunció por un tiempo, se retiró de los comandos, luego volvió y actualmente está dirigiendo una célula de las muchas facciones que tiene el comando. (Sopas [entrevista], junio de 2009)

Esta situación es muy frecuente entre los grupos de barristas, quienes acceden al poder no quieren tener contradictores, por ello dejan de ir al estadio y ejercen presión en la distancia o utilizando a facciones de la barra para hacer oposición y cuestionar las decisiones.

La primera Blue Rain tenía como principio rector la amistad, la hermandad y acompañar incondicionalmente a Millonarios a todas partes, siempre como grupo de amigos.

La Blue Rain actual está procurando traer de nuevo esa esencia, los que nos copiaron los principios, por algo se formó de nuevo, al menos dejó de ser una facción del comando para convertirse en una barra grande; están trayendo de nuevo la hermandad, el amor a la familia, la amistad. (Sopas [entrevista], junio de 2009).

Después de la muerte de Juan Manuel

llegó un líder negativo, el man se llenó de envidia con los miembros antiguos de la Blue Rain y decidió hacerles la guerra. Entonces les puso en contra a la Policía, al periodismo, la Alcaldía no permitía que ningún miembro de la antigua Blue Rain entrara al estadio, mejor dicho, nos quiso desaparecer. (Sopas [entrevista], junio de 2009)

$\mathrm{Al}$ parecer este capo se asoció con delincuentes, se aprovechó de su imagen para derrocarlo y dejarlo por fuera. Este es, según Sopas, el origen de la división al interior de la barra de Millonarios.

"Los actuales líderes son los que están molestando, porque en realidad todos son los mismos hinchas”, señala Sopas. Y continúa:

La Blue Rain se formó en oriental, pero nosotros tomamos la decisión en un partido de Millonarios contra Cali, que en el próximo partido, que era un clásico con Santa Fe, de cambiarnos a lateral norte, pintamos el frente con \$10o.ooo que nos regaló un hermano de otro miembro de la barra y lo pintamos en la casa de Beto. 
Explica que las cosas comenzaron a dañarse cuando hubo plata, boletas y otras dádivas de los equipos, porque afloraron los juegos de poder, así fueron saliendo uno a uno los miembros de la antigua Blue Rain: "hoy todos los que llegan quieren ser líderes, no hay respeto por las jerarquías, ahora cualquiera que tenga un grupo grande se siente con la disposición de ir y bajar un líder, o por lo menos, para hacer sus negocios”. La Blue Rain no estaba asociada a la Unibam (Unión de Barras de Millonarios), agremiación que se ocupa de asistir y representar a las barras en los comités de seguridad, además de organiza eventos y actividades para sostener las necesidades de los grupos, por ejemplo, compra de banderas u otros elementos que se requieran.

Posteriormente la Blue Rain cambió su nombre por Comandos Azules número 13, tal y como lo quería Beto, que deseaba diferenciarla del resto de grupos; el nombre lo sacó de una barra del Alianza Lima. Es claro que el comando es hijo de la Blue Rain: "el que diga lo contrario es que no conoce la historia. Un día tomando unas cervezas en el 7 de agosto dijimos que el nombre de la barra era una mala cábala y decidimos cambiarlo por Comandos Azules D. C." (Sopas [entrevista], junio de 2009). Sopas confirma que en Bogotá hay barras de todos los equipos y que los conflictos son frecuentes porque cada una quiere defender su territorio, cada uno cree que su barra es la mejor y eso es lo que se pelea, nadie admitirá nunca que su grupo es el más débil. La mayor parte de incidentes fuertes se producen con las barras del Nacional, porque según cuenta, ellos creen que son los mejores y vienen a Bogotá a 'creerse más'. Este aspecto se considera actualmente un problema de regionalización del deporte que se ha complicado aún más en las ciudades.

Las barras se organizan en "parches"3 que identifican zonas de la ciudad e indican la procedencia barrial; el número de personas que los componen determina la ubicación dentro del estadio, la importancia en el contexto del barrismo de la ciudad y en la jerarquía de los grupos. En otro sentido, el parche es el grupo de amigos con el que se ocupa

3 Perea define el parche como "forma de pertenencia radical originada en el barrio popular, llama al otro lado susurrando que todo está perdido, enrostrando la soledad y la incertidumbre para ofrecer, a cambio, sentido e inclusión" (p. 33). 
la esquina del barrio, se transgrede el orden y se convierte en molestia para los vecinos; los parches barriales parcelan el territorio que luego da origen a las disputas entre seguidores de equipos. El término también genera desconfianza entre el común de la gente:

Cuando nosotros decimos parche la gente ya piensa que son combos de pandillas, que son muy problemáticos, peligrosos y malos, pero el parche más que todo son gente que va al estadio a alentar a su equipo, son amigos que tienen una pasión por su equipo y quieren estar juntos para alentar a su equipo por su afición. (E.C-37/5 sesión 3, mayo 8 de 2009)

Sopas afirma que estos grupos han llevado al consumo de sustancias y actividades delincuenciales y que en cierta forma se siente culpable, pero espera poder hacer algo para ayudar a la solución de los problemas actuales; piensa que algunos líderes de las barras son los responsables de la degradación que se presenta en algunas de ellas, porque igual son consumidores y tienen montados sus negocios de distribución, ellos son los que han dañado a muchos hinchas.

El fenómeno de las barras ha ido tomando rumbos inesperados en la ciudad y en general en el resto del país. Inicialmente las autoridades intentaron contenerlas, pero mantener el control se ha convertido en un problema de orden público que requiere de grandes operativos policiales dentro y fuera de los estadios para evitar desmanes. Incidentes recientes han demostrado que en estos grupos las luchas por el poder mantienen enfrentadas a las facciones que componen las barras y el fútbol se ha convertido en una excusa para resolver otros asuntos. Nadie estaba preparado para afrontar un problema de tal magnitud, que tiene en el consumo de alcohol, drogas, la delincuencia y el fanatismo sus principales formas de expresión.

En los últimos tiempos las barras del club Los Millonarios se han dividido en dos bandos, al primero lo han denominado Los Charlaos (LCh), al segundo los Comandos Azules (CA), y la hinchada culpa de la situación a la dirigencia del club en cabeza del entonces presidente Juan Carlos López, quien en 2009 generó una disputa que terminó por romper la unidad de la barra tras los malos resultados del equipo. Los Comandos orquestaron desde la tribuna una protesta con cánticos 
en contra de la dirigencia y los jugadores, actos que molestaron a López, quien empezó a condicionar las ayudas a la barra.

Figura 4. División de los Comandos Azules - Conflicto entre barras

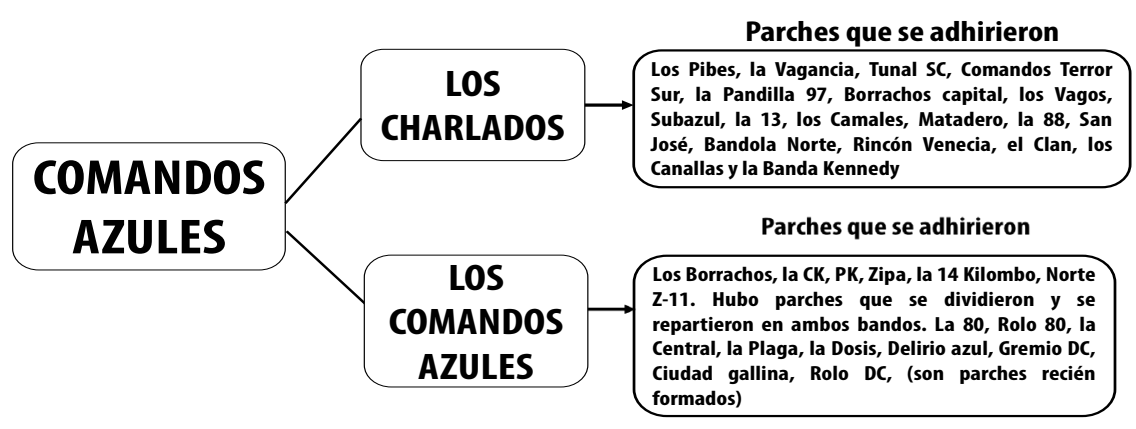

Fuente: elaboración de la autora con base en Pasión Capitalina (2011).

No es un secreto que siempre ha existido una relación barrasdirigentes basada en el otorgamiento de boletas, camisetas, dinero en efectivo, etc. En el momento en que el expresidente notó la posición de la tribuna norte puso en advertencia a la barra: no iban recibir más colaboraciones si seguían con las puteadas y la crítica a la presidencia. (Pasión Capitalina, 2011)

Así, el bando de los LCh se alzó con buena parte del apoyo para acompañar al equipo hasta Ecuador, mientras que la otra facción realizando actividades reunió su dinero. Se dice también que la división se dio porque varios capos de parche no estaban de acuerdo con el manejo de la barra que Moneda, líder de los Comandos Azules, estaba haciendo.

Los Comandos criticaron a Los Charlaos por anteponer el dinero y los beneficios que recibían de la dirigencia, a los problemas por los que estaba atravesando el equipo. Así las cosas, los LCh recibieron como apoyo un bus para el viaje; al regreso las dos facciones se enfrentaron en el estadio por la ubicación en la tribuna, lo que marcaría el predominio de uno de los dos grupos. La policía intervino separándolas y acordonando el espacio, situación que se mantiene actualmente y que es vista como el debilitamiento de los Comandos Azules. 


\section{CONCEPTOS DE BARRA DEL FÚTBOL, BARRABRAVA, BARRISTA Y BARRISMO}

El fútbol se podría decir que es mi pasión, es severa locura, cuando usted pisa la cancha, y están alrededor de 20.000 personas que son del mismo equipo, que todos somos sureños, que todos somos familia, que bajan todos los de Medellín, toda

nuestra barra, con sus tiras, nuestros trapos, eso es una alegría gigante porque en sí somos solo uno, somos la familia de los del sur y ese es nuestro orgullo, el fútbol.

La primera vez que fui al estadio, con unos amigos del colegio dijimos que nos íbamos a hacer una tarea, nos llevamos libros de la casa, para dizque hacer una tarea, nos fuimos para la cancha a ver a los comanditos ahí con su hinchada.

Encuentro en la barra mucha alegría, primero, se toma, se habla de Nacional, uno se siente ahí refugiado porque está con los amigos, porque hay una nenita por ahí sureña que a uno lo motiva para seguir ahí en la barra; algunas veces he sentido que yo me quiero salir de esto, seguir siendo de Nacional, no ser barrista en el sentido de estar en una barra, sino lo que me motiva es estar en eso... en el desorden, que todos somos familia, somos jóvenes y cuando vamos a esas cuestiones vamos todos y la pasamos bien y si hay que comer mierda, pues se come. Eso es lo que me motiva, la unión.

Conde Pátula (2004)

\section{HACIA UNA DEFINICIÓN DE BARRA DE FÚTBOL}

Grupos de seguidores de equipos han existido siempre, solo que sus propósitos varían de acuerdo con el fervor que el espectáculo despierta en sus hinchadas. Una barra es una organización jerarquizada de personas seguidoras del fútbol o cualquier otro deporte, integradas por afinidad de intereses y en la que confluyen fuertes vínculos identitarios que los cohesionan.

En términos sencillos, una barra es la organización de personas que se vincula para seguir a un equipo de fútbol del que son hinchas; un estudiante define a la barra como "aquel parche o grupo de personas 
que siempre van a alentar al equipo y lo entregan todo... hasta la vida" (E.C.14/2 sesión 2, febrero 13 de 2009). La mención del parche por este estudiante indica la organización barrial de la que hace parte y denota el germen de su vinculación, asociada al sentido del barrismo y a la pasión por el equipo. En relación con la denominación de barra brava otorgada a los seguidores del fútbol en Bogotá, Rivera explica que 'barra brava' es un superlativo del término, dado que no corresponde a la realidad de estas organizaciones en Colombia, dicha denominación se aplica más bien a otros contextos donde las barras ostentan mayor poderío: "En Colombia se les rotuló como barras bravas, gracias a los medios de comunicación, por la forma de apoyar a su equipo" (2004). Collazos, Herrera, Restrepo y Suárez (1999) sugieren que se les llame "barras furiosas" (p. 20).

Los jóvenes piensan que una barra es

un grupo de personas que forman parte de un barrio como por ejemplo marcar de dónde viene ese grupo y que las demás barras sepan de dónde se viene, y también se puede decir que es un grupo de hinchas que están en las buenas y en las malas apoyando, cantando al equipo. (E.C- 25/4 sesión 3, mayo 8 de 2009)

Los jóvenes exponen aquí la importancia que para ellos tiene la conformación de su barra, el origen barrial, que en últimas es lo que defienden.

A efectos de esta investigación se asume la expresión 'barra del fútbol", dado que compartimos con otros autores la idea de que, aunque con ellas se hayan presentado incidentes graves, distan mucho de parecerse por ejemplo a las 'barras bravas' argentinas, de quienes emulan muchas de sus prácticas, especialmente por su trayectoria, que supera las seis décadas. Las barras bravas argentinas, consideran algunos expertos, han aprendido la violencia desde sus inicios y la han convertido en un aspecto fundamental que las identifica tanto en el estadio como en los barrios, se han puesto al servicio de intereses políticos y de la dirigencia de los clubes a quienes hacen favores y ayudan a solucionar problemas, esto ha recrudecido la violencia al interior de los grupos, los enfrentamientos son cada vez más frecuentes y de mayor contundencia. 
El hooliganismo, por su parte, identifica al hincha británico, cuya característica es la beligerancia. Tiene sus inicios a finales del siglo XVIII, aunque imágenes de él se tienen desde los mismos inicios del fútbol como deporte. Su presencia en el Mundial de Fútbol de Inglaterra en 1966 se considera el salto en el contexto internacional. Su origen está asociado a grupos marginales y excluidos de las zonas industriales, que con el tiempo han ido adquiriendo tintes xenofóbicos. Las duras políticas de seguridad europeas les mantienen bajo control estricto. En el contexto colombiano, la denominación barra brava, con que se identifica a los seguidores de equipos de fútbol, se debe a los medios de comunicación que han mediatizado sus apariciones públicas e intentado equipararlos con seguidores beligerantes de otros países.

La expresión 'barra del fútbol' que identifica este estudio constituye un fenómeno urbano, en el que se produce la asociación voluntaria o mediante captación (seducción) de un grupo de personas (estudiantes) que adhieren a un equipo de fútbol del cual se hacen seguidores; su propósito fundamental es animar, apoyar y acompañar al club en la gesta deportiva, con despliegue estético que incluye cánticos y símbolos característicos, para cuya ejecución se sigue un ritual propio de este tipo de espectáculos; su nivel de compromiso con el equipo es principalmente afectivo, lo cual delimita su espacio de participación, orientado más a ser un seguidor entusiasta (hincha) de su club, que un fanático violento defensor a ultranza de los intereses de él.

\section{Barrientos (2011) presenta a la barra como}

especie de asociaciones más o menos espontáneas de hinchas que se aglutinan en algún sentido, teórica y discursivamente como una especie de soportes emocionales y operativos -en términos de alentar a sus equipos-pero que por variadas circunstancias han comenzado a mutar a ser una especie de catalizador colectivo de las frustraciones y expectativas de amplios sectores populares urbanos. (s. p.)

La barra llega por momentos a constituir el soporte de sus integrantes, allí es donde radica la familiaridad que pueden desarrollar y que se evidencia en el momento de la confrontación. Este autor señala también la importancia de la agrupación en la manifestación no solo de 
una violencia que para algunos no tiene explicación porque los actos que realizan perturban la tranquilidad social y afectan directamente a la ciudadanía. El análisis que generalmente se hace de la situación es elemental pues no contempla otras variables que pueden asociarse a problemas urbanos sin resolverse. Por ello advierte las condiciones que pueden constituirse en detonantes de una situación social en la cual se presenta un desfase de las expectativas que no se soluciona y en el que la vinculación grupal actúa como sostén para sobrellevar el inconformismo, sería esta la condición en que actúan las barras del fútbol en Bogotá.

\section{EL BARRABRAVA}

Definir al 'barrabrava' depende del punto de vista desde el cual se observe esta condición. Moffat (1998) señala que barra quiere decir "grupo afectivo, con intensa participación emocional, casi una familia, y brava, señala que son personas de acción y violentas" (pp. 16-19). La pertenencia al grupo se media por las relaciones de amistad que se estrechan tanto, que se equiparan con la familia, lo cual explicaría la cohesión que alcanzan en la práctica de su afición y lo emocional daría lugar a las formas como viven su experiencia; el término 'brava' admite la disponibilidad para actuar, sin amedrentarse, aunque tengan que hacerlo con violencia.

El barrabrava es un seguidor extremo o un fanático que tiene una vivencia excesiva de su afición, está siempre presente para demostrarle a su equipo todo lo que es capaz de hacer por él; lleva en la piel y sobre todo en el alma, el amor y la pasión que despierta el deporte. Manifiesta su sentimiento con una afectividad sublimada en la que le es posible entregar hasta la vida. Pareja (2012) lo define como el "individuo integrado a un grupo organizado dentro de la hinchada de un club de fútbol, caracterizado habitualmente por ser protagonista de incidentes violentos, dentro y fuera del estadio de fútbol”. Un barrista consumado, como Sopas, por ejemplo, lo define así:

Barrabrava, seguidor acérrimo de su equipo, entregado a acompañarlo, es una demencia que no tiene límite ni control, 
un barrabrava puede llegar a cualquier extremo. El barrista se diferencia del hincha en que es más entregado, es el que organiza al grupo en el barrio, el que induce a los demás para que también se conviertan en barristas, es el que corta papel, el que impone el coro, el que se descamisa, el que tiene la mayor cantidad de tatuajes. (Sopas [entrevista], junio de 2009)

Sopas enuncia en su concepto otros elementos de los que está compuesta la adhesión de los seguidores del fútbol. El barrabrava se caracteriza por su tenacidad, su vigor y su entrega; el término 'acérrimo' empleado aquí implica también comportamientos como el sectarismo, que puede asociarse al fanatismo, la intransigencia que puede ligarse a la exaltación, es la obsesión que muchos de ellos tienen por el equipo, y un aspecto en el que han acuñado y fortalecido la defensa del honor: la intolerancia, que puede equipararse al radicalismo con el que viven su pasión, que según Sopas es demencia, extremismo y descontrol. La pasión es un concepto que los jóvenes exponen con frecuencia para destacar su compromiso y la experiencia casi paroxística con que disfrutan cada fecha del espectáculo en el estadio:

La pasión para mí significa carnaval, alegría, fiesta, amor, sentimiento, placer y emoción cuando veo a mi equipo con una copa o quedando campeón; la pasión es lo que vive un hincha, lo que siente y lo que expresa al ir al estadio. Para mí la pasión son muchas emociones juntas, una afición que no para; una enfermedad que no tiene cura, un amor propio. (E.C-O36/5 sesión 3, mayo 8 de 2009)

Sopas, igualmente, expresa la diferencia entre hincha y barrista, que según él está en la entrega, en la posibilidad y la voluntad de hacer algo por el equipo, bien sea al organizar un grupo para asistir al estadio, generar organizaciones barriales, o inducir a otros a pertenecer al grupo aprovechando el interés que despierta entre los jóvenes este tipo de actividad. La máxima expresión del amor por el equipo es el tatuaje, significa que su vivencia es suprema, llevar al equipo en la piel, tenerlo siempre no solo en el corazón sino en el cuerpo, de una manera tal que nadie lo puede arrebatar, y mostrarlo cuando se descamisa, con lo que se exhibe amenazante, anunciando su guerrerismo. 


\section{¿QUIÉN ES UN BARRISTA?}

Una pregunta que fue común durante el proceso de investigación buscaba saber si había algún tipo de ritual para vincularse a las barras o alguna condición especial para pertenecer a ella; las manifestaciones al respecto indican que no existen condicionamientos especiales, lo importante es estar dispuesto a participar en los actos que se realizan. Los escolares respondieron al respecto: "Desde que tenga el gusto por el equipo ya después todo va por añadidura. Que se vista así, que los cánticos, todo eso... la vaina es que le guste el equipo...” (E.C-17/3 sesión 14, marzo de 2009). Lo primordial a la hora de ingresar a la barra es demostrar el gusto por el equipo y que una vez se tenga esto se puedan conseguir otras cosas, "pues todo el mundo en las barras se reúne es porque le gusta mucho el equipo, entonces ya de resto todo va pegado a eso, por ejemplo se reúnen muchos hinchas de un equipo y ahí se dan muchas cosas" (E.C-18/3 sesión 14, marzo de 2009).

Recasens (1999) indica que el barrista es aquel "que se declara partidario de un equipo y tiene distinto grado de compromiso con él” (p. 32). Así como existen barristas acérrimos, existen también aquellos que van y disfrutan el espectáculo, sufren por su equipo y terminado el partido marchan a su casa con tranquilidad, no participan de los desmanes que se cometen, incluso muchos de ellos ni siquiera se ubican en el espacio que tienen las barras en el estadio, su nivel de compromiso es diferente; a este se le denomina hincha. Ser barrista es una situación que está rodeada de emociones positivas y negativas, es una experiencia que llena, que marca, "es una forma de vivir muy bonita porque es puro sentimiento, es sufrimiento, lucha, amor, locura” (E.C1/1 sesión 3, febrero 20 de 2009).

Los estudiantes se reconocen como barristas y tienen claro que son generadores de problemas en la comunidad. Al preguntarles quién es un barrista respondieron: "es aquel hincha que alienta a su equipo con el alma, lo sigue, viaja y hace lo que sea por él” (E.C- 24/ 4 sesión 3, mayo 8 de 2009). Nótese que en esta afirmación del joven barrista no hay una opción individual, sino que se reconocen en conjunto, lo que define la afinidad existente al interior de la barra, que en últimas es lo que 
permite afrontar la violencia producida por efectos de la actividad, la garantía de estar con otros, o lo que Ferreiro (2003) ha llamado la "celebración del 'nosotros"' (p. 57) a través de lo cual se desarrollan procesos de identidad que los motivan a constituirse en fuerza para el combate, en el que van a ofrendar la vida si es necesario. Asimismo, es la posibilidad de diferenciarse de los "otros" estableciendo elementos de identidad en los que la lucha es por lograr al máximo la autenticidad en sus prácticas. Es una fuerte decisión, tomar la iniciativa y arriesgarse hasta donde se requiera, finalmente es un compromiso ineludible al que se aferran con valor.

El interés de estos chicos es hacer notar su presencia, que el equipo tenga la garantía de su incondicionalidad, sin importar las circunstancias pueden contar con ellos, como lo expresa este estudiante: "es un grupo de hinchas que están en las buenas y en las malas, cantando al equipo... para que sepan que lo están apoyando" (E.C- 03/1 sesión 3, febrero 20 de 2009). Amigo o enemigo, la barra se integra alrededor de los tres elementos que menciona Garriga (2005): "fidelidad (estar siempre, no importan las condiciones), fervor (saltar, cantar, alentar aun en la adversidad) y práctica violenta (estar dispuestos a entrar en defensa del honor del equipo)" (p. 202); esta es la forma como se sostienen y confrontan. Su interés por el equipo lo supera todo, no interesan las advertencias familiares y de la escuela o las agresiones que han sufrido por otras barras, todo esto es poco al lado del fervor y la emoción que se experimenta al acompañar al equipo:

El orgullo de uno y la fidelidad que le tiene uno al equipo es más grande que todo, eso a usted se le puede venir el mundo encima, su familia, los profesores, le pueden decir a usted, "sálgase que eso es malo, que estos comandos le van a dar duro", pero usted sigue ahí, el orgullo es lo que no lo deja a uno salir. Porque uno dice, "yo soy del verde y yo tengo aguante hasta morir". Nacional es mi vida y puede venir aquí cuanta gallina ${ }^{4}$ sea, pero yo no me voy a dejar, $y$ siempre es con el aguante en la frente, llevar al verde a todo lado. (Conde Pátula, citado por Cañón, 2007, p. 108)5

4 Facción de la barra de Millonarios, denominada Pasión Gallina. El nombre hace alusión al equipo 'hermano' River Plate, de Argentina.

5 Comentario de estudiante barrista contactado en la investigación "Estudio de caso sobre el fenómeno de barras bravas: una mirada desde la escuela", realizada en 2007. 


\section{Y... ¿QUÉ ES EL BARRISMO?}

Definir el barrismo está sujeto a la emocionalidad que se produce, bien sea subjetivamente cuando se provoca la mirada sobre el sí mismo de los seguidores del fútbol, o cuando la mirada del fenómeno se realiza desde afuera. El barrismo es la expresión de un sentimiento, el amor por el equipo. Para algunos de los jóvenes es una forma de vida, es la vitalidad expresada en cánticos y saltos, "el barrismo es una ambición de llevar la camiseta y alentar hasta cansarse” (E.C-36/5 sesión 3, mayo 8 de 2009). Sobre el término 'barrismo' se tejen muchos imaginarios, Aguilar (2009) hace una descripción que muestra con frialdad algunas características de él las cuales intercala con un esbozo del concepto 'barrista' y crea una imagen de los jóvenes que anuncia peligrosidad:

Se apoderan de calles, parques, barrios, estadios. Con el rostro pintado o cubierto con pasamontañas, portan sus "trapos" (banderas), entonan sus cánticos, caminan como si fueran a una batalla, desnudan sus torsos, muestran sus tatuajes y elevan sus manos en señal, muchas veces amenazante, de dominio territorial. Andan en grupos, como los pandilleros violentos urbanos de siempre, y han encontrado en los colores de los equipos de fútbol un pretexto, como lo fue en su momento, el heavy metal o la veneración a las armas y a los narcóticos, o el culto a lo oscuro, para provocar terror. (Aguilar, 2009, pp.1-2)

Este fragmento, difundido en un medio de comunicación nacional, expone en cada una de sus frases una fuerte carga mediática en la que se dibuja el fenómeno del barrismo como un peligro para la comunidad, es la forma como se presenta a la opinión pública. En Colombia muchas de estas palabras tienen significación colectiva y se les asocia con episodios sórdidos de la historia nacional. Decir por ejemplo que transitan con pasamontañas (¿insurgente?) los iguala al guerrillero o a los delincuentes que se amparan en máscaras para cometer sus fechorías; los muestra como una especie de horda primitiva de la que hay que escapar porque produce terror; 'andan en grupos como los pandilleros violentos urbanos de siempre'. Es una categoría que impacta, una descripción que por sí sola genera una imagen colectiva asociada a la inseguridad en las calles. De hecho, comentarios como este son los que 
han generado ataques a las reuniones de jóvenes en cualquier esquina por el solo hecho de estar ahí, a la vez que generaliza una situación que no padecen todos los que asisten al estadio, pero que por ello quedan marcados como delincuentes.

A los escenarios deportivos acuden cada fecha jóvenes de todas las clases sociales; algunos encuentran en la violencia un modo de exorcizar sus frustraciones y otros la utilizan para demostrar poder frente a sus iguales, quieren sobrepasar a los demás. Al fenómeno del barrismo concurren jóvenes y adultos con otros intereses, que afectan no solo el evento en sí, sino las vidas de otros a través de la distribución y el consumo de drogas, los ataques con armas, el chantaje, el robo y hasta el ajuste de cuentas, pero no es la generalidad. Incluso entre los mismos barristas hay facciones que no aceptan la violencia como práctica. Un estudiante dice sobre su asistencia al estadio:

Desde el año pasado comencé a entrar a las barras, tampoco tan así, yo digo yo soy barrista pero a mí no me gusta el término ese de barra brava, me gusta así, barrista; me gusta participar de la barra, me parece que ese término es de la violencia, y la verdad es que no, eso no, más que todo me gusta mucho ir al estadio y todo eso. (E.C-44/5 sesión 3, mayo 8 de 2009)

Lo expuesto por este estudiante indica la forma como muchos jóvenes viven su afición motivados por el mismo espectáculo, solo los anima el gusto por su equipo y el evento que despierta todo tipo de emociones, no quieren ser identificados como barrabravas porque el ideal de estos es la violencia, quieren ser identificado como barristas sencillamente. No aceptan el comportamiento desbordado que se exhibe sin necesidad y sobre todo sin argumentos; valoran aspectos como la amistad, el respeto y la tolerancia, por ello pueden coincidir en el estadio siendo hinchas de equipos diferentes y su relación supera cualquier desacuerdo; siguen siendo hinchas sufridos, que aguantan los resultados de sus equipos, gritan a rabiar, cantan, lucen sus camisas, sus trapos, y acompañan al equipo a donde sea, pero definitivamente su opción no está ligada a la violencia.

"Para otros, sin embargo, son grupos que con comportamientos delictivos, como el chantaje, la intimidación y la agresión, obtienen divi- 
dendos económicos (como las bandas mafiosas o criminales)" (Aguilar, 2009, pp. 1-2). Como dijera Goffman, "del prejuicio al estigma hay un paso”, de esta forma el propósito es exponer a los barristas. Tras esta descripción de un importante medio, son agredidos por las autoridades y por otros que asisten a los encuentros, las generalizaciones son peligrosas y ponen a los jóvenes en el ojo del huracán. Dentro del estadio es posible diferenciar a unos de otros, pero en la calle no. A los ojos de los transeúntes, de las hinchadas enardecidas y de las autoridades, todos son iguales. Esto es lo que en muchas ocasiones ha generado situaciones fatales en las calles.

Nadie puede negar que el fenómeno del barrismo ha empezado a tener repercusiones en otros espacios diferentes a los estadios, que llegó a los barrios y a las escuelas, que habita en el territorio que demarcan y se posiciona cada vez más. Sin embargo, no resulta edificante la estigmatización. La verdad es que estamos frente a una generación insatisfecha que quiere hacerse visible, que necesita creer en sus posibilidades y en su futuro. Recasens (1999) lo confirma cuando dice que el barrismo "ha servido a los jóvenes para expresar lo que piensan en torno a la sociedad, la política, la cultura, etc.” (p. 28).

Cada uno de estos muchachos sabe que la barra tiene una dinámica, saben también cuáles son sus tareas una vez están en medio del espectáculo, es una lección bien aprehendida, "así toque hacerse matar, en las buenas y en las malas siempre hay que estar con el equipo" (E.C45/5 sesión 4, mayo 15 de 2009), o como dice este otro estudiante,

después de que nosotros entramos allá, nosotros vamos es a saltar, a cantar, a dejar a las barras del equipo contrario, dejarlos callados, que no nos ganen, a alentar a ese equipo. Después de que usted entra, lo que tiene es que alentarlo, no dejar de saltar y tener aguante (E.C-26/4 sesión 1, abril 24 de 2009)

especialmente porque aunque se vaya perdiendo hay que hacer respetar la plaza, no se permite la humillación en la propia casa, "por lo menos si el equipo contrario ganó, nosotros salimos a cantarle a las barras bravas del otro equipo si nos ofendieron y tener criterio para parársele a esa gente, no ser niña, no salir corriendo" (E.C-26/4 sesión 1, abril 24 de 2009). Es propio del barrista no eludir la confrontación, sino parársele al contrario, esperarlo sin miedo y responder el ataque. 
Galeano y Blanco (2004) dicen que "la violencia está íntimamente ligada con el fenómeno de las barras, la obligación del hincha es odiar al equipo rival" (p. 31). Esto explica, de alguna manera, las agresiones que se presentan entre una barra y otra. Entendida como una obligación, la violencia se practica aunque no se tenga claridad acerca de los motivos, la cohesión del grupo impone que a la hora del conflicto todos deben responder, lo que se le indica a los barristas es que deben estar dispuestos 'saberse parar y responder'. De la misma manera las expresiones violentas son muestra de la entrega y la pasión que se siente por el equipo, aunque para ello sea necesario fomentar el odio. Consideran igualmente la violencia como algo inherente a su pertenencia barrista, una experiencia que se debe afrontar y algo que hay que vivir:

No pues la primer pelea, ahí en las afueras del estadio, en pocas palabras ahí no hay seguridad de nada y si le pegan... le pegan, pero a uno le toca no dejarse; de primerazo se siente miedo, pero igual son muchas cosas que hay que vivirlas, así como uno tiene amigos también tiene enemigos. (E.C-24/4 sesión 3, mayo 8 de 2009)

Cuando deciden pertenecer deben sumarse a los ideales de la barra y su compromiso es irrestricto, de este modo lo expresan los estudiantes: "Si usted va es porque se compromete con el equipo, tiene que cantar, saltar y alentar y después... pa' las que sea” (E.C- 01/1 sesión 3, febrero 20 de 2009). Esta sentencia deja claro que los jóvenes viven con intensidad su adhesión, tienen muy presente su papel en el contexto del grupo y están dispuestos a todo por mantenerse allí; si se comprometen es como dicen ellos, "pa' las que sea”. Esta expresión denota la disponibilidad y disposición, no importa lo que sea, ahí estarán; encuentran en ello una posibilidad de liberarse de las situaciones que han vivido durante la semana; en los cantos, saltos y el festejo descubren la forma de conjurar sus vivencias negativas, es por eso que se imponen a sí mismos el hacerlo a rabiar:

Uno allá tiene la oportunidad de explotar digamos todo lo que durante una semana ha guardado, las groserías, toda la mala energía, además que uno se siente muy bacano porque está rodeado de mucha gente, conoce diferentes cosas, pasa un rato muy agradable, dependiendo de lo que uno vaya a hacer. (E.C25/4 sesión 3, mayo 8 de 2009) 
El fenómeno del barrismo escolar se puede definir como aquellos comportamientos adoptados por escolares que reflejan actitudes y prácticas del barrismo organizado de la ciudad, trasladado del estadio al entorno escolar y barrial. Consiste en llevar a la escuela las adherencias a equipos de fútbol con sus manifestaciones y expresiones, incluida la violencia, la territorialización, los símbolos y los rituales. Sus principales características están asociadas a la apropiación del espacio escolar y sus alrededores, así como la defensa a ultranza de los ideales del barrismo, sostenidos por el conflicto interno y externo como expresión de sentido. Pueden ser grupos visibles o no dentro de la escuela, con una fuerte cohesión y un altísimo poder de convocatoria a la hora de la confrontación con otros barristas e instituciones.

Dentro de la institución, como en el estadio, existe una jerarquía, un líder que es determinador de lo que pasa con la barra dentro y fuera de la escuela. Cuando el líder se consolida, lo hace a través de la violencia, se rodea de seguidores y aparece en la escena escolar como jefe de las confrontaciones que se presentan adentro y afuera de la institución; inteligentemente ubica las diferentes facciones barristas y sopesa el poderío numérico que representan, hecho esto, genera actos de intolerancia que lo posicionarán, de este modo se gana el respeto de los otros y procede entonces a marcar los territorios, así asume como organizador de las salidas (viajes), recoge los dineros para el pago de los pasajes y la participación del grupo en el estadio, controla y hace exigencias, ostenta poder y amenaza, extiende su superioridad a extramuros del colegio y deja clara su supremacía; en la institución 4 se pudo identificar al líder del grupo, quien cuando hablaba de los demás miembros de la barra se refería a ellos como "mis muchachos". 


\section{LOS JÓVENES BARRISTAS ESCOLARES}

Mucho se ha escrito en Colombia sobre la participación de jóvenes en los grupos de barristas del fútbol. Son numerosas también las formas como se observa el fenómeno y sus seguidores, al punto que ya se les puede identificar con diferentes calificativos: se dice que son vándalos, desadaptados, marihuaneros, hampones, criminales o asesinos; se les ha señalado como grupos delincuenciales, comparado con terroristas, con insurgentes; otros más piensan que se pueden equiparar con hordas primitivas, o como se les llamara en un diario de circulación nacional, "hordas de puñales, drogas y agresión" (Aguilar, 2009, p. 1), huestes de guerreros, en fin, de cualquier modo que quiera abordarse esta compleja situación por parte de las autoridades, los medios de comunicación o la comunidad, la carga estigmatizante que llevan estos y otros calificativos hacen que la imagen de los barristas no sea la mejor, pero, y lo más grave de todo esto, es la legitimación de la violencia en contra de estos muchachos por parte de las autoridades, de los mismos barristas y de las comunidades.

Con este conjunto de características, se justifica cualquier medida que se tome para contenerlos. El representante Granados, quien presentó el proyecto de ley del deporte, dice por ejemplo:

Lo que nosotros creemos es que las medidas administrativas y las medidas policivas ya se agotaron y la dificultad sobre lo que pasa en los estadios no se ha resuelto. Son comportamientos criminales que deben ser entendidos como tales. $(2009, \text { p. } 2)^{6}$.

En estas declaraciones no se aportó en ningún momento una solución en la que el Estado muestre que tiene previsto atender situaciones, sea el caso, en lo que tiene que ver con la desocupación de los jóvenes, la educación, el tema de la salud y específicamente la prevención del embarazo adolescente y otros asuntos relativos a la sexualidad, los consumos, entre otras, o alguna estrategia en la que vincule a los barristas de manera comprometida al espectáculo. Tampoco ha ofrecido una regulación seria a las actividades desarrolladas por las organiza-

6 Declaraciones al periódico El Tiempo a propósito de la radicación del proyecto de Ley del Deporte, agosto 11 de 2009. 
ciones del barrismo, a través de la cual se hagan responsables de las acciones de sus asociados (carnetización, personería jurídica, registro de listado oficial de quienes conforman estos grupos, entre otras alternativas).

Si bien es cierto que los barristas son reconocidos socialmente como beligerantes y no tienen buena reputación, más grave es que la misma administración, a través de alguno de sus agentes, declare públicamente que se han agotado todas las vías para controlarlos, con lo que muestra un desconocimiento total de la situación y abre la posibilidad para que puedan tomarse acciones de hecho que justifiquen la violencia indiscriminada en contra de los jóvenes, incluso generar la terrorífica limpieza social, cuando lo que se requiere es atender las problemáticas sociales que comprometen su futuro.

Lo que buscaba el representante Granados (2009) era repetir lo que ha venido sucediendo en los últimos tiempos en el país, demostrar que hay mano dura para atender los temas de seguridad, cuando en realidad lo que ocurre es sencillamente un ofuscamiento temporal que en nada contribuye a mejorar la situación. Es un discurso para los medios que busca resonancia. Este tipo de discursos, muy utilizados por los políticos, buscan "una respuesta inmunológica a los problemas, pretende localizar el mal, delimitarlo y combatirlo" (Imbert, 1992, p. 137). En este caso, el mal sería la violencia de los hinchas que se produce en los estadios, por tanto contrarrestarla con el uso de la fuerza, judicializar a los responsables y aplicar la normatividad, de este modo la mirada a la problemática tiene un carácter causa-efecto, se atacan los síntomas cuando se presentan, pero no hay soluciones de fondo, por ello se ha logrado muy poco hasta el momento. Por el contrario, la situación de violencia ha escalado en la mayoría de ciudades. Estas declaraciones lo que reflejan es que las autoridades se encuentran impotentes frente al manejo que deben hacer porque han aplicado paliativos a una situación social que requiere otro tipo de atención que ellos no reconocen; además hay intereses en el mundo del fútbol que necesitan que el espectáculo se desarrolle de una cierta manera, de modo que permita alcanzar los propósitos de quienes están detrás de los negocios y los dividendos que deja. 
El proyecto de ley radicado por Granados (2009) contempla que los barristas podrían ser acusados de terrorismo simple y recibir penas hasta de quince años de prisión. Muchos en este país hemos asistido perplejos a juicios de paramilitares, narcotraficantes y otros delincuentes acogidos a la ley después de haber participado en masacres y otros crímenes de lesa humanidad, que han recibido condenas irrisorias que no se compadecen con el daño causado. La promesa de implantar semejante condena para los barristas no solo es desproporcionada, sino que el Estado quiere aplicar castigos ejemplarizantes para justificar su respuesta punitiva, lo cual no contribuye a la solución de los problemas estructurales que afectan la vida y el desarrollo de los jóvenes. Los barristas son el chivo expiatorio que se sacrifica para inmunizar la violencia urbana.

La Ley 1445 de 2011 que rige el deporte en la actualidad, con respecto al tema de la convivencia en los estadios determina, en el artículo V, las sanciones y multas para los seguidores de los equipos profesionales que incurran en el porte de armas, la violencia verbal y física, el daño en bienes oficiales y privados y la forma como se van a penalizar estas actitudes de los hinchas. No hace alusión a las propuestas del congresista Granados (2009).

Necesitamos llamar a todos los actores del espectáculo futbolístico para que se devele la responsabilidad de cada uno, especialmente a la dirigencia de los clubes deportivos que sostienen a las barras con dádivas como boletas, viajes, trapos, ropa deportiva de marca, con lo que han generado luchas internas por el poder, es decir, cohonestan el mal comportamiento de los jóvenes en los escenarios deportivos, al tiempo que ellos mismos son los que piden que se les judicialice, que se endurezcan las penas y se actúe con firmeza y contundencia en la aplicación de normas para su control.

\section{CARACTERIZACIÓN DEL GRUPO DE BARRISTAS}

El grupo de investigación para el presente trabajo se conformó con sesenta y ocho jóvenes que participaron en forma voluntaria y con autorización de los padres; sus edades oscilan entre los 12 y 18 años, 
cursan los grados $6 .^{\circ}$ a $11 .^{\circ}$, y presentan las siguientes características: el 24\% (dieciséis casos) presenta extraedad, es decir, son estudiantes que sobrepasan la edad del resto de niños del grado que cursan; así, encontramos estudiantes de 16 y 17 años cursando grado $6 .^{\circ}$ en los colegios 1 y 4; cinco son repitentes (7\%); dieciocho (27,\%) pertenecen a familias monoparentales; seis $(8,8 \%)$ viven en zonas de la ciudad a donde no llega el transporte público; cuatro (6\%) son consumidores de sustancias psicoactivas y los restantes diecinueve (28\%) son muchachos que, aunque barristas, dicen no participar en los desmanes que se producen en el estadio y afirman tener una familia consolidada con la que mantienen relaciones calificadas por ellos como normales. Esta cifra resulta significativa en la medida en que es un porcentaje alto de chicos que solo van a disfrutar del espectáculo sin tener a la violencia como centro de su afición.

El tiempo de permanencia en la barra oscila entre uno y tres años, inician muy jóvenes su participación como aficionados y en general manifiestan que fueron por primera vez al estadio con familiares, en especial padres, hermanos, tíos, primos, cuñados, y con amigos del colegio, cuadra o barrio: "Hace un año también, que voy al estadio, yo voy con mis amigos pero no de acá, gente que se graduó hace rato, con gente de la cuadra, del barrio" (E.C-24/4 sesión 2, abril 24 de 2009).

Algunos dependen de sus parientes para ir al estadio, básicamente en lo que corresponde al costo de la boleta, y otros trabajan para conseguir el dinero; cuando quieren ir a un partido hacen lo que sea para sufragar la entrada, eso incluye trabajar, apostar dinero en el colegio, guardar parte de lo que sus padres les dan para comer en la escuela, e incluso se presenta el robo de objetos y dinero a familiares y amigos, la idea es estar en el estadio en los partidos más significativos para el equipo al cual siguen.

No... es que, mire, yo empecé a ir primero con mi tío, que me llevaba a oriental, ahí después me metía en trinchera, ahí fue cuando con todos mis primos me metía a sur con la Blue Rain. Ahora voy con mi hermano y voy cuando se le da la gana llevarme (risas). (E.C-o3/1 sesión 2, febrero 20 de 2009) 
El hermano lo lleva al estadio siempre y cuando el dinero alcance para los dos, de lo contrario va solo, aunque el estudiante manifiesta que él busca lo de su boleta cuando quiere ir.

Datos adicionales con respecto a los barristas escolares indican que algunas instituciones tienen plenamente identificados a los estudiantes que componen estos grupos, sin embargo no constituyen un problema para ellas, incluso algunos docentes bromean con estos acerca de los resultados de los partidos (colegio 4),

pues la verdad, también es que ya nos conocen, nos tienen identificados, yo soy bastante conocido aquí, la verdad se me hace normal que un profesor me diga "usted es de la barra brava", me da igual, porque yo voy con una mentalidad diferente así ellos digan que es que uno va es a buscar tropel, aquí en el colegio sí tuvimos un enfrentamiento con los de Santa Fe. (E.C-25/4 [entrevista], mayo 8 de 2009)

Se convive con la problemática debido a que los enfrentamientos se dan por lo general fuera de la institución, razón que se expone con frecuencia, lo que pasa en el exterior no se considera responsabilidad de los colegios; en este, igualmente, el grupo dominante trabaja dentro de la institución para vincular a otros a las barras. En una conversación informal afirmaron que el fin de semana asistirían al campo de entrenamiento de su equipo con estudiantes interesados y para animarlos les prometieron rifar distintivos como camisetas y botones.

Ser reconocido en el colegio como miembro de las barras es un capital que administran y utilizan muy bien los líderes para amedrentar, chantajear y mantener bajo control a los barristas de equipos que son minoría, los estudiantes refirieron cómo el estudiante E.C-25/4 "le pegó su viaja'o (puños) a un man del Cali que era todo crecido, le rompió la ceja y le cogieron puntos. Pero ahora el chino es todo bien, nos respetamos y no hay problema" (E.C-24/4 [entrevista], mayo 8 de 2009). El joven agredido también participó en el grupo y sobre la anécdota de la golpiza que recibió de su compañero dijo que lo había cogido desprevenido, al parecer lo que se presentó fue un conflicto por el poder, el chico quiso liderar a los hinchas del Deportivo Cali y 
E.C-25/4, que es seguidor de Millonarios, no lo permitió, ostenta un poder amplio en el colegio y no acepta competencia en el control de los barristas.

Cuando el estudiante E.C-25/4 se ausentó del grupo para cumplir una tarea, los demás integrantes aprovecharon el momento para hablar mal de él; dice que

a ellos (su grupo) les parece que él es muy lámpara ${ }^{7}$, que manda a callar a todos y que no tiene por qué, que no sabe ni fumar $y$ que no pierde oportunidad para estar "cayéndole" a las novias de los amigos. (E.C- 30/4 sesión 3, mayo 8 de 2009)

Esto provocó que E.C-27/4 aprovechara para quejarse porque "un día que él no vino al colegio, el estudiante E.C-25/4 se acercó a su novia y le habló cosas feas de él y luego para arreglar la situación le dijo que estaba bromeando" (E.C-27/4 sesión 3, mayo 8 de 2009). Esto indica que las relaciones de poder están matizadas por muchas circunstancias, el descontento generado al interior de la barra terminará por derrocar al líder, sobre todo cuando su comportamiento produce desconfianza o es visto como desleal.

Se considera deber de un barrista convencer a otros de vincularse al movimiento, para tal fin se ofrecen dádivas y los más veteranos se encargan de la formación del nuevo integrante, lo conducen en el estadio y lo ilustran sobre cómo debe comportarse, le enseñan las canciones y lo orientan sobre los compromisos que adquiere. Esto se observó en la institución 5 , donde existe un semillero de barristas compuesto por estudiantes del grados $6 .^{\circ}$ y $7 .^{\circ}$, liderado por un joven de grado $11 .^{\circ}$. Llegaron al grupo focal con camiseta del equipo, cachuchas y botones, contaron anécdotas sobre su participación y el más grande narraba las experiencias, fue claro que él tenía el control sobre los más jóvenes, a quienes autorizaba los temas que se podían tocar; los pequeños entonaron canciones de sus equipos saltando y repitiendo los ademanes que se ven en el estadio. El estudiante mayor indica que se reúnen con los barristas de la institución en un parque ubicado a una cuadra del colegio, para organizar en cada fecha su participación en el estadio.

7 Lámpara: persona a la que le gusta llamar la atención a través de actos molestos para los demás. 
En la institución 4 los estudiantes aseveraron que se encuentran en un parque aledaño, frente a la estación de policía, en el $\mathrm{CAI}^{8}$ de la zona, "acá hay unos que se reúnen todos los miércoles por la noche, si uno pasa por las noches siempre hay seis o siete" (E.C-26/4 sesión 6, recorrido barrial, mayo 29 de 2009); al preguntar por la actitud de las autoridades afirmaron que ellos no les dicen nada, " ahí hasta fuman marihuana, se traban con pegante y no les dicen nada” (EC-26/4 sesión 6, mayo 29 de 2009).

Otros grupos se reúnen en el parque detrás del centro comercial Suba Imperial, allí diseñaron en el piso un escudo de Millonarios con la hierba y el pasto circundantes; los temas que generalmente tratan se relacionan con la organización de los clásicos o los viajes con todas las tareas para acompañar al equipo. En el sector de Suba al parecer los grupos de barristas ocupan diferentes espacios, que constituyen su territorio de influencia, sin embargo los jóvenes han dicho que las juntas de acción comunal los sacan de ellos al parecer porque "hacen mucho desorden, fuman y les dijeron que como está el escudo pegado en el pasto, les quitaban el escudo si no se iban para otro lado" (E.C-28/4 sesión 6, recorrido barrial, mayo 29 de 2009).

Uno de los estudiantes relata cierta situación que vivió en este parque, refiriéndose a un altercado que tuvo con miembros de otra barra en el sector de Suba, en el cual fue agredido:

Por aquí yo iba y cuando volteo a mirar el 'hp' hablando mal de mí y me devuelvo así, muy ofendido... "iQué va, gonorrea! No me moleste". Y le dije: "Como quiera", y estaba ahí mi hermano, apenas escuchó esa mierda, salieron mi abuelita y mi mamá... mi hermano no salió a apoyarme sino a pararme, y claro: el pirobo me iba dando... es que esos pirobos son unas lámparas, me caen mal. (E.C-24/4 sesión 6, mayo 29 de 2009)

Estos son ejemplos de las situaciones que se viven en los barrios, los estudiantes no toleran mención alguna sobre sí mismos o sobre sus equipos, son contestatarios y agresivos.

8 CAl: Comando de Atención Inmediata, servicio de atención policial que se ubica en los barrios para atender de manera rápida las situaciones que se les presentan a los ciudadanos. 
Por otra parte, quieren que sus barras sean más originales y copien menos las formas del barrismo argentino, aunque en las barras se entonan

cumbias argentinas o cumbias villeras, aquí todo el mundo casi es de Argentina... pues la cumbia argentina nació de la cumbia colombiana, además la cumbia villera es una cumbia de baja extracción... sí, de barrio. A mí no me gusta eso, personalmente no me gusta... E.C-22/3 sesión 3, marzo 14 de 2009)

También se relataron episodios que muestran la gran influencia que tienen sobre los grupos en Bogotá y en otras ciudades algunas acciones que realizan los seguidores de equipos argentinos que buscan pedir cuentas a los clubes y a los jugadores sobre el bajo rendimiento y las malas campañas de los equipos. Dos casos parecidos ocurrieron en Bogotá y Medellín:

Hace como una semana o dos semanas se metieron los hinchas de Nacional al entrenamiento de Nacional a decirle que le metieran 'güevos al equipo, que qué pasa, que qué falta de respeto con los hinchas”. Igual hicieron los de Millonarios ese mismo día, se metieron y dijeron: "bueno, ¿̇cuál es su vaina, que ustedes no ganan nada? (E.C-18/3 sesión 3, marzo 14 de 2009).

La solidaridad entre los barristas hace que al momento de ser amenazado alguno de sus miembros la respuesta sea masiva, en eso consiste el respaldo que ellos mencionan a veces con pedantería. El respaldo es de toda índole y los muchachos valoran todo lo que la barra haga por ellos, no importa lo que sea, no hay límites:

Digamos, ahí hay gente que no tiene plata, entonces tiene que estar temprano allá pa'ver si le colaboran o si llega Moneda lo entra; digamos, es que Moneda ${ }^{9}$ tiene permiso de entrar a nueve personas. (E.C-O1/1 [entrevista], febrero 20 de 2009).

Esta evidencia confirma la relación que hay entre los capos y quienes están al frente del espectáculo, así como una muestra del poder que ostentan.

La solidaridad se realiza con las prebendas que recibe el capo, pero a los ojos del barrista se entiende como un acto de generosidad de este y le es útil para mantener cautivo al barrista y generarles compromisos. 
Según confirmó Sopas, también sirve al capo para mover sus negocios. El medio en el que los chicos cultivan su afición fomenta la transgresión permanente de la norma, el porte de armas, los consumos y la distribución; muchos de ellos trasladan sus negocios a las escuelas, donde las autoridades que hacen las requisas han encontrado armas y drogas, situaciones que la Secretaría de Educación ha denunciado ante la opinión pública.

Un caso respecto de la distribución de sustancias en las escuelas fue observado abiertamente por el equipo de investigación durante una entrevista en el colegio 1. A la hora de iniciar el descanso un grupo de jíbaros ${ }^{10}$ adultos empezó a merodear el colegio. Esta institución está comunicada con la calle porque solo la separan de ella rejas que dejan al descubierto su interior; desde afuera se observa muy bien lo que pasa adentro y viceversa. En la entrevista con estudiantes seguidores de Millonarios, uno de los alumnos (E.C1/1 sesión 3, febrero 20 de 2009) la detuvo para recibir a través de la malla un paquete de uno de los sujetos, conocido en el sector como distribuidor, y repartió su contenido a estudiantes que se le acercaron, incluso se presentó un incidente cuando algunos quisieron introducir la mano dentro del paquete, a lo que el chico respondió "ihuy!, ñero", no me raquetee"12. La relación de este estudiante con el grupo de distribuidores fue confirmada por un docente. Hay temor entre los profesores debido a que es muy riesgoso intervenir, pues según ellos detrás de todo esto hay grupos muy peligrosos, y también es preocupante por la seguridad de este joven.

\footnotetext{
10 Jíbaro: expendedor de sustancias psicoactivas.

11 Nero: apócope de compañero en el lenguaje de la calle, define al habitante de calle, al indigente. Coloquialmente los jóvenes lo emplean para designar al amigo; pueden considerarse también los términos 'parce' y 'parcero'.

12 Raquetiar [raquetear]: requisar, robar aprovechando el desorden.
} 


\section{BARRISMO, MASCULINIDAD Y VIOLENCIA}

¿Qué hace que los jóvenes sean susceptibles a la participación en estos grupos de barristas? Los estudiantes responden, casi de manera automática, que les gusta el fútbol, que lo hacen por la defensa del equipo, por posicionarlo; piensan que es una forma de expresar la fuerza y demostrar qué nivel de capacidad se tiene tanto en lo físico como en manifestación de virilidad; se escuchó la expresión "el fútbol es pa' machos" (E.C 64 sesión 2, abril 24 de 2009). En este sentido, por ejemplo, en la escuela los más pequeños no son convocados a la fiesta y al goce del fútbol, son desplazados de los espacios deportivos cuando aparecen los más grandes, los que van al estadio los domingos y pertenecen a las barras; lo hacen sin protestar, en medio de la burla de los otros; saben que su reclamo no tendrá eco, son las "niñitas" que lloran si les pegan o empujan. Un pequeño dijo: "hay que dejarlos, algún día también estaremos en 11. " (E.C-67/5 sesión 2, abril 24 de 2009). Estos episodios son frecuentes en las escuelas, los pequeños llegan más rápido a las canchas, pero en cuanto aparecen los grandes, sin mediar explicación o argumento posible deben desalojar la cancha y la mayoría de ellos se desplaza a los pasillos para continuar el juego.

Por otra parte, la afición de algunos constituye una tradición familiar, se les transmite. Los chicos dicen que sus primeras experiencias respecto de la simpatía por el equipo las han aprendido en la familia y se afianzan con los amigos, aunque también hay jóvenes que son iniciados por los amigos, no necesariamente son parientes los iniciadores:

Pues yo llevo como año y dos meses, no es que lleve mucho, pues yo tengo hartos amigos que son de Millonarios y desde polluelo soy de Millonarios [...] y que no, que camine y que no sé qué, la primera vez que fui a alentar pues de una me metí allá y ya después eso me quedó fue gustando, ya eso es muy difícil salirse, es muy bacano... es como llevar otro ritmo de vida, distinto a lo que ha vivido en su familia, uno en la familia... no es que a uno lo apoyen mucho, pero es muy bacano ir allá, uno se desquita de todos los problemas que tiene, si hay que pelear se pelea, es muy bacano ir ahí con su gente. (E.C-24/4 sesión 3, mayo 8 de 2009) 
La masculinidad es uno de los elementos del comportamiento barrista que está siendo estudiado como parte de la construcción de las identidades colectivas. Garriga (2005) admite que

los cantos de algunos grupos de barristas expresan elementos que se conectan con identidades masculinas, el fin último de estos es establecer quién es más hombre, situación que también se dirime en las gradas, en las diversas expresiones que diferencian unas hinchadas de otras. (p. 204)

En este sentido, el cuerpo es un elemento importante de la masculinidad, constituye un mecanismo con el que se da sentido a la pertenencia al grupo. Archetti (citado por citado por Garriga, 2005), afirma que el fútbol es un

espacio estrictamente masculino, en donde los hombres tratan de construir un orden y un mundo varonil... Esta construcción de órdenes se transforma en discursos morales, estableciendo fronteras entre lo permitido y lo prohibido, entre los atributos positivos y negativos de lo que idealmente se define como masculino (citado por Calderón \& Melgar, 2010); discursos morales que constituyen prácticas distintivas. (p. 204)

Lo masculino aquí se entiende como una construcción que se da en relación con otros que exponen, igualmente, modelos diferentes de ser (otras masculinidades), que se forjan en otros contextos, pero que en espacios como las gradas del estadio pueden ligarse a formas exacerbadas del comportamiento asociadas al 'aguante', que se vuelven específicas al momento de expresarse en actos demostrativos de la virilidad, manifestadas en forma colectiva.

Ser diferente entre estos grupos es prácticamente una necesidad y esa diferenciación refiere, según lo expone Garriga (2005), a "ciertas acciones y conductas grupales que expresan identidades colectivas a través de las cuales se forma un 'nosotros' diferente a un 'ellos"' (pp. 203-204). Esta forma de diferenciación expresada en el texto de Garriga explica entonces el reconocimiento que los sujetos hacen de la barra respecto de una serie de valores colectivos con los que se identifican y que separa a unos grupos de otros, bien por sus prácticas o bien por sus maneras de ser, a la vez que muestra la construcción de 
unas identidades que desde lo colectivo se convierten en referentes de masculinidad, formas que también son objeto de confrontación.

Desafiar a las barras contrarias es la máxima expresión de la masculinidad, es la fortaleza requerida para las demostraciones de fidelidad y entrega por el equipo y no es necesario encontrarse en el estadio para asistir a estas manifestaciones, basta con reconocerse en las calles de los barrios o en espacios como la escuela, donde hechos aparentemente triviales permiten expresar la cohesión de los hinchas en espacios que los jóvenes utilizan para exhibir su beligerancia.

Como se explicó, Garriga (2005) define tres características que aglutinan a una hinchada: la fidelidad, el fervor y la violencia (p. 202). La fidelidad se manifiesta en el compromiso con el equipo y consiste en acompañarlo en todo momento, aun cuando la situación sea adversa. El fervor se concreta en acciones como animar, saltar, cantar, alentar al equipo; los barristas llaman a esto pasión, no se puede desfallecer, es la fuerza hecha canción, grito y júbilo para mantener en alto la motivación del equipo. La violencia es el instrumento que garantiza la defensa del honor del equipo, requiere del enfrentamiento como expresión de la lealtad y el acatamiento a las reglas de la barra, que no solo pone en juego la supremacía del grupo en el estadio o en la calle, sino que tiene la función de preservar el prestigio del club, de la ciudad, del barrio y de los hinchas.

El aguante, por su parte, es la expresión máxima de masculinidad, remite inmediatamente al cuerpo, elemento por definición para el barrista, pues con el cuerpo se alienta, se amenaza y se confronta; el cuerpo se interpone para la defensa, es resistencia y territorio. El aguante es el valor más grande que tiene una barra. Aguantar, etimológicamente, es soportar, sufrir, resistir, actos que son cotidianos para los seguidores de equipos; se soporta la lluvia, el sol, el frío, un mal partido. Se sufre con y por el equipo, se llega al llanto, al dolor excesivo, a la frustración, pero la clave es no flaquear. Se resiste a todo, a los otros, a la autoridad, a lo establecido, la idea es no perderse en el ruido de las otras barras, ni correr cuando se presenta un disturbio, es esperar al otro sin miedo: 
Esta palabra nos inspira garra, amor por el equipo, una pasión que día tras día crece más, es soportar lo que sea, la que nos inspira mucho amor por la camiseta; es aquel parche o grupo de personas que siempre van a alentar al equipo y lo entregan todo, hasta la vida. La palabra aguante significa alentar, 'frentiar' por el equipo en las buenas y en las malas, cantar siempre con todas las fuerzas y todo el corazón para que el equipo no se sienta solo, sino que se sienta que un grupo muy grande de personas lo van a alentar y así hace que los jugadores metan más 'güevos' (E.C25/4 sesión 3, mayo 8 de 2009).

Para un barrista el cuerpo constituye el arma que esgrime para la defensa del honor de su equipo. Muchos de los relatos de los escolares sobre su participación en las barras en general remiten a situaciones que se orientan hacia el reconocimiento de aspectos relativos a la masculinidad:

Porque yo no sé... había un parchecito, había como cinco chinitos ahí, así como este man [señalando al más pequeño del grupo] y llegó un amigo, me empuja, nos empujaron desde atrás y yo le cojo al chino la cabeza y el chino qué marica, qué pirobo, todo bocón, y yo pues “¿qué le pasa?”, y el man me pegó un cabezazo y yo se lo devolví, ahí fue cuando llegó un man y nos separó, es que hay chinos bocones como este man (el más pequeño), un gamín, hay mucho gamín. (E.C-7/1 sesión 3, febrero 20 de 2009).

Interviene otro (003/): "Y a esos boconcitos les llega rápido su hora" (E.C-3/1 sesión 3, febrero 20 de 2009). Y remata el estudiante E.C1/1: "Y no pelean las nenitas, son concha, salen a correr; hay gente que... ¿̇sí o no?... se las dan de los más barristas, los más comandos, los más tales... hay una pelea y son los que más están corriendo”.

Una segunda justificación de pertenencia al barrismo por parte de los escolares tiene que ver con lo mediático; dicen que mejora su imagen en el entorno, que los visibiliza, aparecer en los medios de comunicación como parte de los desórdenes en la ciudad es un orgullo en relación con el desafío a la autoridad, permite también tener unos minutos de gloria. Además aducen que genera respeto y reconocimiento frente a los demás compañeros, que los ven aguerridos, diríase incluso que son admirados. Javier Hernández Bonnet, reconocido periodista deportivo plantea sobre los medios y el barrismo: 
Los medios han sido unos multiplicadores del fenómeno como tal, digamos patrocinando el ego de quienes hacen parte de estos actos de maldad, está más que comprobado en todas las historias criminalísticas del mundo, que los grandes asesinos, los grandes anarquistas, gozaban viéndose en televisión, gozaban viendo la obra, el retrato de su maldad volando un edificio o matando prostitutas y se divierten con eso; entonces los medios de comunicación tienen en el caso de las barras una responsabilidad, nosotros ya decidimos que a las barras no les vamos a dar publicidad, no los vamos a convertir en protagonistas del espectáculo, los protagonistas son los jugadores y son los técnicos, nosotros entramos ya en esa etapa. (Hernández [entrevista], julio 31 de 2009)

Dadas las circunstancias del barrismo en Bogotá, los cronistas deportivos han acordado que no reseñarán los actos que producen los barristas y que no serán ellos quienes les den protagonismo en el contexto noticioso, la idea es no concederles el espacio para evitar que satisfagan su necesidad de reconocimiento.

Otro elemento que valida la opción por el barrismo es el concerniente al "respaldo", entendido como soporte para la confrontación, posibilidad de defensa y apoyo relativo más a lo afectivo, la solidaridad. La barra es portadora del espacio para 'ser' sin límite; allí se puede todo: beber, fumar, drogarse, arriesgarse, aprender, en fin, es un espacio de afiliación que goza de credibilidad, que promete experiencias extremas (adrenalina), autonomía y libertad. Ser barrista en el contexto de la escuela implica la admiración de los otros, algo de lo que se alardea. Su participación como miembros del barrismo les permite ser populares entre las niñas; ellas, de igual manera, se ufanan de su relación con ellos, obtienen dividendos a través de los cuales manejan sus disputas con otras utilizando el chantaje y la amenaza. Este aspecto del respaldo se evidencia en las instituciones a medida que los grupos de barristas no solo apoyan a alguno de sus miembros por razones relativas a su adherencia deportiva, también lo hacen en cualquier conflicto que tenga la persona dentro o fuera del colegio, y esto se presenta por ejemplo en los enfrentamientos entre pandillas, cuyas motivaciones pueden ser muy diferentes a las del barrismo. 
Hay respaldo, mucho, y no es del grupo de amigos sino de diferentes barrios, después que estos manes... que los cojan... las garzas (hinchas de Santa Fe)... el man tiene amigos de diferentes barrios y me dice por ejemplo, a mí, que yo soy aquí del Girardot, yo tengo cuatro amigos, me bajo pa'l barrio del man y lo respaldo, lo mismo yo, los de la Roca... ¿̇sí pilla?, los chinos bajan, los del Rocío también... iClaro!, ¿no ve que es la camiseta, el color? Sí, pero si ese chino lleva la camiseta de Millos y le van a dar entre dos, si yo tengo mi grupito de amigos yo lo respaldo. (E.C-7/1 sesión 3, febrero 20 de 2009)

Ser barrista genera en estos jóvenes empoderamiento; viven a la defensiva, y cuando no tienen problemas los buscan; se persiguen en las calles por llevar una camiseta o cualquier distintivo, se agreden con armas, transgreden el espacio de los otros, se citan y se provocan vía Internet: "Hay un grupo en Facebook que se llama antilocas... que con machetes - busquen en Facebook y ahí sale-, que con machetes rompen una boleta, dañándola y todo, rompiéndola... En Facebook hay hartísimas fotos”. Se buscan en los colegios y destrozan a piedra las instituciones. Quizá lo más delicado de todo esto es la opción que eligen algunos de vincularse a grupos al margen de la ley, como dijera Sopas, "para potenciar su poderío", son tan fuertes pero a la vez tan vulnerables que se someten a trabajos para la delincuencia a cambio de dinero, porque su vulnerabilidad radica precisamente en la necesidad de ostentar fortaleza al portar armas, lucir ropa de marca, tener dinero para boletas, y esto finalmente es también acceder a experiencias mayores que les garantizan riesgo a través del cual construyen una imagen frente a los demás que les sirve en el espacio escolar y barrial para amedrentar, chantajear y obtener dividendos a través del miedo. Así entonces, las motivaciones de los jóvenes para participar en los grupos de barristas están relacionadas, además, con la experiencia del riesgo, uno de ellos, el consumo de drogas. Cuando se pregunta cuál es el mayor consumo dentro de la barra, exponen:

Las pepas, las pepas... son las que más se consumen afuera, porque eso primero se tienen que estallar... se tienen que estallar... se puede estallar con marihuana, con pegante, con tinto, con aguardiente, con lo que sea se estallan rápido, pero con lo que más se demora es con agua; pa' que se le estalle una pepa con agua usté se demora, tiene que durar un día pa' que se le estalle; 
en cambio usté se toma un tinto, se echa dos pepas y un tinto $y$ son cinco minutos y eso ya están estalladas esas dos pepas ahí, usté ya está así en el piso [se acuesta en el piso, saca la lengua y expone los ojos desorbitados). (E.C-O1/1 sesión 3, febrero 20 de 2009)

Esta es la experiencia delirante que permite vivir desenfrenadamente el espectáculo; son el fervor y la emoción exacerbadas, la posibilidad de estar ensimismado, con el cuerpo dispuesto, después del cotejo o en la vida cotidiana. El consumo es una opción para sobrellevar las dificultades familiares, las derrotas escolares y la persecución barrial. Se evidencia el consumo de marihuana como el más frecuente entre barristas escolares, aunque se mencionaron, entre otras sustancias, el popper (explicaron la forma de consumirlo), unas píldoras que ellos llaman 'troche'. Afirman también consumir alcohol, pero fuera del estadio, y en el colegio 4 los estudiantes confirmaron que se inhala pegante en las aulas, adherido a las mangas de los sacos. Asimismo, ingresan marihuana al estadio en compartimientos que fabrican dentro de sus zapatos; en los teléfonos móviles; los que tienen el cabello largo se lo recogen para introducir papeletas. Las autoridades han hecho exigencias para el ingreso de las jóvenes a los escenarios deportivos, relativas a la indumentaria que deben llevar los barristas, ha de ser ropa holgada, sin medias, sin cinturones ni elementos contundentes.

¿Cuál es la explicación de estas circunstancias? Las manifestaciones de los jóvenes como parte de la barra deben verse como indicios de la incertidumbre social que se exterioriza utilizando al grupo como fuerza y resistencia, donde la colectividad amplía la capacidad de afrontamiento; engrandece y empodera frente a circunstancias como la exclusión y la desigualdad, que son en la actualidad los pilares de la inquietud de los jóvenes. Molina (citando a Blumer, 1975) indica que la excitación social produce la expresión del comportamiento colectivo, en otras palabras, cuando las personas perciben injusticia social existe mayor predisposición a las reacciones grupales, quizá esto permita sustentar la idea de que los jóvenes han perdido todo horizonte, no solo por desadaptación, sino porque experimentan un vacío existencial en el que no encuentran sentido a las cosas, perciben ausencia de futuro y es precisamente esta incertidumbre la que los 
congrega. Blumer lo expresa con claridad: "La inquietud social es un indicio del desmoronamiento de las certezas a las que todos tenemos derecho para mantener el equilibrio" (p. 5).

\section{VIAJAR CON EL EQUIPO:}

\section{LA PROMESA CUMPLIDA DE RIESGO, AVENTURA Y EMOCIÓN}

Una forma de atraer a nuevos seguidores es ofrecer vivencias emocionantes y aventura. Viajar con el equipo a otra ciudad es para los jóvenes toda una odisea, se someten a cualquier situación con tal de salir con sus amigos y cumplirle al equipo. Viajar por \$20.00o implica hacer el trayecto a pie y en condiciones difíciles, sin comer ni beber, considerando que el desplazamiento entre ciudades puede durar unas ocho o diez horas. Otras veces, cuando no logran reunir el dinero para el pasaje, viajan poniendo en riesgo sus vidas colgados de camiones (irse 'guerriao'), durmiendo en la calle, pidiendo plata a los transeúntes para poder comer...

Un joven expresa sobre los viajes:

Digamos... ahora el viaje... a mí me llevan por veinte mil pesos a Neiva, me toca conseguir lo de la boleta, que son seis mil pesos, y lo que coma, o sea, dos mil de pan y mil de salchichón, y ahí quedé... cigarrillo no hay necesidad de llevar, porque allá dan... ni 'bareto"13... uno está pasando y le dicen: "tome chino, fume", y uno fuma... (E.C-01/1 [entrevista], febrero 20 de 2009).

La anterior es una muestra de que al mundo del consumo se puede entrar muy fácilmente. Se ufanan de su astucia para burlar a las autoridades: "Lo que hay es retenes, como tres, cuatro retenes, y lo más chistoso es que nunca encuentran la marihuana, eso meten cuchillos, marihuana o navajas"... (E.C-07/1 [entrevista], febrero 20 de 2009). Los controles en las carreteras son muchos, sin embargo los jóvenes se las ingenian para 'encaletar' con mucha facilidad marihuana y armas; hay momentos en que la participación de las mujeres es importante,

13 Bareto: cigarrillo de marihuana; rollo conformado por una droga psicoactiva cualquiera: bazuco, marihuana u otra, envuelta en un papel y que se fuma. También se le dice 'cacho'. 
ya que guardan en sus cuerpos elementos prohibidos y las requisas para ellas son menos estrictas. "Hay ocasiones que utilizan a las mujeres para entrar la droga, como los policías no pueden requisar a las mujeres”... (E.C-17/3 sesión 3, marzo 14 de 2009).

La organización de los viajes corre por cuenta de los capos, buscan el transporte y recogen el dinero a través de los líderes de parche.

Toca alquilar bus y eso cualquier bus no los lleva, los dirigentes de cada parche... ellos son los que organizan quiénes van a viajar, hacen la lista ahí, cuando va a llevar la plata; o sea, tiene que estar en la lista y cuando ya se vayan a viajar tienen que dar la plata porque obviamente ellos le dan a uno un voto de confianza para la entrega de la plata y eso a veces el pasaje incluye boleta o uno viaja y allá las boletas son más baratas que acá, ida y vuelta con boleta o sin boleta. (E.C-28/4 sesión 1, abril 24 de 2009)

Pueden acudir todos aquellos que tengan el dinero y cada uno organiza lo que necesita llevar, por ejemplo, alimentos o bebidas, que en muchas ocasiones tiene que compartir con los demás:

A mí una vez me pasó, uno compra algo para el viaje, pero no termina comiendo nada... (risas), a lo bien, loco, usted llega, una gaseosita... pongámosle usted pide la gaseosa, voltea y ya tiene diez manes ahí, todo bien, un sorbito, y si usted se pone de pesado pues va llevando, es obligatorio ser solidario con la barra porque le pueden cobrar con violencia su falta de fidelidad a la barra. (E.C-25/4 sesión 1, abril 24 de 2009)

Los estudiantes planifican sus viajes de acuerdo con la importancia del partido:

Lo que pasa es que uno mismo es el que organiza todo, sabe cuáles partidos hay, entonces usted dice "voy a viajar a tal sitio", y ahí mirará cómo es que consigue su plata.... iLa vida de nosotros es muy dura! (E.C-25/4 sesión 1, abril 24 de 2009)

Los viajes frecuentes con el equipo son muestra del amor por el equipo y configuran la idea del buen hincha, el que ve siempre a su equipo donde quiera que se presente: "La gente que vive aquí en Bogotá va cada quince días al Campín y esperar otros quince días para ir otra 
vez al Campín, pero la gente que es verdadera viaja y viaja y viaja” (E.C-36/5 sesión 3, mayo 8 de 2009). Aunque los jóvenes dicen que acompañarían a su equipo a cualquier parte, hay ciudades lejanas a las que no irían porque es mucho trayecto para recorrer, esto implica obviamente más gastos y más tiempo invertido, dado que algunos viajan sin permiso de los padres, lo ideal es viajar y regresar el mismo día.

Al preguntarles cuál es la ciudad a la que no viajarían dicen que a Pasto, porque el viaje es muy largo y pesado, son veintidós horas; otros estudiantes pensarían en viajar a ciertas ciudades, especialmente por los conflictos que se pueden encontrar, por ejemplo, ir a Medellín es para las barras bogotanas sinónimo de problemas. Consideran como las mejores salidas Neiva, Ibagué y Boyacá porque se van temprano y regresan en la noche o la madrugada; el viaje que más disfrutan es a Barranquilla, por el tiempo que pueden estar allí.

Muchas veces las barras locales los esperan y confrontan con los visitantes, esto es considerado por ellos lo máximo, así lo documentó un joven:

iNooo! Es que Medellín es recaliente, o sea, es lo máximo, es que llegando a un pueblito, yo no me acuerdo cómo se llama, ya nos están esperando, que nos encienden a roca y que le dan al bus, ieso es lo mero!... (E.C-o7/1 [entrevista], febrero 20 de 2009)

'Encenderse a roca' es agredirse con piedras. Esta situación les gusta a los muchachos porque fluye adrenalina, es no dejarse, defenderse y enfrentar a las autoridades pese a que los esperan en las entradas de las ciudades para guiarlos hasta el estadio; también lo hacen al terminar el partido: los dejan en el límite de la ciudad, por lo que deben abandonar los escenarios deportivos antes de que termine el partido, esta es una forma que tienen las autoridades de evitar los pleitos entre barras, sacar al visitante antes y escoltarlos hasta las afueras. Las contiendas que suceden en las carreteras se han salido varias veces de control, se han usado armas y por cuenta del espectáculo del fútbol han resultado muertos varios jóvenes.

Estas experiencias son consideradas como lo natural que debe hacer y soportar un hincha por su equipo. Cada cicatriz, cada golpe, tienen un 
significado que los identifica ante los otros como aguerridos, arriesgados, comprometidos; las cicatrices constituyen trofeos que se exponen con orgullo y generan el respeto de los demás. Los estudiantes hablan de ello con fascinación y viven estas situaciones de forma extrema, como lo relató un joven del colegio 5 :

Nos fuimos con el equipo para Ibagué, cuando llegamos nos estaban esperando los del Tolima, inos dieron qué paliza!, con piedras y palos, todo lo que se apareció, uno de la barra resultó apuñalado. El man andaba solo; cuando ya nos íbamos a venir, dijeron que quién se podía quedar a acompañarlo hasta que saliera del hospital, entonces yo me ofrecí porque nadie quiso. Todos los demás se devolvieron el mismo domingo. Estuve con él toda la semana hasta que se mejoró y nos pudimos venir para Bogotá. Perdí toda esa semana de clases, pero pues ya qué podía hacer, además pensé: yo el colegio lo paso breve... (E.C36/5 sesión 3, mayo 8 de 2009)

Las situaciones en las que se ven envueltos los jóvenes son en ocasiones de mucha responsabilidad, como en este caso, o de exposición al riesgo. En un caso como este, los gastos que demanda acompañar al herido son cubiertos por la barra a través de colectas que se hacen entre ellos mismos, es una forma de apoyar y de proveer a quienes asumen estas tareas (respaldo). Algo que llama la atención es que en toda la semana el joven herido no fue buscado por su familia, ya que llamó a su mamá y le dijo que se iba a demorar porque el equipo iba a hacer una actividad en esta ciudad y todos estaban invitados, esto fue suficiente explicación para no estar en su casa durante una semana, después llegó a su hogar como si nada hubiese pasado. También es común que los jóvenes viajen con la anuencia de los padres.

En el colegio 3 encontramos un estudiante que también había sido apuñalado por miembros de barras en Fontibón; los hechos habían ocurrido por un conflicto durante un viaje, que posteriormente se solucionó en el barrio, "yo hace rato que no voy al estadio porque es que cuando estaba con mis amigos, un día me cogieron a la salida (del colegio), solo, y me apuñalaron” (E.C22/3 sesión 2, marzo 7 de 2009). En ocasiones los organizadores de los viajes convocan a muchos hinchas, viajan en caravana como una forma de protección, sin embargo 
esto no evita que se presenten inconvenientes; la narración de un hincha del Nacional de Medellín así lo confirma:

De Bogotá, solo de Nacional salieron diez buses para Ibagué, y tres buses se salieron de la caravana, porque íbamos en caravana, y a esos tres buses los rompieron todos, y a un man que... yo iba al lado, le metieron una puñalada por acá (el costado), duro. Digamos que parquean los buses en una esquina y nosotros nos encontramos con hinchas del Tolima, pero así... (cantidad), con banderas, $y$ cuando de pronto, ihuy!, que los sureños, y nos caen a roca (piedra), eran unas piedrotas; todos los tres buses rotos, todas las ventanas rotas. $Y$ en el bus que íbamos el fercho (chofer), el que nos maneja, llevaba los dos niños y la mujer, y nosotros: "fercho, ábranos y los frentiamos", y él se encierra con la familia en el baño y nosotros afuera en el piso y dénos roca, y al fin como que se despertó y echó reversa, y ni un policía ni nada, entonces yo cojo al man, paramos un taxi y iclaro!, severo hueco acá (costado), tocó llevarlo a un hospital y yo me quedé como cuatro días en Ibagué. (E.C-36/5 sesión 3, mayo 8 de 2009)

\section{BARRISTAS ESCOLARES: LA SENSIBLE FRONTERA ENTRE LA AFICIÓN Y LA DELINCUENCIA}

A medida que se estrecha la relación del joven con la barra, es mayor la posibilidad de que este se inicie en la comisión de contravenciones a la ley; respaldado por el grupo, se arriesga con mayor facilidad en la realización de actos que suelen convertirse en retos para conservar su posición; según los estudiantes, las primeras aproximaciones se dan dentro de la misma barra, donde, aprovechando el tumulto y la confusión, se puede acceder a pequeños elementos como camisetas, gorros, cornetas, buzos, entre otros. Estos hechos han sido motivo de discordia entre los miembros de la colectividad que no están dispuestos a tolerar esas conductas consideradas desleales, la osadía puede pagarse con la exclusión del grupo e incluso la muerte si las actitudes son frecuentes en contra de la barra. Se agrava con el hecho de que en la ciudad el acceso y porte de armas es considerable; el porte de armas por escolares es una preocupación por parte de las autoridades y de las secretarías de Educación en todo el país. 
Un estudiante admitió:

Es que a mi primo lo iban a matar por un gorro, se salió del barrismo por eso. Mi primo lo compró y entonces a él le dijeron que ya no pertenecía a esa barra, entonces mi primo les dijo que no, que no lo entregaba y se rompieron en Neiva, hace dos años se rompieron en Neiva, de ahí pa'lla mi primo no ha vuelto al Campín. (E.C1/1 sesión 3, febrero 20 de 2009)

En Bogotá un caso parecido dejó un joven muerto dentro del estadio después de ser acusado de cometer robos; miembros de la misma barra lo agredieron con arma blanca y lo asesinaron. El hecho fue calificado por las autoridades como una demostración del conflicto entre barras que se libra en el estadio.

Sopas comentó que capos de las barras se involucran en redes de consumo y distribución de sustancias, implicando a su vez a miembros de la colectividad que son responsables del microtráfico en el barrio y dentro de las instituciones educativas.

Los jóvenes que se posicionan en las instituciones a través de la fuerza recurren a agentes externos para magnificar su poder frente a sus iguales, se alían con pandillas barriales que son, según las describe Perea (2008), "un ejemplo de individualización, pero también búsqueda de inclusión y pertenencia” (p. 33); por definición la pandilla es el lado conflictivo de lo joven, y al respecto complementa Perea: "La condición de joven se convirtió en una ventana privilegiada, sin la menor duda, para atisbar la sociedad contemporánea y sus tempestades” (p. 14), desde esta apreciación la pandilla es síntoma de la situación social y sus actuaciones muestran el estallido de las dificultades que afrontan los jóvenes en las ciudades a través del desafío y la resistencia a lo establecido.

La alianza de la pandilla con los escolares facilita la ostentación de poder. Cuando se presentan conflictos entre estudiantes en las afueras de los colegios, el pandillero es la imagen de la transgresión y el conflicto social, pero también para la mirada juvenil es la expresión de libertad y fortaleza, la cual es reconocida en el ambiente escolar, temida por algunos y añorada por otros. Esta relación genera unos compro- 
misos en los que se exige informar sobre situaciones de la vida escolar tales como el porte de elementos costosos, celulares, computadores portátiles, joyas, entre otros, que portan estudiantes y son atacados a la salida de clases para despojarlos de ellos. Esta es una de las formas como los jóvenes entran en la delincuencia. Cruz y Carranza (2006) comentan que

los pandilleros están cada vez más cerca de un perfil que se acerca indiscutiblemente al del crimen organizado: grupos bien estructurados con una clara motivación criminal que viven de una especie de economía ilegal a través de acciones como la extorsión, el secuestro y el robo. (p. 143)

En la institución educativa 2 los estudiantes relataron cómo muchas veces quienes les roban van preguntando directamente por los objetos que han llevado al colegio, es decir, van a la fija; incluso les han introducido las manos en los bolsillos para sacarles el dinero.

También se sabe de estudiantes que buscan defensa en grupos que no pertenecen al colegio y que los menores identifican como pandillas que operan en la localidad: "El año pasado uno, que le decían Dumbo porque tenía las orejas grandes, le pegó a uno más pequeño y el chino habló con unos manes y vinieron, lo cascaron (le pegaron) aquí a la salida del colegio" (E.C-13/2 sesión 5, marzo 6 de 2009). Son actos que evidencian la relación entre escolares y pandillas. A este mismo joven, al preguntarle si había estudiantes pertenecientes a pandillas, dijo que "sí, un primo mío, al que echaron del colegio, a él lo pusieron en otro colegio y también lo echaron por robarse un MP3, ahora está trabajando". Cuando son expulsados denominan a esto la "entrega de los papeles': les devuelven la carpeta con sus documentos, con lo que se concreta la desvinculación de la institución.

Se menciona que con frecuencia hay grupos que buscan a estudiantes a la salida del colegio o personas que son enviadas a agredir a otros:

Vinieron unos manes el año pasado a chuzar a un compañero de aquí... dos niños como de 10 y 12 años... con cuchillos... el chino de aquí traía una chaqueta gruesa, el man se cayó y los chinos comenzaron a mandarle (cuchillo)... uno de ellos era el 
Chimbita ${ }^{14}$... iAh! sí, el Chimbita le dicen, el de 10 años, eso fuma marihuana y echa pegante (inhala)... y el hermano también peleó con ellos, iAh!, sí, esa pelea yo sí la vi, el "S"15 se agarró a pelear con ellos, los encontró, iba él con la mamá y los chinos chuzaron a la mamá... y esa señora estaba con un bebé, después se agarraron a cabra (tipo de navaja) y al "S" lo chuzaron por la espalda y en el brazo, se lo llevaron por allá y no se supo más; pero el papá del "S" $y$ la hermana fueron a buscar a los chinos $y$ salieron las hermanas y ellas no les quisieron decir nada, entonces el papá de "S" cascó (les pegó) a las chinas. (E.C-13-16/2 sesión 5, marzo 6 de 2009)

Estas agresiones entre escolares llevan a una escalada de la violencia que involucra a otros miembros de la familia y se crean de este modo problemas relacionales entre vecinos que afectan directamente a la comunidad.

En la institución 3,

una joven seguidora de un equipo de la ciudad señaló a la salida del colegio a uno de sus compañeros, inmediatamente una pandilla de seis jóvenes la agredió con palos, argumentando que era una seguidora de Millonarios y que había ofendido a unos hinchas de Santa Fe, el resultado: un brazo fracturado" (personera estudiantil, 7 de marzo de 2009).

Por otra parte, la vulnerabilidad de los jóvenes frente a la solución de problemas inmediatos o el deseo de poseer objetos costosos, ropa de marca, tecnología de última generación, entre otros, los convierte en presa fácil de los grupos aliados con distribuidores de sustancias que, a la vez, son los responsables del mayor consumo en las instituciones. No es extraño encontrarlos a la entrada y salida de los colegios reclamando los dividendos de las ventas del día o profiriendo amenazas contra aquellos que no han cumplido. Relatos de personas de la comunidad alertan sobre golpizas que han recibido estudiantes de un colegio por parte de adultos que se desplazan en vehículos con vidrios

14 Chimbita, alias de un delincuente de 12 años; consumidor de drogas, porta armas con las que amedrenta para cometer hurtos y realizar ataques; debe su apodo a que cuando se encuentra bajo efectos de las drogas mendiga pidiendo una 'chimbita', es decir, una moneda. "S": inicial del nombre de un estudiante de esta institución que se vio implicado en el incidente. 
oscuros y les esperan a la salida de las escuelas (una mujer de la comunidad del colegio 3 llegó a la institución educativa a solicitar ayuda para un joven que estaba siendo golpeado por dos adultos en una calle de este sector, julio 26 de 2012).

Santacruz y Concha-Eastman (citados en Cruz \& Carranza, 2006) admiten que si bien los jóvenes suelen involucrarse en incidentes de violencia colectiva por su vinculación con grupos,

la magnitud de sus acciones criminales se ensancha. De allí que en la medida en que se avanza en la ruta de la violencia, la intervención de los jóvenes es más reducida, es decir, hay menos jóvenes participando en el crimen organizado que los que participan en las barras o grupos juveniles; pero al mismo tiempo, la capacidad en los grupos de producir perjuicios a la sociedad, por pequeños que sean, es mayor. (p. 145)

Es lo que ellos llaman la ruta de la violencia; colectivamente las acciones de los jóvenes pueden alcanzar magnitudes insospechadas (aumento de la violencia, delincuencia); a medida que estas se complejizan y se hacen más fuertes disminuye el número de chicos dispuestos a participar en actos que pueden considerarse criminales; pero la posibilidad de grupos, como las barras de fútbol, para causar daño social (vandalismo, lesiones, hurto, entre otras) es mayor. Es decir, a mayor complejidad de las acciones delictivas menor implicación de jóvenes, pero en grupos como las barras existe mayor predisposición al daño social que al crimen; esto es importante, toda vez que indicaría la diferenciación entre los actos delincuenciales y las transgresiones juveniles (contravención a la ley), con lo que es posible evitar las generalizaciones que hacen las autoridades y los medios de comunicación al referirse al fenómeno.

$\mathrm{Al}$ respecto, el respaldo sería por ejemplo un caso en el que se involucra un barrista en desórdenes dentro y fuera del estadio o en los barrios y apoyar a ese compañero, aunque si la situación se torna violenta, acarrea daños a bienes públicos y privados, hay lesionados, si se corre el riesgo de salirse de orden porque el barrista tiene problemas graves con otros, el respaldo disminuye. Así lo indica un estudiante: 
Si es un chino que lleva la camiseta de Millos y le van a dar entre dos, si yo tengo mi grupito de amigos yo lo respaldo, pero después que ya sea un problema así, muy 'hp', yo no lo respaldaría porque salgo perdiendo. (E.C-7/1 sesión 3, febrero 20 de 2009)

En el estudio de Santacruz y Concha-Eastman (citados en Cruz \& Carranza, 2006) en torno a las maras y pandillas en El Salvador, se explica claramente la ruta de la violencia juvenil (el esquema fue aplicado a la evolución de las maras y pandillas centroamericanas, pero creemos que algunas consideraciones son válidas en el contexto del barrismo futbolero). (El planteamiento de los autores puede observarse en la Figura 5).

Figura 5. La ruta de la violencia

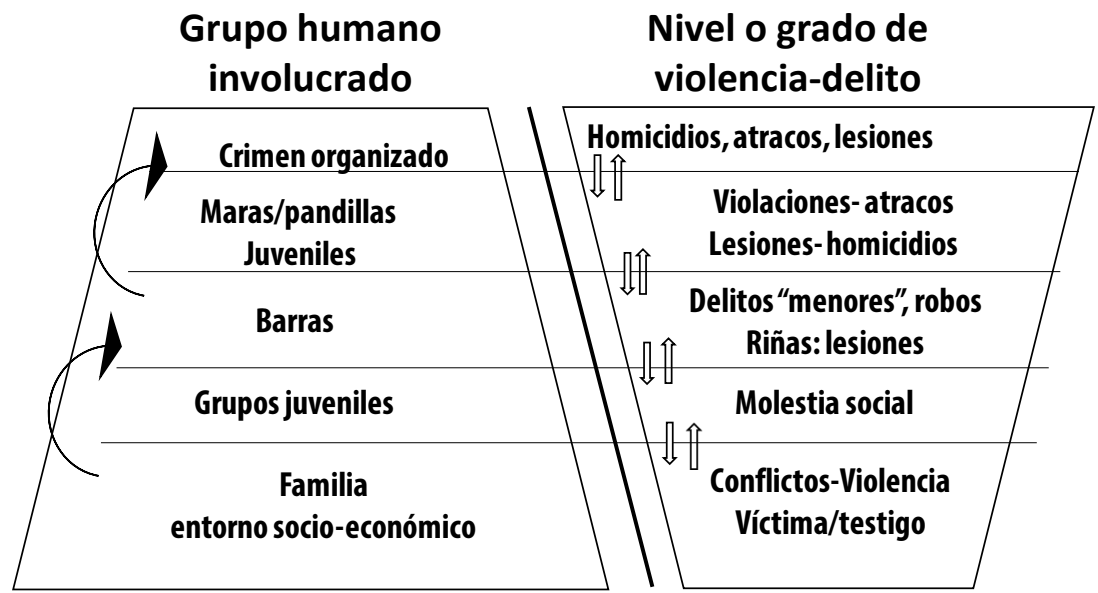

Fuente: Santacruz y Concha-Eastman (citados en Cruz \& Carranza, 2006)

Aunque es evidente que varios integrantes de las barras del fútbol han optado por vincularse con grupos al margen de la ley, también es cierto que el barrismo como tal no hace parte de las organizaciones criminales que tienen identificadas las autoridades en la ciudad; cuando se debe judicializar a alguno de sus miembros, se le acusa por el delito cometido, mas no por su membresía, por ejemplo daño en bien ajeno o lesiones personales, por esta razón no se registra la problemática como tal; sin embargo es importante reconocer que algunas facciones se han transformado al amparo de este fenómeno, en grupos en los cuales la ruta de la violencia los ha ido conduciendo a la comisión 
de delitos cada vez más graves (como los asesinatos que se han presentado en el estadio y fuera de él en Bogotá y otras ciudades, hurto, sicariato, tráfico de sustancias y armas, entre otros.). Cruz y Carranza (2006) señalan que "las barras pueden dar lugar a pandillas juveniles" (p. 144), en tal caso las contravenciones en las que con más frecuencia se involucran se consideran delitos menores tales como riñas, hurto de menor cuantía, vandalismo, agresiones y lesiones personales, tal vez asociadas al apoyo que el grupo brinda al barrista cuando este se encuentra en problemas con otros (respaldo).

Las agresiones entre barras tienen mucha incidencia en la mayoría de los desórdenes en las ciudades, incluso barras del mismo equipo se enfrentan por el dominio de los estadios. Los estudiantes afirman que en el estadio son recurrentes los robos de objetos personales (camisetas, gorras, teléfonos, etc.), ante los cuales no es posible actuar so pena de poner en riesgo la vida.

Entre gente de las mismas barras se roban, se roban la camisa, los que den papaya (oportunidad) los roban. Por ejemplo, un amigo me contó que estaba grabando con el celular y que hicieron un gol y fun pa'delante (avalancha) y le raparon el celular, y fiel con toda esa gente. Roban gorras o las camisas, a la gente güevona le ven la cara y los roban (risas)... y vaya diga algo, se gana es una puñalada. (E.C18/3 sesión 3, marzo 14 de 2009).

Estas situaciones quedan impunes pues no se denuncian por temor a retaliaciones, la frase final de este joven indica que lo mejor es permitir que lo roben y no tener más problemas.

Los estudiantes señalan ser un motivo recurrente de peleas en el estadio "llevarse en la mala" o no caerse bien entre sí, lo cual no solo sucede entre barras de diferentes equipos, sino entre parches pertenecientes a una misma barra. "Llevarse en la mala" entre parches aun del mismo sector aumenta la tensión tanto en el estadio como en los barrios:

Por decir, hay momentos en que está todo el parche de uno y que uno va por ahí y empiezan los "malmiraos" y no falta el crecido o dentro del mismo parche o de los de afuera, a veces uno va por ahí y entonces dicen hay que ahí van las lámparas de Millos, si toca con uno... toca. (E.C-24/4 sesión 3, mayo 8 de 2009) 
La mayoría de veces esto obedece igualmente a juegos de poder o a otro tipo de rencillas y enemistades que se han forjado en la relación dentro de la comunidad barrial, bien por desavenencias del vecindario en las que han intervenido los estudiantes, por situaciones que el parche considera desleales, o porque son un pretexto para cobrar viejas cuentas,

como ese man que botaron del segundo piso de la barra de Santa Fe, ese man era un ladrón de la barra, el man robaba a los otros, hasta que la barra se le rebotó (no lo admitió) y le cascaron, fue por eso, por ladrón y porque se llevan en la mala entre combos, entonces no es tanto que va perdiendo o va ganando el equipo, eso es lo de menos. (E.C22/3 sesión 3, marzo 14 de 2009)

La versión que ofrecieron los medios sobre este episodio indica que los hechos ocurrieron el 5 de mayo de 2005, cuando un hincha del Independiente Santa Fe fue golpeado, herido con arma blanca en el estadio y arrojado desde el segundo piso por sus compañeros de barra; falleció en un hospital de Bogotá. En este caso los hinchas atribuyeron la tragedia a decisiones arbitrales que no ofrecieron las suficientes garantías para el desarrollo del partido. Las autoridades denunciaron que el trasfondo de esta agresión fueron los malos manejos de dinero en el grupo; el joven muerto, según parece, fue acusado de robo por la dirigencia de la barra. A raíz de este incidente se sancionó el estadio de Bogotá prohibiendo a las barras la entrada. Esto revela que no todos los eventos sucedidos en los estadios están asociados siempre al barrismo en sí, este puede en ocasiones ser el argumento que se esgrime para generar agresiones y se utiliza como excusa, pero en el fondo las problemáticas tienen diferentes orígenes.

Se mencionó también la participación de estudiantes de la institución 5 con una banda del crimen organizado, calificada por las autoridades como de alta peligrosidad. En la investigación, uno de los barristas fue acusado por otro estudiante de portar armas y fantochear (presumir) con ellas en el salón de clases; este desmiente el comentario, pero en ese momento fue acusado por otro chico de tener relación con una banda grande y el muchacho solo atina a responder que es su hermano el que le brinda apoyo; otro más sentenció: "hay otros más duros detrás suyo" (E.C-41/5 sesión 5, mayo 22 de 2009). Al ser un comentario 
generalizado del grupo se presume que lo dicho allí es una situación que se maneja por los alumnos en el entorno de la escuela, es decir, todos saben a qué se dedica este joven, y se ratifica en el hecho de que el estudiante no pudo desmentir las aseveraciones hechas en su contra. Es importante anotar que la banda a la cual se hizo referencia mantiene asolado este sector y es reconocida por miembros de la comunidad como el mayor problema de seguridad.

Los capos de las barras muchas veces son obligados a dimitir por los rumores de malos manejos y disputas por el poder. Una seguidora de la Blue Rain a quien identificaremos como "Q" (2012), afirma al respecto:

Los capos salen de la barra es por malos manejos de dinero, esto lo he visto en un par de ocasiones, pero por lo que más he visto que salen es por disputas por el poder, básicamente porque entre los líderes de parche y miembros de lo que se podría llamar la cúpula de estos grupos se empiezan a presentar envidias por el manejo que se hace del dinero, en pocas palabras, las ganancias hay que compartirlas con muchos para que todos estén contentos y si al final alguno queda por fuera, ese es quien empieza a gestar la salida de un capo. (Entrevista, agosto 12 de 2012)

Según lo anterior, la expulsión del capo tras poner a los parches en su contra, ocurre en general con evidentes amenazas a la integridad, por lo que estos prefieren esconderse y dejar de ir al estadio durante algún tiempo. También puede suceder, según la entrevistada, que opten por el cambio de ciudad y el dedicarse a otra actividad, muchos capos abandonan los grupos cuando constituyen familia. Normalmente quienes se relacionan y conocen a los capos son los más antiguos de la barra o los líderes de los parches más representativos, el grueso de la barra solo los conoce por su apodo o sabe quiénes son por el lugar en el que se ubican en el estadio, y solo quienes fueron amigos de los capos saben de su paradero luego de salir de una barra, lo cual también puede ser el origen de las confrontaciones barriales, toda vez que el derrocamiento de un capo puede inducir a su defensa por parte de algunos parches, que entran en confrontación para resguardar su honor y posición en el espacio barrial y local. 
Estos capos, pasado un tiempo (aproximadamente dos o tres años) regresan a la barra, y cuando su salida se debió a disputas de poder se les respeta su antigüedad, al punto que al llegar al estadio se les permite ocupar su lugar en los rompeolas y participar en la logística del partido, eso sí, sin ganar dinero. Dichos capos, si lo desearan, podrían volver a recuperar su lugar en la barra, pero lo que usualmente se ve es que no les interesa y se conforman con tener un lugar privilegiado cada vez que decidan hacer presencia, por lo general cuando el equipo llega a la final o a un nivel destacado en algún torneo. En los casos en que realmente hubo malos manejos, irrespeto o traiciones a algún parche o líder, estos capos solo pueden ir de manera clandestina al estadio, con mayor frecuencia a la tribuna oriental, y corren el riesgo de ser agredidos en caso de ser vistos.

Por último, es importante establecer que no todos los jóvenes participan en los eventos violentos que producen las barras en los estadios y sus alrededores, tienen muy claro el tema de su afición y del amor por su equipo, frente a lo cual es normal que dicha adhesión se viva no solo como parte de un momento de esparcimiento en las fechas futboleras, sino que también se hace extensiva a la vida cotidiana, en la que les es prácticamente imposible despojarse de su sentimientos hacia el equipo; así entonces, el fútbol constituye tema de conversación durante la semana, les anima para practicar el deporte y solidifica las relaciones en su parche, con lo que el territorio se convierte en un espacio sacralizado que defienden a costa de las agresiones a las barras contrarias que quieren acceder a él. En relación con la escuela, les fortalece frente a sus contrarios, a quienes someten a burla e incluso violentan; del mismo modo, el espacio escolar es también objeto de 'colonización' por la barra dominante y no podemos negar que dicho proceso se efectúa en no pocas ocasiones, mediado por agresiones.

Los grafitis (Figura 6) constituyen una muestra de la manera como se delimita el territorio. Estos aparecen en un baño y un mueble del colegio 3; el edificio de tres pisos presenta diversas muestras de colonización por parte de los barristas de Millonarios, quienes han demarcado el espacio en las paredes, el mobiliario, los vidrios, etcétera. 
Figura 6. El grafiti como demarcación del territorio
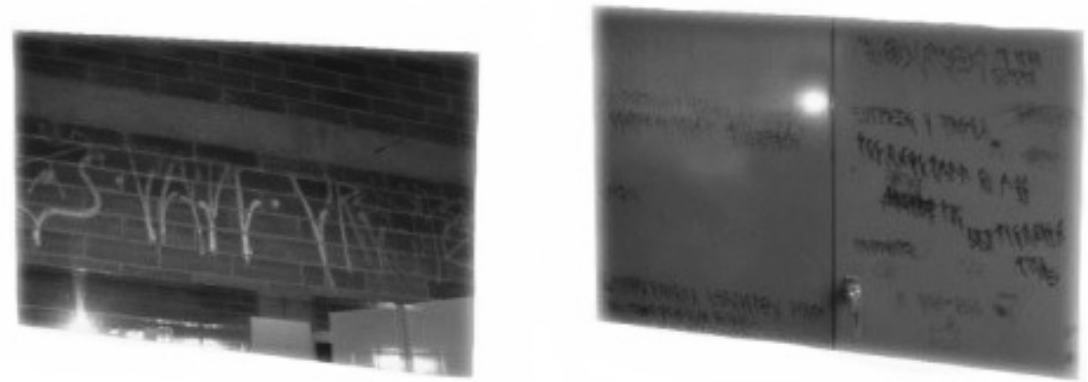

\section{MUJER Y BARRISMO:}

UNA PARTICIPACIÓN QUE SE TRANSFORMA

Por mucho tiempo se ha considerado el fútbol como una actividad netamente masculina; es a los hombres a quienes se les dota con el saber necesario para participar de esta actividad, a quienes les es dado hablar del tema y quienes culturalmente comparten la experiencia y vivencia de los encuentros que pueden ocurrir en cualquier circunstancia, bien como simple pasaje lúdico o como fecha memorable en el estadio. Las mujeres que han empezado a incursionar en el fútbol como practicantes se han mezclado con los fanáticos y participan abiertamente de los desmanes que se producen, pero aún es muy difícil que ese espacio sagrado se libere para permitirles entrar en condiciones de igualdad. Archetti (citado por Calderón \& Melgar, 2010) sentencia con claridad que el fútbol

no solo forma parte de las dimensiones más generales de una sociedad y su cultura sino que, paralelamente, se relaciona con la construcción de un orden y un mundo masculino, de una arena, en principio, reservada a los hombres. En América Latina el fútbol es un mundo de hombres, es un discurso masculino con sus reglas, estrategias y su "moral". Entonces, el lugar de la mujer, se ha mantenido regularmente en un segundo plano. ( $p .7)$

A la mujer se le permite participar, pero en realidad el espacio está dotado con todas las condiciones para que se dé la exhibición de lo mas- 
culino donde ellas a duras penas llegan como invitadas. Conde (2008) señala al respecto que

las mujeres acceden a grados diversos de inserción, que pasan por la negación, la aceptación, la resistencia y la exclusión. El saber sobre fútbol, por ejemplo, les está negado a las mujeres, ya sea en sus versiones más formalizadas (periodistas) como en las conversaciones de la vida cotidiana. ( $p .122)$

Su credibilidad, por lo tanto, es limitada, bien sea en calidad de hincha, o como profesional de las comunicaciones.

No obstante, la participación de las mujeres en las justas deportivas no es reciente. Dunning (2003) resalta que

en Perugia, mil o más hombres y mujeres se reunían en un combate anual a pedradas, que se volvía tan violento que las autoridades trataron de atemperar el derrame de sangre en 1273, amenazando a los que mataban a sus oponentes con ser juzgados por asesinato. (p. 68)

Este episodio sobre la práctica de una modalidad antigua del fútbol, el giocco del pugno, muestra cómo desde tiempo atrás la participación femenina en estos eventos se permitió de forma activa, sin importar que terminaran violentamente, igual que hoy, pero ello no implica que se les considere como miembros representativos. Calderón y Melgar (2010) comentan sobre la historia del fútbol de mujeres:

El primer partido internacional de mujeres se jugó en 1920 entre Inglaterra y Escocia, con un marcador final de 22-O a favor de las inglesas; en 1921 un encuentro entre dos equipos de mujeres inglesas atrajo 53 mil espectadores. Desafortunadamente, la "Football-Association" de ese país decidió que el fútbol femenino era "desagradable" y prohibió los cotejos de fútbol femeninos. A pesar de esto, las mujeres formaron su propia asociación, que comenzó a jugar en campos de rugby. La prohibición de la "Football-Association" contra la mujer no se levantó hasta 1971. (s. p.)

La exclusión de la mujer de las actividades futbolísticas, más concretamente de su práctica, fue considerada inapropiada más por desarrollar una actividad que se reconoció en su momento como un 
terreno estrictamente masculino. La situación ha comenzado a cambiar en el sentido de que se han creado las asociaciones de fútbol en diferentes partes del mundo, con lo que se comienza a promover la actividad entre las mujeres; no obstante, la trascendencia que tiene en el calendario de las agremiaciones internacionales del deporte es muy poca. A nivel escolar, por ejemplo, el fútbol femenino que se desarrolla en algunas instituciones es objeto de burla por parte de los hombres, que lo miran más como un espectáculo donde las mujeres "solo hacen el ridículo y son todas bobas para jugar... eso es para morirse de la risa, que se descachan y no cogen ni una (risas), pobrecitas, eso es ahí como para mirarlas, nada más” (E.C-24/4 sesión 4, mayo 15 de 2009).

En esta investigación los estudiantes describieron el papel de la mujer mucho más orientado hacia lo estético, lo sexual, lo erótico. Conde (2008) explica que "las adolescentes suelen participar, sobre todo si concurren en grupo a la cancha, convertida de este modo en espacio de tráfico sexual" (p. 124). Los chicos, por su parte, dicen que las niñas son "para alimentar el ojo" (E.C-7/1 sesión 3, febrero 20 de 2009). Así mismo, al preguntar si hay muchachas en la barra contestan:

“iMuchachotas!... iHuyy! La mujer del capo, la de Moneda, es una nenota, ese man es refeo, tiene la misma cara del chamo que estaba allá, mézclele la cara al man y mézclele la cara al man y verá (dice señalando a dos estudiantes que se ven en el pasillo) y esos dientes feos, y qué man tan feo, pero tiene una viejota... pero la vieja es solo para que la entre gratis (risas). Noo, si la vieja tiene la replata, le compró carro. (E.C-3-7/1 sesión 3, febrero 20 de 2009).

Los estudiantes también señalaron que las mujeres no van a las correrías de las barras, ese es únicamente privilegio masculino, es lo que Conde (2008) llama 'poner en juego la masculinidad'. La mujer se excluye, según la autora, del "disfrute de la pasión” (p. 124). Sin embargo, encontramos mención de lo contrario en una entrevista de Mancera a una joven que participa vigorosamente en las barras de Santa Fe, específicamente en la GARS ${ }^{16}$ :

16 GARS: sigla con la cual se conoce a la Guardia Albiroja Sur, barra del equipo bogotano 
Le dicen "Chiquilei" y desde el 2008 comenzó a viajar por Colombia para seguir a su equipo, dice que los hombres dentro de la tribuna la tratan bien y la protegen, sobre todo en las celebraciones de los goles ('avalanchas', en la jerga de los barristas): "con respeto y delicadeza... lo cuidan a uno para que no se caiga en las avalanchas o que no la manoseen". En el caso de los viajes que se realizan para ir a ver a Santa Fe, nunca ha tenido ningún problema importante y los hombres que la rodean siempre buscan que ella esté bien. (2010)

La asistencia de las mujeres al estadio y su vinculación al barrismo tiene un tinte más social, se utiliza para consolidar una trama de relaciones que se alimenta de su cooperación en la fiesta del fútbol, pero, como lo admite Conde (2008), "el universo construido, practicado, narrado y disfrutado históricamente les pertenece a los hombres" (p. 126). Es muy común en los estadios observar a las mujeres con los elementos distintivos de los equipos (Figura 7), portando banderas, e incluso se han atrevido a conformar equipos; existen equipos de chicas en algunas ciudades y el país cuenta incluso con su selección de fútbol femenino.

Muchas de ellas se han convertido en hinchas fervientes, viven su pasión al límite y han ganado su espacio a fuerza de apoyar, de gritar, saltar y algunas veces agredir, durante los partidos. En este sentido, encontramos en una institución educativa a una joven a quien apodan la Comando; según los estudiantes, es una persona a la que hay que temer, se mueve por el colegio en cualquiera de las tres jornadas que tiene esta institución, intimida, amenaza y tiene alianzas con grupos de la calle que propinan golpizas a quienes se atreven a enfrentarla. No se pudo establecer si ella es la misma que persiguió a un seguidor de Millonarios, en una motocicleta en la que iba como pasajera y portando un arma; este joven tuvo que ser asistido por la comunidad al permitirle el ingreso a una casa, este relato lo hizo un líder comunal que incluso nos llevó al lugar de los hechos, donde pudimos hablar con quien lo auxilió, y esta es su versión:

Hace 15 días [a] un muchacho que tenía una camiseta de Millonarios lo estaban siguiendo unos muchachos de una barra del Nacional y pasó [sic] una muchacha y un muchacho en una moto, la policía los detuvo, pero en realidad no les hicieron 
Figura 7. Participación de la mujer como aficionada al fútbol

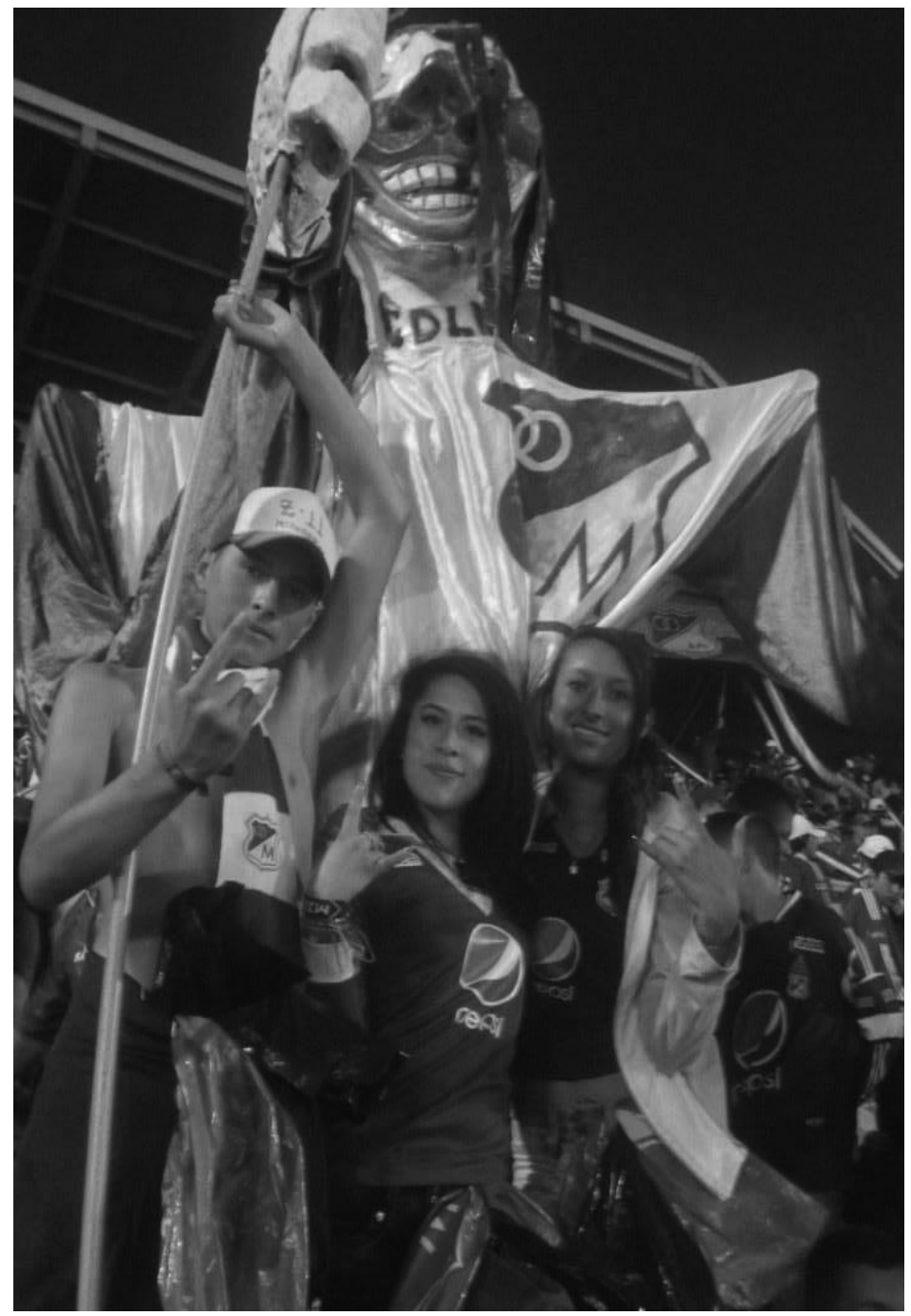

Fuente: www.freewebs.com/cantosazuleso3/92.htmlwww.freewebs.com/cantosazuleso3/92. html 
nada y al muchacho que tenía así armas lo dejaron ir y al chico de la barra de Millonarios le tocó protegerse acá, porque a él lo querían matar, y entonces él le dio el número de celular a otro compañero para que llamara a otro amigo para que lo recogiera; la policía vino y lo escoltó hasta la puerta de su casa porque a él lo estaban esperando y los vecinos acá le ayudaron a poner cuidado, pero en realidad la patrulla no hizo nada con los muchachos que estaban en la moto. (Entrevista a líder barrial, sesión 6, abril 18 de 2009) ${ }^{17}$

Al preguntar a los jóvenes la razón de su sobrenombre, dicen que la Comando es la novia de uno de los capos de las barras de Millonarios, conocido por su guerrerismo. Lo que se puede anotar al respecto es que ella persona utiliza esta relación para sus propios fines, y llama la atención el empoderamiento que ha alcanzado dentro del colegio, en especial la forma como entra y sale a cualquier hora del día. Y este no es el único episodio, refieren que en cierta ocasión

se agarró también a cuchillo ahí afuera, esa niña (la Comando) y... una ñera ñera, el hablado no más que tenía... tuvo un problema antes y le cogieron puntos y de lo duro que le hizo con el puño se los descoció, dijo que eso no se quedaba así, que, mejor dicho, que se descuidara no más; le iban a robar un celular... entonces la otra chica no se dejó, sacó un cuchillo y se agarraron ahí afuera, se cortaron y todo. (E.C-19/3 sesión 4, marzo 7 de 2009)

Los hechos de violencia que ostentaba la Comando le ayudaban frente a los demás a tener una imagen de lo que ellos llaman "respeto". Según los estudiantes, esta niña estaba atracando a otra más fuerte que ella y la confrontó con un arma, se hirieron.

Los medios de comunicación han referenciado confrontaciones protagonizadas por mujeres que participan en las barras del fútbol. Valencia y Sitter relataron la siguiente:

En Soacha, León XIII, el principal problema son las barras de Santa Fe y Millonarios (en las que hay integrantes mujeres), se

17 Relato de una comerciante de esta localidad, en su negocio se refugió el estudiante barrista que fue perseguido por un hombre y una muchacha que se desplazaban en una motocicleta e iban armados. La comerciante resguardó la integridad del joven perseguido entrándolo a su casa hasta que llegó la policía. 
están pasando a delinquir en Bosa. Se estima que cada barra puede tener entre 30 y 40 integrantes. Se citan en los parques a pelear. Hay una banda de cinco personas (hombres y mujeres) dedicada al hurto (sin nombre). San Mateo también es actualmente uno de los sectores más violentos. Hay un grupo de punks (integrado por hombres y mujeres) que forma peleas callejeras. (El Tiempo, 2009b).

El lugar que las mujeres ocupan dentro de las barras es aún intrascendente en materia futbolística, pero ha servido a muchas de ellas para asumir socialmente una posición de fuerza desde la cual se dedican a otras actividades, apoyadas en la imagen que han construido por su participación o su relación con personas de estos grupos. La presencia femenina en los eventos deportivos ha sido una constante histórica, participan de las actividades y se unen al desorden, pero se les diferencia de los hombres por la forma en que vivencian con fervor y gran despliegue emocional su amor por el equipo. La diferencia más notoria radica en el tema del aguante, que requiere de fuerza y enfrentamiento con el cuerpo, es decir, del ejercicio de la masculinidad; las niñas no se exponen a esta confrontación a menos que sea con otra mujer, dado que en condiciones de igualdad en la tribuna es una posición que, por obvias razones, resulta desventajosa para ellas, por eso, como lo reconoce Conde (2008), "la defensa del equipo merece el tributo más grande porque es el bien más valioso. Esa posibilidad de ‘dar la vida por el equipo' le es negada a las mujeres” (p. 125).

Mancera (2010) comenta respecto de la violencia y el riesgo para la mujer en las barras, que Chiquilei admitió: "si se meten conmigo, pues ahí sí me toca hacerme respetar, y si se va a los golpes, pues toca, sobre todo cuando se meten con alguna de las personas que están dentro de mi círculo afectivo del estadio". Estas actitudes de las barristas denotan la beligerancia que pueden asumir llegado el caso, especialmente si amenazan al círculo de amigos, aquí surge el respaldo y las mujeres no retroceden si deben afrontarlo. La entrevista la concedió esta joven desde el exterior porque sus padres la sacaron del país para alejarla de su barra.

Las manifestaciones femeninas en el espectáculo tienden a imitar los comportamientos masculinos y en las chicas se observa el deseo de participar cada día más activamente, su presencia constituye una es- 
pecie de complemento, que puede entenderse como una forma de suavizar las acciones de los hinchas; ellas no representan para el común de los hinchas ningún problema, aunque Mancera termina su artículo aludiendo a una situación que es clara muestra de que el papel femenino en este tipo de agrupaciones presenta una fuerte tendencia a la transformación a medida que se hace más notoria su vinculación en actos que deslucen este deporte:

Las mujeres no son vistas como mayores amenazas, aunque se han presentado incidentes como el del pasado mes de junio en el que uno de los miembros de los CADC ${ }^{18}$, 'Marioneto', fue asesinado con arma blanca por la novia de otro barrista con el que tenía problemas. Aun así no existen mayores regulaciones cuando de mujeres se trata. (2010).

Por lo tanto, las mujeres van transitando de convidadas al espectáculo del fútbol -más como elemento llamativo que le da vistosidad- (Figura 8), a tener una participación más activa en relación con el fanatismo; también, como los hombres, hoy hacen parte de la violencia irracional en el estadio, confrontan, viajan, cohonestan el porte de armas apoyando a barristas experimentados, ocultan armas y drogas en sus cuerpos, e incluso, como lo menciona Mancera (2010), cobran cuentas y asesinan.

Se antepone su imagen femenina, que se estereotipa mostrándola como parte central del espectáculo por su belleza y delicadeza. En el fútbol la mujer es cuerpo que engalana el partido y esa imagen se difunde en los medios de comunicación; el hombre es conocimiento y sentimiento, pero lo cierto es que tras el fervor y la emoción propias del partido las chicas van transformando su delicadeza en guerrerismo, además de los dividendos que recaudan por ser miembros de estos grupos, empleados estratégicamente para posicionarse en otros espacios (amenaza y chantaje), mucho más si sostienen una relación amorosa con un capo, un 'duro'.

18. CADC: sigla que identifica a la barra más grande del equipo Los Millonarios, de Bogotá, significa: Comandos Azules del Distrito Capital. 
Figura 8. El estereotipo de la mujer en el fútbol

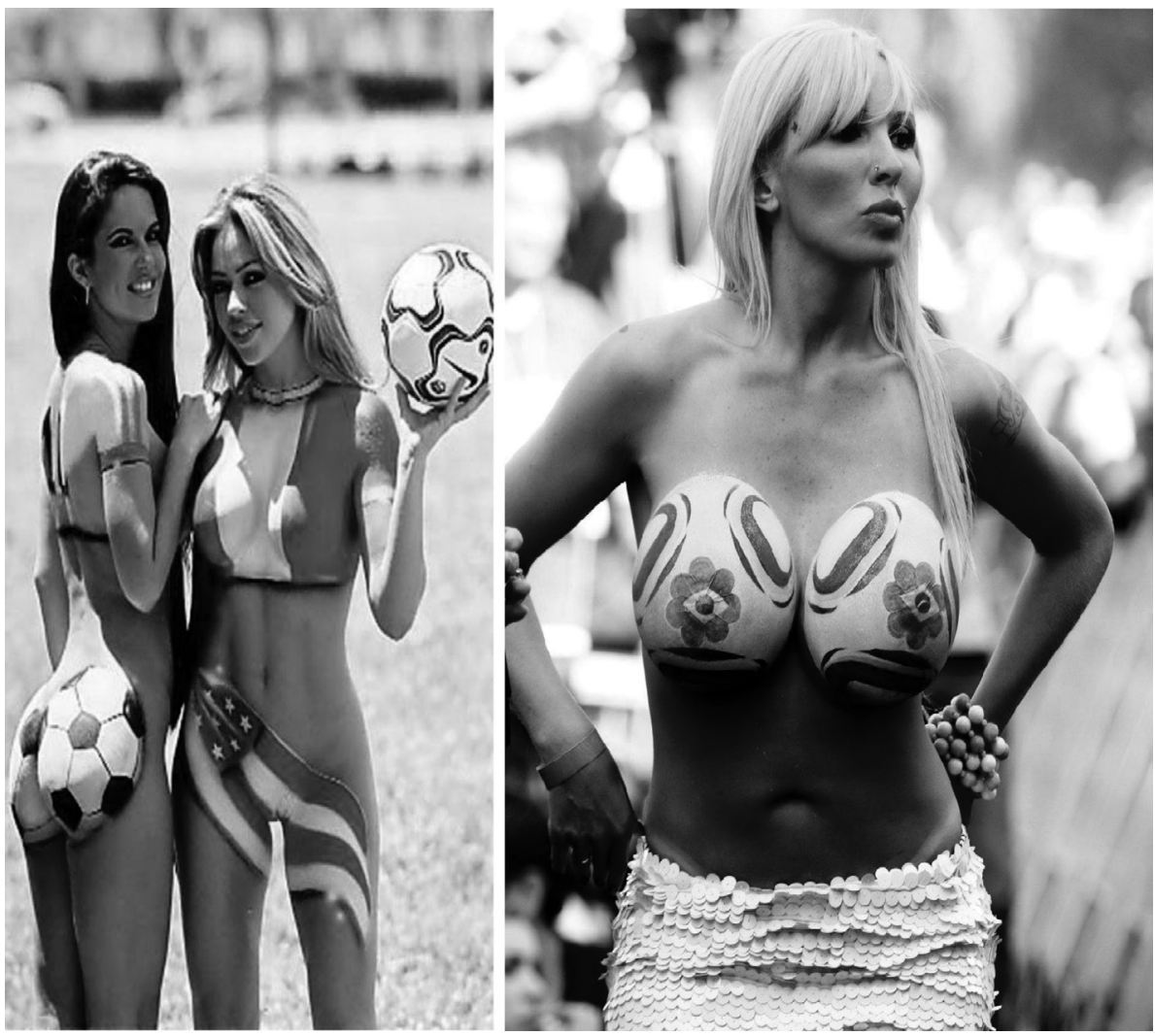

Fuente: http://www.google.com.co/imgres?q=mujeres+en+el+futbol\&um 



\section{FAMILIA Y BARRISMO: NORMATIVIDAD VS. AUTORIDAD}

\section{CONTEXTO}

Las familias han venido experimentando profundas transformaciones asociadas básicamente con las dificultades, las problemáticas sociales y los cambios culturales, que muestran variación en las relaciones de autoridad; en el ámbito jurídico se han marcado nuevas formas de interactuar entre adultos, niños y jóvenes. García y Guerrero (2011) sostienen que: "Las familias han venido experimentando profundas transformaciones asociadas básicamente con las dificultades de la segunda mitad del siglo XX, la antigua patria potestad en la que se fundamentaba el derecho de la autoridad paterna, se transformó en autoridad parental" (p. 299). El concepto de patria potestad que tradicionalmente le había conferido al padre el derecho sobre los hijos, se convierte ahora en autoridad parental, reconociendo en el padre y la madre, de manera compartida, el ejercicio de la autoridad sobre los hijos, a partir de considerar las nuevas formas familiares en los contextos legal y social, así como el reconocimiento de los derechos de los niños, y en Colombia el surgimiento, a instancias de estos, de la Ley 1098 de 2006 (Congreso de la República, 2006), que procura la protección de niños y jóvenes facultando a cualquiera de los miembros de la pareja para asumir su cuidado.

La Ley de Infancia y Adolescencia, en su artículo $3 .^{\circ}$ (Congreso de la República, 2006), titula los derechos de toda persona menor de 18 años, y en el artículo 14 introduce el concepto de responsabilidad parental al indicar que es un complemento de la patria potestad, frente al cual señala la obligación inherente a la

orientación, cuidado, acompañamiento y crianza de los niños, las niñas y los adolescentes durante su proceso de formación. 
Esto incluye la responsabilidad compartida y solidaria del padre y la madre de asegurarse que los niños, las niñas y los adolescentes puedan lograr el máximo nivel de satisfacción de sus derechos. En ningún caso el ejercicio de la responsabilidad parental puede conllevar violencia física, psicológica o actos que impidan el ejercicio de sus derechos. (Congreso de la República, 2006).

La prohibición de la violencia, como vía empleada hasta ese momento en la educación de los niños limita el poder que anteriormente tenían los padres sobre los hijos, con lo que cambia radicalmente su rol por el de orientador o guía, de este modo se pasa de la verticalidad en las relaciones al reconocimiento de niños y jóvenes como sujetos activos y de derecho.

García y Guerrero (2011) consideran que

en la transición de unas configuraciones familiares a otras y en los cambios de autoridad que ello implica, la violencia se expresa como manifestación de incomprensión, miedo, incertidumbre e impreparación de los padres, madres y educadores frente al nuevo estatus jurídico de hijos, hijas y estudiantes. (p. 299)

Esta nueva condición, de cara a las relaciones familiares y escolares, genera empoderamiento de los niños, niñas y adolescentes, frente al cual padres y maestros no saben cómo responder, en últimas ejercen su autoridad de la única manera que saben hacerlo (agresivamente), si bien encuentran que jurídicamente esto es causa de sanciones, dada la nueva posición de los niños y jóvenes.

En el análisis de documentos de las comisarías de familia en Bogotá, los casos de denuncias de los hijos en contra de los padres y de estos contra los hijos muestran una realidad la cual permite reafirmar que esta impreparación ha dejado a los padres, docentes y cuidadores ante la evidencia de que el tiempo de la sumisión y la subordinación ha pasado. Ante el desconcierto, los padres, docentes y cuidadores optan entonces por "dejar hacer y dejar pasar", situación que ha resultado contraproducente. 
En el caso de los jóvenes escolares que pertenecen al barrismo, ese cambio en las relaciones de autoridad se manifiesta en una mejor percepción del joven sobre sí mismo y sobre su función, se han empoderado porque los entornos en los que interactúan también lo han hecho. Los jóvenes ya no viven de espaldas a su realidad y utilizan los mecanismos que jurídica y políticamente tienen para manifestarse, los hemos visto en los últimos tiempos liderando alzamientos en los que quieren reivindicar sus derechos y cuestionar el orden instituido; es el caso, por ejemplo, de la Primavera Árabe en Túnez y Egipto, en el 2010, cuando hubo protestas populares por mejoras en la calidad de vida y el reconocimiento del derecho a participar, descontento general fundado en la escasez del empleo y la corrupción. El movimiento Occupied Wall Street en Estados Unidos, en el 2011, protestó frente al poder de las empresas y a la evasión fiscal; Anonymous viene operando desde el año 2008 y se constituyó como un colectivo por la independencia de internet, que se ha ido consolidando en un movimiento que convoca a la conciencia colectiva frente a problemáticas como el empleo; el movimiento estudiantil chileno aboga por la calidad de la educación, y en Colombia el movimiento universitario de la Mesa Ampliada Nacional de Estudiantes (MANE) enfrenta las reformas educativas planteadas por el Gobierno.

Una característica común de estos movimientos es el uso de los medios tecnológicos que permiten la movilización masiva en cualquier parte del mundo a través de las redes sociales. Estos nuevos espacios de convocatoria han creado lugares para la opinión libre y estructurado fuerzas colectivas que están reclamando su lugar en el escenario social y político. Los jóvenes son contestatarios y expresan una transformación en sus relaciones con la autoridad, un resquebrajamiento del poder, donde se impone una nueva mirada a las relaciones de todo orden. Al respecto Naím (2013) indica que "el poder ya no es lo que era. Se ha vuelto más fácil de obtener, más difícil de usar y mucho más fácil de perder" porque una mayor disposición para retar a la autoridad. Los jóvenes participan, generan opinión, proponen y se comprometen en acciones que les interesan. Hoy tienen un mejor y más amplio poder de convocatoria y más capacidad de organización y argumentación, así como una posición crítica frente a las cuestiones sociales y comunitarias que les legitiman para exigir. 


\section{FORMAS DE ORGANIZACIÓN FAMILIAR EN COLOMBIA}

Las situaciones por las que atraviesa la familia desde finales del siglo $\mathrm{XX}$ han sido interpretadas como el deterioro de las relaciones y dificultades en su estructuración. Cicerchia (1999) indica como aspectos que han contribuido a la vigente crisis de la familia, "la desacralización del matrimonio, la pérdida del 'orden' familiar directamente proporcional a la erosión del poder del pater, y la disociación entre el sexo (placer) y la reproducción (mandato)" (p. 49). Desde esta perspectiva, emergen, en contraposición al modelo tradicional de familia, otros modelos de unión que surgen de arreglos sociales y la configuración de otros modos de organización familiar que estaban presentes pero que fueron desconocidos socialmente. La crisis a la cual se hace referencia ocurre realmente en el modelo tradicional católico que ha imperado en nuestras sociedades por largo tiempo.

En los resultados del censo de 1993 emerge una gran variedad de formas familiares y se presentan algunas particularidades que evidencian las transformaciones ocurridas. Rico (1999) explica: "Aunque la llamada 'familia nuclear completa' (pareja e hijos) reúne el mayor número y proporción, muestra una fuerte disminución en tanto aumentan los hogares con un solo progenitor" (p. 113). Las circunstancias que han producido este cambio, dice la autora, se relacionan con un mayor número de divorcios y la viudez debido al impacto del conflicto armado sobre la vida familiar y mujeres que han optado por asumir la maternidad solas. Las formas familiares en Colombia se pueden resumir de la siguiente forma:

- Familia nuclear: la unión que se constituye por la vía del matrimonio.

- Familia extensa: aquella que recoge varias generaciones unidas por consanguinidad. Cohabitan en un mismo espacio los abuelos, el padre, la madre, los hijos, las hijas, los nietos, las nietas y demás.

- Familia sucesiva o poligenética: es la resultante de una anterior unión legal o de hecho en la que se tuvo uno o varios hijos. Esta familia se constituye de la nueva unión de uno o ambos miembros de la pareja, en la que se unen los hijos de cada persona y los comunes. A esta 
familia corresponde el dicho popular: los tuyos, los míos y los nuestros (Jiménez, 1999, p. 104). Cuando la segunda unión se conforma por la vía del matrimonio, se denomina familia nuclear poligenética.

- Familia unipersonal: conformada por una sola persona, por lo general soltera o soltero, separados o viudos sin hijos.

- Familia monoparental: cuando los hijos viven solamente con un progenitor, ya sea por díada materna o díada paterna como cabeza de familia.

- Familias de parejas sin hijos: parejas que por voluntad propia, o problemas de salud, no tienen hijos.

\section{PARTICULARIDADES DE LA ORGANIZACIÓN FAMILIAR DE LOS JÓVENES BARRISTAS}

En este apartado se referencian formas significativas de conformación familiar de los barristas, encontradas durante la investigación. El propósito es presentar la realidad que afrontan muchos hogares de la ciudad, de manera que permitan comprender ciertos comportamientos de los jóvenes y plantear situaciones relativas a la interacción familiar y los modos de habitar que pueden constituirse en un factor importante para generar comportamientos sociales inadecuados.

La organización familiar de los jóvenes barristas presenta las siguientes particularidades: se encontraron sobre todo modelos de familias monoparentales con regencia femenina y uniones consensuales consecutivas; las madres informaron que tenían problemas de autoridad con los hijos, a quienes no podían controlar porque eran desobedientes: "él es muy altanero, no ayuda a hacer nada en la casa, nosotros vivimos con el hermano de él, mi otro hijo, él y yo trabajamos y este se queda en la casa durmiendo después del colegio" (madre del estudiante E.C-27/4, entrega de boletines, mayo 29 de 2009). Se encontró también una familia extensa en la que el padre asumió el cuidado de dos hijos y no había conformado nueva pareja, organiza su hogar con el apoyo de sus padres. 
La mayoría de parejas conformadas se caracterizan por haber presentado maternidad y paternidad tempranas en edades entre los 13 y 16 años. Los padres y los hijos tienen relaciones conflictivas, unos culpan a los otros y justifican sus reacciones debido al maltrato por parte de la pareja, bien sea verbal, físico o psicológico; se mencionaron los consumos como generadores de la violencia, específicamente alcohol, marihuana y 'perica', es decir, padres o hijos consumidores. Se ha establecido en el país el inicio temprano de los niños al consumo de alcohol, esto sucede entre los 10 y los 12 años; así mismo, los consumos se aprenden a través del modelo familiar y los chicos beben en compañía de sus amigos en sus casas (Instituto para la Investigación Educativa y el Desarrollo Pedagógico - Claustro Moderno, 2010, p. 168).

Otro aspecto de interés fue la información que aportaron seis familias que vivieron el desplazamiento forzado por la violencia armada en otras regiones del país; dos familias revelaron haber sufrido también desplazamiento interurbano (dentro de la ciudad), lo que revela exposición a la violencia en diferentes contextos y momentos de la vida de los adolescentes. Los estudiantes cuyos padres habían organizado una segunda unión expresaron que tenían mala relación con sus nuevos padres y madres, al igual que se presenta conflicto entre hermanos. Se pudo evidenciar grupos de familias en los que hay comportamiento delincuencial, padres e hijos que roban, especialmente en el sector de Santa Fe. Algunos estudiantes refirieron haber pasado por situaciones económicas difíciles, en las que sus padres se vieron en la necesidad de dejarlos en casas de familiares, produciéndose la disgregación familiar y el traslado de la responsabilidad a personas que no representan ningún tipo de autoridad para los jóvenes, esta situación les crea resentimiento, de suerte que cuando regresan a sus hogares se comportan de modo inadecuado. También se ven niños que habían estado temporalmente en internados u hogares de paso del Instituto Colombiano de Bienestar Familiar por causa de la situación económica de los padres.

El nivel de escolaridad de los padres en general es educación básica completa y media completa, aunque se encontraron casos de educación técnica y el caso de una madre con formación profesional (abo- 
gada). Un aspecto concerniente a la educación es la deserción escolar de los hijos porque no les gusta la escuela y se dedican a actividades orientadas a la formación laboral. Se menciona, por ejemplo, el caso de tres hermanos del barrista E.C-36/5, que cursaron educación básica incompleta, uno de ellos se dedicó a la música y solo cursó hasta grado $6 .^{\circ}$, los otros dos cursaron $9 .^{\circ}$ y se formaron como carpintero y ebanista. Se encontró también que algunos padres, para controlar a sus hijos durante el tiempo que no están en la escuela, los llevan a trabajar con ellos y les enseñan las labores que realizan, pero lo usual es que los niños queden al cuidado de parientes, vecinos o sencillamente permanezcan en la calle. Igualmente, los chicos comentaron que asisten a fundaciones que los apoyan en sus tareas y desarrollan actividades lúdicas. Fue notoria en el colegio 1 la referencia que hacen los estudiantes sobre su afición por los juegos electrónicos y el billar, considerando que este tipo de actividades se realizan en espacios donde existe la posibilidad de consumos y algún tipo de riesgo.

Se percibe ruptura en los procesos de autoridad en los hogares. Una docente comenta, respecto de visitas domiciliarias realizadas a hogares de estudiantes:

La mayoría son madres cabeza de hogar, y son mamás que les lloran a los muchachos, o sea que su autoridad es cero, ellos son los que manipulan, ellas les ruegan y les dicen: "terminen lo que yo nunca pude hacer", entonces el chico se siente, pues imagínese, le están rogando para que estudie. (D.C-33/4 [entrevista], mayo 22 de 2009).

No podemos decir que tal o cual modelo de organización familiar sea el adecuado para el desarrollo de los hijos. Lo importante es que los grupos se estructuren de manera tal que se identifiquen claramente los roles y que la autoridad sea reconocida tanto por los hijos como por la figura ausente, con quien las relaciones deben ajustarse a un patrón de acompañamiento que fortalezca el papel de quien se encuentra al frente de la familia.

La organización familiar ha venido sufriendo múltiples transformaciones originadas en situaciones diversas, tales como la fecundidad y la economía. 
Desde el punto de vista económico, la crisis de los ochenta en Latinoamérica y sus ajustes produjeron que el costo del ajuste fuera absorbido prácticamente en su totalidad por los trabajadores, cuya masa de ingresos laborales disminuyó, lo que produjo el empobrecimiento de la población [y] esto generó la reagrupación del núcleo familiar para poder soportar la situación. (Uribe, 2007, p. 84)

Este caso es representativo en la familia del barrista E.C-2/1, en ella se fueron vinculando miembros de forma tal que se pudiera lograr un ingreso que les permitiera solucionar sus problemas de subsistencia. Esta es una forma que se ha mantenido en el tiempo, persiste, lo cual deja entrever que las dificultades para algunas familias de sectores populares están aún muy lejos de solucionarse.

Los aspectos biográficos reseñados a continuación fueron aportados por los participantes, quienes explicaron las diferentes formas como se organizan sus familias y las situaciones por las que atraviesan. Los gráficos permiten observar la dinámica familiar y sus problemáticas. Los estudiantes aparecen identificados dentro del grupo parental con color rojo (Figura 9).

Figura 9. Organización de las familias y las situaciones por las que atraviesan

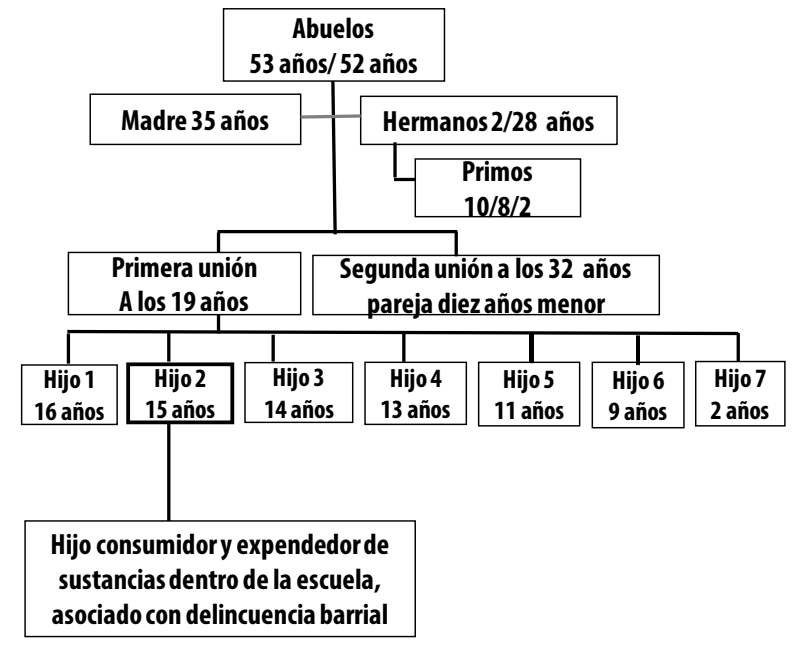

Fuente: elaboración de la autora con base en información recolectada en el trabajo de campo. 
En una familia extensa viven dieciséis personas en la misma casa; la mujer, con dos uniones, tiene seis hijos de la primera y uno de la segunda, es relativamente joven para el número de estos; las condiciones de pobreza hacen que este tipo de habitabilidad se presente con frecuencia, es una modalidad en la que las familias se apoyan para poder mitigar el impacto de sus precarias condiciones de vida, además permite garantizar el cuidado de los hijos de los miembros de la familia que salen a trabajar, pero situaciones como esta representan hacinamiento y conflicto entre los miembros de la familia, así como riesgo de abuso sexual. El acceso a los servicios públicos se limita; la casa en la que viven es arrendada; una exdocente de la institución comenta que en el sector hay familias que pagan a sus vecinos para que les permitan bañar a sus hijos (exdocente de institución 1 [entrevista], 13 de marzo de 2009). En la encuesta de cultura ciudadana en población escolar, Sierra y Gómez (2010) encontraron que "un 25\% de los niños tiene habitación propia, 40\% comparte habitación con una persona, $21 \%$ con dos personas y $14 \%$ con más de tres personas" (p. 155), lo que mostraría condiciones difíciles de habitabilidad que obligan a las familias a compartir los espacios en condiciones de hacinamiento, con todo lo que ello implica.

El joven perteneciente a este núcleo familiar y participante de la investigación, es consumidor y distribuye sustancias en el colegio; durante ella, fue observado cuando recibía un paquete a través de la malla del patio del colegio. Los docentes informaron que son jíbaros ${ }^{1}$ del sector, a quienes todos en la escuela conocen, pero no se atreven a hacer nada por temor, debido a que se encuentran aliados a grupos delincuenciales de amplia trayectoria criminal. Una vez que el muchacho recibe el paquete comienzan a llegar estudiantes y él procede a distribuir lo que acaban de entregarle.

Características importantes encontradas en la organización familiar permiten identificar situaciones que afectan directamente la convivencia en las familias, por ejemplo, las relaciones que entablan los muchachos con personas que luego les inducen a cometer actos delictivos en las escuelas y en la comunidad; son frecuentes los casos 
de familias separadas en que las relaciones con las exparejas están mediadas por la violencia y falta de compromiso en el sostenimiento de los hijos. Uribe (2007) afirma al respecto que las crisis familiares "en la actualidad se reflejan en las altas tasas de divorcio que se están presentando a nivel mundial, lo que hace que familias compuestas y monoparentales cada vez tiendan a aumentar; también un alto número de maternidades y paternidades tempranas" (p. 83); por ejemplo, el caso que se ilustra en la Figura 10.

Figura 1o. Familia monoparental con regencia femenina-1

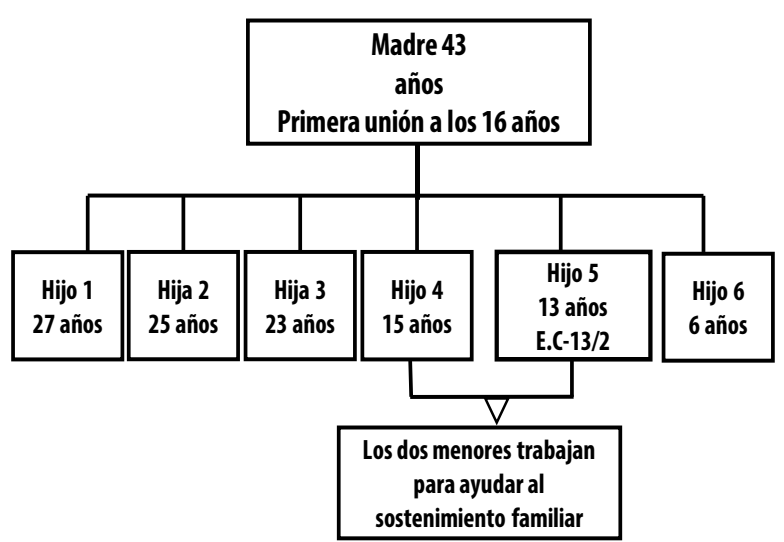

Fuente: elaboración de la autora con base en información recolectada en el trabajo de campo.

Familia monoparental con regencia femenina: la madre inicia su maternidad a los 16 años; tiene seis hijos, los tres mayores ya han organizado sus familias y los otros tres viven con ella, derivan su sustento de las ventas de productos alimenticios en una tienda propiedad de la segunda hermana. La familia trabaja junta para poder sostenerse, la madre se encuentra sola con los hijos más jóvenes y no tiene un trabajo estable, el estudiante que participó en esta investigación trabaja también en la jornada contraria con la hermana; el trabajo de los menores de edad, como en este caso, es una constante y está prohibido en el país.

En las familias monoparentales el tema de la autoridad es difícil de manejar. Una madre, en la entrega de calificaciones en el colegio 4, solicita: "por favor, ayúdenme, yo sé que están trabajando con ellos, díganle que 
colabore, que me ayude, que no tome (beber licor), que por favor venga a la casa. Es que él no me hace caso" (madre del estudiante E.C-27/4, entrega de boletines, mayo 29 de 2009). La edad de los muchachos complica las relaciones familiares, son rebeldes, no colaboran en sus hogares y descuidan sus estudios mezclándose en actividades que no les benefician, varios de los participantes han repetido el año escolar. Este estudiante en particular ha repetido todos los cursos de la secundaria. Las madres aducen que esto se debe a las amistades que tienen los muchachos y esto es motivo de preocupación permanente para ellas.

Lo que más me molesta es que es muy grosero y agresivo con uno. Yo lo controlo por teléfono y me tiene que contestar porque o si no tiene problemas, pero algunas veces se queda toda la tarde por la calle y llega oliendo a trago (licor) a la casa, le llamo la atención y dice que es mentira, que no ha tomado, pero está que se cae de borracho, eso son los amigos de aquí del colegio. (Entrevista, madre del estudiante E.C-27/4, mayo 29 de 20o9)

Al parecer tampoco existen normas claras ni límites y los chicos evaden las responsabilidades que les asignan para hacer cosas que les interesan más; no atienden las recomendaciones de los padres y, al contrario, se comportan de manera indiferente; o no se les han inculcado valores como la solidaridad, la responsabilidad y las consecuencias de los actos, o actitudes como el autocuidado; algunos de ellos admiten que consumen alcohol en forma desmedida y las reglas familiares se transgreden. Las relaciones de noviazgo son otro factor que contribuye en las dificultades con los hijos; cuando se le mencionó a la madre que el estudiante pretendía presentarle a la novia, respondió:

iHuuuy!, doctora, esa niña ni me la nombre, que ni me la vaya a traer porque le tengo mucha rabia... los vecinos me han dicho que ella se la pasa en el apartamento con él toda la tarde y se va cuando sabe que yo voy a llegar, es una niña sin Dios ni ley. ¿Usted qué piensa de una niñita que nadie controla, que se va para fiestas y llega a la madrugada a la casa y nadie pregunta por ella? La madre se encuentra molesta, a veces le hablo de la niña esa y se pone como una fiera, me dice: "a ella no me la toque, ni me diga nada". Con decirle que ni siquiera lava las medias, hay que hacerle todo, recogerle el reguero de la habitación porque ni siquiera es capaz de limpiar su cuarto. (Entrevista, madre del estudiante E.C-27/4, mayo 29 de 2009) 
Este día ha sido difícil tanto para los padres y madres como para los estudiantes, hay tristeza y frustración, los chicos terminan el día pensando seriamente en los problemas que tendrán cuando lleguen a sus casas. Un caso particular es el del estudiante E.C-24/4: tiene miedo porque su mamá es muy agresiva y él ha tenido muchos conflictos en la calle y en el colegio; comenta:

Le están dando quejas a mi mamá y esa señora está furiosa; la situación mía es muy grave en la casa porque mi mamá me amenazó con sacarme del colegio y ponerme a trabajar o que tengo que irme de la casa. (estudiante E.C-24/4)

La mamá aparece y dice: “Él no los acompañará porque no merece nada, va muy mal y no pienso dejarlo ir al recorrido" (entrevista, madre del estudiante E.C-24/4, mayo 29 de 2009). Está muy enojada, salen del colegio y ella lo va regañando por el camino, increpándolo con dureza, él camina a su lado agachado y con las manos en los bolsillos.

Este joven de 17 años ha sido golpeado cinco veces en el último mes, una de ellas dentro del colegio: en medio de un tumulto le arrojaron un cestillo en el que guardan el refrigerio, le rompieron una ceja y le cogieron puntos, no se supo quién lo hizo, entre ellos dicen de manera jocosa que están averiguando. Por otra parte, tiene una novia que tiene un hijo de otra persona. El antiguo novio ha golpeado al estudiante en dos ocasiones y la madre ha tenido que poner una caución ante las autoridades; como el hombre no puede acercarse al muchacho, ha enviado dos veces a una pandilla a golpearlo; la novia es mucho mayor que él. La familia del chico desea que termine la relación con esta persona, pero él está empecinado.

A este joven le gusta el riesgo. Es bebedor, cohonestado por la madre, quien atiende un bar de su propiedad y admite que el chico consuma licor, ha participado en agresiones a barras en las calles del barrio, así como en peleas dentro del colegio. Mantiene estrecha relación con el joven que lidera el grupo de barristas en esta institución; admite que cuando están aburridos salen a "azotar garzas," es decir, a buscar a los hinchas del Independiente Santa Fe, que tienen su espacio de reunión a unas cuadras del colegio. 'Azotarlos' significa que los persiguen y, si hay posibilidad, confrontan con ellos, en general lo que hacen es 
desalojarlos agresivamente. Este tipo de afrentas son las que muchas veces generan conflicto en las afueras de las instituciones y corresponden a retaliaciones de los agredidos, quienes se organizan y los esperan al finalizar la jornada escolar.

Familia monoparental con regencia femenina. La edad del hijo mayor sugiere que la madre tuvo una maternidad temprana, actualmente no tiene pareja; todos sus hijos viven con ella, aunque los dos mayores ya conformaron sus hogares; el estudiante participante es el menor, tuvo una hija a los 16 años y al momento de la investigación sostenía un pleito judicial con la madre de la niña para que le permitiera verla; admitió el consumo de marihuana y que lo hace para ir al estadio: "yo no le voy a negar que cuando voy al estadio me fumo mi mariguanita... pero aquí en el colegio no" (E.C-36/5, sesión 1, abril 18 de 2009). Asimismo dice que es hincha furibundo de su equipo, el Nacional de Medellín. Los hermanos mayores y la mamá lo sostienen por completo, apoyándolo incluso con la cuota de manutención para la hija (Figura 11).

Figura 11. Familia monoparental con regencia femenina-2

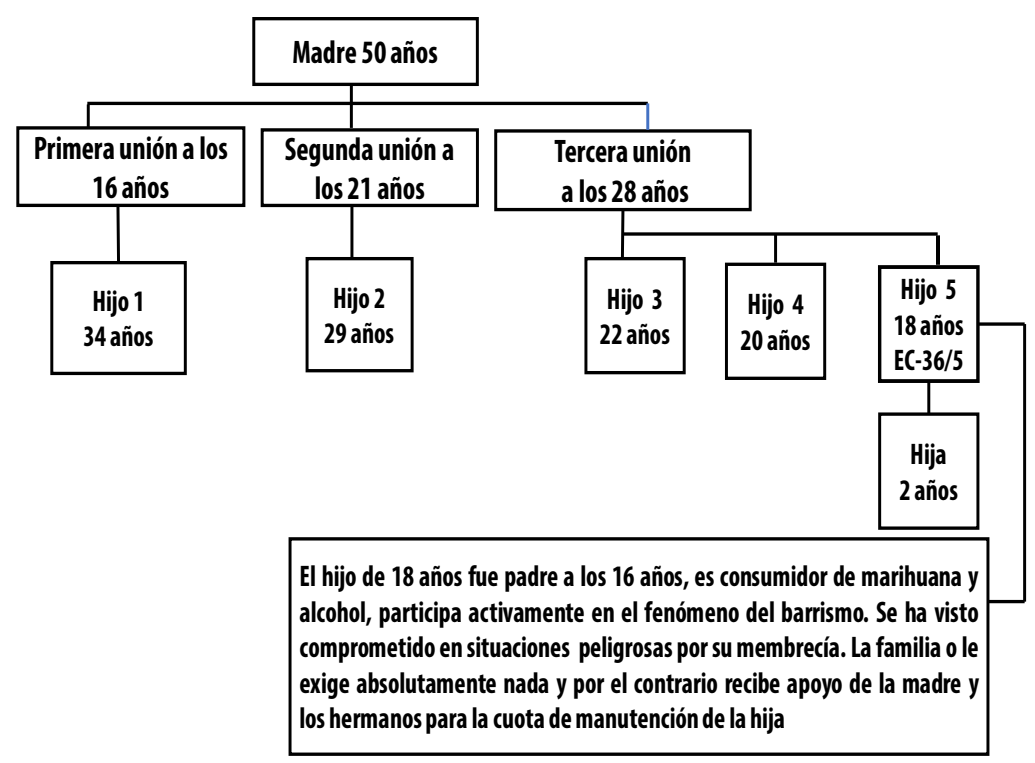

Fuente: elaboración de la autora con base en información recolectada en el trabajo de campo. 
El joven es bebedor de fin de semana, situación que le impide cumplir normalmente con sus clases, se ufana de su resistencia para beber y relata: "puedo durar hasta tres días bebiendo. Mi mamá me regaña pero... iah, qué!... ella ya está acostumbrada” (E.C-36/5, sesión 1, abril 18 de 2009). Viaja con frecuencia con su equipo y se ha visto envuelto en conflictos entre barras en los que ha salido herido con navaja. Participa activamente en el barrismo desde que era muy niño:

Yo sigo yendo al estadio, desde $6 .^{\circ}$ y como hasta $8 .^{\circ}$ yo me la pasaba era viajando, lo que pasa es que ahora yo ya tengo una hija y entonces las cosas cambian, ya todo es distinto... pero yo me la pasaba era viajando; en ese tiempo yo fui dos veces a $\mathrm{Ma}$ nizales, una vez a Cali. (E.C-36/5, sesión 3, mayo 8 de 2009)

El muchacho, que se ausenta por largo tiempo de su casa para viajar con el equipo, es señalado de portar armas - cabras- y es admirado por los más pequeños debido a la vivencia de su afición; tiene organizado un semillero de barristas más jóvenes a quienes está orientando y formando para su ingreso. Los más pequeños dicen que no se deja de nadie y que pelea con manoplas. También confirman que se reúnen con otros miembros de las barras en un parque cercano al colegio en el que organizan la jornada futbolera a la que asistirán, preparan sus trapos (banderas), ensayan los cantos y de paso ilustran a los más pequeños; estos no pueden asistir a las barras dado que son menores de 14 años, pero ya están iniciándose, orientados por los que ellos consideran 'duros'; en estos encuentros se bebe licor y en ocasiones se consumen drogas.

La familia no le genera ninguna responsabilidad, aunque ya es mayor de edad, así que tiene amplia libertad de hacer lo que quiere; nadie le toma cuentas y recibe todo en su casa sin ningún tipo de exigencia. Este joven se vio envuelto en un episodio de enfrentamiento entre barras. En una carretera, cuando viajaban para Ibagué, un joven fue herido y él se quedó a cuidarlo en la clínica. Solo le dijo a su mamá que se quedaba unos días, sin ninguna otra explicación. Al preguntarle cuál fue la reacción de ella, respondió:

¿En la casa? Pues yo llamé a mi mamá y le dije que me iba a quedar unos días allá. Mi mamá siempre ha sido comprensiva 
conmigo, yo soy el menor, dicen que yo soy el mimao, pero dicen que soy la oveja negra. (E.C-36/5, sesión 3, mayo 8 de 2009)

No hay control de la familia frente a los viajes del estudiante, cualquier justificación es válida, él se encarga de manejar la situación para hacer lo que quiere. Los padres de muchos barristas ni siquiera imaginan en qué andan sus hijos y las situaciones que atraviesan, no preguntan, son permisivos y se han relajado frente a la autoridad, aspecto que ha conducido a la temprana autonomización de aquellos. El joven dice encontrarse con su mamá esporádicamente, su relación se reduce al aporte de dinero:

Es que de cinco hermanos yo soy el menor y todos somos hombres; yo soy el más casposo, soy el que he durado una semana sin llegar a mi casa y eso que con mi mamá yo casi no hablo, yo salgo del colegio por la noche y mi mamá ya está durmiendo, me despierto a las 10 de la mañana y mi mamá ya no está; entonces no la veo, digamos a veces me deja plata o vainas así, yo la veo es por ahí los domingos...si no llego enguayabado, porque yo no perdono sábado, los sábados siempre hay reunión de la barra y siempre uno tiene que estar o tomando o jugando en barras, esa es la vida de un barrista (E.C-36/5, sesión 3, mayo 8 de 2009)

Este joven no conoce límites y su comportamiento es mal indicador de sus actividades. Las relaciones con su familia son distantes y se limitan exclusivamente a ser proveedores, condición que aprovecha el muchacho para abusar de la madre y los hermanos. Cuando lo invitamos a reflexionar sobre esto afirma que no le pueden decir nada porque él aprueba todos sus años, es decir, cumple. Por otra parte, aunque el joven ya es mayor de edad, sus comportamientos son admitidos por la familia, lo que denota negligencia en la formación y cuidado del chico. Su obligación consiste en reportarse para que su familia esté tranquila, después de esto no hay recriminaciones ni apoyo alguno para él en los problemas que tiene con grupos en la calle, muchas veces ni se enteran de golpizas y peleas que sostiene con otros grupos .

Familia monoparental con regencia femenina: la madre sostiene a la familia; tiene dos hijos de su primera unión, uno de la segunda y otro de la tercera, ninguno de ellos reconocido por sus padres. La mujer 
no tiene ascendencia sobre sus hijos mayores, no le obedecen y, según ella, hacen lo que quieren. El mayor tiene muy bajo rendimiento académico, consume alcohol, marihuana y perica, con frecuencia no llega a su casa y tiene muy mala relación con la madre. Según ella, el segundo hijo está siguiendo los pasos del primero (Figura 12).

Figura 12. Familia monoparental con regencia femenina-3

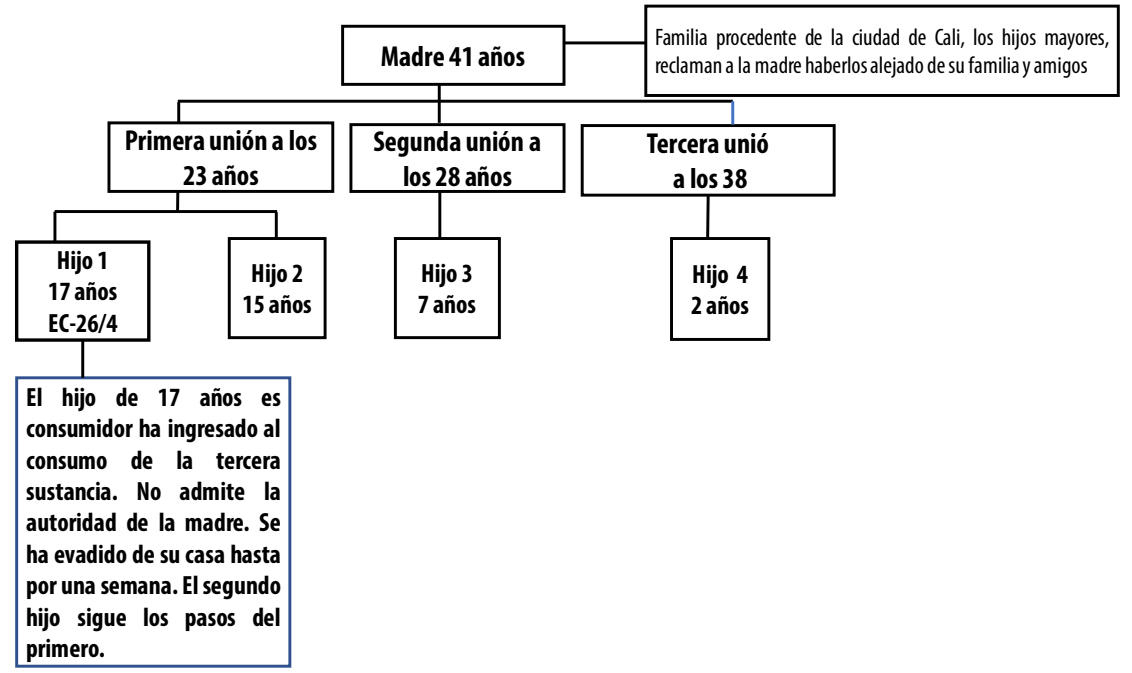

Fuente: elaboración de la autora con base en información recolectada en el trabajo de campo

Se observa durante la entrega de informes académicos a esta madre haciendo una reconvención a su hijo, quien le manotea y grita, ella solo atina a llorar en medio de la frustración. Su hijo ha perdido todas las asignaturas, se ve muy preocupada, se acerca y afirma que "le duele mucho no saber cómo ayudar a su hijo". Me pide que hable con él y le aconseje que se comporte mejor, que colabore y le ayude con los otros tres hermanos" (Entrevista, madre del estudiante E.C-26/4, mayo 29 de 2009). La señora es una mujer joven; en medio del llanto comenta que sus hijos "la pasan solos, pues ella trabaja para sostenerlos". Además, explica que está bebiendo y fumando demasiado, es muy altanero y no le puede decir nada, porque siempre le contesta que él ya va a cumplir 18 años. Me cuenta que ella tiene cuatro hijos y es sola, que tenía mucha esperanza en su hijo mayor. 
El chico tiene resentimiento con la madre por cuanto considera que les ha tocado muy duro y que su situación económica es difícil; dice que no les da todo lo que necesitan y quieren, que la madre los separó de sus amigos y familia al traerlos a Bogotá (esta familia procede de Cali). Trato de consolarla y le prometo que hablaré con el muchacho para saber que está pasando, sin embargo me cuestiona el hecho de la soledad de los niños de esta familia en el sentido de que el hijo mayor, que participa en el NES, se ha vinculado con personas que distribuyen sustancias, para ese momento el joven había entrado en el consumo de la tercera sustancia psicoactiva.

Otra situación que afecta la vida familiar en el país es el tema del desplazamiento forzado. Esto produce fragmentación de la familia, afecta seriamente a los escolares, que ven deteriorar cada día sus condiciones de vida y sus posibilidades de estabilidad. Actualmente es considerado un fenómeno social de grandes proporciones; la llegada a las ciudades plantea para el desplazado una transformación total de sus hábitos de vida y la trasposición de sus valores familiares primarios a la solución de sus necesidades básicas; el desplazado sufre un estigma que al llegar le genera problemas, se sabe que viene de regiones donde el conflicto se ha exacerbado y en muchas ocasiones las comunidades lo rechazan, con lo que se produce el desplazamiento interurbano, que ahonda su situación de vulnerabilidad. En el caso de esta familia, existe una vinculación del padre con actividades del narcotráfico que termina trágicamente, por lo cual el joven debe abandonar la región de la que es oriundo. En el siguiente apartado se explica con amplitud la situación (Figura 13):

Familia extensa. La situación de este estudiante es compleja. Llegó a la ciudad hace dos años; vive con un tío y su familia; se desplaza de su lugar de origen por la muerte de los padres, el padre era escolta de un narcotraficante, fue asesinado y por eso la familia saca al joven de la zona por temor a retaliaciones. Es un joven que aparentemente se comporta bien, acata las normas y tiene muy buenas relaciones con los compañeros; habla mucho, añora el regreso a su ciudad y domina su grupo. Al terminar la actividad en esta institución nos enteramos, por el servicio de orientación escolar, que al parecer está implicado en la distribución en el colegio de sustancias psicoactivas, específicamente popper. 
Figura 13. Familia extensa

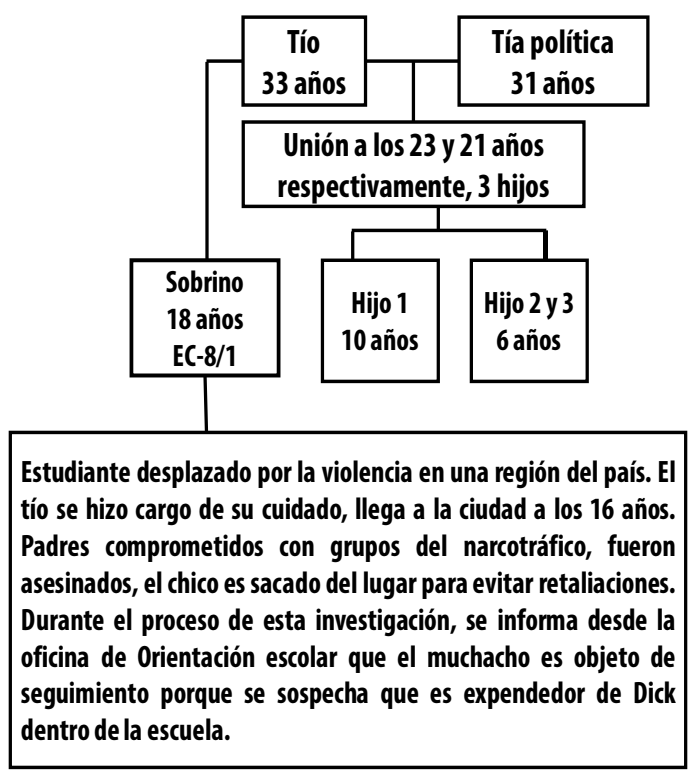

Fuente: elaboración de la autora con base en información recolectada en el trabajo de campo.

La historia de este joven es la de muchos niños en el país que han perdido a su familia por situaciones como el narcotráfico; en este caso, el chico es buen estudiante, pero de ser ciertas las percepciones que tienen sobre él en el colegio, su futuro no se ve claro. El desplazamiento desestructuró a su familia y ya ha alcanzado el tiempo de la autonomía, es mayor de edad. La preocupación es la de que si es distribuidor de sustancias, tiene relación con redes de traficantes.

Familia nuclear: en este caso se presentan maternidad y paternidad tempranas y un grupo familiar relativamente grande para la edad de los padres (cinco hijos). Sus condiciones de vida son precarias, el chico participante roba en el colegio, tiene problemas de convivencia con sus compañeros y bajo rendimiento académico. Un episodio presentado durante la sesión lo mostró temperamental y agresivo. Cuando pierde el control arremete a golpes y patadas empleando lenguaje soez. Los docentes informan que evade clase y en ocasiones se fuga del colegio, entra y sale a voluntad. El pequeño es agredido física y verbalmente 
por sus compañeros de curso. Por otra parte, según información de la Oficina de Orientación Escolar, la madre roba en las calles; el estudiante ha referido agresión física entre los padres y también de ellos hacia los hijos (Figura 14).

Al momento de esta investigación el padre no tenía trabajo. El colegio gestionó la inscripción de los niños a los comedores comunitarios. Puede apreciarse que este grupo familiar se encuentra en riesgo, no solo por la situación económica, pues el barrio en el que viven también constituye un factor de riesgo, en especial por el tema de la seguridad y el consumo de sustancias; es un barrio subnormal, que está levantándose en terrenos baldíos y aún no cuenta con los servicios domiciliarios básicos porque no ha sido reconocido como tal. Aunque es un niño muy pequeño, pasa tiempo en la calle sin el control de los padres. Asiste al NES como aprendiz de barrista.

Figura 14. Familia nuclear-1

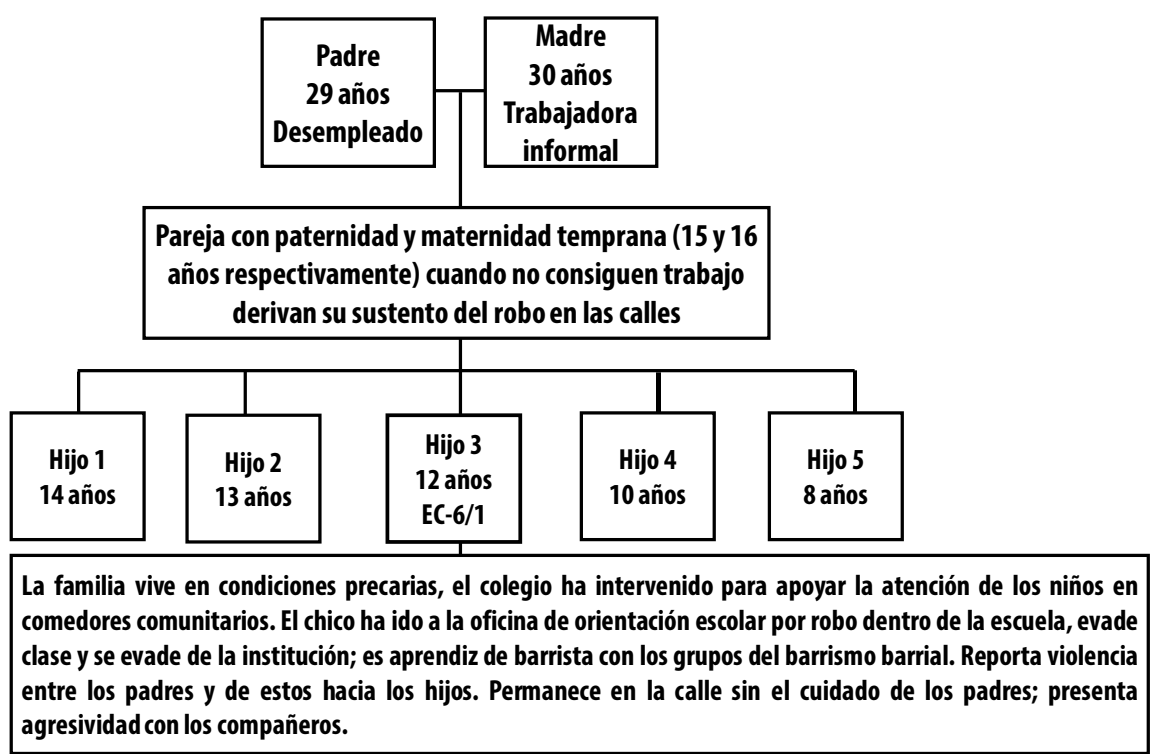

Fuente: elaboración de la autora con base en información recolectada en el trabajo de campo. 
Familia nuclear: seis hijos; los padres trabajan para sostener a la familia, los más grandes colaboran con el sostenimiento de la casa. La edad de la madre sugiere una maternidad temprana. Habitan en una zona limítrofe entre lo rural y lo urbano de la ciudad, con barrios sin servicios, población de reinsertados y milicias, en algunos se presenta delincuencia organizada, sin rutas de transporte público, el acceso se realiza en vehículos particulares que prestan este servicio. Líderes comunales afirmaron que para entrar en estos barrios se requiere permiso de la comunidad. Se consideran barrios subnormales con fuerte control social, tal vez por el tipo de población que los conforman. El estudiante afirma que el carro que lo lleva a su casa lo deja lejos y debe caminar quince minutos (Figura 15).

Familia monoparental con regencia femenina, tres hijos mayores que no fueron reconocidos por el padre; el único que sí lo fue es el último, de su segunda unión, que actualmente repite el grado $8 .^{\circ}$. El tercer hijo está escolarizado en grado $9 .^{\circ}$ y presenta extraedad para este. Los otros dos hermanos culminaron estudios de secundaria y colaboran

Figura 15. Familia nuclear-2

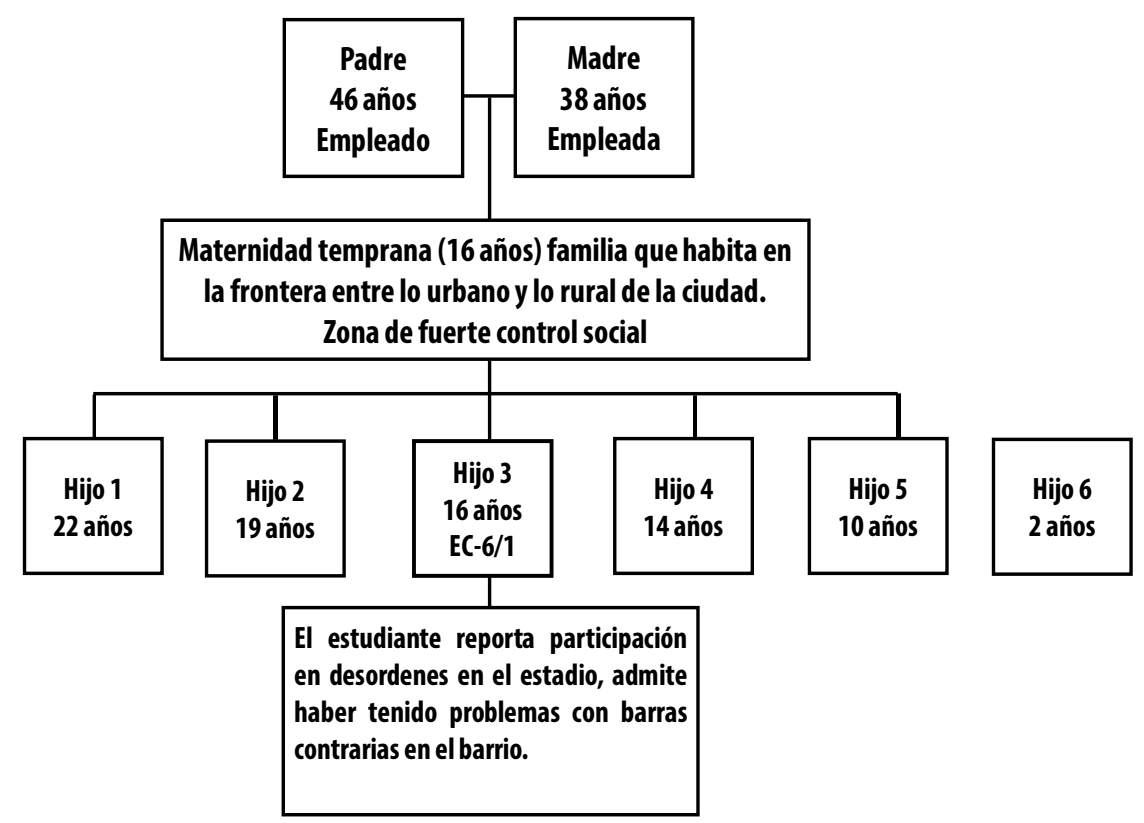

Fuente: elaboración de la autora con base en información recolectada en el trabajo de campo. 
con el sostenimiento del hogar. La madre cursó solo hasta grado 6. ${ }^{\circ}$, su edad sugiere una maternidad temprana. El menor ha participado en peleas dentro del colegio, hace parte del grupo de barristas de la institución y admite que asiste al estadio con sus compañeros; por otra parte, dice que es activo en el tema del barrismo y le gusta todo lo que tiene que ver con la organización al respecto. Indica que se ha visto envuelto en desórdenes de las barras dentro y fuera del estadio e incluso que ha sido llevado a la comisaría en varias ocasiones, pero que eso no le preocupa porque su hermano lo saca de allí. Este estudiante dice que ser barrista es solo acompañar al equipo, "no como dice la gente, que uno es un vándalo y un marihuanero"; reconoce que algunas veces se exceden, pero que eso es por el calor del espectáculo (Figura 16).

Familia sucesiva; segunda unión de la madre, con dos hijos adultos de la primera unión. Unión posterior con pareja trece años menor, dos hijos menores de esta unión, con edades de 12 y 14 años; el padre trabaja como soldador y la madre es ama de casa. Los hijos mayores trabajan y aportan al ingreso familiar. El estudiante pertenece a un

Figura 16 Familia nuclear-3

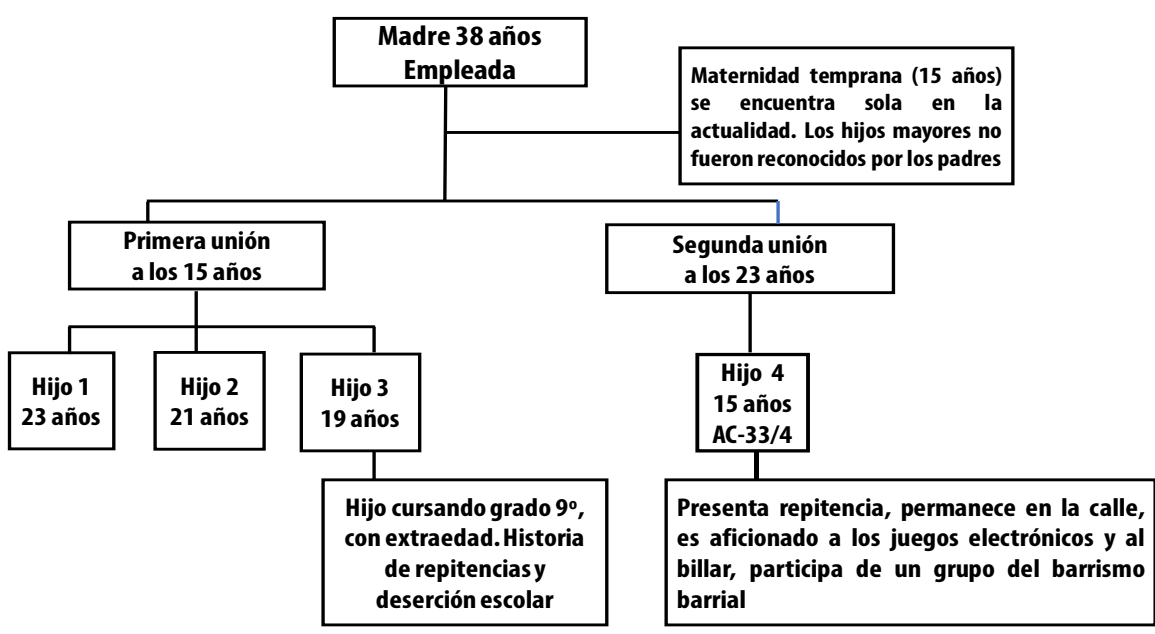

Fuente: elaboración de la autora con base en información recolectada en el trabajo de campo. 
grupo que recibe orientación de compañeros para su ingreso al barrismo. Manifiesta haber asistido al estadio en compañía del papá, esto lo admiten varios barristas: muchas veces la afición se aprende en la familia, e incluso algunos adultos también participan en los desórdenes del estadio (Figura 17):

La primera vez que fui al estadio, ese día me asusté un resto (mucho), porque se hizo un tropel ni el hijuemadre y yo era rechinche (muy pequeño), yo metido entre todo el mundo, mi papá y mi hermano ahí agarrándose y yo era escondiéndome de todo el mundo; pero se siente superáspero (E.C-27/4, sesión 1, abril 24 de 2009)

Figura 17. Familia sucesiva-1

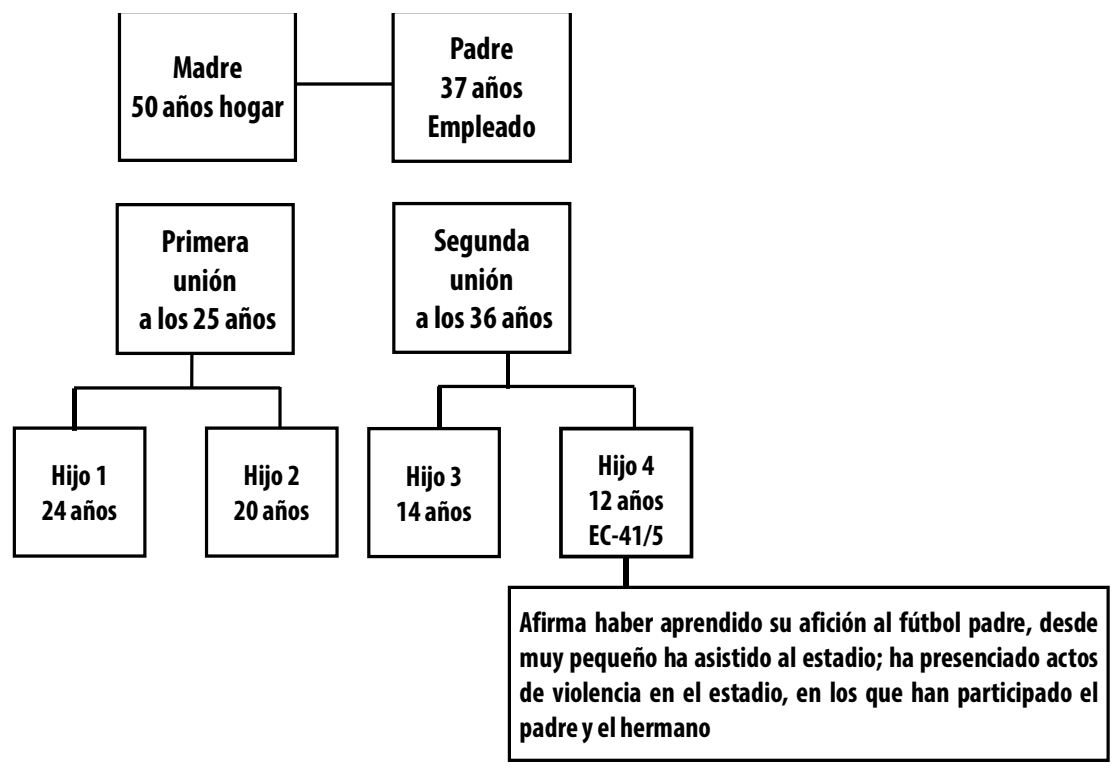

Fuente: elaboración de la autora con base en información recolectada en el trabajo de campo. 
Familia monoparental, de regencia femenina, con un hijo que no fue reconocido por el padre. La madre deriva el sustento de realizar trabajos varios, actualmente está desempleada. Debido a que su situación económica es difícil el chico pasa de casa en casa de parientes que les colaboran con el sostenimiento (Figura 18). El niño pasa mucho tiempo en la calle, su higiene personal revela descuido, tiene muy mala relación con la madre porque lo deja "en cualquier parte," no le gusta su vida inestable, dice que su relación con el tío es muy buena y tiene excelente imagen de él. Participa activamente en el barrismo, al que está siendo introducido por un grupo del barrio seguidor de Millonarios y quiere posicionarse con su grupo, eso ha hecho que sea muy arriesgado y conflictivo. En el colegio participa en peleas con guantes de boxeo, los alumnos las organizan en sitios alejados de la mirada de los docentes.

Figura 18. Familia sucesiva-2

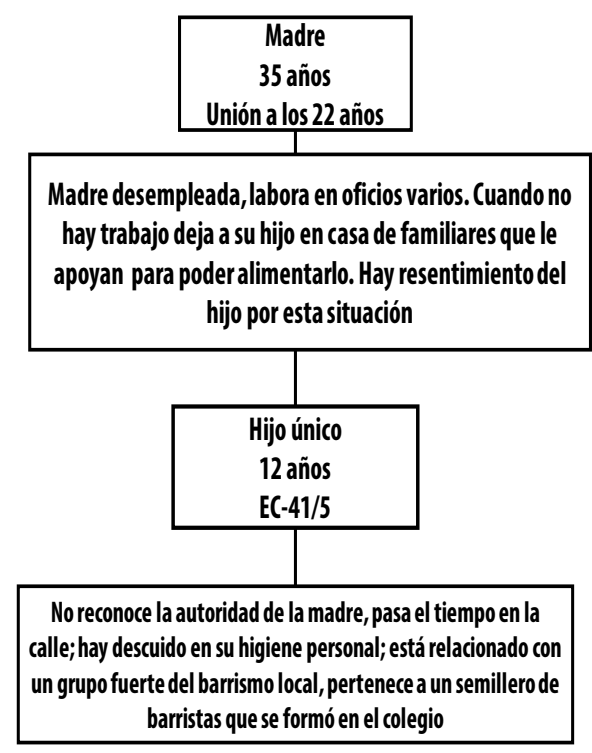

Fuente: elaboración de la autora con base en información recolectada en el trabajo de campo. 
Carga manoplas y en los zapatos tiene un orificio donde guarda una navaja; exhibe estos dos objetos ante sus compañeros, le gusta hacer alarde de ellos frente a sus compañeros y se ufana de la forma como los maneja.

Familia extensa, padre separado que se hizo cargo de los dos hijos con la ayuda de sus padres (Figura 19). La abuela ha cumplido el rol materno y es quien se encarga del cuidado y atención de la familia. Todos los miembros han culminado la secundaria. El padre y el abuelo sostienen el hogar, los dos hijos están escolarizados en $9 .^{\circ}$ y $11 .^{\circ}$ respectivamente. El estudiante sostiene:

Me relaciono bien con mi padre, los momentos más significativos que he vivido en familia son cuando salimos de paseo; mi familia me ha enseñado a ser honesto, responsable, y siempre me he relacionado bien con todos; la situación económica es normal.

Figura 19. Familia extensa y padre separado

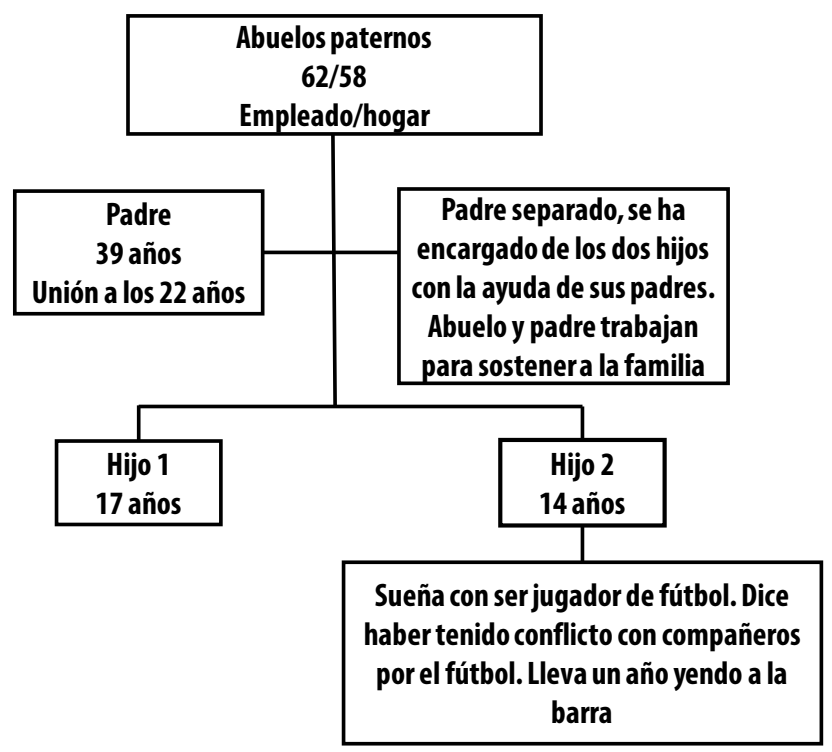

Fuente: elaboración de la autora con base en información recolectada en el trabajo de campo. 
Lo anterior constituye una pequeña muestra de la realidad familiar de los barristas participantes y las situaciones por las que atraviesan. Un docente de la institución 1 indica que situaciones como las descritas se dan por falta de compromiso de los padres, que dejan los hijos a la deriva, sin cuidado:

Yo creo que la problemática acá es que no hay padres, que falta esa asesoría de padres, que falta el papá o la mamá o los dos, ustedes saben que las mamás son más hábiles para criar los hijos y la naturaleza las dotó para eso, entonces suerte si quedan con la mamá y de malas si quedan con el papá. (D.C-1/1 [entrevista docente], febrero 6 de 2009)

Este docente revisa las problemáticas de las familias en las que se presenta la falta de interés y cuidado de los hijos, indica que en la eventualidad de una separación lo mejor que les puede suceder a los chicos es quedar bajo responsabilidad de la madre, discurso que expone una presunta incapacidad del padre para asumir como cuidador. En el barrio donde viven la situación es difícil por cuanto la delincuencia es parte de la vida cotidiana, hay violencia intrafamiliar y carencias de toda índole.

En relación con nuestro estudio, los jóvenes reportan soledad debido a las condiciones laborales de sus padres, tiempo que es aprovechado para estar en la calle expuestos a riesgos, experiencias y situaciones negativas; las actividades más comunes en las que ocupan su tiempo libre los estudiantes indican asistencia a jugar $X$-box; en varias instituciones los docentes y líderes de las comunidades revelan que se expenden sustancias y que las maquinitas (juegos electrónicos), como les dicen los chicos, son solo una fachada para sostener este negocio; los jóvenes más grandes admiten que juegan al billar, práctica que se relaciona con el consumo de alcohol y tabaco. Aunque también se vinculan a actividades barriales orientadas por profesionales, como las escuelas de fútbol y otros deportes, al culminar los entrenamientos se quedan en la calle jugando o van a las casas de amigos que se encuentran también solos, donde no hay un adulto que los supervise.

El fútbol es una afición casi generalizada desde el punto de vista recreativo y como hinchas; además, es importante destacar que la actividad del barrismo no es una limitante para tener un proyecto de vida, 
vale la aclaración, en el sentido de que los barristas son considerados vagos, desocupados, sin horizonte:

Quiero salir adelante, me gustaría ser técnico en computadores; en mi tiempo libre juego micro, estoy con mis amigos; por la noche estoy estudiando en un instituto reparación de computadores, y los fines de semana ir a la cancha (el estadio).

Este joven explica que sus mayores conflictos los ha tenido en el estadio, en las barras. La familia lo respeta: "En mi familia me siento bien, creo que ellos me han apoyado y respetado siempre; estoy a gusto con lo que tengo en mi casa, ellos también siempre se han esforzado para que tenga lo mejor" (E.C-28/4 sesión 1, abril 17 de 2009).

No siempre el barrista tiene una vida familiar conflictiva, muchas veces pesan más las acciones del grupo y la orientación que hay sobre el respaldo que se debe dar en momentos difíciles a la barra o a cualquier miembro de ella. Otro estudiante que pertenece a las divisiones inferiores de Millonarios refiere sobre su futuro: "Me proyecto con mucha prosperidad y siendo jugador de fútbol; llegar a ser un gran futbolista y teniendo una gran carrera" (E.C-12/2 sesión 1, febrero 6 de 2009).

Algunos muchachos y muchachas han debido asumir tareas como el cuidado y crianza de sus hermanos o primos pequeños: "Mi tiempo libre lo ocupo cuidando a mis primitos y escuchando música, y algunas veces estudiando o repasando mis cuadernos" (E.C-8/1 sesión 1, febrero 6 de 2009). Otros deben asumir labores domésticas como el arreglo de la casa, el lavado y planchado de la ropa, la preparación de alimentos, recoger a los hermanos en sus escuelas y dirigir tareas, todo ello les resta tiempo y energía para realizar sus propios deberes y son trabajos que competen sobre todo a los adultos; hay incluso pequeños que atienden estas labores, por ejemplo, un niño de 12 años atiende a sus hermanitos de 4 y 8 años; las niñas son a quienes principalmente los padres encargan estas tareas.

La situación barrial ha hecho que en ciertos casos los padres tomen medidas y mantienen el control de los hijos a distancia; se establece como regla no salir a la calle, como lo cuenta este estudiante: 
Yo no tengo casi amigos porque yo vivo en un barrio [en el] que se ven muchas cosas, que un amigo le vende a otro amigo (drogas), entonces es mejor solo que mal acompañado y los pocos amigos que tengo, ihuy!, poco los trato porque unos ya fuman y otros roban. (E.C-2/1 sesión 1, febrero 6 de 2009)

Si bien el interés de los padres es resguardar a los hijos de peligros, la interacción que estos tienen con el medio es pobre y las relaciones con otros son casi inexistentes, eso también es un factor negativo. Además, este estudiante manifiesta tener muy malas relaciones con su padrastro: "Con mi padrastro yo casi no hablo pero con mi mamá sí, es súper, yo trato con ella lo que me pasa, lo bueno y lo malo”. Entonces, la pregunta es: si no tiene amigos y sus relaciones familiares están deterioradas, ¿qué le queda? En el colegio fue reportado como conflictivo, al parecer vive situaciones de violencia intrafamiliar que son el motivo de sus malas relaciones en el hogar. Hace un año está yendo al estadio y pertenece a la barra de la Banda Azurra.

Un aspecto referido con énfasis por los jóvenes son las malas relaciones familiares; el motivo de las discordias es diverso, empezando por cuestiones de dinero: "Los conflictos más frecuentes en la familia son porque a veces le llega a mi papá la quincena muy baja” (E.C-7/1 sesión 1, febrero 6 de 2009).

\section{CONCEPCIONES DE LA FAMILIA EN TORNO A LA PARTICIPACIÓN DE LOS HIJOS EN EL BARRISMO}

Los estudiantes comentan que su adhesión a las barras les ha generado problemas con los padres:

Mi padre en el momento está bien, aunque es todo peleador, pero a ratos se pone bravo y después vuelve a hablar. En la casa me han enseñado a respetar a las gentes y no robar y con mi mamá estoy bien, con mi padre no muy bien porque pelea mucho conmigo por el barrismo. (E.C-1/1 sesión 1, febrero 6 de 2009) 
También hay padres que fomentan esta adhesión más como una herencia que recuerda sus regiones de procedencia:

Desde muy pequeño, mi mamá, mi papá, pues son hinchas de Nacional, me decían que tenía que ser hincha de Nacional. Siempre me ha gustado ser hincha de Nacional; a mí me han dicho compañeros que me meta a los de Millonarios, pero no, nunca me ha gustado. (E.C-23/4 sesión 1, abril 24 de 2009)

Un barrista que organiza una familia se vuelve más prudente al participar en los eventos del estadio:

Más que todo los barristas cuando tienen un hijo se salen de eso, porque usted diga: quince mil que se gaste en el Campín y pues con esos quince mil yo saco a mi hijo, un heladito o algo nos comemos... eso hay mucha gente ahí donde yo vivo que tienen hijos y que están tatuados, que ya no van al Campín. (E.C-1/1 sesión 1, febrero 6 de 2009).

$\mathrm{Al}$ indagar a los jóvenes qué opinan los padres sobre su participación en las hinchadas de equipos, algunos dicen que ellos les permiten esta pertenencia siempre que tengan cuidado y no se mezclen en los desórdenes; hay en cambio otros, que son prevenidos frente al tema y que afirman:

Pues en la mía sí hay problema, porque mi mamá es de esas viejitas que son todas chapadas a la antigua, que no le gusta que los hijos tomen, que los hijos fumen, que los hijos salgan a bailar, que estén en cosas así, entonces a ella no le trama nada de eso. Ella me ve con las cosas de Millonarios y se pone toda rabona (enojada) que porque ve las cosas en los noticieros, que matan gente por las camisetas, a ella no le trama nada de eso y con ella sí es una pelea por todo esto. (E.C-27/4 sesión 1, abril 24 de 2009)

Algunos muchachos dicen que sus acciones los han llevado a tener encuentros con la autoridad que culminan en la comisaría; la sanción son veinticuatro horas de arresto, si los padres no los recogen: "yo llamo a mi papá y ese sí me saca, así, callado” (E.C-24/4 sesión 1, abril 24 de 2009), para que la madre no se entere porque el tema se le vuelve un problema, de este modo también hay padres que fomentan el mal comportamiento de los hijos. Las normas exigen que los padres vayan a las estaciones de policía y recojan a los muchachos, como una 
especie de reconvención a la familia por las actividades de los jóvenes; sin embargo, entre los estudiantes se afirma que "hay chinos que los llevan cada ocho días a la estación y eso no pasa nada; después va el papá y los recoge iy ya!” (E.C-24/4 sesión 1, abril 24 de 2009). Esta es una situación que citan frecuentemente las autoridades, dado que la situación no cambia y deja en duda el papel de los padres frente al control de los hijos, tampoco se ha sabido de alguna sanción para la familia por la reincidencia de los hijos.

En el caso mío no se presentan casi los problemas familiares, porque la verdad, tanto mi papá como mi mamá confían en mí, saben qué es lo que voy a hacer, saben que me voy a ir a meter a una tribuna, no como dicen en noticias, últimamente se saben muchos casos que por una simple camiseta van a matar, la verdad ellos saben el riesgo al que me expongo, pero también saben que simplemente voy al estadio a alentar al equipo, no voy a buscar tropel. (E.C-25/4 sesión 1, abril 24 de 2009).

Cuando hay violencia en el estadio y los padres se enteran por los medios de comunicación contactan a los hijos telefónicamente:

Claro, claro, inmediatamente pues nos llaman, por ejemplo, el incidente que hubo con el Cali... inmediatamente llaman a ver cómo está uno, yo personalmente, dirán estos, no les parecerá como tan a lo bien, pero yo llamo a mi papá apenas voy a entrar al estadio y cuando vamos para la casa también y él calcula el tiempo. (E.C-25/4 sesión 1, abril 24 de 2009)

Los jóvenes que tienen la oportunidad hablan con sus padres o hermanos acerca de las actividades en los partidos y los mantienen enterados de lo que pasa como una forma preventiva:

Pues yo hablo más con mi hermano, pero con mi papá también, él sabe quiénes son los duros (los capos) y nos ha escuchado. La que la monta es mi abuelita porque a ella le parece eso, no nos lo ha dicho así de frente, pero sí de ladito, que nos vamos por allá donde todos esos vagabundos, con esa ñeramenta, que mariguaneros... (E.C-25/4 sesión 1, abril 24 de 2009).

Para algunos padres es peligroso lo que se mueve alrededor de las barras, la misma violencia, hay temor por el tema de los consumos, los problemas con la autoridad, muchos preferirían que sus hijos no fue- 
ran al estadio, pero finalmente lo permiten haciendo todas las recomendaciones del caso:

El problema con mi familia no es que uno se meta a las barras bravas, que tenga cuidado, que cuando se acabe el partido uno se vaya para la casa, que no se meta en problemas; es que allá echan mucho vicio y dicen que uno no se meta en ese cuento, que vaya a ver el partido y no a enviciarse; $y$ cuando uno va al estadio le dicen a uno que iqué va a hacer por allá a gastarse la plata y a ver perder a ese equipo! [...] unos tíos que son hinchas de Nacional, que lo cogen a uno de parche (burla), que marica $y$ que no sé qué... pero problemas con mi papá y mi mamá no, me dan libertad en eso, pues si lo llaman a uno le dicen "con cuidado por ahí" y con los amigos que voy les toman el número y eso, me sobreprotegen. (E.C-28/4 sesión 1, abril 24 de 2009)

Otros padres consideran que el hijo, cuando supera los quince años, puede responder por sí mismo; es frecuente escuchar: "él verá qué hace, ya está grande", y según esta idea les dan libertad ilimitada para que vayan y vengan siempre que no los metan en problemas:

A mí me dejan salir a donde yo quiera y me dan plata, y me dijeron: vea, usted puede hacer lo que quiera, pero cuídese, después no vaya a venir aquí llorando, o jodido, haga lo que usted quiera pero cuídese. (E.C-22/3 sesión 2, marzo 7 de 2009).

Este chico, por ejemplo, fue apuñalado por integrantes de una barra que lo esperaron a la salida del colegio 3 , y no informó a los padres sobre esta cuestión para no perder lo que ha ganado. Afortunadamente la herida no fue grave y él mismo se atendió, asistió al NES convaleciente por herida en un brazo.

Todo lo anterior es indicador de la forma como las familias afrontan las problemáticas con los jóvenes. Hay negligencia, para algunos autonomización temprana como una forma de responsabilizarlos a ellos de sus acciones. Se evidencia asimismo por parte de los padres afán emancipatorio, tras lo cual en diversas ocasiones los chicos son dejados a la deriva cuando tienen dificultades; por otra parte, hay un fuerte resquebrajamiento de la autoridad de los padres que, aunado a otras condiciones de los jóvenes tales como los consumos, las amistades complicadas, la pertenencia a barras, pandillas, parches, hacen 
que la práctica del barrismo se convierta en una actividad de riesgo en la que no es difícil predecir que quienes son más avezados se vinculen con grupos delictivos que los captan a través de la promesa de dinero fácil, que incluso usufructúa la familia sin preguntar la procedencia.

\section{EL CÓDIGO DE INFANCIA Y ADOLESCENCIA Y LA PROTECCIÓN DE LOS MENORES (LEY 1098 DE 2006)}

El Código de Infancia y Adolescencia (Congreso de la República, 2006) hace parte de la normatividad nacional para el manejo de las cuestiones relativas a la protección de los menores de edad; nace de la necesidad de reformar la Ley 2737 de 1989, que ya no se ajustaba a las nuevas realidades del país. También busca revalidar la Ley 12 de 1991, por la cual se ratificó la Convención Internacional de los Derechos de los Niños, y finalmente alinear esta norma a la Constitución de 1991. Su finalidad quedó planteada en el artículo $1 .^{\circ}$ :

Garantizar a los niños, a las niñas y a los adolescentes su pleno y armonioso desarrollo para que crezcan en el seno de la familia y de la comunidad, en un ambiente de felicidad, amor y comprensión. Prevalecerá el reconocimiento a la igualdad y la dignidad humana, sin discriminación alguna. (Congreso de Colombia, 2006)

De este modo los reconoce como sujetos de derechos, a quienes debe garantizárseles, y se obliga a la prevención de cualquier hecho que los vulnere. Un aspecto relevante es que todos Estado, sociedad y familia deben ser garantes de dicho proceso.

Si bien la norma representa un avance importante en la regulación de las relaciones de los padres, los hijos y los adultos en general, son los padres quienes piensan que a la luz de las nuevas disposiciones legales han quedado sin piso para el logro del propósito de la ley. Una madre decía al respecto:

Con estas leyes que sacaron tan estúpidas, para mí son estúpidas, que cuidado uno le llama la atención al niño porque ahí mismo lo castigan a uno, ¿̀y a uno de padre qué, cuáles son los 
derechos del padre?; ahora esa ley que sacaron de que el consumo de la droga personal... es que no respetan... mire allí, son grupitos de diez, quince muchachos, les dicen los sopladores, $y$ todo ese humo se entra a la casa (madre 21, marzo 14 de 2009NES 3, Familia),

alusión que hace la madre a las sanciones de que puede ser objeto por castigos físicos, abandono o negligencia en el cuidado de los niños; la norma permite a los hijos demandar a los padres cuando sientan que sus derechos o dignidad han sido vulnerados.

Culturalmente se entiende la formación de los hijos bajo unos patrones de crianza que se repiten de una generación a otra, por esta razón algunos padres piensan que la forma como ellos fueron educados puede ser replicada en la formación de sus propios hijos, pero en ello se incluye el castigo físico, el maltrato psicológico, el trato degradante y la humillación; todas las reconvenciones que se plantearon en esta norma para las familias ha hecho percibir a los padres que no tienen autoridad frente a los hijos y que el Estado es responsable del aumento de los delitos por cuenta de los menores de edad. Un frente importante de atender, desde esta perspectiva, es la formación de los padres y las familias para mejorar las relaciones personales, mediante la provisión de estrategias que les permitan avanzar en la solución eficaz del conflicto y la estructuración de modelos familiares más comprometidos, formativos y diligentes en el cuidado de los niños. Igualmente es importante, y más que ello urgente, que las familias lleguen a la comprensión profunda de sus deberes, los cuales no se circunscriben únicamente a la manutención, sino que van más allá y responden a la corresponsabilidad en la formación de mejores ciudadanos.

Desde el punto de vista de la responsabilidad en contravenciones a la ley, los menores de 14 años se consideran inimputables y se tendrá en cuenta el procedimiento que ordena la ley según sea el caso, atendiendo siempre al principio de prevalencia para garantizar sus derechos. El artículo 161 indica:

Para los efectos de la responsabilidad penal para adolescentes, la privación de la libertad sólo procede para las personas que al momento de cometer el hecho hayan cumplido catorce (14) y 
sean menores de dieciocho (18) años. La privación de la libertad sólo procederá como medida pedagógica. (Congreso de Colombia, 2006)

Bajo este supuesto muchos menores delinquen, atribuyéndose la minoría de edad como argumento que les evita sanciones, tal es el caso de los chicos que participan en los eventos de vandalismo y desorden en la ciudad por el tema del fútbol, las lesiones personales y el porte de armas.

La otra cara de esta situación la representan los adultos que inducen a los menores al delito, que en la mayoría de los casos son desconocidos por la ley a la hora de aplicar sanciones, tal es el caso del microtráfico, el porte de armas, utilización de los niños en casos de mendicidad o hurto y la vinculación de menores al sicariato. Muchos de ellos portan documentos falsos para mantener por mayor tiempo su estatus de menor de edad, en Bogotá y el resto del país, además existen redes de falsificadores que proveen estos documentos.

En la ciudad la violencia de los jóvenes ha aumentado y las voces de la comunidad y la política se alzan con el fin de pedir el aumento de las penas para los menores. Algunos datos significativos suministrados por el Instituto Colombiano de Bienestar Familiar (ICBF), la Policía de Infancia y Adolescencia y el Centro Especializado Puente Aranda (Cespa), sitios a los que son llevados en primera instancia los menores infractores, indican que

en el 2008 se registraron 3.548 delitos, mientras que el año pasado alcanzaron los 4.357, es decir, un crecimiento de 809 casos. El hurto a personas fue el delito que más se incrementó, pues tuvo un aumento de 53,73 por ciento (807 casos): de 1.502 casos en 2008 se pasó a 2.309, en 2009. Sólo en el Cespa se denunciaron 3.479 delitos cometidos desde el primero de enero hasta el 30 de noviembre de 2009. (El Tiempo, 2010b)

Un dato preocupante reseña la participación de los menores en porte, tráfico y fabricación de estupefacientes; las entidades reportaron los siguientes datos: "Las cifras muestran un incremento del 37,16 por ciento. En el 2008 fueron detenidos 662 menores por ese delito y en el 2009, 908” (El Tiempo, 2010b). 
Aunque el asunto responde a problemáticas sociales más complejas, se exige que el Sistema de Responsabilidad Penal para Adolescentes endurezca las penas y sea menos pedagógico a la hora de aplicar sanciones, con el argumento de que muchos delitos cometidos por jóvenes ameritan más que una medida de este tipo. A la par consideran que es necesario disminuir la edad de penalización. Ávila (2010) afirma:

El debate sobre la reforma y aplicación del Sistema de Responsabilidad Penal Adolescente evidencia la crisis de institucionalidad del Estado, la ineficacia del sistema judicial y la ausencia de políticas sociales que aporten a la solución de los problemas de los niños y adolescentes que infringen la ley. ( $p .22)$

En contraposición el concejal (de Bogotá) Javier Palacio Mejía, demandaba la aplicación de la ley 1098/o6 para penalizar a los jóvenes infractores:

Sabemos de los grandes esfuerzos que a través de medidas pedagógicas hace la Comunidad Terciarios Capuchinos, que es el operador contratado por el ICBF para el manejo de responsabilidad penal en el caso de adolescentes, pero precisamente esta situación es la que obliga al Concejo de Bogotá a buscar y tomar las medidas necesarias para que las autoridades distritales asuman con responsabilidad el cumplimiento de la Ley de Infancia y Adolescencia en lo que se refiere a responsabilidad penal. (Oficina de Prensa del Concejo de Bogotá, 2010)

Cuando se toca el tema, se contemplan las medidas que se pueden tomar desde el punto de vista legal y los políticos no son propositivos a la hora de ofrecer soluciones de fondo. La Tabla 12 muestra las sanciones aplicadas a menores entre los años 2007 y 2010.

Tabla 12. Sanciones a menores infractores, 2007-2010

\begin{tabular}{|l|c|c|c|c|c|}
\hline Sanciones & $\mathbf{2 0 0 7}$ & $\mathbf{2 0 0 8}$ & $\mathbf{2 0 0 9}$ & $\mathbf{2 0 1 0}$ & Total \\
\hline Libertad asistida & 116 & 823 & 1.490 & 1.051 & 3.480 \\
\hline $\begin{array}{l}\text { Imposición de reglas de } \\
\text { conducta }\end{array}$ & 97 & 682 & 1.198 & 813 & 2.790 \\
\hline Amonestación & 79 & 487 & 599 & 339 & 1.504 \\
\hline $\begin{array}{l}\text { Internamiento en medio } \\
\text { semicerrado }\end{array}$ & 54 & 314 & 759 & 525 & 1.652 \\
\hline
\end{tabular}


Tabla 12. Sanciones a menores infractores, 2007-2010

\begin{tabular}{|l|c|c|c|c|c|}
\hline Sanciones & $\mathbf{2 0 0 7}$ & $\mathbf{2 0 0 8}$ & $\mathbf{2 0 0 9}$ & $\mathbf{2 0 1 0}$ & \multicolumn{1}{c|}{ Total } \\
\hline $\begin{array}{l}\text { Privación de la libertad, } \\
\text { CAE1 }\end{array}$ & 45 & 66 & 229 & 776 & 1.116 \\
\hline $\begin{array}{l}\text { Prestación servicio a la } \\
\text { comunidad }\end{array}$ & 23 & 127 & 154 & 150 & 454 \\
\hline Otras & 39 & 152 & 88 & 90 & 389 \\
\hline Total & 453 & 2.651 & 4.517 & 3.744 & 11.365 \\
\hline
\end{tabular}

1 CAE: Centro de Atención Especializado.

Fuente: elaboración de la autora con base en Acero (2010).

Acero (2010) hace un llamado a la sensatez e indica que la violencia de los jóvenes supone reconocer que es un fenómeno multicausal y que su implicación se da en ambos sentidos, como víctimas y como victimarios; llama a:

- Evitar criminalizar a todos los jóvenes.

- No confundir la política de juventud con la política criminal juvenil, que debe tener acciones en los campos preventivo, disuasivo y de control del delito.

- Conciliar las dos posiciones, que antes que antagónicas son complementarias: la que considera que estos problemas se arreglan con acciones fuertes de las autoridades de seguridad y de justicia en el marco del Estado de Derecho; y la que piensa que con solo inversión social se resuelven estos problemas. (s. p.)

Una mirada concienzuda al fenómeno del barrismo exige la observación de las anteriores tres variables, comprender que las acciones de hecho o la observancia de la Ley de Infancia y Adolescencia no son suficientes para solucionar las problemáticas que se presentan. Hay cuestiones mucho más preocupantes que nos comprometen como sociedad. No todo lo que pasa con los jóvenes adolescentes requiere el despliegue de un operativo policial o el uso de la fuerza, es necesario ayudarlos a superar sus múltiples carencias afectivas, nutricionales, de salud, educación, trabajo y demás; crear una especie de piso en el que se sientan seguros y logren asumir sus vidas en mejores con- 
diciones, con percepción de esperanza en el futuro. Si bien algunos optan por unirse a la delincuencia organizada, es obligado garantizarles la posibilidad de una justicia restaurativa que les permita un trato acorde a sus condiciones, ello implica un juicio justo, la detención en condiciones dignas, la posibilidad de seguirse educando aun cuando se encuentren privados de la libertad, apoyo psicosocial, intervención a la familia, entre otros.

La exposición de los estudiantes a la violencia y la delincuencia, en este caso al fenómeno del barrismo, requiere el apoyo de fuerzas sociales como familia, escuela, comunidad, con el ánimo de que cada una de ellas asuma el deber que tienen como corresponsables de su formación.

Finalmente, el artículo 170 reconoce a los padres como "representantes legales, solidariamente responsables" del comportamiento de los menores. El Estado debe apersonarse para que la función de la familia se cumpla, este es el primer paso para que los niños, niñas y adolescentes no engrosen las redes de reclutadores para las mafias y las guerrillas, ni caigan en situaciones delictivas, en los consumos, el porte armas, entre otras situaciones. Asimismo, que familia, escuela y sociedad restablezcan relaciones a favor de los menores a fin de garantizarles su pleno desarrollo, tal y como se propone la Ley de Infancia y Adolescencia. 


\section{ESCUELA Y BARRISMO}

La preocupación por la función que debe cumplir la educación viene discutiéndose desde la década de 1990, con ocasión de la Conferencia Mundial sobre Educación para Todos, que plantea como aspecto fundamental la necesidad de que "la educación conduzca a garantizar a la población mundial cubrir las necesidades básicas de aprendizaje en todas las edades" (Delors, 2000, p. 1), y que dichos procesos formativos deben responder a los desafíos que plantea un mundo en constante transformación. De igual forma, el informe de la Comisión Internacional de Educación para el Siglo XXI, presentado por Delors (2000), ratifica la importancia de la educación al destacar que su función primordial ha de ser la "vía esencial, entre otras, pero más que otras, al servicio de un desarrollo humano más armonioso, más genuino, para hacer retroceder la pobreza, la exclusión, las incomprensiones, las opresiones y las guerras" (p. 7), con lo que se le confiere a la educación una función social. La propuesta de la Comisión Internacional es la educación a lo largo de la vida fundada en cuatro pilares: aprender a ser, aprender a conocer, aprender a hacer y aprender a vivir juntos.

La apuesta es por el fortalecimiento de los vínculos sociales que permitan el desarrollo armónico de los escolares reconociendo su derecho a ser tratados con equidad, a tener un espacio para estudiar respetando las diferencias y evitando la exclusión. De cara a la profesión docente, la recomendación de la Comisión es el mejoramiento de las relaciones entre estudiantes y profesores, al indicar:

Nada puede sustituir a la relación de autoridad, pero también de diálogo, entre el maestro y el alumno. Todos los grandes pensadores clásicos que han estudiado el problema de la educación lo han dicho y lo han repetido. Es el maestro quien ha de transmitir al alumno lo que la humanidad ha aprendido sobre sí misma y sobre la naturaleza, todo lo que ha creado e inventado de esencial. (Delors, 2002, p. 15) 
Esto significa apropiarse de su papel y desarrollar una educación de calidad, fundada en la preparación, en el respeto y la autoridad reconocida por los estudiantes Asimismo, conmina a la educación a crear las condiciones necesarias para que los niños y jóvenes puedan concretar su proyecto de vida, en lo relativo a la inclusión, la equidad y las fuentes necesarias de empleo y capacitación.

Por su parte, García y Ortiz (2012c), particularmente en Colombia, explican que

el cambio en la denominación de la educación como función social y posteriormente con la Ley General de Educación 115/94, como servicio público, desarrolló el derecho a la educación consagrado en la Constitución de 1991, como el derecho de la persona sin esclarecer el tipo de derecho ( $p$. 14),

tras algunas conceptualizaciones ambiguas lo reconoce como un servicio público, lo que no garantiza la concreción del derecho a la educación. Los estudios realizados sobre educación tanto en América Latina como a nivel local destacan algunos puntos neurálgicos en la prestación del servicio educativo que son considerados como el foco de atención para alcanzar la calidad, tales como la inversión, la calidad, la cobertura, la deserción, la centralización del sistema, el desprestigio de la profesión docente, por mencionar algunas.

Martínez (2004), en alusión al trabajo realizado por el Programa de Promoción de la Reforma Educativa en América Latina y el Caribe (Preal) en 1998, indica respecto de los puntos anteriores que el informe del Preal muestra un descenso de la inversión en educación, no toma en cuenta el aumento de la población en edad escolar; la deficiente administración de los recursos para el sector, que se dedican a atender de manera prioritaria al funcionamiento y la burocracia, deja de lado necesidades apremiantes; la centralización del sistema restringe la autonomía y reduce la transparencia; finalmente, la decadencia de la profesión docente se manifiesta en la baja preparación para el ejercicio docente, que persiste aún en muchos de nuestros países.

En Colombia, aunque se han hecho esfuerzos para mejorar la cobertura, disminuir la deserción y, en los últimos años -especialmente 
en Bogotá- invertir en formación docente, subsisten aún aspectos que deben ser atendidos y que se asocian directamente a la calidad de la educación, por ejemplo la implementación de estrategias para vincular al sistema la población en edad escolar en todo el país y específicamente en la educación rural, así como mejorar sus condiciones (infraestructura, dotación); la inclusión de las tecnologías de la información y la comunicación (TIC) en las aulas, lo que supondría también una transformación del trabajo docente; el acceso a la educación técnica y superior, que sigue siendo insuficiente; actualmente se trabaja en la renovación curricular y el Estado ha avanzado en el Sistema General de Evaluación de la Educación.

Desde el punto de vista de la descentralización de la educación pública, se han dado pasos para certificar la educación, lo que a largo plazo la dejará en manos de las administraciones municipales, lo cual plantea otras problemáticas, tales como: la administración del personal docente, la financiación de la educación, la responsabilidad de la nación frente a la educación en los diferentes entes territoriales, entre otras.

\section{LA VIOLENCIA DE LA ESCUELA}

Se define la violencia de la escuela como aquella que es ejercida en contra de los estudiantes, representada en la violencia de las aulas, ejercida por los profesores o cualquier otro funcionario de la institución. Este tipo de violencia puede ser psicológica, e incluye acciones como la ridiculización en público, normas de conducta excesivamente rígidas, ignorar a los estudiantes impidiéndoles su participación; físicas, por ejemplo los castigos corporales y la exclusión, con su forma más representativa, que es el fracaso escolar; se consideran igualmente situaciones de violencia de la escuela el exceso de trabajo y el estrés. Palomero y Fernández (2001) indican que "lo más grave de este tipo de agresión es que los chicos pasan a convertirse en objeto de rechazo, burla y agresión de sus propios compañeros" (p. 28).

La violencia contra los docentes es una contravención a las normas escolares, la cual se manifiesta en formas como el insulto, la amenaza 
y el chantaje, las faltas de respeto, interrupciones intencionales de la clase, indisciplina o agresiones por parte de los estudiantes y las familias. Las investigaciones europeas han trabajado la indisciplina y posteriormente orientaron los estudios hacia la violencia de las instituciones, fundados en los conceptos de Bourdieu y Passeron (1970) y Baudelet y Establet (1970).

\section{BARRAS DEL FÚTBOL: VIOLENCIA CONTRA LA ESCUELA}

Como se ha dicho, la violencia en el entorno escolar se manifiesta en dos vías, una de carácter institucional, relacionada con las prácticas pedagógicas, y la otra proveniente de hechos que los escolares o cualquier otro miembro de la comunidad promueven en contra de la escuela para generar situaciones que atentan contra la convivencia institucional, manifiesta en actos de intolerancia, violencia simbólica, amenaza, acoso, chantaje, consumo y distribución de sustancias, porte y uso de armas, aspectos que se evidencian también en la pertenencia de estudiantes a los grupos del barrismo deportivo. La expresión de rivalidad entre grupos tiene manifestaciones tanto internas como externas que afectan directamente a la escuela y la comunidad con expresiones como el vandalismo, la territorialización, la demarcación de los espacios, la destrucción y el deterioro de edificios, producto en algunos casos de la confrontación con otras instituciones escolares. En la Figura 20 se muestra un caso de vandalismo contra el mobiliario en una de las instituciones contactadas. Este edificio (colegio 3) llevaba un año de inaugurado.

La organización barrista escolar es estricta y jerarquizada. En los colegios existen líderes que están pendientes de las actividades deportivas dentro de las instituciones y determinan la confrontación. Por ejemplo, cuando se pierde un partido intercursos se genera una situación en la que el conflicto se presenta; en realidad puede darse el caso de que se juegue un partido y en el equipo contrario haya hinchas de una barra enemiga, entonces se aprovecha para 'marcarle el territorio', también se reconocen los parches barriales y las alianzas que estos puedan establecer con otros actores de la comunidad, "algunas veces 
Figura 2o. Vandalismo en la escuela

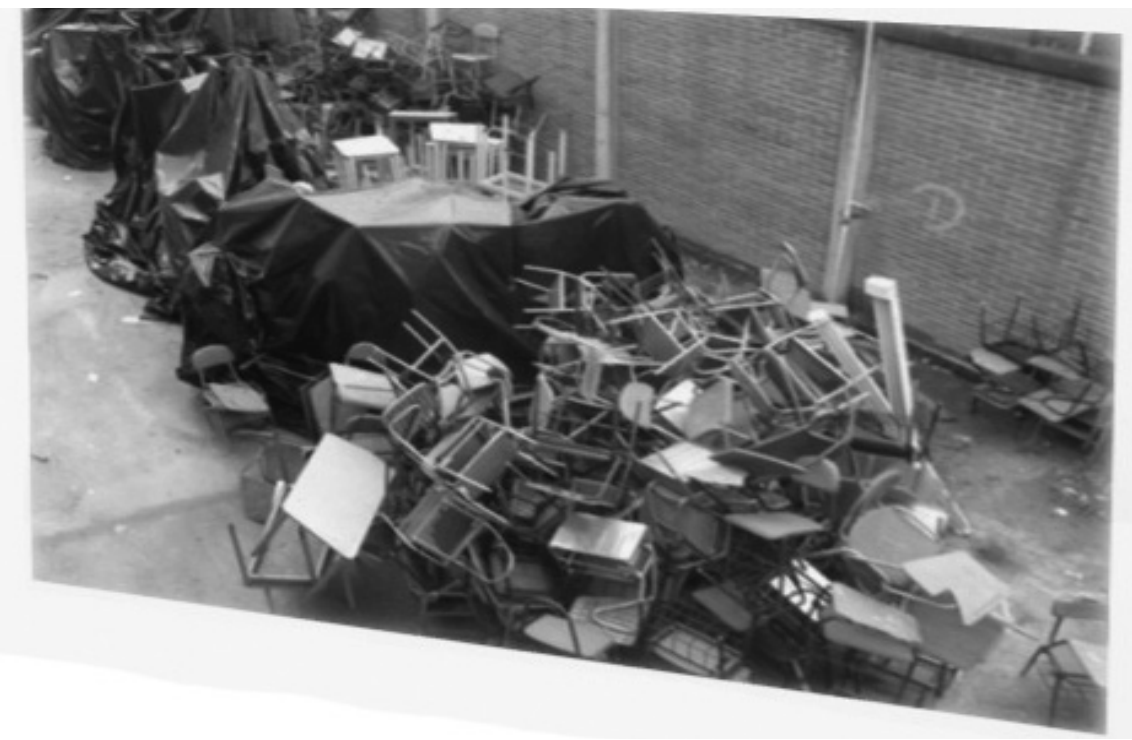

que se dan peleas, que no faltan... toca parar el partido y suspender el campeonato" (E.C- 18/3 sesión 2, marzo 7 de 2009).

Así, la percepción de los estudiantes se da en dos sentidos, el conflicto se genera dentro de la institución pero se resuelve afuera, considerando con ello que puede haber mayores problemas; esto representa un riesgo y es la escalada del conflicto por la intromisión de grupos y agentes externos que complican aún más la situación con el porte de armas o provocación de la violencia masiva. En contraposición, otros prefieren resolver sus asuntos dentro de la institución, ya que esto les garantiza que no haya intervención de agentes externos (pandillas) y en la mayoría de los casos el colegio trabaja para detener las diferencias entre los jóvenes, algo que consideran más conveniente y representa la tregua entre los grupos en conflicto, motivada por las sanciones de que pueden ser objeto:

Pues yo pienso que sí es mejor la pelea en el colegio, porque digamos, a uno se la tienen dedicada, uno no le va a decir 'a la salida', porque si se queda a la salida va a ser peor, porque en algunos casos pues hay chinos que creen que es mejor traer su parchecito $y$ ahí se puede ocasionar una puñalada, un tiro, de todo. (E.C-18/3 sesión 6, abril 4 de 2009) 
Algunos chicos indican que su comportamiento en el colegio es bueno y que no han tenido dificultades en el centro educativo, pero sí afuera, por el fútbol: "En el colegio realmente no he tenido conflictos, fuera de él más que todo he tenido conflictos en el estadio, entre barras (E.C.28/4 sesión 1, abril 17 de 2009). Las peleas que se pactan dentro del colegio se resuelven en sitios de los barrios que los estudiantes han elegido para ello, especialmente parques en los alrededores:

Uno adentro lo que hace es cazar la pelea, y quedan en que ya van a ir a darse a la salida y entonces ahí es cuando uno se prepara. (E.C-19/3 sesión 2, marzo 7 de 2009)

Por la noche, como nosotros prestamos vigilancia en el parque, llegó un grupo como más o menos de unos quince o veinte muchachos vestidos todos de azul, alistándose con cadenas, con palos, con cuchillos, piedras, con todo lo que se les presentó, ya estaban como llamando a los del problema para enfrentarse ahí. (Líder comunal [entrevista], abril 18 de 2009)1

Quien tiene un conflicto dentro del colegio organiza su defensa vinculando a sus amigos o compañeros, el rumor corre por la institución y al final, como dicen ellos, medio colegio participa en las peleas, sumándose a uno de los bandos en contienda. Cuando la pelea incluye a un agente externo, por ejemplo un equipo invitado de otra institución, se hace "respetar" el espacio escolar y las provocaciones que se presenten durante el juego se cobran con bronca; este relato se obtuvo en el colegio 3:

Acá hace como unos cuatro años, antes el colegio estaba lleno de gaminería, hubo un campeonato intercolegiado y se armó severo problema y empezamos a tirarnos piedra y esa vez cerraron el colegio como por tres días. El problema fue grave, porque tuvo que venir la policía, habíamos volteado las canecas y las cogimos de bombo (tambor), todo como en el estadio; los del otro equipo comenzaron a dar pata y eso sí no, porque ellos estaban en nuestro colegio, hay que respetar. La policía se metió a arreglar el lío y no pudo, entonces metieron una tanqueta al colegio y sacaron a los del equipo del otro colegio, unos salieron con la cabeza rota porque hubo mucha piedra. (EC-16/3 sesión 2, marzo 7 de 2009) 
El encuentro con el grupo en el colegio 4 estuvo marcado por la desconfianza; al lugar llegaron 22 estudiantes de los grados $7 .^{\circ}$ a $11.0^{\circ}$ y les explicamos el proceso que llevaríamos indicándoles los principios generales que orientarían el trabajo. Solicitamos permiso para grabar las sesiones... un estudiante hizo ademán de silencio al resto del grupo y dijo: "Ahí sí se complica la cosa, porque nosotros estamos dispuestos a ayudar y le contamos lo que necesita, pero es que no sabemos cómo va a utilizar lo que se está grabando" (E.C-25 sesión 1, abril 17 de 2009). Advertimos que lo más importante es la fidelidad de la información cuando se haga el registro escrito; el joven, con actitud autosuficiente, le advirtió a sus compañeros que se encontraban llenando la ficha de inscripción: "Vengan, revisen bien lo que están firmando, lean bien lo que les están preguntando, porque uno no sabe qué va a pasar con esto" (E.C-25 sesión 1, abril 17 de 2009).

Luego de un proceso de persuasión sobre la reserva de identidad y la forma como se manejará el tema de los seudónimos, consintió: "Bueno, vamos a confiar en usted, pero es mejor si podemos ver lo que escribe sobre nosotros", así acordamos que leeríamos en cada sesión lo que se había tratado en la anterior. Mientras esta discusión se resolvía, los demás chicos habían suspendido la actividad que se realizaba en ese momento, y una mirada de mi interlocutor fue suficiente para que se reanudaran las tareas. Queda claro que es el líder de los barristas.

Este es un chico muy particular, domina en el grupo, maneja soterradamente la opinión de los demás y va indicando con diferentes mecanismos lo que deben hacer; interrumpe cuando alguien está dando más información de la que se ha acordado. Al indagar sobre su actuación en el colegio, hace un ademán disimulado, coloca su dedo sobre la boca indicando a los demás que no hablen y enseguida responde por todos. Se ufana de hacer lo que quiere en las clases, genera disrupción y es quien determina a qué docentes "se la montan" (molestan). Definitivamente es la cabeza visible de las barras en esta institución. El estudiante tiene 16 años, ha elaborado un censo de las barras que hay en el colegio, las tiene clasificadas por equipos, por "parches", sabe quiénes son los que las conforman, de esta manera ha neutralizado a las barras contrarias. Su información permitió saber que la barra de Millonarios tiene 54 miembros y es la más numerosa del colegio: 
"Aquí somos 54, éramos más, lo que pasa es que el año pasado se graduaron” (E.C-25 sesión 1, abril17 de 2009). Su relación con los demás incluye juegos fuertes y agresivos, que estos aceptan resignados; cuando no estaba en las sesiones los otros hablaban muy mal de él (son los juegos de poder que también en este espacio se viven), varios de ellos quisieran estar en su posición; le reconocen que cuando hay conflicto él puede ser un mediador eficaz y cuando se arma una pelea tiene gran poder de convocatoria; ha peleado con estudiantes más grandes y fuertes que él pero no tienen respaldo, debido a que sus barras son minoritarias; un alumno cercano a él dice que es incondicional.

Las autoridades escolares y policiales reconocen en las barras del fútbol un detonante que genera violencia en las instituciones, agravado con otras situaciones como el microtráfico y la delincuencia. Un incidente de este orden se presentó en el sur de la ciudad y fue difundido ampliamente por los medios. Se presentó como un enfrentamiento entre colegios, pero la realidad indica que los encapuchados que atacaron el colegio portaban uniformes de las instituciones mencionadas y mantuvieron en vilo a la comunidad escolar y barrial durante tres días, interrumpiendo la normalidad académica y la tranquilidad en los alrededores. Uno de los rectores explicó la situación, refiere que hay presencia de delincuencia común, microtráfico y barras bravas que alteran la buena marcha del colegio.

La reapertura de la sede principal del colegio (sede A) se dio con la presencia del Escuadrón Móvil Antidisturbios (Esmad) de la Policía, pero esto tampoco logró contener los ánimos de los chicos encapuchados que, armados con ladrillos y otros elementos, se tomaron la sede $\mathrm{B}$ de la institución, donde había estudiantes de primaria con edades entre 5 y 8 años, con lo que sembraron el miedo y la zozobra entre los habitantes del barrio y los padres de los niños, que fueron alertados de la situación. La preocupación mayor de la institución es que quienes han generado estos disturbios no solo quieren entorpecer la marcha del colegio, sino que el cometido es entrar por la fuerza en sus instalaciones: "Esta institución lleva incontables meses padeciendo un entorno de violencia externo que intenta entrar por la fuerza. El problema pasa por grupos de barras bravas, parches de chicos desocupados, microtráfico de drogas y armas: cuchillos, chuzos...” (Ardila, 2011). 
Pasa en muchos de los 128 colegios (100 privados y 28 públicos) que funcionan en la localidad de Bosa, con más de ciento veinte mil estudiantes. Hoy les tocó al Mazuera y al Carlos Albán Holguín, cuyo uniforme llevaban varios de los encapuchados el pasado martes. Por eso al principio la noticia oficial se limitó a hablar de una guerra entre instituciones. Pero para el rector, la situación es menos sencilla:

Lo que uno palpa es que en esto tienen que ver las barras bravas, la delincuencia común y el microtráfico, pero el problema es tan complicado que uno no puede entrar a identificar a nadie. iAh!, ies muy complicado meterse con esa gente! (Ardila, 2011)

Los incidentes que se presentan en las instituciones educativas suelen ser banalizados tanto por las autoridades como por la comunidad barrial y escolar, con lo que muchos de los problemas se salen de las manos porque no se atienden a tiempo. Este es un caso de los muchos que ocurren en la ciudad y que pasan desapercibidos. Para los estudiantes representa también una preocupación en el sentido de que se afectan directamente las relaciones, la disciplina, el desarrollo académico, y generan temor. Un estudiante miembro de la red de personeros escolares de Bogotá expuso al respecto:

La violencia juvenil al interior de las barras bravas es una de las formas de violencia más visibles en la sociedad colombiana, con mayor auge en las ciudades. En el Distrito Capital, la violencia juvenil de pandillas en las escuelas y en las calles, de barras bravas dentro y fuera de los estadios de fútbol, afectan el desarrollo humano y el progreso, ya que daña no solamente a las víctimas, sino también a sus familias, amigos y comunidades. Sus efectos no solo se ven en los casos de muerte y discapacidad, sino también en la calidad de vida. (Atencio, 2010, p. 13)

Los estudiantes identifican el fenómeno del barrismo como una de las situaciones que afectan el clima institucional de los colegios y dejan secuelas de diverso orden tanto en los estudiantes como en las familias, los barrios y las instituciones. Es afortunado que los mismos jóvenes han aprendido a analizar las problemáticas del entorno y expresar sobre ellas sus propias visiones. Cada vez se nota de manera promisoria una mayor conciencia de los jóvenes frente a los problemas escolares. La realización de esta investigación es rica precisamente porque 
reconocen las situaciones e intervienen de forma positiva para lograr soluciones efectivas.

Los estudiantes admiten que son ellos quienes buscan los problemas. Durante una entrevista con tres barristas del colegio 1, admitieron abiertamente ser consumidores de marihuana y popper. Al iniciarse el descanso comienzan a pasar los estudiantes hacia la tienda escolar y uno de los entrevistados le dice a los otros: "al parche de ese man lo tenemos azotado"; al interpelarlo por las razones, responde: "me caen mal, son de Santa Fe (E.C-8/1 sesión 3, febrero 20 de 2009). Tenerlos 'azotados' es buscarlos para pelear o armar conflicto por cualquier situación dentro del colegio, indica también que los persiguen en las calles y se amenazan, por lo cual mantienen a las instituciones en una tranquilidad precaria que estalla con facilidad. Asimismo, dicen que es común en el colegio el uso de lenguaje grosero, que suele ser motivo de discordia entre los jóvenes. En los registros de observación se encuentra el empleo del lenguaje soez como práctica de la cotidianidad escolar.

Eso hay veces se la montan, pero, echándole, es que en este colegio lo que se ve es madres pa' arriba y madres pa' abajo, ese es el vocabulario de este colegio, así es como se entienden acá, pues por eso mismo se ponen una camisa de Nacional y a uno del colegio no le gusta y a pues qué Nacional es esto, o que el que tiene la camiseta es esto y lo otro, entonces pues lo hieren a uno, o no que lo hieran, a uno no le gusta, lo subestiman a uno entonces, uno también responde, yo digo que es eso. (E.C-8/1 sesión 4, febrero 27 de 2009)

Los conflictos de escolares por cuenta del barrismo se presentan sin que para los adultos haya claridad de lo que pasa. El grupo del colegio 3 comentó al respecto que se han presentado episodios violentos por esta causa en el que grupos de hinchas de Nacional se han enfrentado a los de Millonarios, un grupo grande de los primeros ocupaba el edificio A y el otro el C: "Los de Nacional eran del A, y los demás eran de acá del C... se agarraba el bloque de allá contra este bloque... palos, sombrillas, de todo aquí dentro del colegio" (E.C-18/3 sesión 3, marzo 14 de 2009); al indagar por la actitud de los docentes frente a la situación afirmaron: "Esconderse, se escondían en la cafetería (risas)" 
(E.C-19/3 sesión 3, marzo 14 de 2009). La pelea finalizó por voluntad de los estudiantes, pero ellos informaron que

aquí en la tarde antes habían mil seiscientos estudiantes y se dividían entre este bloque y el bloque de allá, y en cualquier momento había un roce entre unos y ya después se mandaban era todos, y a la salida era peor. (E.C-18/3 sesión 3, marzo 14 de 2009)

Se evidencia de esa forma la intensificación del conflicto a la salida de las escuelas y la impotencia de los docentes frente a la violencia dentro de ellas, que puede convertirse en un acto masivo incontrolable dada la cantidad de población que ocupa los centros educativos.

Un aspecto importante para tomar en cuenta es que Bogotá viene implementando la modalidad de megacolegios, aquellos pensados para muchos estudiantes, con muy buena dotación en todos los sentidos: nutrida biblioteca, excelentes laboratorios de ciencia e idiomas, tecnologías para el apoyo de las clases, entre otras. Sin embargo, el número de estudiantes que albergan, que en muchos casos supera los mil por jornada, es lo que preocupa, dado que hay localidades que tienen tres o cuatro de estos edificios en el mismo sector, lo que sitúa en el mismo escenario una cantidad grande de población joven con todas sus problemáticas y diferencias relacionales. Esto produce conflictos entre instituciones que lleva en ocasiones a la confrontación.

$\mathrm{Al}$ respecto, Jordán y Segovia (2005) señalan que la Comisión Económica para América Latina y el Caribe (Cepal) revela que el $78 \%$ de los jóvenes latinoamericanos vive en ciudades y sufre las consecuencias de los problemas derivados de la concentración urbana, que para las autoridades nacionales constituye el principal problema de la juventud (p. 177). El problema de concentrar población joven a gran escala, amén de la ya altísima ocupación urbana en Bogotá, en barrios con dificultades, donde se ubican buena parte de los colegios oficiales, hace previsible la aparición de complejas problemáticas sociales relacionadas con la marginalidad, como hurto, pandillismo, violencia y otras conductas delictivas. La violencia es un problema de las sociedades actuales que ha alcanzado mayor visibilidad y los ámbitos de ocurrencia 
son aquellos en los que se presente interacción humana, es decir, cualquier lugar o contexto puede ser generador de una respuesta violenta.

\section{CONTRAVENCIONES JUVENILES EN LA ESCUELA}

En la legislación nacional se consideran las contravenciones juveniles como aquellas acciones cometidas por jóvenes que no constituyen un delito, pero que se asumen como comportamientos socialmente nocivos y perjudiciales en contra de quien los produce o contra la sociedad. En relación con este tipo de faltas y por efectos de la práctica del barrismo se reconocen como tales, en esta investigación, el vandalismo (escolar y en la comunidad), porte y uso de armas, distribución y consumo de sustancias psicoactivas (microtráfico dentro y fuera de las instituciones), riñas y hurto. Las amenazas y la intimidación proferidas contra niños y jóvenes, actos que en las instituciones educativas son muy comunes, no se consideran delitos en el sistema penal colombiano.

La implicación de los colegios en el tema de las contravenciones a la ley es directa. El Estado ha establecido que las instituciones educativas se convierten en el primer responsable de las situaciones en que se involucren los estudiantes, así como en las de carácter médico, hasta que aparezcan los padres y asuman su responsabilidad. Con relativa frecuencia los padres no acuden y son los docentes quienes deben acompañarlos ante las autoridades, algunos padres aducen incluso que ya están cansados de la situación. Los estudiantes señalan el hurto como una de las cosas graves que les pasan en los colegios, seguidas por las peleas dentro y fuera de la institución.

Por ejemplo, la institución 5 cuenta con "parches" que roban dentro del colegio, asaltan los casilleros y tienen una red que hurta teléfonos móviles y objetos de valor. Los estudiantes del grupo dicen que hay una pandilla en el colegio que roba para una banda del sector, organización criminal estructurada y de amplio historial delictivo, conformada por personas muy peligrosas e informantes.

Dentro y fuera del colegio hay pandillas y algunos estudiantes les comunican cuando alguien trae cosas de valor; cuando asaltan en la calle los pandilleros van de una vez pidiendo lo que uno 
lleva, por ejemplo, dicen: "entrégueme el celular o la cámara", es decir, esos van a la fija. (E.C-35/5 sesión 5, mayo 22 de 2009)

Los estudiantes refieren que les avisan desde adentro a los ladrones y que de esto han sido víctimas tanto estudiantes como docentes; relatan el caso de un profesor del colegio que fue atacado a la salida para hurtarle el computador. Sobre el particular, Berger y Lisboa (2008) explican que "en términos generales, se estima que entre el $3 \%$ y el $20 \%$ de los estudiantes se involucran en actos de agresión en contextos educativos, ya sea como víctima, o como quien ejerce el acto, o como ambos" (p. 15).

Se menciona con insistencia el porte de armas y las amenazas por parte de estudiantes que a través del amedrentamiento mantienen el control del colegio l. A los demás estudiantes y a sus víctimas les produce miedo enfrentarse con ellos, pues saben que hay otros más poderosos que les pueden hacer daño, por eso impera el silencio, no hay denuncia, simplemente las cosas pasan y nadie habla de ello. Un estudiante relató una captura que se presentó dentro del colegio en la que intervinieron agentes de las fuerzas de seguridad del Estado, "cuando sacaron a (nombre de un estudiante), que lo sacaron con metralleta, la policía entró acá... Encontraron una miniuzi y vino la policía, los del DAS creo que vinieron, entraron como cuatro camionetas y lo sacaron esposado y se lo llevaron” (E.C-18/3 sesión 3, marzo 14 de 2009).

Durante una de las sesiones fuimos informados de la presencia de armas en el aula en la que trabajamos, al parecer uno de los chicos porta una 'pate'cabra' en su bolso de libros, inicialmente lo niega, pero al final nos muestra el estuche de sus gafas, donde guarda esta arma, y se apresura a decir: "Eso no es mío, es de un amigo de $7 .^{\circ}$ que me la dio a guardar un día de requisa y no me la volvió a pedir, entonces la guardo para devolvérsela" (E.C-37/5 sesión 5, mayo 22 de 2009). Existen diferentes niveles de implicación de los alumnos con quienes cometen contravenciones, algunos se prestan para guardar armas o drogas, otros las ingresan, hay informantes, quienes cuidan objetos robados, quienes distraen a otros mientras son asaltados, quienes sacan objetos del colegio... 
Igual sucede con el tráfico de sustancias psicoactivas, hay expendedores y consumo en los colegios, pero se ignora por parte de las directivas de la instituciones, quienes lo saben prefieren mantenerse al margen porque para todos es claro que estas actividades dependen de organizaciones criminales muy peligrosas. Se conoce por los estudiantes que los sitios más comunes para el consumo de sustancias son los baños y las aulas:

En los baños se fuma marihuana y cigarrillo, hay gente que trae licor al colegio y se lo toman dentro de los salones, cuando alguien se da cuenta [de] que están fumando o consumiendo licor o drogas hay amenaza para que se queden callados. (E.C-44/5 sesión 5, mayo 22 de 2009)

A espaldas del profesorado se presentan peleas dentro del colegio, en las aulas a veces comienzan siendo un juego, pero terminan en agresión física fuerte. Los docentes no se dan cuenta de esto porque los estudiantes organizan estos enfrentamientos de tal forma que pueden ser avisados de su presencia. En ocasiones la pelea continúa en la calle y puede haber intervención de grupos fuera de la ley que apoyan a los estudiantes, pero eso no es gratuito (Registro sesión 5/5, mayo 22 de 2009). Pudimos observar un tumulto al ingreso a la institución: al acercarnos había dos chicos golpeándose con guantes de boxeo, como no había presencia de docentes en este sector procedimos a dispersar al grupo y nos llevamos a quienes peleaban, dado que pertenecían al NES sobre barrismo. Al preguntarles sobre las razones que los llevan a esta práctica, admiten que "eso es normal, los grandes también lo hacen, ya nos han decomisado los guantes, pero nos los devuelven y los volvemos a traer escondidos" (E.C-44/5 sesión 5, mayo 22 de 2009).

En las instituciones visitadas los manuales de convivencia contienen las sanciones para este tipo de situaciones; en el caso mencionado las peleas eran organizadas y se salían de control, pues los que se implicaban tenían algún motivo o una cuestión pendiente por resolver. Los chicos admitieron que esta misma práctica la realizan en un parque cercano al colegio y mencionaron algunos elementos que se utilizan en las confrontaciones dentro del colegio y en las calles, además exponen que están amenazados y que los portan porque necesitan protegerse (Figura 21). 
Figura 21. Porte de armas y elementos usados en el conflicto escolar y barrial
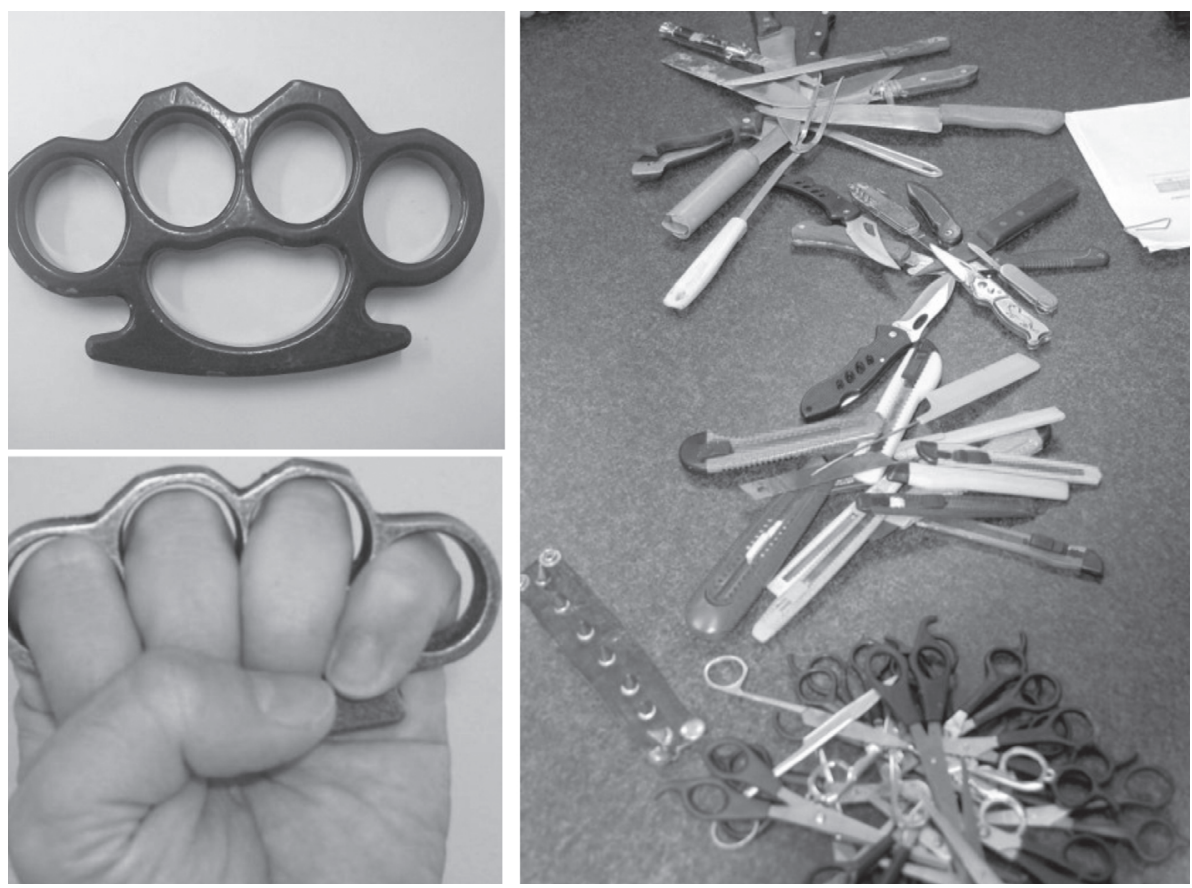

Estos elementos fueron mencionados por los estudiantes como los que se llevan a una confrontación escolar y barrial: armas blancas (pate'cabras, bisturí y cuchillo); elementos contundentes (manoplas metálicas). También se refiere porte de revólveres y cadenas. En una jornada de sensibilización sobre el porte de armas, realizada por la Secretaría de Educación de Bogotá, se informó que "se han visitado once colegios de las localidades de Tunjuelito, Ciudad Bolívar, Kennedy, San Cristóbal, Engativá, Los Mártires y Usaquén. En las acciones realizadas se hallaron 5 puñales, 27 navajas de las comúnmente conocidas como 'pate' cabra"' (2008).

Los estudiantes implicados se remitieron a los comités de convivencia a efectos de establecer las sanciones, el control y el seguimiento. En lo que respecta al colegio, entraron en un proceso de acompañamiento por parte de las autoridades. La escuela se doblega, es sometida por el temor, los docentes se repliegan para escapar de la violencia y mientras tanto afuera se va colonizando el espacio, se va apropiando, se 
vende y se compra a voluntad en tanto permanecemos de espaldas a la realidad que nos sobrepasa.

El porte de armas en algunos casos está relacionado con la necesidad que tienen ciertos jóvenes de sentirse superiores frente a los demás. El que lleva un arma se gana el 'respeto de los otros', nadie se mete con él por miedo. Un joven dice que

la mayoría de los estudiantes porta armas, sobre todo las que son armas blancas. ¿Porque las portan? Porque se sienten más grandes que otros y también en un caso de pelea las usan para defenderse, esas son algunas razones por lo cual los estudiantes usan armas (E.C-23/4 sesión 5, mayo 22 de 2009)

Es preciso establecer que, si bien en la escuela hacen presencia diversas formas de violencia, el fenómeno de las barras del fútbol emerge como un problema que afecta la dinámica escolar, al punto que pudiéramos considerarlo un detonante que en determinadas circunstancias constituye hechos de violencia generalizada, o sencillamente es el pretexto para agredir a otros que consideran sus enemigos por diferentes situaciones dado que se ha comprobado la vinculación de jóvenes escolarizados con bandas y pandillas. 


\section{BARRIO Y CIUDAD: \\ LOS TERRITORIOS DEL BARRISTA}

\section{VIOLENCIA URBANA}

Desde la década de los ochenta América Latina ha venido experimentando un crecimiento urbano acelerado, especialmente en países como Argentina, Chile, Uruguay, Brasil, Venezuela y Colombia, no así en el resto de ellos. Giraldo, García, Ferrari y Bateman (2009) acotan:

En aquellos países en los que se produjo, el proceso de urbanización se caracterizó, al igual que en otras latitudes, por un proceso de transición demográfica; un cambio en la estructura económica y un mayor crecimiento económico; un mejor acceso a servicios y bienes públicos; $y$, de manera agregada, un incremento del desarrollo humano. (pp.150-151)

Es decir, la población tuvo acceso a un mejor nivel de vida donde se redujeron los índices de mortalidad/natalidad, e igualmente hubo mejoría en las condiciones económicas que se sustentaron sobre todo en el desarrollo industrial. En el caso particular de Colombia, el DANE indica que el país

está atravesando por la etapa del "bono demográfico" o "ventana de oportunidad", que es aquel período en que la proporción de personas en edades potencialmente productivas crece de manera sostenida en relación con la de personas en edades potencialmente inactivas, cuyo inicio se remonta al año $2005 y$ podría prolongarse durante diez años. Esto le plantea al Estado retos para fortalecer el acceso de los y las jóvenes a la educación, la salud y el bienestar social, entre otros, para que ellos puedan tener un papel transformador de la sociedad, particularmente la ruptura de los círculos de pobreza que se transmiten de generación en generación. (Secretaría Distrital de Hacienda, 2013, p. 19) 
Este proceso está acompañado por rápida urbanización de las ciudades, la cual concentra gran cantidad de población en centros urbanos que demandan acceso a servicios, sociales, laborales, entre otros, con lo que se congregan las carencias y problemas de las personas. Esto implica el decrecimiento de la población joven en relación con la disminución de los índices de natalidad y el envejecimiento de la población, es decir, se está registrando un relevo poblacional. Asimismo, a diferencia de otros Estados latinoamericanos como Chile, Perú o Uruguay,

un solo gran centro urbano concentra la mayor parte de la población y la actividad económica; en Colombia coexisten, en segundo lugar y como anunciamos, al menos cuatro centros urbanos de importancia, lo que ha dado lugar a que éste se conozca como un país de ciudades. (Giraldo et al., 2009, p. 153)

Con la urbanización vertiginosa de las ciudades latinoamericanas resulta previsible la aparición de la violencia urbana, que se expresa de diversas formas, bien como acciones de hecho o en las formas de habitar, donde la exclusión y la desigualdad están presentes. Monsiváis (1999) define la violencia urbana como "el amplio espectro de situaciones delincuenciales, ejercicios de supremacía machista, ignorancia y desprecio de los derechos humanos, tradiciones de indiferencia aterrada ante los desmanes, anarquía salvaje y desconocimiento de la norma" (p. 3). La violencia urbana es también una trayectoria en la que se ha dejado pasar por indiferencia situaciones de carácter ciudadano que son inadmisibles en las relaciones de las personas; no en vano muchos de estos comportamientos, como dice Monsiváis, son anárquicos y expresan el desconocimiento de todo límite, pero también hay aspectos de ella que inmovilizan, que impiden la reacción colectiva.

Algunas situaciones pueden constituirse en predictores de las manifestaciones del delito, por ejemplo, que las personas tengan acceso a drogas y armas. Velásquez \& Giraldo (2009) explican que gran parte de los lugares en la mayoría de las ciudades son seguros y que "la mayor parte de los delitos comunes callejeros tienden a ocurrir repetidamente en ciertas zonas - hot spots- que son bien conocidos por los ciudadanos y por los funcionarios públicos. Son, por lo tanto, eventos 
razonablemente predecibles" (p. 25). Al ser un fenómeno vigente en las sociedades de hoy, puede hacer presencia en cualquier espacio de las ciudades a través de diferentes fuerzas que se conjugan para crear el caos.

En Colombia, asevera Perea (2004), "más de la mitad de los homicidios cometidos tienen como asiento la ciudad" (p. 142), y contrario a lo que pudiera creerse, la violencia de las ciudades produce más muertes que el conflicto armado. Los jóvenes son reconocidos como los principales generadores de la violencia urbana, por ello se habla de violencia juvenil urbana al describir la violencia que ejercen los muchachos. Las razones que se esgrimen para considerar esta idea se relacionan con la vulnerabilidad juvenil, por ejemplo, a las presiones de grupo que les exigen manifestaciones de fortaleza y ser aguerridos, lo que los hace proclives a este tipo de expresiones. Los hinchas del fútbol sienten que deben defender el honor de sus equipos aun a costa de la propia vida, al pertenecer a estos grupos buscan constituir una identidad colectiva que los diferencie de los demás. De esta forma aparece la violencia como una necesidad de pertenencia y reconocimiento; ser reconocido por el uso de la fuerza posiciona frente a los iguales, como señalan Berger y Lisboa (2008), "la violencia aparece asociada a la popularidad en la adolescencia” (p. 285).

Monsiváis (1999) admite en la violencia urbana tres elementos fundamentales: "Es la combinación de atmósferas del temor creciente. Se pierde el uso confiado de la calle, la certeza de la impunidad, las megalópolis que generan presiones devastadoras, para empezar, sobre los sectores populares" (p. 3). Los hechos de violencia tienden a banalizarse en relación por ser actos de común ocurrencia y que se haga lo que se haga jamás recibirán castigo, producto de las dinámicas que se dan en las grandes ciudades. García y Guerrero (2012b) encuentran que algunas causas de la inacción se asocian a "la ineficacia y la corrupción, la debilidad institucional[,] que hacen que los cuerpos policiales tengan que competir con poderosas organizaciones criminales, que permanentemente amedrentan e interfieren la acción de la justicia” (p. 56). 
Un tema que adquiere importancia en las ciudades, no solo en Colombia sino en muchas partes del mundo, es la seguridad. Cada día es más notorio que las formas de urbanización y fenómenos como el conflicto han ido construyendo un imaginario de ciudad en el que la idea de vulnerabilidad siempre está presente, manifiesta en las maneras de habitar, de percibir el entorno. Como afirma Perea (2005), se vive un "sentimiento que expresa la incertidumbre ante un orden donde se precarizan las condiciones de trabajo y las políticas públicas de bienestar" (p. 18). El miedo es una sensación permanente en cualquier ciudad del mundo, es una inquietud generalizada por los avances del terrorismo y la violencia, en todo caso se manifiesta mayor interés por estos temas, dada en especial por la sensibilidad que despiertan en la gente, así como por la difusión que hacen los medios de comunicación. Velásquez y Giraldo (2009) afirman que "en América Latina los medios juegan un papel clave al construir la imagen de temor, de inseguridad y de violencia debido al cubrimiento fenomenal y, a veces, sensacionalista, que se otorga a la violencia juvenil y a las pandillas juveniles" (pag. 155). De esta forma la percepción de inseguridad se convierte en certeza.

\section{JÓVENES:}

\section{FORMAS DE HABITAR Y APROPIAR EL ESPACIO BARRIAL}

Conceptualizar el barrio implica el abordaje de diversas nociones desde diferentes perspectivas. Buraglia (citado por Franco, 1999) define el barrio como "una unidad de análisis socio-espacial, es decir como formas específicas y relativamente autónomas de organización espacial que operan como reguladoras de las relaciones sociales" (p. 3); de este modo, se refiere al barrio como un organizador o estructurador de las relaciones sociales, e indica además que "estas formas de organización espacial son vistas como el soporte de determinados modos de vida y por lo tanto el análisis se enfoca hacia las relaciones que establece el espacio construido con dichos modos de vida" (p. 3). El concepto implica la relación del espacio con la vida, la forma como las personas lo reconocen y lo apropian; desde una mirada cultural el barrio es "el lugar de confluencia y comunicación: las calles, esquinas, 
tiendas y puertas de las casas representan centros de sociabilidad popular y encuentro comunicativo" (p. 3). El significado de los espacios barriales se orienta hacia lugares que son comunes o que hacen parte de las situaciones de vida que para el habitante guardan relación con hechos particulares de la experiencia comunitaria. Se expresa así una visión multifacética del barrio que concluye con el reconocimiento de lugares significativos, de modos de vida y espacios de vinculación habitual que constituyen en últimas procesos relacionales a través de los cuales se integran para conformar comunidad.

El barrio describe, para quien lo habita, unos lugares de confluencia en los que se estructuran procesos de identidad y socialización que denotan pertenencia y se van identificando por sus mismas particularidades; los hitos barriales guardan para sus habitantes unas significaciones que solo a ellos interesan y que valoran por las situaciones de vida transcurridas en ellos.

Los sujetos hacen su primera asociación con el barrio cuando lo recorren y descubren toda la oferta que tiene para ellos, aprenden a integrarse a los espacios, a usarlos, y los apropian de diferentes modos. Los jóvenes, por ejemplo, desarrollan formas significativas de asociación que les permiten vincularse al espacio barrial, se identifican el 'parche' y la pandilla como expresiones juveniles genéricas que se adoptarán también, en este caso en el estadio, que expresarán e identificarán con símbolos ideados para ello; el tamaño del parche expresará el nivel de compromiso con la barra en tanto logra vincular a un buen número de jóvenes con los que pueda hacerse notar en la gradería y demostrar su poderío. El parche está constituido por chicos cuya procedencia es el mismo barrio o localidad, establecen relaciones de amistad y su objetivo es representar al barrio y representarse a sí mismos como miembros activos, decididos y aguerridos en el estadio y el barrio.

Cuando se habla de parche no solo se alude al grupo de amigos, parche también es el lugar de encuentro, la esquina, 'vamos a parchar' es la expresión que invita al encuentro, un modo de organización que denota una vinculación ligada al territorio, no es un simple corrillo de jóvenes, es también una forma de habitar que se apropia de los espacios barriales. Perea (2008) explica que el parche "es una forma de 
pertenencia radical ofrecida por el barrio popular, llama al otro lado susurrando que todo está perdido, enrostrando la soledad y la incertidumbre para ofrecer a cambio, sentido e inclusión" (p. 33). El parche es lo evidente de la soledad, es la socialización de los tiempos que se construye en la calle; el parche entroniza la búsqueda de sentido y su utilidad radica en la posibilidad de sentirse parte de algo y poder afrontar juntos la incertidumbre. Pérez y Mejía (1999) conceptúan que el proceso de conformación

se describe mejor a través de una figura en espiral, cada organización se nutre de la anterior y, al tiempo, conserva algunos de sus rasgos. En la pandilla está la gallada y en ésta el parche. La banda se alimenta de jóvenes que integran pandillas, galladas y parches. (p. 79)

La pandilla constituye un fenómeno urbano de presencia significativa en la ciudad. Anteriormente el termino podía incluir por igual a agrupaciones de amigos dedicados a cuestiones culturales o actividades delictivas, sin embargo, con el paso del tiempo y la mayor dedicación al delito el concepto se ha generalizado para identificar a los jóvenes que se organizan con la finalidad de delinquir o que se ponen al servicio de otras estructuras a fin de cometer delitos.

Es importante aclarar que en la actualidad el término 'parche' se emplea al identificar a cualquier grupo de jóvenes que aparentemente no realiza ninguna actividad y que en las comunidades resulta incómodo, es la estigmatización del joven, se utiliza el término de forma peyorativa para identificar la reunión de muchachos. Perea (2005) diferencia al pandillero, cuando explica que "al pandillo lo define la transgresión violenta... Sus prácticas conflictivas tienen patrones definidos, los que le dan un lugar preciso en los espectros del crimen y la violencia en la ciudad: el pandillero es uno más de los protagonistas de la inseguridad urbana, no su personificación” (p. 8) De esta forma, el pandillero y la pandilla son parte de las expresiones delictivas urbanas que se asocian con la inseguridad, sin que ello implique la identificación del joven como imagen del crimen y el delito.

Las comunidades reconocen a los parches como generadores de conflicto y desorden barrial, los asocian con pandillas, marihuaneros y la- 
drones en una simbiosis del término que profundiza aún más el estigma; esto hace que los jóvenes se sientan excluidos de sus comunidades y no les gusta que los vecinos hablen mal de ellos; así mismo, sienten que el colegio no es importante para la vida barrial. Los jóvenes tienen claro que ellos son los que han generado tal situación, conocen las razones por las cuales su comunidad los repudia; cuando se les pregunta cuál es la imagen del colegio en el barrio responden: "Pues ¿̇qué?, normal; siempre decían que el colegio era muy violento, casi uno de los colegios más violentos acá en la localidad" (E.C-18/3 sesión 5, marzo 6 de 2009); tampoco aceptan que los identifiquen con apelativos denigrantes, por ejemplo, 'gamín' o ‘ñero', como se les conoce en el barrio por los conflictos y enfrentamientos que generan.

Los jóvenes parcero y pandillero constituyen la imagen transgresora del barrio, enrostran problemas sociales que aún no se resuelven y deambulan en busca de actividades gratificantes como la reunión con amigos, el juego del fútbol improvisado con sus propias reglas, y algunos buscan oportunidad para lanzarse al robo y al atraco. Muchos de estos parches han asumido su propia defensa y consideran el uso de la violencia como una forma legítima de responder a las amenazas del entorno, es por ello que la pertenencia al parche es más un acopio de fuerza, de fortaleza, en la que encuentran seguridad y apoyo en todo sentido.

Por otra parte, los chicos participantes reconocen sus barrios como espacios problemáticos:

Mi barrio es una porquería (un pichal)2. ¿Por qué? Primero que todo no está pavimentado, segundo no hay seguridad, tercero los vecinos son una porquería, bueno..., la mayoría, y la razón de esto es la desconfianza, puesto que nació de gamines, mejor dicho, se encuentran muchas pandillas y entre ellos rateros $y$ violadores. (E.C-14/2 sesión 7, marzo 20 de 2009)

El estudiante informa en este relato el origen del barrio y las relaciones de vecindad, al igual que las condiciones físicas de su entorno. En la descripción de este joven se percibe, por ejemplo, la situación de

2 Pichal: regionalismo utilizado en Colombia para identificar una zona anegada o inundada en la que hay barro. 
violencia barrial y la diferencia que hace de esta con respecto al día y la noche. Esta narración la hace un chico de una localidad que tiene uno de los más altos niveles de criminalidad de la ciudad: "El barrio donde vivo es pasivo de día porque están trabajando y los jóvenes estudiando, pero en la noche a veces hay problemas, me disgusta cuando hay muertos”. Al interrogarlo en torno a cómo le gustaría que fuera su barrio, indica: "Ojalá que no hubiera muertes ni problemas y todos sean amigables en el barrio y en los juegos" (E.C-1/1 sesión 7, marzo 13 de 2009). Los jóvenes reconocen las dinámicas de sus barrios y han aprendido a manejarlas, ubican con facilidad los sitios significativos y los utilizan, tales como parques, centros comunitarios y los sitios conflictivos.

Algo que se destaca en los relatos de los jóvenes de las localidades estudiadas es la experiencia con la muerte, tanto en el colegio como fuera de él. Las muertes dentro de las instituciones, según informan estudiantes y docentes, se han producido de manera accidental, pero han sido de gran impacto para la comunidad escolar. El tema de la muerte está presente en la dinámica local y barrial, pues muchas veces ha sido presenciada por los jóvenes, bien como una situación que ha afectado a la familia, o por ser de común ocurrencia en su entorno. Es también un relato sobre la implicación de los estudiantes con grupos que ejercen la violencia en sus comunidades y de la cual el joven escolar ha sido objeto. Las narraciones de muerte incluyen de manera reiterativa las acciones de eliminación sistemática de jóvenes en las localidades por considerarlos responsables de alterar la convivencia. Esta práctica se emplea para atemorizarlos y producir escarmiento.

El mapa del recorrido barrial del E.C-20/3 sesión 7, abril 18 de 2009, identifica los lugares conflictivos alrededor de la institución. Se observa la presencia de pandillas y grupos de ladrones, atracadores que esperan a los estudiantes a la entrada y salida de la jornada escolar, expendio y consumo de sustancias en la zona externa aledaña al colegio, y refiere también el porte de armas por estos grupos y los escolares, al igual que un sitio señalado por la comunidad como espacio donde han ocurrido violaciones sexuales. Los parques son elementos del territorio que identifican a los grupos que los ocupan, pues estos los han demarcado para dicho fin. 


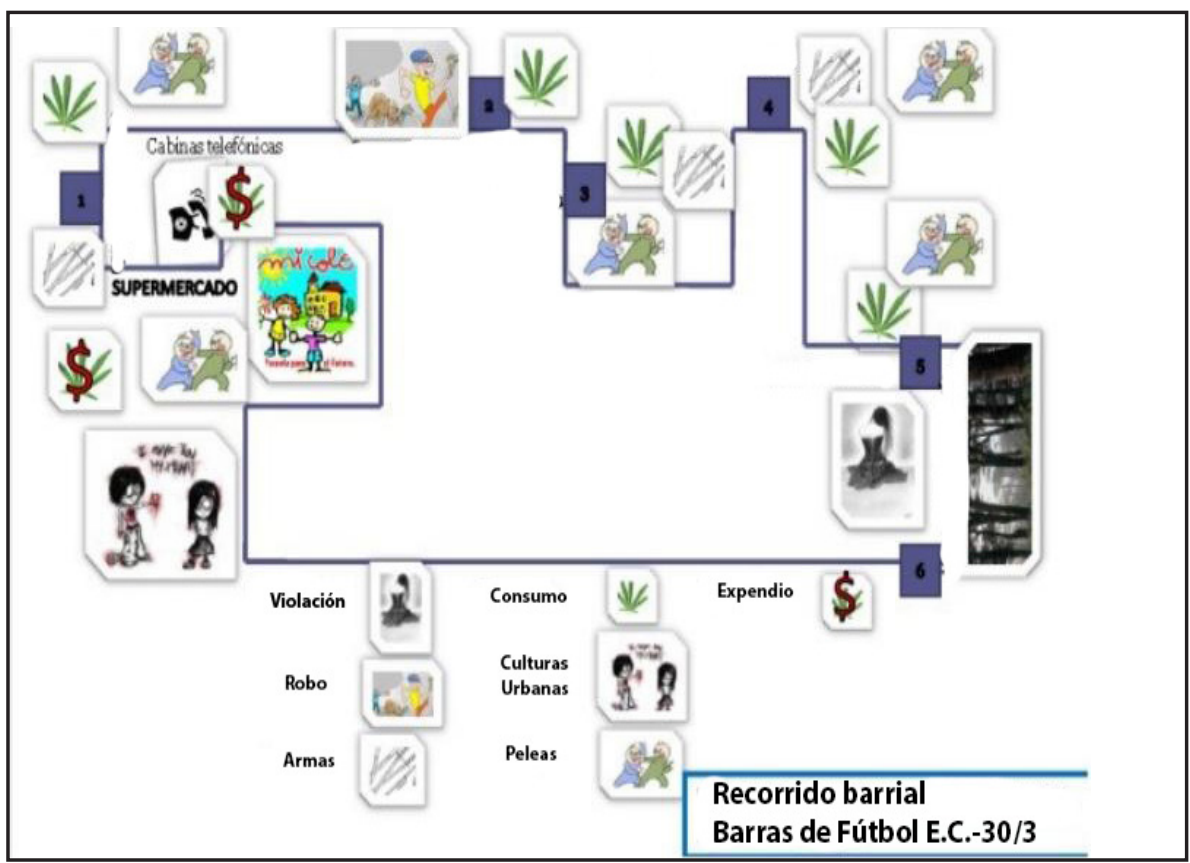

\section{EL TERRITORIO.}

\section{ACEPCIONES Y PARTICULARIDADES PARA EL BARRISTA}

"El territorio es pues, un texto que hay que saber leer, un texto que nos conforma, que nos descifra.

No solo porque 'dentro de cada persona y cada cosa, en cada resquicio y grieta del mundo, hay sabiduría', sino porque ya nos enseñó la semiología que los procesos de enunciación son procesos de configuración de sujetos. El primer saber que nos trasmite el territorio es el de unidad y diversidad".

Gloria Restrepo (Aproximación cultural al concepto de territorio)

Los jóvenes, en este caso los seguidores de equipos de fútbol, valoran y dan vida a los territorios que habitan, bien sea el barrio, la escuela, el estadio, la gradería, el campo de juego y el cuerpo mismo; han construido en él un entramado relacional que vincula las angustias, los dolores y la miseria; también, alegría, logros y sueños. El territorio está constituido de momentos compartidos y soledades, de vida y muerte, 
por eso es tan valioso. El territorio es un espacio difuso para el común de la gente, la mayoría de las veces no se tiene conciencia de él, por eso pasa inadvertido en la vida cotidiana. No es así para el barrista: marcar una calle o un espacio tiene un sentido y es sostener la supremacía sobre él, que en últimas expresa identidad y apropiación del mismo. Restrepo (1998) expresa de manera muy hermosa la concreción del concepto 'territorio':

El territorio es pues, espacio y tiempo que fluyen y permanecen, es decir, que cambia; se parece a cada uno de nosotros, que de alguna manera somos también espacio y tiempo materializados en el pequeño territorio de nuestro cuerpo. Visto así, el territorio es una relación entre vida natural y vida humana, entre pasado y futuro. (s. p)

Un hecho ocurrido en una de las instituciones investigadas es buen ejemplo de ello: un bloque lo ocupan los estudiantes seguidores de una facción del equipo Millonarios, en el otro hay diversidad; durante los descansos los docentes ocupan un espacio que será en el futuro la biblioteca y se encuentra al frente. La presión de los alumnos ha sido tal que los profesores observan desde las ventanas el transcurrir del descanso: los muchachos son los dueños del patio, que es en ese momento expresión de propiedad y superioridad frente a las otras barras que se ubican por fuera del perímetro, los grupos de Millonarios han ocupado las canchas y las van rotando por turnos a otros estudiantes seguidores del mismo equipo; es también la expresión de rebeldía de los chicos, que no admiten la presencia de los adultos en el patio porque no confían en ellos. Aquí las relaciones entre estudiantes y docentes son difíciles, ha habido agresiones y amenazas, e incluso confrontación de docentes con estudiantes. Al mencionar el tema a los docentes, explican que han visto marcas de equipos en los edificios revelando la presencia de grupos de fanáticos, pero la mayoría de ellos no tiene claro el significado de ellas.

La territorialidad es un concepto derivado del territorio; dicen los etólogos, herencia de nuestra animalidad. Sack (1986) manifiesta que la territorialidad es "una conducta humana que intenta influir, afectar o controlar acciones mediante el establecimiento de un control sobre un área geográfica específica: el territorio” (p. 19), corresponde por tanto 
a las acciones humanas que suceden dentro de ese territorio que de algún modo representan una interacción social. El autor indica que la territorialidad humana cumple cuatro funciones:

- Fortalecer el control sobre el acceso.

- Reificar el poder a través de su vinculación directa al territorio.

- Desplazar la atención de la relación social de dominación.

- Actuar como contenedor espacial de hechos y actitudes.

Así se evidencia que

la territorialidad es construida socialmente. Es un componente necesario de toda relación de poder, que, en definitiva, participa en la creación y mantenimiento del orden social, así como en la producción del contexto espacial a través del que experimentamos el mundo, legal y simbólicamente. (Sack, 1986, s. p.)

Esta experiencia del territorio apropiado por los jóvenes, barristas o no, es lo que los identifica con él y les permite realizar procesos de socialización.

En esta investigación la territorialidad no se circunscribe únicamente al espacio físico del barrio o de la institución escolar. Sostenemos que la barra lo es también, dado que representa, en el caso de los parches, la identidad barrial y colectiva que se concreta en la tribuna. Es la presencia de una fracción de ciudad puesta en el estadio al servicio del equipo, por ello cada grupo se esmera en elaborar sus distintivos, en hacerlos más vistosos, más grandes, para que se aprecien; son útiles también para demarcar un espacio que les dará reconocimiento en el estadio y fuera de él. En esto consiste también el conflicto barrial.

Entendemos el territorio como una construcción social, un límite o una frontera que individualiza y nos hace diferentes social, cultural y políticamente. Creemos, como dice Ardila (2006), que

hay una territorialidad inmediata que es nuestro cuerpo; un segundo nivel que se define por las relaciones íntimas con nuestros allegados más cercanos a quienes, por lo general, llama- 
mos familia; un tercer nivel se define como la comunidad, esa unidad mínima con la que compartimos un universo de significados; un cuarto nivel consiste en la unidad mayor en la que se articulan las pequeñas comunidades locales que forman una sociedad. (pp. 14-15)

Esta forma de comprensión del territorio resulta clave para definir la experiencia que el barrista vive en cada uno de ellos. Analizar el cuerpo como territorio significa adentrarse en la incertidumbre que plantea el mundo actual. El cuerpo es expresión de la situación misma de la sociedad y del individuo, es el depositario de las contradicciones y ambigüedades sociales, del sinsentido que desubica al sujeto en el mundo. El cuerpo en el fútbol es territorio por cuanto es la expresión de la identidad barrial y de la pertenencia a la fanaticada, con el cuerpo se confronta y se efectúa la entrega del sujeto a su equipo. El cuerpo descamisado es la imagen del guerrero, del que está dispuesto a todo. El cuerpo tatuado es la máxima identificación con el equipo. En la contienda futbolera se puede perder todo, la bandera, los objetos propios del festejo, lo que sea, pero no se puede arrancar la piel, no se puede arrancar al equipo que se lleva dibujado, más allá de la significación del tatuaje lo primordial, el amor por el equipo, está en el alma. El cuerpo constituye así una prolongación del territorio físico del barrio que se lleva al estadio para el encuentro:

Para mí la palabra 'barra' es un grupo de personas que forman una parte de un barrio, como por ejemplo, marcar de dónde viene ese grupo y que las demás barras sepan de dónde se viene; también se puede decir que es grupo de hinchas que están en las buenas y en las malas, cantando al equipo para que sepan que lo están apoyando (E.C-25/4 sesión 3, mayo 8 de 2009) (Barra como territorio)

Desde el punto de vista del territorio de significados, la violencia que ejercen los barristas en el espacio barrial, con el pretexto de la defensa territorial, tiene un componente simbólico y otro vital, como lo expresa Imbert (1992): "La violencia, está ligada a la noción de territorio: espacio físico (vital, existencial) y espacio simbólico (de identidad), y de representación (espacio urbano y espacio político), espacio lúdicoutópico" (p. 197). Territorios como la escuela se han constituido en puente para solucionar algunos conflictos personales: 
Actualmente mi colegio es grande; parece una cárcel, porque por fuera parece una cárcel; por fuera es grande, tiene cafetería, biblioteca, también tiene sitio para almorzar. Mi colegio es uno de los refugios míos para salir un poco de la monotonía de la calle, de los problemas con la barra. (E.C-39/5 sesión 7, mayo 29 de 2009)

En los colegios, como en la ciudad, los barristas tienen diferentes sitios de procedencia. Bogotá es la ciudad en la que confluyen facciones poblacionales de diversos sectores del país y que han llegado aquí por motivos que van desde el simple traslado de residencia hasta el desplazamiento forzado. El barrista tiene claro que esta es su ciudad y que son minoría. Por ello el concepto de territorio está muy arraigado, creen que tienen el deber y la obligación de hacer respetar su localía, frente a lo cual los demás grupos de barristas son segregados y deben asumir una actitud sumisa en el espacio del estadio, en los barrios y las localidades que no les pertenecen. Esto es lo que se ha denominado regionalización del deporte, que es quizá una de las razones más contundentes para el enfrentamiento entre los barristas. Los barristas foráneos son considerados provincianos y la vinculación de personas de Bogotá a estas barras se considera una traición, al punto que han desarrollado un odio visceral contra ellos, que se cobra con fuerza en el conflicto barrial. Al respecto un estudiante confirmó que

el deber es cantar y tratar de dejar callada a la otra hinchada para silenciar a los de Nacional, o sea cantar en todo momento y no darle oportunidad a los otros, hacer sentir que estamos en casa, como para bajarles el ánimo a los jugadores de allá. (E.C 28/4 sesión 2, abril 24 de 2009)

La violencia en la ciudad ha tenido repercusiones que se sienten en la escuela. La situación por la que atraviesan algunas escuelas ha conducido a que las autoridades escolares recurran a diversas formas de control para poder realizar algún tipo de manejo de la violencia dentro y fuera de ellas. La presencia cada vez más frecuente de contingentes policiales, ubicación de cámaras dentro y alrededor de los colegios, es la muestra fehaciente de que las cosas no son fáciles.

Finalmente, un último territorio es la tribuna; allí se escenifica la fiesta del fútbol, es el espacio sagrado y consagrado, aquí convergen fac- 
tores futbolísticos y extrafutbolísticos que incitan a la violencia; los grupos se ubican siempre en la misma gradería, lo cual hace que la pertenencia del espacio sea una realidad. Los elementos simbólicos constituyen significatividad a medida que identifican a la barra, el barrio y el parche; en este espacio se construye la relación de 'nosotros' y 'ellos' que busca en la expresión de la ritualidad diferenciarse los unos de los otros. 


\section{Conclusiones y RECOMENDACIONES}

Estamos ante una juventud que ha desarrollado, más que en cualquier otro tiempo, habilidades para interrogarse acerca de las cuestiones que les afectan sobre su papel político y la exigencia de sus derechos o su lugar en la sociedad, lo que ha llevado a que se manifiesten en contra de la inequidad, la desigualdad, la exclusión y la injusticia, situaciones de las que ha sido víctima y que han resquebrajado las certezas que todos necesitamos para creer en el futuro. Esto ha reforzado su desconfianza en las instituciones y alimenta la percepción de que todo está perdido.

Los jóvenes atraviesan por un proceso de desciudadanización, caracterizado porque la persona no siente que se le reconocen sus derechos $y$, por el contrario, se percibe fuera de la sociedad y de los compromisos que ella le impone, esto trae consigo desaliento cuando no encuentra nadie a quién recurrir, lo cual ha hecho que pierda incluso el sentido de su propia existencia. El joven es un sujeto al que cada día se le dificultad más la concreción de su proyecto vital.

La situación actual de la población juvenil en el contexto latinoamericano es deficitaria. Asistimos a un deterioro paulatino de las condiciones de vida que se manifiesta en la ampliación de la brecha de pobreza, cuyas características más visibles son el bajo acceso a la educación, precarización del empleo e incertidumbre hacia el futuro.

Los medios de comunicación han producido una sobreexposición mediática de las problemáticas juveniles, al punto que han construido una imagen colectiva que se asocia a peligrosidad e inseguridad, formas desde las cuales se legitiman ataques y amenazas a jóvenes e incluso prácticas de eliminación sistemática al vincularlos arbitrariamente con grupos al margen de la ley. 
La intolerancia en contra de los jóvenes se presenta de muchas formas, en los barrios, en las escuelas, en la ciudad. Algunas veces se manifiesta con situaciones de hecho, otras mediante un estricto control social barrial que busca intervenir en las dificultades que presentan los muchachos considerados problemáticos, el impedirles la circulación (toque de queda para menores) e incluso la limpieza social, que ataca de raíz eliminando al sujeto, con lo que se cree estar erradicando un problema que en realidad es político y estructural.

Las violencias escolares están asociadas básicamente al robo. En los últimos tiempos se ha pasado del hurto de pequeños objetos a la participación de alumnos en redes de robo de objetos como teléfonos móviles, computadores portátiles y otros, organizadas por bandas delincuenciales que inducen a los escolares al delito.

Los estudiantes que hacen parte de los grupos de barristas en la ciudad son señalados como instigadores de la violencia escolar, unidos ejercen el matoneo para amedrentar o contrarrestar las acciones de los contrarios, generan tensión que se traduce en respuesta violenta; dentro y fuera de las instituciones amenazan e insultan a los hinchas de otros equipos, y sus relaciones con los docentes son conflictivas, para la comunidad constituyen un factor más de inseguridad.

En Bogotá las barras futboleras están conformadas heterogéneamente. No se puede afirmar que las circunstancias sociales de pobreza, marginalidad, desempleo, sean condición suficiente para la aparición de la violencia; consideramos que esta se produce por diversas causas, bien por el tipo de relaciones intergrupales que se producen, por infiltrarse en la barra grupos interesados en producir desmanes en los estadios y sus alrededores, por las dinámicas mismas del espectáculo, por la vinculación de otros actores a quienes interesa que el espectáculo del fútbol se desarrolle de una manera que beneficie a personas ligadas al fútbol...

Más allá de establecer las causas que conducen a los jóvenes a participar en hechos de violencia juvenil, la tarea primordial ha de ser la prevención dirigida desde diversos ámbitos sociales, a fin de evitar que 
se conviertan en infractores de la ley. El Estado, la escuela, la familia, la comunidad barrial y local están llamados a proveer y garantizar el desarrollo adecuado de niños y jóvenes que requieren un trato diferenciado mediante políticas aplicables y eficaces.

Los jóvenes en la ciudad, por sus acciones y por efectos mediáticos, constituyen la cara de la inseguridad, pero son asimismo vulnerables, muchachos que se forjan con graves dificultades en su tránsito generacional, expuestos a riesgos por su misma condición, que encuentran en la violencia una forma de manifestar su descontento por las diferentes problemáticas que afrontan, específicamente desigualdad y exclusión.

Un problema que fue mencionado reiteradamente en las cinco instituciones analizadas es el del porte y uso de armas por parte de los estudiantes, lo cual refleja la situación que vive en la ciudad, donde cualquiera tiene acceso a un arma debido a la falta de control de las autoridades. También existe gran preocupación por el consumo y distribución de sustancias en los colegios.

Por su parte, el fenómeno del barrismo ha ido tomando rumbos insospechados en la ciudad y en el resto del país. Al inicio las autoridades intentaron contenerlos, pero en la actualidad mantener el control se ha convertido en un problema de orden público que requiere la organización de grandes operativos policiales dentro y fuera de los estadios. En estos grupos las luchas por el poder mantienen enfrentadas a las facciones que componen la barra y el fútbol se ha convertido en una excusa para resolver otros asuntos.

Se requiere que cada uno de los actores del espectáculo futbolístico devele en forma definitiva la responsabilidad que tiene en el escalamiento de la violencia. En primer lugar, la dirigencia de los clubes deportivos, la cual sostiene a las barras con dádivas como boletas, viajes, trapos, ropa deportiva de marca, con lo cual ha generado luchas internas por el poder, cohonestando el mal comportamiento de los jóvenes en los escenarios deportivos, al paso que son ellos mismos quienes piden que se les judicialice, se endurezcan las penas y se realicen acciones contundentes para su control. 
A medida que se estrecha la relación del joven con la barra, es mayor la posibilidad de que este se inicie en la comisión de contravenciones a la ley; respaldado por el grupo, se arriesga con mayor facilidad a realizar actos que suelen convertirse en retos para conservar su posición. Según los estudiantes, las primeras aproximaciones se dan dentro de la misma barra, en las que aprovechando el tumulto y la confusión se puede acceder a pequeños elementos como camisetas, gorros, cornetas, buzos, entre otros.

La alianza de la pandilla con los escolares facilita la ostentación de poder cuando se presentan conflictos entre estudiantes en las afueras de los colegios. El pandillero es la imagen de la transgresión y el conflicto social, pero también es para los jóvenes la expresión de libertad y fortaleza, la misma que es reconocida en el ambiente escolar, temida por algunos y añorada por otros.

La escuela, como parte de la sociedad, se ve atomizada por las distintas problemáticas que se viven, muchas veces desbordada y agobiada por situaciones que no sabe cómo enfrentar. Hoy la dinámica escolar está seriamente afectada por el tema de la violencia, la misma que emula aquella que es ejercida por los adultos en las calles. La idea no es estigmatizar a los jóvenes o a las instituciones, sino un llamado a la reflexión de la comunidad educativa en torno a las dificultades que enfrentan nuestros estudiantes, a la poca eficacia de las políticas públicas frente a la solución de los problemas juveniles, a la participación de la familia y de la misma escuela en las tareas formativas que conduzcan a mejorar la convivencia. 
Abramovay, M. (2005a). Victimización en las escuelas. Ambiente escolar, robos y agresiones físicas. Revista Mexicana de Investigación Educativa, 10(26). Recuperado de: http://redalyc.uaemex. $\mathrm{mx} / \mathrm{pdf} / 140 / 14002611 . \mathrm{pdf}$

Acero, H. (2010). Jóvenes delincuentes: zanahoria y justicia. Consejo Superior de la Judicatura. Razón Pública. Recuperado de: http:// www.razonpublica.com/index.php/conflicto-drogas-y-paz-temas-30/1427-

Aguilar, R. (2009). ¿Qué es un barrabrava? El Tiempo, edición del 9 de agosto, Sección Domingo a Domingo.

Arcanxel (2010). El impacto sociocultural del fútbol: el harpastum romano y la disciplina militar. Recuperado de: http://co.globedia. com/impacto-sociocultural-futbol-harpastum-romano-disciplinamilitar

Ardila, L. (2011). Un colegio bajo amenaza. El Espectador, edición del 5 de agosto. Recuperado de: www.elespectador.com

Atencio, J. (2010). Bogotá, viviendo entre violencia y barras bravas. La Revista, órgano informativo de la Red Distrital de Personeros y Personeras Estudiantiles. Personería de Bogotá, D. C. [En línea]. Recuperado de: http://www.personeriabogota.gov.co/sites/default/files/publicaciones/LA\%20 REDVISTA\%202010.pdf

Ávila, C. (2010). Adolescentes infractores: entre el código y la falta de oportunidad. Unimedios, UN-periódico impreso, 139.

Barrientos, P. (2011). Fútbol y barras bravas en América Latina: una aproximación. Recuperado de: http://suite101.net/article/futboly-barras-bravas-en-america-latina-unaproxximacion-a54067 
Berger, C., \& Lisboa, C. (2008). Hacia una comprensión ecológica de la agresividad entre pares en el microsistema escolar en violencia escolar. En Estudios y posibilidades de intervención en Latinoamérica. Santiago: Editorial Universitaria.

Bogotá Cómo Vamos (2009b). Evaluación de los cambios en la calidad de vida en Bogotá durante 2008. Sector Seguridad. Bogotá: Casa Editorial El Tiempo, Cámara de Comercio de Bogotá, Fundación Corona. Recuperado de: http://www.bogotacomovamos.org/ datos/AA_45_evaluacion_seguridad

Bourdieu, P. (1980). Le capital social. Actes de la Recherche en Sciences Sociales, 31, 2-3. Recuperado de: http://www.persee.

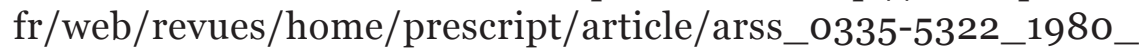
num_31_1_2069

Bourdieu, P. (1984). Questiones de Sociologie. París: Les Editions de Minuit.

Bourdieu, P., \& Passeron, J. (1970). La reproduction. Eléments pour une théorie du système d'enseignement. París: Minuit.

Brater, M. (1999). Escuela y formación bajo el signo de la individualización. En Hijos de la libertad. Buenos Aires: Fondo de Cultura Económica.

Calderón, L., \& Melgar, R. (2010). Masculinidad y femineidad en el fútbol. Hypatia, 33. Recuperado de: http://hypatia.morelos.gob. $\mathrm{mx}$

Caputo, L., \& Palau, M. (2004). Sobre los conceptos de juventud. En Juventud y exclusión social. Conceptos, hipótesis y conocimientos interpretativos de la condición juvenil. Recuperado de: http://168.96.200.17/ar/libros/paraguay/base/107/Primera\%20 parte.doc

Cepeda, I. (2009). La nueva fase de la "limpieza social". El Espectador. Recuperado de: http://www.elespectador.com/opinion

Chaux, E. (2006). Estudio de convivencia y seguridad en ámbitos escolares de Bogotá. Comité intersectorial. Bogotá: Secretaría de Gobierno Distrital, Secretaría de Educación Distrital, Oficina de 
Jóvenes sin Indiferencia, Departamento Administrativo Nacional de Estadística, Proyecto Educación: Compromiso de Todos.

Cicerchia, R. (1999). Alianzas, redes y estrategias. El encanto y la crisis de las formas familiares. Nómadas, 11.

Cid, P., Díaz, A., Pérez, M.V., Torruella, M., Valderrama, A. (2008). Agresión y violencia en la escuela como factor de riesgo de aprendizaje escolar. Revista de Ciencia y Enfermería, 14(2).

Clavijo, J. (2004). Estudio de barras de fútbol en Bogotá: los Comandos azules. Universitas Humanística, XXXI(58).

Collazos, R., Herrera, S., Restrepo, N., Suárez, K. (1999). Barras bravas o barras furiosas. Camaleón, 18.

Conde, M. (2008). El poder de la razón: las mujeres en el fútbol. Nueva Sociedad, 218. Recuperado de: www.http://dialnet.unirioja.es/ servlet/articulo?codigo $=3989103$

Cruz, J., \& Carranza, M. (2006). Pandillas y políticas públicas: el caso de El Salvador. En J. Cruz \& M. Carranza, Juventudes, violencia y exclusión: desafios para las políticas públicas (pp. 133-176). Guatemala: Magna Torres Ediciones. Recuperado de: http://www.uca. edu.sv/publica/iudop/ articulos/JMC1.pdf

Delors, J. (2000). La educación encierra un tesoro. Informe a la Unesco de la Comisión Internacional sobre la Educación para el Siglo XXI. París: Unesco-Santillana.

De Roux, C. (2010). Balance de la política pública de juventud. Recuperado de: www.issuu.com/carlosvicente/docs/pol_tica_de_juventud

Donas, S. (2001). Adolescencia y juventud en América Latina. Costa Rica: LUR.

Duarte, K. (2001). ¿Juventud o juventudes? Acerca de cómo mirar y remirar a las juventudes de nuestro continente. En Adolescencia y juventud en América Latina. Costa Rica: LUR. 
Dunning, E. (2003). El fenómeno deportivo. Estudios sociológicos en torno al deporte, la violencia y la civilización. Barcelona: Editorial Paidotribo.

El Espectador (2010b). Redes sociales han propagado violencia en colegios de Bogotá. La alerta fue extendida por la Secretaría de Educación, luego del asesinato de una joven de 16 años a manos de su compañera de la misma edad, edición del 27 de agosto. Recuperado de: www.elespectador.com

El Tiempo (2011d). Medicina Legal muestra la 'anatomía' de la violencia colombiana, edición del 6 de agosto. Recuperado de: http://www.eltiempo.com/justicia/articulo-web-new_nota_interior-10107532.html

El Tiempo (2011g). En Bogotá se alquila un arma por \$100.0oo. Porte ilegal de armas en Bogotá, edición del 28 de febrero.

Farrington, D. (2005). Childhood origins of antisocial behavior. Clinical Psycology and Psychoterapy, 12(3), 177-190. doi: 10.1002/ pp.448

Ferreiro, J. (2003). Apuntes sobre identidad y fútbol. En: Futbologías: fútbol, identidad y violencia en América Latina. Buenos Aires: Clacso.

Franco, F. (1999). El barrio como lugar de vida. Entre lo apropiable y lo enajenable. Serie Ciudad y Hábitat, 6. Recuperado de: www. barriotaller.org.co

García, B., \& Guerrero, F. (2011). Nuevas concepciones de autoridad y cambios en las relaciones de violencia en la familia y la escuela. Magis, revista internacional de investigación en educación, 4(8).

García, B., Guerrero, F., \& Ortiz, B. (2012a). La violencia escolar en Bogotá desde la mirada de las familias. Bogotá: Fondo Editorial Universidad Distrital Francisco José de Caldas.

García, B., \& Guerrero, F. (2012b). Violencias en contexto. Bogotá: Fondo Editorial Universidad Distrital Francisco José de Caldas. 
García, B., \& Ortiz, B. (2012c). Los maestros ante la violencia escolar. Bogotá: Fondo Editorial Universidad Distrital Francisco José de Caldas.

García, M. (2004). Violencia en las aulas: bullying. Santiago de Chile: En el Refugio de Esjo. [En línea]. Recuperado de: http://usuarios. lycos.es/atenealunaes/115-jokin.htm

Garriga, J. (2005). Lomo de macho. Cuerpo, masculinidad y violencia de un grupo de simpatizantes del fútbol. Cuadernos de antropología social, 22, 201-216. Recuperado de: http://ica.institutos.filo. uba.ar/seanso/modulos/cas/n22/n22a12.pdf

Giraldo, F., García, J., Ferrari, C., \& Bateman, A. (2009). Urbanización para el desarrollo humano. Políticas para un mundo de ciudades. Bogotá: UN-Hábitat.

Goffman, E. (1970). Ritual de la interacción. Buenos Aires: Ediciones Tiempo Contemporáneo.

Hernández, A., \& Gutiérrez, M. (2010). Vulnerabilidad y exclusión en salud. Datos y relatos de la situación de la población desplazada en Bogotá. Bogotá: Pontificia Universidad Javeriana.

Hopenhayn, M. (2006). La juventud latinoamericana en sus tensiones y sus violencias. En Juventudes, violencia y exclusión: desafios para las políticas públicas. Guatemala: Magna Terra Editores.

Instituto para la Investigación Educativa y el Desarrollo Pedagógico, \& Claustro Moderno (2010). Caracterización de la población escolar de Bogotá de los grados 6 a 11 desde los ámbitos del desarrollo cognoscitivo, físico y socioafectivo. Bogotá: IDEP.

Jiménez, B. (1999). Las familias nucleares poligenéticas: cambios y permanencias. Nómadas, 11.

Jordán, R., \& Segovia, O. (2005). Espacios públicos urbanos, pobreza y construcción social. Santiago de Chile: División de Desarrollo Sostenible y Asentamientos Humanos, Naciones Unidas-Cepal.

Justicia, F., Benítez, J., Pichardo, M., Fernández, E., García, T., \& Fernández, M. (2006). Aproximación a un nuevo modelo explicativo 
del comportamiento antisocial. Electronic Journal of Research in Educational Psychology, 4(9). Recuperado de: www.redalyc.org

Kazdin, A. (1993). Adolescence mental health: prevention and treatment programs. Department of Psychology, Yale University, New Haven, CT 06520-7447.

Kesler, G. (2006). Inseguridad subjetiva, sociedad y política: aportes para un debate latinoamericano. En Juventudes, violencia y exclusión: desafíos para las políticas públicas. Guatemala: Magna Terra Editores.

Kliksberg, B. (1999) Capital social y cultura, claves esenciales del desarrollo. Revista de Cepal, 69.

Leccardi, C., \& Feixa, C. (2011). El concepto de generación en las teorías sobre la juventud. Última Década, 34.

Londoño, B. (2004). Bogotá, una ciudad receptora de migrantes y desplazados, con graves carencias en materia de recursos e institucionalidad para garantizarles sus derechos. Estudios Socio-Jurídicos, 6(1).

López, M. (2006). Delincuencia juvenil. En ¿̇ué es esa cosa llamada violencia? México: Diario de Campo, noviembre-diciembre.

Lozano, M. (2003). Nociones de juventud. Última Década, 18.

Mancera, I. (2010). Las mujeres en las barras bravas colombianas juegan un rol y desarrollan un estilo de vida. Testimonios de jóvenes ligadas a estos grupos de hinchas cuentan cómo es su vida, sus intereses y el trato que reciben. El Tiempo, edición del 29 de septiembre. Recuperado de: http://m.eltiempo.com/vida-de-hoy/ educacion/las-mujeres-en-las-barras-bravas-colombianas-juegan-un-rol/8171868/2

Margulis, M., \& Urresti, M. (2002). La construcción social de la condición de juventud. En Viviendo a toda. Jóvenes, territorios culturales y nuevas sensibilidades. Bogotá: Siglo del Hombre Editores.

Martínez, F. (2004). ¿Aprobar o reprobar? El sentido de la educación en educación básica. Revista de Investigación Educativa, IX(23). 
Moffat, A. (1998). Barras, broncas y mafias. La Maga. Recuperado de: http://cresa.en.eresmas.com/ nc261003.pdf

Monsiváis, C. (1999). Notas sobre violencia urbana. Revista digital letras libres.com. Recuperado el 25 de septiembre de 2007.

Naim, M. (2013). ¿Qué les está pasando a los poderosos? Recuperado de: http://elpais.com/elpais/2013/ 03/15/opinion/1363367584_135358.html

Nullvalue (1992). Nubarrones en el fútbol. Recuperado de: www.eltiempo.com (edición del 15 de septiembre).

Palomero, J., \& Fernández, M. (2001). La violencia escolar: un punto de vista global. Revista interuniversitaria de formación del profesorado, 41.

Pareja, R. (2012). Definición de barrabrava. informadorpublico.com Recuperado de: http://site.informadorpublico.com/?p=12683

Perea, C. (2004). Joven, crimen y estigma. Revista Joven-es, 8(20).

Perea, C. (2005). El parche es parche: pandillas, pánicos y violencias. Bogotá: Instituto de Estudios Políticos y Relaciones Internacionales, Iepri, Universidad Nacional de Colombia.

Perea, C. (2008). ¿Qué nos une? En Jóvenes, cultura y ciudadanía. Medellín: La Carreta Editores.

Pérez, D., \& Mejía, M. (1999). De calles, parches, galladas y escuelas. Transformaciones en los procesos de socialización de los jóvenes de hoy. Bogotá: Cinep.

Pino, A. (2010). Fútbol, callejón sin salida. Razón Pública. Recuperado de: http://www.razonpublica.com/ index.php/econom-y-sociedad-temas-29/1366-futbol-callejon-sin-salida.html

Puerta, J. (2002). Las barras bravas en Medellín: un desbordamiento de pasión. Periódico El Mundo, marzo 13.

Puryear, J., \& Malloy, J. (2009). Diálogo Interamericano. Política Social. Boletín. Recuperado de: http://www.thedialogue.org/Pu- 
blicationFiles/Politica\%20Social\%20Sintesis\%20No\%201\%20Pobreza\%20y\%20Desigualdad\%20en\%20America\%20Latina.pdf

Quevedo, N. (2001). Los autogoles de Millos. Periódico El Espectador, edición del 4 febrero de 2001. Recuperado de: www.elespectador. com

Recasens, A. (1999). Diagnóstico antropológico de las barras bravas y de la violencia ligada al fútbol. Santiago de Chile: Facultad de Ciencias Sociales, Universidad de Chile.

Restrepo, G. (1998). Aproximación cultural al concepto de territorio. Perspectiva Geográfica. Tesis de Maestría en Geografía, Convenio UPTC-IGAC, Bogotá.

Rico, A. (1999). Formas, cambios y tendencias en la organización familiar en Colombia. Nómadas, 11.

Rodríguez, C. (2009). Grupos juveniles de carácter violento: estrategias de intervención. Las instituciones ante el conflicto social de los grupos juveniles violentos. Magistrado del Juzgado de Menores N. ${ }^{0} 1$ de Madrid. Recuperado de: www.comunidadyprevencion. org/wp/docs/.../presentacion_curso_xdias.pdf

Rodríguez, E. (2002). Juventud, desarrollo social y políticas públicas en América Latina y el Caribe: oportunidades y desafíos. [En línea]. Recuperado de: biblioteca.clacso.edu.ar/ar/libros/costar/ america/cap4.pdf

Rodríguez, E. (2005). Prevención social del delito y la violencia juvenil. Experiencias innovadoras en América Latina. Experiencias latinoamericanas de trabajo con jóvenes. Buenos Aires, Ciudad de La Plata: Instituto Interamericano de Derechos Humanos y Ministerio de Seguridad de la Provincia.

Rojas, C. (1994). La violencia llamada limpieza social. Bogotá: Cinep.

Saiz, J., \& Rangel, J. (2008). Capital social: una revisión del concepto. CIFE, 13 .

Sack, R. (1986). Human Territoriality: its Theory and History. Cambridge: Cambridge University Press. Recuperado de: www.ucm.es/ info/eurotheo/diccionario/T/territorialidad.htm 
Saravi, G. (2006). Los eslabones de la violencia juvenil: acumulación de desventajas en la transición a la adultez. En Juventudes, violencia y exclusión: desafíos para las políticas públicas. Guatemala: Magna Terra Editores.

Secretaría de Educación de Bogotá (2008). En marcha acciones para controlar el porte de armas en colegios de Bogotá. Recuperado de: www.sedbogota.edu.co /.../274-acciones-para-controlar-portede-arm

Sierra, Y., \& Gómez, R. (2010). Primera encuesta de cultura ciudadana en población escolar. Educación y Ciudad, 19.

Torres, C. (2005). Jóvenes y violencia. Revista Iberoamericana de Educación, 37.

Torres, E. (1988). Escépticos, narcisos y rebeldes: seis estudios sobre juventud. San José, Costa Rica: Flacso.

Trigilia, C. (2003). El capital social. Instrucciones de uso. Buenos Aires: Fondo de Cultura Económica de Argentina.

Trudel, M., Puentes-Neuman, G. (2000): The contemporary concepts of at risk children: theoretical models and approaches in the early years, Pan Canadian Education Research Agenda Symposium, Adolescence. En Hein, Blanco \& Mertz (2003), Factores de riesgo y delincuencia juvenil. Una revisión a la literatura nacional e internacional. Chile: Fundación Paz Ciudadana.

Uribe, P. (2007). Familias monoparentales con jefatura femenina, una de las expresiones de las familias contemporáneas. Tendencia y Retos, 12, 81-90.

Vásquez, C. (2003). Teorías criminológicas sobre delincuencia juvenil. [En línea]. Recuperado de: http://www.uned.es/dpto_pen/ delincuencia-juv/documentos/delincuencia/teorias-criminologicas. pdf

Velásquez, E., Giraldo, F. (2009). Hábitat y seguridad urbana. Tendencias, prevención y gobernanza de la seguridad. Bogotá: Alcaldía Mayor de Bogotá, Secretaría Distrital de Gobierno, PNUD-UNHábitat. 
Veeduría Distrital (2008). Condiciones de seguridad en Bogotá 20o82009-2010. Recuperado de: www.veeduriadistrital.gov.co

Verlinde, S., Hersen, M., \& Thomas, J. (2000). Risk factors in school shootings. Clinical Psychology Review, 20(1), 3-56.

Weber, M. (1984). Economía y sociedad. Conceptos de la sociología y del "significado" en la acción social. México, D. F.: Fondo de Cultura Económica. 


El presente estudio constituye un esfuerzo por comprender una de las violencias que afecta la vida de las escuelas en Bogotá, producida por la vinculación de jóvenes escolarizados con el fenómeno del barrismo del fútbol y las diversas situaciones a las que se encuentra ligado, entre otras, el consumo y distribución de sustancias psicoactivas, el porte y uso de armas, el acercamiento a pandillas y bandas delincuenciales. Del mismo modo, el propósito es encontrar una explicación a los comportamientos de los estudiantes que se adhieren a estos grupos, de ahí que se da una mirada a la situación que deben afrontar en espacios de socialización como la escuela, la familia y el barrio. 